Aus der Klinik für Nephrologie und Rheumatologie

(Prof. Dr. med. G. A. Müller)

der Medizinischen Fakultät der Universität Göttingen

\title{
Die Rolle der Proteindisulfidisomerase ERp57 in der Chemoresistenz des Nierenzellkarzinoms
}

\author{
INAUGURAL-DISSERTATION \\ zur Erlangung des Doktorgrades \\ der Medizinischen Fakultät der \\ Georg-August-Universität zu Göttingen
}

vorgelegt von

Olga Katzendorn

aus

Dshambul/Kasachstan 
Dekan:

Referent:

Ko-Referent:
Prof. Dr. rer. nat. H. K. Kroemer

Prof. Dr. H. Dihazi

Prof. Dr. H. Urlaub

Datum der mündlichen Prüfung: 21.03.2019 
Hiermit erkläre ich, die Dissertation mit dem Titel " Die Rolle der Proteindisulfidisomerase ERp57 in der Chemoresistenz des Nierenzellkarzinoms" eigenständig angefertigt und keine anderen als die von mir angegebenen Quellen und Hilfsmittel verwendet zu haben.

Göttingen, den 


\section{Inhaltsverzeichnis}

Abbildungsverzeichnis ......................................................................................... III

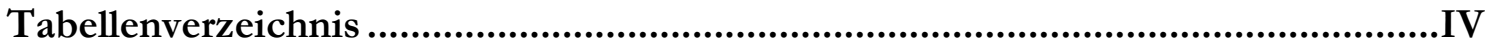

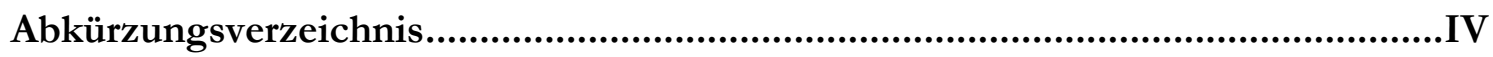

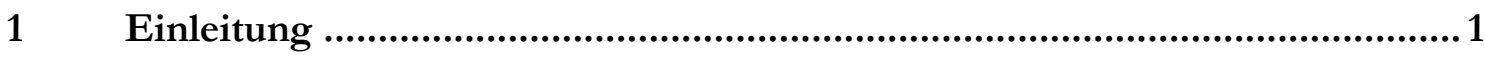

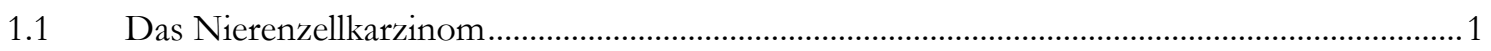

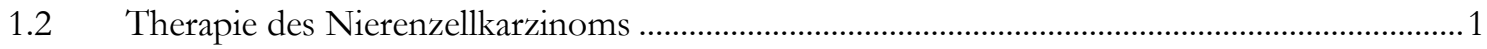

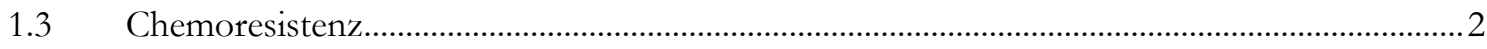

1.4 Der endoplasmatisches-Retikulum-Stress und die unfolded protein response.................................. 4

1.5 ER-Stress und UPR in Karzinomen.............................................................................6

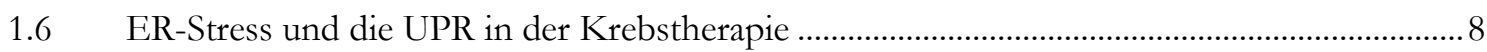

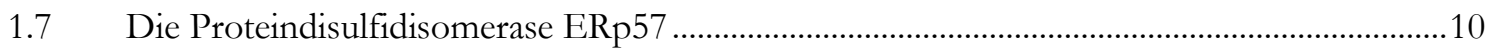

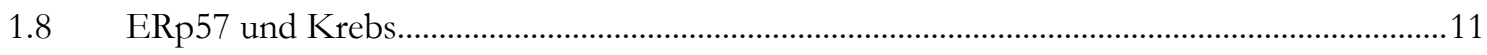

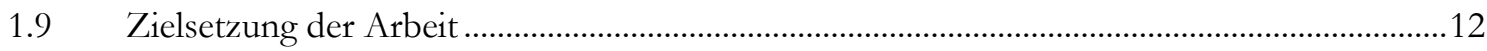

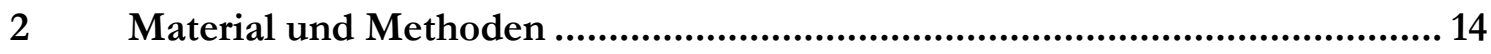

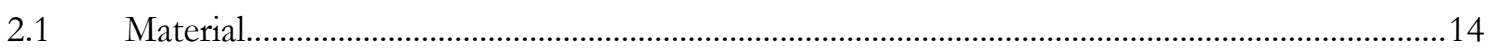

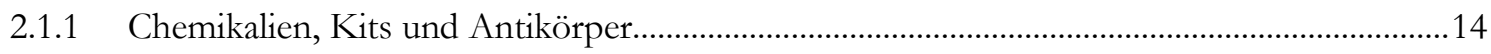

2.1.2 Zusammensetzung von Puffern und Lösungen ...............................................................17

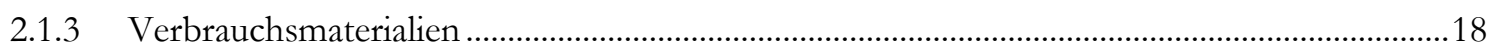

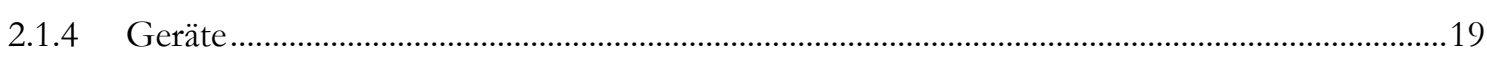

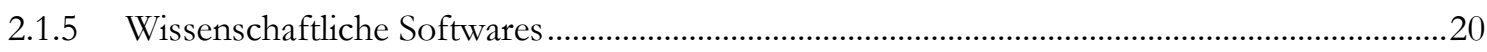

2.1.6 Biologisches Material .......................................................................................................21

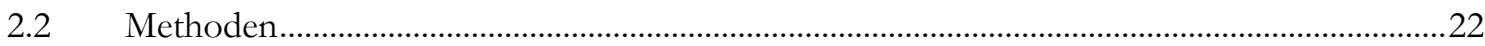

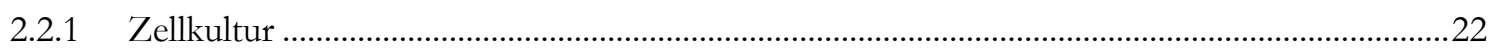

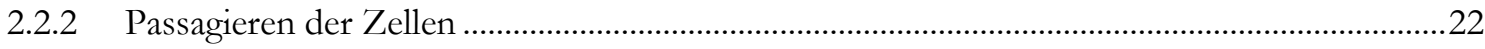

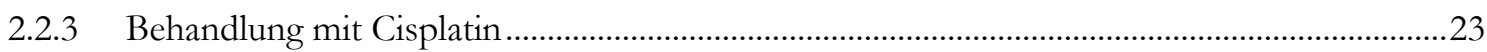

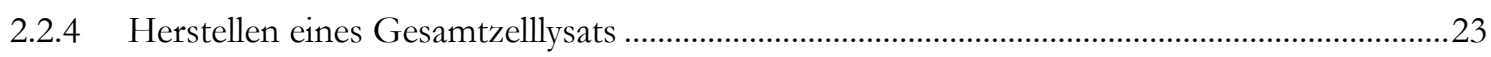

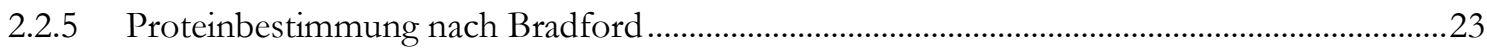

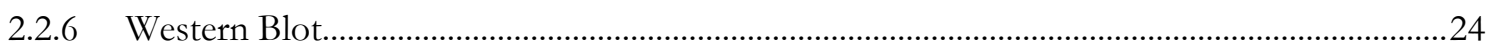

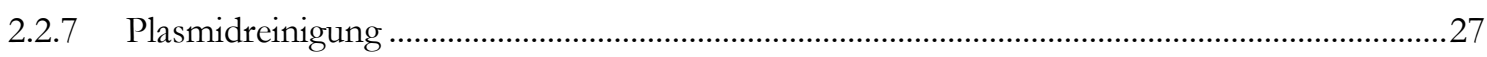

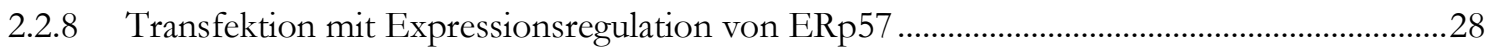

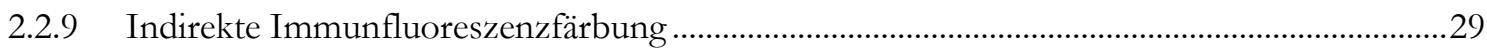

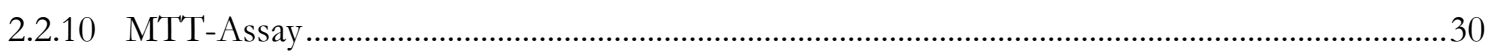

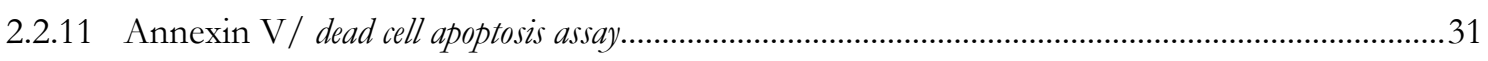

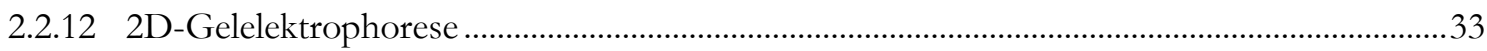

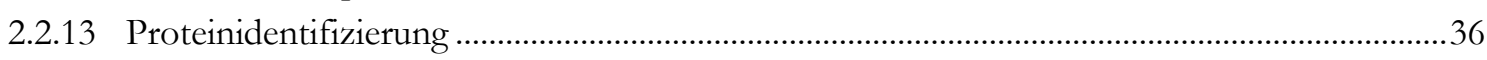

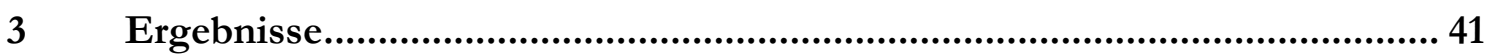


3.1 Auswirkungen der Behandlung mit Cisplatin auf das Überleben der

Nierenzellkarzinom-Zelllinien

3.2 Auswirkung der Behandlung mit Cisplatin auf die Zellviabilität der Nierenzellkarzinom-Zelllinien.

3.2.1 Auswirkung der Behandlung mit Cisplatin auf die Apoptoseinduktion in Nierenzellkarzinom-Zelllinien.

3.3 Auswirkung der Behandlung mit Cisplatin auf das Proteom der NierenzellkarzinomZelllinien

3.3.1 Zweidimensionale Proteinprofile ohne und nach Behandlung mit Cisplatin........................45

3.3.2 Analyse des Expressionsprofils einzelner Spots und Proteinidentifizierung ..........................47

3.3.3 Differenziell unterexprimierte Proteine nach Behandlung mit Cisplatin ................................53

3.3.4 Differenziell überexprimierte Proteine nach Behandlung mit Cisplatin.................................55

3.4 Auswirkung der Behandlung mit Cisplatin auf ER-Stressproteine in Nierenzellkarzinom-Zelllinien am Beispiel der Proteindisulfidisomerase ERp57....

3.4.1 Auswirkung der Behandlung mit Cisplatin auf Spots des ER-Stressproteins ERp57 in 2D-Gelen der Nierenzellkarzinom-Zelllinien

3.4.2 Auswirkung der Behandlung mit Cisplatin auf die Expression des ER-Stressproteins ERp57 in Nierenzellkarzinom-Zelllinien im Western Blot

3.5 Expressionsregulation von ERp57 in Caki-2- und A498-Zelllinien: siRNAHerunterregulation und Plasmid-Hochregulation.

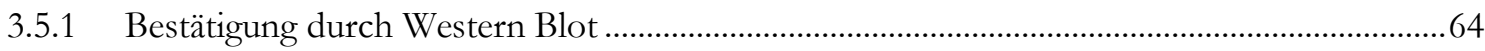

3.5.2 Bestätigung durch indirekte Immunfluoreszenzfärbung......................................................65

3.6 Einfluss der ERp57-Expressionsregulation auf die Zellviabilität und Zellproliferation der Nierenzellkarzinom-Zelllinien.

3.7 Einfluss der ERp57-Expressionsregulation auf das Überleben der NierenzellkarzinomZelllinien nach Behandlung mit Cisplatin

3.7.1 Einfluss der ERp57-Expressionsregulation auf die Zellviabilität in Nierenzellkarzinom-Zelllinien nach Behandlung mit Cisplatin

3.7.2 Einfluss der ERp57-Expressionsregulation auf die Apoptoseinduktion in Nierenzellkarzinom-Zelllinien nach Behandlung mit Cisplatin

Diskussion.

4.1 Auswahl der Zelllinien und des zytotoxischen Agens

4.2 Veränderungen des Proteoms der Nierenzellkarzinom-Zelllinien nach Behandlung mit Cisplatin

4.2.1 Unterexprimierte Proteine nach Behandlung mit Cisplatin.....................................................79

4.2.2 Überexprimierte Proteine nach Behandlung mit Cisplatin.....................................................81

4.3 Rolle der UPR in Nierenzellkarzinom-Zelllinien nach Behandlung mit Cisplatin ................85

4.4 Rolle des ER-Stressproteins ERp57 in der Chemoresistenz von NierenzellkarzinomZelllinien gegenüber einer Behandlung mit Cisplatin.....

4.5 Rolle des ER-Stressproteins ERp57 in der Proliferation von NierenzellkarzinomZelllinien .... 


\section{Abbildungsverzeichnis}

Abbildung 1: Anordnung des Blot-Sandwich

Abbildung 2: Beispiel für ein fusioniertes Bild mit Spotentdeckung mit dem Programm „Delta2D“ .36

Abbildung 3: Beispiel für das MS/MS-Spektrum des Peptids YGVSGYPTLK eines Spots des Proteins ERp57

Abbildung 4: Beispiel der Ergebnisse einer Suche mit der Datenbank „Mascot“

Abbildung 5: Diagramm der Ergebnisse des MTT-Assays für nicht behandelte Caki-2-Zellen und mit Cisplatin behandelte Caki-2-Zellen.....

Abbildung 6: Diagramm der Ergebnisse des MTT-Assays für nicht behandelte A498-Zellen und mit Cisplatin behandelte A498-Zellen

Abbildung 7: Diagramm der apoptotischen Zellfraktion nach Behandlung mit Cisplatin in der Caki-2-Zelllinie und der A498-Zelllinie.

Abbildung 9: Diagramm des Annexin V/dead cell apoptosis assay mit Annexin V-/PI-Markierung von A498-Kontrollzellen und mit Cisplatin behandelten A498-Zellen

Abbildung 8: Diagramm des Annexin V/dead cell apoptosis assay mit Annexin V-/PI-Markierung von Caki-2-Kontrollzellen und mit Cisplatin behandelten Caki-2-Zellen.

Abbildung 10: 2D-Gelelektrophorese von Caki-2-Kontrollzellen .........................................................45

Abbildung 11: 2D-Gelelektrophorese von mit Cisplatin behandelten Caki-2-Zellen...........................45

Abbildung 12: 2D-Gelelektrophorese von A498-Kontrollzellen ........................................................46

Abbildung 13: 2D-Gelelektrophorese von mit Cisplatin behandelten A498-Zellen..............................46

Abbildung 14: Identifizierte Proteine der Caki-2-Zelllinie in einem übereinandergelegten Bild........47

Abbildung 15: Identifizierte Proteine der A498-Zelllinie in einem übereinandergelegten Bild...........50

Abbildung 16: Übersicht über die Spotintensität der unterexprimierten Proteine nach Behandlung mit Cisplatin für Caki-2-Zellen

Abbildung 17: Übersicht über die Spotintensität der unterexprimierten Proteine nach Behandlung mit Cisplatin für A498-Zellen.

Abbildung 18: Übersicht über die Spotintensität der überexprimierten Proteine nach

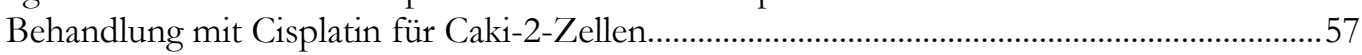

Abbildung 19: Übersicht über die Spotintensität der überexprimierten Proteine nach Behandlung mit Cisplatin für A498-Zellen.

Abbildung 20: Übersicht der Spotintensität der einzelnen ERp57-Spots für Caki-2-Zellen im Vergleich.

Abbildung 21: Übersicht der Spotintensität der einzelnen ERp57-Spots für A498-Zellen im Vergleich.

Abbildung 22: ERp57- und Beta-Aktin-Expression im zeitlichen Verlauf nach Behandlung mit Cisplatin in Caki-2-Zellen im Western Blot

Abbildung 23: Diagramm des Verhältnisses der ERp57-Expression zu der Beta-AktinExpression in Caki-2-Zellen im zeitlichen Verlauf nach Behandlung mit Cisplatin.

Abbildung 24: ERp57- und Beta-Aktin-Expression im zeitlichen Verlauf nach Behandlung mit Cisplatin in A498-Zellen im Western Blot.

Abbildung 25: Diagramm des Verhältnisses der ERp57-Expression zu der Beta-AktinExpression in A498-Zellen im zeitlichen Verlauf nach Behandlung mit Cisplatin

Abbildung 26: ERp57- und Beta-Aktin-Expression in der Kontrolle und nach Transfektion in Caki-2-Zellen im Western Blot.

Abbildung 27: ERp57- und Beta-Aktin-Expression in der Kontrolle und nach Transfektion in A498-Zellen im Western Blot.

Abbildung 28: Indirekte Immunfluoreszenzfärbung von Caki-2-Kontrollzellen 
Abbildung 29: Indirekte Immunfluoreszenzfärbung von mit dem Plasmid transfizierten Caki2-Zellen

Abbildung 30: Indirekte Immunfluoreszenzfärbung von A498-Kontrollzellen

Abbildung 31: Indirekte Immunfluoreszenzfärbung von mit dem Plasmid transfizierten A498Zellen

Abbildung 32: Diagramm des MT'T-Assays für Caki-2-Kontrollzellen und transfizierte Caki-2Zellen.....

Abbildung 33: Diagramm des MTT'-Assays für A498-Kontrollzellen und transfizierte A498Zellen.....

Abbildung 34: Diagramm der prozentualen Zellviabilität für Caki-2-Kontrollzellen und transfizierte Caki-2-Zellen nach Behandlung mit Cisplatin

Abbildung 35: Diagramm der prozentualen Zellviabilität für A498-Kontrollzellen und transfizierte A498-Zellen nach Behandlung mit Cisplatin

Abbildung 36: Diagramm des Annexin V/dead cell apoptosis assay von mit dem Plasmid transfizierten Caki-2-Zellen und von mit Cisplatin behandelten und mit dem Plasmid transfizierten Caki-2-Zellen...

Abbildung 37: Diagramm des Annexin V/dead cell apoptosis assay von mit siRNA transfizierten Caki-2-Zellen und von mit Cisplatin behandelten und mit siRNA transfizierten Caki2-Zellen.....

Abbildung 38: Diagramm der mit dem Annexin V/dead cell apoptosis assay ermittelten apoptotischen Zellfraktion von Caki-2-Kontrollzellen und transfizierten Caki-2-Zellen ....75

Abbildung 39: Diagramm des Annexin V/dead cell apoptosis assay von mit dem Plasmid transfizierten A498-Zellen und von mit Cisplatin behandelten und mit dem Plasmid transfizierten A498-Zellen.

Abbildung 40: Diagramm des Annexin V/dead cell apoptosis assay von mit siRNA transfizierten A498-Zellen und von mit Cisplatin behandelten und mit siRNA transfizierten A498Zellen .....

Abbildung 41: Diagramm der mit dem Annexin V/ dead cell apoptosis assay ermittelten apoptotischen Zellfraktion von A498-Kontrollzellen und transfizierten A498-Zellen.........77

\section{Tabellenverzeichnis}

Tabelle 1: Pipettierschema zur Erstellung einer Eichkurve .24

Tabelle 2: Empfohlenes Verhältnis für Antikörper im Western Blot.................................................26

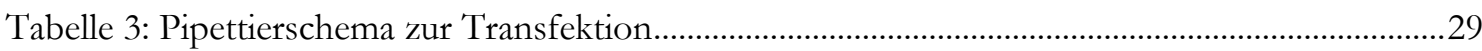

Tabelle 4: Empfohlenes Verhältnis für Antikörper in Immunofluoreszenzfärbungen........................30

Tabelle 5: Schema zur Interpretation der Ergebnisse des Annexin V/ dead cell apoptosis assay .............32

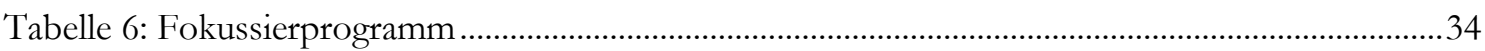

Tabelle 7: Einstellungen für die MS/MS-Ionensuche mit der Datenbank „Mascot“ .........................39

Tabelle 8: Liste der identifizierten Proteine der Caki-2-Zelllinie und Ratio der Expression der Spots.

Tabelle 9: Liste der identifizierten Proteine der A498-Zelllinie und Ratio der Expression der Spots.

Tabelle 10: Zuordnung der differenziell unterexprimierten Proteine in Gruppen entsprechend ihrer biologischen Funktion

Tabelle 11: Zuordnung der differenziell überexprimierten Proteine in Gruppen nach ihrer biologischen Funktion 


\section{Abkürzungsverzeichnis}

AML akute myeloische Leukämie

ATF activating transcription factor

CGI-99 UPF0568 protein C14orf166

DAPI Diamidin-2-phenylindol

$\mathrm{ddH}_{2} \mathrm{O} \quad$ doppelt destilliertes Wasser

DMEM Dulbecco's Modified Eagle Medium

DNA Desoxyribonukleinsäure

DPBS Dulbecco's Phosphate-Buffered Saline

eIF eukaryotic translation initiation factor

ER endoplasmatisches Retikulum

ERp endoplasmic reticulum resident protein

FACS fluorescence-activated cell sorting

GRP glucose-regulated protein

HIF bypoxia-inducible factor

hnRNP K heterogeneous nuclear ribonucleoprotein $K$

HSP beat shock protein

IRE inositol-requiring protein

LMNA Prelamin A/C

MDR multi-drug resistance

mRNA messenger-Ribonukleinsäure

mTOR mechanistic target of rapamycin

MTT 3-(4,5-Dimethylthiauol-2-yl)-2,5-diphenyltetrazoliumbromid

MYDGF myeloid-derived growth factor

PERK protein kinase RNA-like ER kinase

PI Propidiumiodid

pI isoelektrischer Punkt

Q-TOF quadrupole-time-of-flight

SDS-PAGE sodium dodecyl sulfate polyacrylamide gel electrophoresis

SF3B1 splicing factor 3B subunit 1

SRSF1 serine/ arginine-rich splicing factor 1

UPR unfolded protein response

VEGF vascular endothelial growth factor

VHL Von-Hippel-Lindau 


\section{$1 \quad$ Einleitung}

\subsection{Das Nierenzellkarzinom}

Das Nierenzellkarzinom ist eine vom Nierengewebe ausgehende maligne Erkrankung, die mit 15030 Neuerkrankungen im Jahr bei Männern an 6. Stelle und bei Frauen an 10. Stelle der Krebsneuerkrankungen steht. Seit 1998 zeigt sich die absolute Anzahl der Neuerkrankungen steigend bei konstant bleibender Anzahl von Sterbefällen (Robert Koch-Institut und Gesellschaft der epidemiologischen Krebsregister in Deutschland 2015). Mit einem Anteil von $90 \%$ sind sie die häufigsten Tumoren unter den Nierentumoren des Erwachsenen (Herold 2014). Histologisch wird zwischen dem klarzelligen, dem papillären, dem chromophoben und dem Ductus-Bellini-Karzinom unterschieden, wovon das klarzellige Karzinom mit Abstand am häufigsten vorkommt (Kellner 2010). In der Geschlechterverteilung erkranken Männer etwa doppelt so häufig wie Frauen. Der Altersgipfel für Neuerkrankungen findet sich bei beiden Geschlechtern bei 75-79 Jahren. Bei Diagnosestellung befinden sich die Tumoren in drei Viertel der Fälle in einem lokal begrenzten Stadium (T1-T2), was zu einer guten relativen 5-Jahres-Überlebensrate von 76-78\% führt (Robert Koch-Institut und Gesellschaft der epidemiologischen Krebsregister in Deutschland 2015). Als Risikofaktoren konnten Nikotinabusus (Hunt et al. 2005), Übergewicht, arterielle Hypertonie (Shapiro et al. 1999; Chow et al. 2000) und erworbene Nierenzysten bei dialysepflichtiger Niereninsuffizienz (Kabaria et al. 2016) beobachtet werden. Des Weiteren sind hereditäre Tumorsyndrome zu erwähnen, die zu einem erhöhten Nierenzellkarzinomrisiko führen. Das am häufigsten Vorkommende ist hier das von-Hippel-Lindau (VHL)-Syndrom (Leitlinie Nierenzellkarzinom 2015). Klinisch sind die meisten Nierenzellkarzinome asymptomatisch, so dass sie häufig Zufallsbefunde in der Bildgebung sind. Wenn sie sich klinisch manifestieren, treten als Leitsymptome Hämaturie und Flankenschmerzen auf (Herold 2014).

\subsection{Therapie des Nierenzellkarzinoms}

Für die kurative Behandlung ist eine chirurgische Therapie notwendig. Das Ausmaß der Resektion richtet sich hierbei nach der Tumorausdehnung. So kann je nach Tumorgröße sowohl eine nierenerhaltende Operation als auch eine radikale Nephrektomie indiziert sein (Leitlinie Nierenzellkarzinom 2015). Problematisch ist die Therapie des metastasierten Nierenzellkarzinoms. Die relative 5-Jahres-Überlebensrate dieses Tumors, der dem „Union internationale contre le cancer (UICC)“- Stadium IV entspricht, ist mit nur 16\% immer noch niedrig (Tumorregister München 2016). Eine Schwierigkeit hat hier in der Vergangenheit das fehlende Ansprechen auf konventionelle Chemotherapeutika bereitet (Costa und Drabkin 
2007). Als Alternativen wurde der Erfolg von Immuntherapie mit Interferon und Interleukin-2, Chemoimmuntherapie und zielgerichteter Therapie untersucht. Durchgesetzt hat sich hier in der Erstlinientherapie die zielgerichtete Therapie mit Tyrosinkinaseinhibitoren wie Sunitinib und Pazopanib, dem vascular endothelial growth factor (VEGF)-Inhibitor Bevacizumab plus Interferon und dem mechanistic target of rapamycin (mTOR)-Inhibitor Temsirolimus. Diese Empfehlung bezieht sich in den Leitlinien auf die Therapie des fortgeschrittenen und/oder metastasierten histologischen Typ des klarzelligen Nierenzellkarzinoms. Die Auswahl des Präparats soll bei der Therapiefindung nach Bestimmung des individuellen Risikoprofils des Patienten erfolgen (Leitlinie Nierenzellkarzinom 2015). Das Gesamtüberleben im fortgeschrittenen Krankheitsstadium konnte zwar durch die oben genannten Therapieoptionen verlängert werden, durch die Entwicklung von Resistenzen während der Therapie oder bereits initial nur teilweisem Ansprechen des Tumors gibt es in der Therapie des Nierenzellkarzinoms jedoch weiterhin erheblichen Forschungsbedarf (Fischer et al. 2015).

\subsection{Chemoresistenz}

Chemoresistenz ist ein limitierender Faktor in der medikamentösen Krebstherapie. Die Mechanismen, die dazu führen, sind noch nicht vollends verstanden, es wird jedoch angenommen, dass sie multifaktoriell bedingt sind. Als eine Methode zur Identifizierung von Proteinen oder Signalwegen, die Chemoresistenz beeinflussen, haben sich proteomische Analysen bewährt (Taba et al. 2010; Santana-Codina et al. 2013; Trivedi et al. 2016b; Gao et al. 2017). Im Folgenden sind einige Forschungsergebnisse zusammengefasst, die insbesondere die Chemoresistenz des Nierenzellkarzinoms und die Resistenz gegenüber dem Chemotherapeutikum Cisplatin betreffen, das häufig in der Therapie maligner Erkrankungen genutzt und intensiv erforscht wurde.

Galluzzi et al. (2012) gruppierten zusammenfassend Mechanismen, die in der Resistenz gegenüber Cisplatin eine Rolle spielten: Hierbei zeigte sich, dass eine Resistenz durch Veränderungen der Zelle auf unterschiedlichen Ebenen bedingt sein kann.

- Verminderte Verfügbarkeit des Medikaments am Wirkort durch verminderte Aufnahme in die Zelle, erhöhtes Ausschleusen aus der Zelle oder Inaktivierung (pre-target resistance)

- Verminderte Wirkung am Wirkort des Medikaments durch eine erhöhte Verfügbarkeit von Desoxyribonukleinsäure (DNA)-Reparaturmechanismen oder durch eine erhöhte Toleranz gegenüber DNA-Schäden (on-target resistance)

- Veränderungen in der Signaltransduktion, die zu Apoptose bei DNA-Schäden führt oder Veränderungen im Ablauf der Apoptose an sich (post-target resistance)

- Veränderungen in Signalwegen, die zu einer Hemmung oder Kompensation der zum Zelltod führenden Signale führen, ohne direkt in die durch Cisplatin ausgelöste Kaskade einzugreifen (off-target resistance) 
Das Vorkommen von Pumpen in der Zellmembran von Tumorzellen, die zu einem Herausschleusen von Medikamenten aus der Zelle führen, stellt einen Mechanismus im Sinne der pre-target resistance dar. Es wurden insbesondere zwei Membranproteine beschrieben, die durch ihr Vorkommen zu einer multi-drug resistance (MDR) führten - P-Glykoprotein (MDR1) und das multi-drug resistance protein 1 (MRP1). Beide Proteine gehören zu der Gruppe der ATP-binding cassette (ABC)-Transporter (Ling V. 1997; O’Connor 2007). Das Vorkommen dieser Proteine wurde in dem Nierenzellkarzinom untersucht, das als chemoresistent auffällig geworden war. Dabei kam es zu unterschiedlichen Ergebnissen. Ferguson et al. (2005) konnten kein erhöhtes Vorkommen von P-Glykoprotein in Gewebeproben von Patienten zeigen, die an einem Nierenzellkarzinom erkrankt waren. Im Gegensatz dazu ergab sich in einer weiteren Untersuchung an Patientenproben von Nierentumorgewebe eine hohe Expression von MRP1 und P-Glykoprotein (Walsh et al. 2009), so dass unklar ist, ob das Vorkommen dieser beiden Proteine die Pathophysiologie dieses Tumors bestimmt.

Der Zusammenhang zwischen dem Vorkommen beider Proteine und der prognostischen Relevanz für das Nierenzellkarzinom wurde ebenfalls untersucht. Während sich in einigen Studien eine Korrelation zwischen hoher Expression von P-Glykoprotein und einer ungünstigen Prognose zeigte (Duensing et al. 1994; Mignogna et al. 2006), konnte dies von Baytekin et al. (2011) nicht bestätigt werden. Hofmockel et al. (1997) beschrieben eine hohe Expression von P-Glykoprotein sogar als prognostisch günstig, da die Expression als Hinweis auf eine bessere Differenzierung des Tumors dient. Insgesamt bleibt also unklar, ob das Vorkommen dieser beiden Proteine in dem Nierenzellkarzinom von Relevanz ist. Versuche, die Effektivität der Therapie chemoresistenter Tumoren mit Hilfe von Inhibitoren des P-Glykoproteins zu steigern, waren bisher nicht erfolgreich (Bates et al. 2004; Greenberg et al. 2004; Friedenberg et al. 2006; Lhommé et al. 2008).

Für die Karzinogenese des Nierenzellkarzinoms spielt in vielen Fällen eine Inaktivierung des Von-Hippel-Lindau-Tumorsuppressor (VHL)-Gens eine Rolle. Durch die Inaktivierung des Gens kommt es zu einer Aktivierung des hypoxia-inducible factor (HIF), was primär mit einer vermehrten Angiogenese und einer besseren Tumorvaskularisation einhergeht. Dies führt zu einer gewissen Widerstandsfähigkeit des Tumors (Baldewijns et al. 2010). In gastrointestinalen Tumoren wurde außerdem ein Anstieg der Expression von P-Glykoprotein bei hohem HIF-1-Level beschrieben (Chen et al. 2014; Zhang et al. 2014). Für die Entfaltung der Wirkung von HIF-1-alpha werden die Mikrotubuli des Zytoskeletts benötigt. Im Falle des Nierenzellkarzinoms zeigte sich, dass die Wirkung des HIF-1-alpha bei Hemmung der Mikrotubuli durch Spindelgifte unbeeinträchtigt blieb. Es wurde daher eine Entkopplung der Wirkung von HIF-1-alpha vom Zytoskelett angenommen, was eine Erklärung für die Resistenz gegenüber Spindelgiften darstellen könnte (Carbonaro et al. 2012).

Ein weiteres im Zusammenhang mit MDR beschriebenes Protein ist das lung resistance protein (LRP). Es wird angenommen, dass LRP an dem nukleo-zytoplasmatischen Transportsystem 
für Medikamente beteiligt ist (Scheffer et al. 2000). In Tumoren, die klinisch als chemoresistent auffielen, wurde ein hohes Vorkommen von LRP beschrieben (Izquierdo et al. 1996). Ferguson et al. (2005) wiesen auch in Tumorgewebe von Patienten mit Nierenzellkarzinom ein hohes Vorkommen von LRP nach. LRP-positive Nierentumoren waren in der Mehrzahl schlechter differenziert als LRP-negative Tumoren (Hodorová et al. 2008).

Speziell für eine Resistenz des Nierenzellkarzinoms gegenüber Cisplatin ergaben sich in der experimentellen Forschung zwei weitere Proteine. So zeigten Zhang et al. (2016), dass in Patientenproben von Nierenzellkarzinomen im Vergleich zu anderen urogenitalen Tumoren vermehrt xeroderma pigmentosum complementation group F (XPF) exprimiert wurde, ein Protein, das eine Rolle in der DNA-Reparatur spielt. Das Ausmaß der Expression von XPF korrelierte mit der Resistenz gegenüber Cisplatin, und eine Regulation nach unten resultierte in invitro- und in-vivo-Mausexperimenten in einem vermehrten Ansprechen auf die Behandlung. Trivedi et al. (2016b) untersuchten die Rolle von Parkinson disease protein 7 (PARK7), einem Protein, das unter anderem die Antwort der Zelle auf oxidativen Stress reguliert. Das Ansprechen auf eine Behandlung mit Cisplatin konnte in-vitro durch Regulation des Proteins nach unten gesteigert und durch Regulation nach oben gesenkt werden.

\subsection{Der endoplasmatisches-Retikulum-Stress und die unfolded protein response}

Das endoplasmatische Retikulum (ER) ist ein Zellorganell, in dem Proteinbiosythese, Proteinfaltung und Proteinmodifikation stattfinden. Weiter spielt das ER eine wichtige Rolle in der Calcium-Homöostase und ist beteiligt in der Synthese von Membranlipiden (Bravo et al. 2013). Proteine, die im ER synthetisiert werden, sind Teil der Zellmembran oder zur Sekretion bestimmt. Bevor sie das ER verlassen, gibt es Mechanismen, die sicherstellen, dass nur korrekt gefaltete Proteine weitertransportiert und fehlerhaft gefaltete Proteine abgebaut werden (Ellgaard et al. 1999; Schröder 2008). ER-Stress liegt vor, wenn die Funktion des ERs und somit die Kapazität der Proteinfaltung durch Veränderungen der metabolischen Situation der Zelle eingeschränkt ist. Dies führt zu einer Ansammlung von ungefalteten Proteinen im ER-Lumen (Szegezdi et al. 2006; Schröder 2008; Bahar et al. 2016) und einer Stressantwort, die mit einem erhöhten Vorkommen von ER-Stress-Proteinen, wie zum Beispiel von glucose-regulated protein 78 (GRP78), einhergeht (Kozutsumi et al. 1988; Normington et al. 1989). Diese Reaktion der Zelle wurde als unfolded protein response (UPR) bekannt (Mori 2015). Das Ziel dieser Reaktion ist zunächst durch veränderte Genexpression die Menge an Proteinen zu reduzieren, die sich im ER befindet (Friedlander et al. 2000; Travers et al. 2000) und darüber hinaus die Faltkapazität des ERs durch vermehrte Expression von Chaperonen zu steigern, also von Enzymen, die an der Proteinfaltung beteiligt sind. Chaperone sind zum Beispiel GRP78, Calreticulin (Kozutsumi et al. 1988; Yoshida et al. 1998; Kaufman 1999) und heat shock proteins (HSPs) (Ciocca et al. 2013). Eine Reduktion der ungefalteten Proteine 
im ER-Lumen wird außerdem dadurch erreicht, dass ihr Abbau durch den Prozess der endoplasmic reticulum-associated protein degradation (ERAD) erfolgt (Bravo et al. 2013). So soll die Zelle an den Stress angepasst, die Homöostase des ER wiederhergestellt und das Überleben der Zelle gesichert werden (Schröder und Kaufman 2005a; Ron und Walter 2007). Nimmt das Stressniveau jedoch ein zu hohes Ausmaß an oder liegt dauerhaft vor, kann dies von der Zelle nicht kompensiert werden und der Zelltod wird eingeleitet (Nakagawa et al. 2000; Rao et al. 2001).

Bei der Weiterleitung des Stresssignals über die Membran des ER zum Nukleus sind im Wesentlichen drei Transmembranproteinkinasen beteiligt, und zwar protein kinase RNA-like ER kinase (PERK), inositol-requiring protein-1 (IRE1) und activating transcription factor-6 (ATF6) (Schröder und Kaufman 2005b; Ron und Walter 2007; Mei et al. 2013). Für das Erkennen von ER-Stress und die Einleitung der UPR spielt GRP78 eine besondere Rolle. In Zellen, in denen kein ER-Stress herrscht, bildet GRP78 im ER-Lumen einen stabilen Komplex mit den luminal gelegenen Domänen von PERK und IRE1. Kommt es zu einer Ansammlung von ungefalteten Proteinen, dissoziiert GRP78, und PERK und IRE1 werden aktiviert (Bertolotti et al. 2000). Die Signalkaskade, die dann durch PERK ausgelöst wird, führt zu einer Phosphorylierung des Transkriptionsfaktors eukaryotic translation initiation factor $2 \mathrm{~A}$ (eIF2a). Dies hemmt die Proteinbiosynthese im Allgemeinen. Allerdings wird die Translation bestimmter messenger-Ribonukleinsäuren (mRNA)s gefördert, wie die des Transkriptionsfaktors ATF4 (Wang und Kaufman 2016). Dieser wiederum initiiert die Transkription von Genen, die mit der UPR zusammenhängen, wie zum Beispiel die von Chaperonen (Tameire et al. 2015). Es kann aber auch zur Transkription von C/EBP-homologous protein (CHOP) kommen, was eine Apoptose induzierende Kaskade auslösen kann (Fawcett et al. 1999). Die zweite Signalkaskade, die durch aktiviertes IRE1 angestoßen wird, beginnt mit dem Spleißen von X-box binding protein 1 (XBP1) in seine aktive Form sXBP1. sXBP1 führt ebenfalls zu einer vermehrten Bildung von Proteinen, die an der Proteinfaltung und dem Abbau von Proteinen beteiligt sind (Wang und Kaufman 2016). IRE1 ist zudem selbst in der Lage, mRNAs zu zerstören und dadurch die Proteinladung des ERs zu vermindern (Hollien und Weissman 2006). Die dritte Kaskade beginnt mit einer Translokation von ATF6 in den Golgi-Apparat (Chen X et al. 2002). In der Folge kommt es zur Abspaltung einer löslichen Form von ATF6, die dann im Nukleus die Expression von Genen, wie beispielsweise Chaperonen und CHOP, aktiviert (Yoshida et al. 2000).

ER-Stress erregte ein besonderes Interesse, da er im Zusammenhang mit Erkrankungen wie Diabetes, neurodegenerativen Erkrankungen, Herzerkrankungen (Oyadomari und Mori 2004; Kim et al. 2008), malignen Erkrankungen (siehe 1.5) und Nierenfibrose (Dihazi et al. 2013) beschrieben wurde. 


\subsection{ER-Stress und UPR in Karzinomen}

ER-Stress und die UPR wurden in Zusammenhang mit malignen Erkrankungen untersucht. Da die UPR sowohl eine Überlebensstrategie darstellt als auch zu Apoptose führen kann, stellt sich die Frage, welche Funktion die UPR im Zusammenhang mit Krebserkrankungen einnimmt. Bisher konnte in mehreren soliden Tumoren wie dem hepatozellulären Karzinom (Shuda et al. 2003), dem Magenkarzinom (Song et al. 2001), dem Prostatakarzinom (Daneshmand et al. 2007) und dem Nierenzellkarzinom (Fu et al. 2010) eine Aktivierung der UPR nachgewiesen werden. Dies zeigte sich in den oben genannten Studien unter anderem in einem erhöhten Vorkommen von GRP78.

Tumorzellen befinden sich häufig in ER-Stress Situationen. Die Faktoren, die dazu führen, können in extrinsische und intrinsische Faktoren unterteilt werden. $\mathrm{Zu}$ den extrinsischen Faktoren zählt die Umgebung, in der sich Tumorzellen häufig befinden und die den Zellen das Überleben erschwert (Tameire et al. 2015). So müssen die Zellen in der Lage sein, in Hypoxie, Azidose und Glukosemangel überleben zu können (Ma und Hendershot 2004). Es konnte gezeigt werden, dass eine sauerstoffarme Umgebung neben der Aktivierung von HIF1 alpha zu einer davon unabhängigen Aktivierung des PERK/eIF2a/ATF4-Arms der UPR führte und ein Verlust der Aktivierung mit einem geringeren Überleben der Zellen einherging (Ameri 2004; Bi et al. 2005; Koumenis und Wouters 2006). Weiter wurde der UPR eine Beteiligung an der Regulation der Bildung von VEGF und somit direkt an der Angiogenese zugeschrieben (Ozawa et al. 2001; Blais et al. 2006). Auch ein Mangel an Nährstoffen in Tumorzellen, wie zum Beispiel von Glukose, führte zu einer Aktivierung von ATF4. Dies war für das Tumorwachstum im Nährstoffmangel essentiell (Ye et al. 2010; Huber et al. 2013).

Als intrinsische Faktoren werden Veränderungen der Tumorzelle selbst bezeichnet, die zu einer metabolischen Stresssituation führen (Tameire et al. 2015). Dies kann zum Beispiel durch eine gesteigerte Proliferation, die mit einer gesteigerten Proteinbiosynthese einhergeht, bedingt sein (Buszczak et al. 2014). Ursächlich für die Veränderungen der Zelle sind oft Mutationen in Onkogenen wie c-myc und BRAF. Sowohl in myc- (Hart et al. 2012) als auch in $B R A F^{V 600 E}$ - (Corazzari et al. 2007; Croft et al. 2014) mutierten Zellen wurde eine Aktivierung der UPR nachgewiesen, die für die Tumorgenese und das Überleben der mutierten Zellen essentiell war. Eine Vermutung, weshalb die UPR in Tumorzellen trotz anhaltendem ERStress nicht zu einer Aktivierung der Apoptose-auslösenden Kaskaden führt, betrifft Mutationen von pro-apoptotischen Genen. Diese können die Apoptose-auslösenden Mechanismen der UPR außer Kraft setzten (Ma und Hendershot 2004). Außerdem wurde gezeigt, dass ein verändertes Vorkommen von microRNAs die ER-Stressantwort der Zelle zugunsten der überlebensfördernden Kaskaden verlagerte (Chitnis et al. 2012).

Weitere Untersuchungen befassen sich mit dem Einfluss der UPR auf die Metastasierung. Metastasierende Zellen sind dadurch gekennzeichnet, dass sie sekretorisch sehr aktiv sind, um durch eine Veränderung der extrazellulären Matrix eine Invasion zu ermöglichen. Dieser 
Prozess wird epithelial-to-mesenchymal transition (EMT) genannt und kann durch den Verlust von Adhäsionskontakten und die Sekretion von Matrix-Matalloproteasen oder Komponenten der extrazellulären Matrix erreicht werden (Kalluri und Weinberg 2009). Liegt eine hohe Syntheseleistung in der Zelle vor, kann dies, wie schon oben erwähnt, mit ER-Stress vergesellschaftet sein. In unterschiedlichen Tumoren zeigte sich in vitro und in vivo während der EMT eine Aktivierung der PERK-Kaskade, was die Metastasierung begünstigte (Nagelkerke et al. 2013; Feng et al. 2014). Außerdem konnte ein Zusammenhang von hoher Expression von GRP78 und Bildung von Metastasen in klinischen Studien beobachtet werden (Zhang et al. 2006; Zheng et al. 2008; Zhang et al. 2015).

Ein weiterer interessanter Punkt ist die prognostische Relevanz der UPR. Davies et al. (2008) und Andruska et al. (2015) untersuchten dies in Zellen von Brustkrebspatientinnen. Beide Studien korrelierten eine ausgeprägte Aktivierung der UPR mit einer negativen Prognose bezüglich des Überlebens. In anderen Studien wurde der Zusammenhang der GRP78-Expression und dem klinischen Outcome von Patienten untersucht, die an unterschiedlichen soliden Tumoren erkrankt waren (Hsu et al. 2005; Daneshmand et al. 2007; Zheng et al. 2008; Niu et al. 2015; Shimizu et al. 2016). Mit Ausnahme von Hsu et al. (2005) wiesen alle diese Studien einen Zusammenhang von hohem Vorkommen von GRP78 und einer negativen Prognose bezüglich des Überlebens nach. In Widerspruch dazu korrelierte das Vorkommen von GRP78 in der Studie von Hsu et al. (2005) mit einer besseren Prognose bezüglich des Überlebens.

Insgesamt weisen die vergangenen Forschungsergebnisse darauf hin, dass die UPR für Tumorzellen eine Überlebensstrategie in schwierigen Bedingungen darstellt und die Entstehung und das Fortschreiten von Tumoren fördert (Galmiche et al. 2017).

Im Nierenzellkarzinom konnte ebenfalls ein höheres Vorkommen von GRP78 als in nicht entartetem Vergleichsgewebe nachgewiesen werden. Dabei war ein hohes Level von GRP78 mit einem aggressiveren Verhalten des Tumors assoziiert. Dies zeigte sich in einem größeren Tumor und in einem höheren Tumorstadium (Fu et al. 2010). Weiter bestand eine Assoziation von GRP78-positiven Tumoren und lokal weit fortgeschritten oder metastasierten Tumoren. Patienten, deren Tumoren positiv für GRP78 waren, zeigten ein kürzeres krankheitsspezifisches sowie ein kürzeres progressionsfreies Überleben (Kuroda et al. 2011). Unter hypoxischen oder hypoglykämischen Bedingungen wurde auch bei Zellen des Nierenzellkarzinoms eine Aktivierung der ER-Stressantwort mit Hochregulation von GRP78 beobachtet (Han et al. 2015). Durch eine Hemmung der GRP78-Expression konnte in vitro das Überleben von Tumorzellen in stressauslösenden Bedingungen gesenkt werden (Matsumura et al. 2014; Han et al. 2015). Außerdem zeigte sich im Tierexperiment von Han et al. (2015), dass GRP78 eine wichtige Rolle in der Tumorgenese spielt. Die UPR führte über den IRE1-Arm zu einer Aktivierung von NF- $\varkappa \mathrm{B}$, einem Transkriptionsfaktor, von dem bekannt ist, dass er die Tumorgenese fördert (Tam et al. 2012). Die UPR kann also auch im Nierenzellkarzinom vor allem als tumorfördernd angesehen werden. 
Trotzdem wird auch in Zellen des Nierenzellkarzinoms durch die UPR Apoptose ausgelöst. Eine infolge von Glukosemangel induzierte, länger anhaltende Aktivierung des ATF3-Arms der UPR führte zum Tod von Zellen des Nierenzellkarzinoms in vitro. Eine komplette Blockade der UPR hatte im Glukosemangel den gleichen Effekt (Isono et al. 2014). Dies lässt den Schluss zu, dass insbesondere eine anhaltende Aktivierung der UPR, wie auch in nicht malignen Zellen, zytotoxisch für die Karzinomzellen sein kann.

Interessanterweise sind weitere Mechanismen bekannt, die es Zellen des Nierenzellkarzinoms ermöglichen, ER-Stress zu überwinden. Einen davon stellt der Wildtyp des VHLGens dar, der als Schutz vor ER-Stress beschrieben wurde (Gorospe et al. 1999). Glukosemangel führte in vitro bei VHL-mutierten Zellen im Vergleich zum Wildtyp zu einem erhöhten Maß an Zelluntergang. Auch die Toxizität durch fehlerhaft prozessierte Proteine war für Zellen deutlich geringer, die Träger des Wildtyps des VHL-Gens waren. Einen weiteren Schutz vor durch ER-Stress induzierter Apoptose boten die für das klarzellige Nierenzellkarzinom charakteristischen intrazellulären Lipidtropfen (Qiu et al. 2015). Es konnten gezeigt werden, dass diese Lipidtropfen ER-Stress senken und die Zelle so vor potentiell zytotoxischem ER-Stress schützen. Die Progression des Karzinoms wird dadurch begünstigt.

Es ergeben sich für Tumorzellen also mehrere Wege, der toxischen Wirkung von ER-Stress zu entkommen. Der physiologische Mechanismus der Aktivierung der UPR trägt in Tumorzellen durch Verlagerung in Richtung der überlebensfördernden Kaskaden zur Pathophysiologie von malignen Erkrankungen bei.

\subsection{ER-Stress und die UPR in der Krebstherapie}

Es gibt unterschiedliche Ansätze die durch ER-Stress ausgelösten Kaskaden therapeutisch zu nutzen. Eine Strategie besteht darin, die Apoptose durch ein hohes Niveau an ER-Stress auszulösen (Tameire et al. 2015). Ein Beispiel hierfür ist der Einsatz des Proteasom-Inhibitors Bortezomib (Wang und Kaufman 2016). Das Proteasom übernimmt in der Zelle den Abbau von Proteinen. Dies kann auch ER-Proteine betreffen (Ciechanover und Schwartz 1998). In-vitro-Experimente zeigten, dass die Anwendung von Bortezomib zu einer Akkumulation von ungefalteten Proteinen in der Zelle und somit zu ER-Stress führte, was die proapoptotischen Signalwege der UPR induzierte (Obeng et al. 2006; Meister et al. 2007). Klinisch hat sich Bortezomib in der Therapie des multiplen Myeloms durchgesetzt (Kane et al. 2003), einem Tumor, der durch eine hohe sekretorische Leistung mit exzessiver Produktion von monoklonalen Antikörpern gekennzeichnet ist (The International Myeloma Working Group 2003). In Zellen des multiplen Myeloms wurde eine Aktivierung der UPR, die das Überleben in dieser metabolischen Ausnahmesituation ermöglicht, nachgewiesen (Bagratuni et al. 2010). Vermutlich führt die Therapie mit Bortezomib zu einer Dekompensation dieses Überlebensmechanismuses (Obeng et al. 2006).

Eine weitere Strategie befasst sich mit der gezielten Hemmung von Komponenten der überlebensfördernden Signalwege der UPR in Tumorzellen (Tameire et al. 2015). Wie schon in 
Kapitel 1.5 beschrieben, zeigte sich in unterschiedlichen Karzinomen eine Aktivierung der UPR, die den Tumorzellen ein Überleben unter stressauslösenden Bedingungen ermöglicht. Zur Hemmung eines der drei wesentlichen Arme der UPR wurde ein PERK-Inhibitor entwickelt (Tameire et al. 2015; Cubillos-Ruiz et al. 2017). In in-vivo-Experimenten mit Mäusen, die als Xenograft-Modell für das humane Pankreaskarzinom und das multiple Myelom fungierten, konnte das Tumorwachstums durch eine Behandlung mit dem PERK-Inhibitor gehemmt werden. Außerdem wurde eine schlechtere Gefäßversorgung des Tumors unter Medikation beobachtet (Atkins et al. 2013). Zur Hemmung einer weiteren Achse der UPR wurden Inhibitoren des IRE1/XBP1-Arms entwickelt und erforscht (Papandreou et al. 2011; Tang et al. 2014). Auch hier wurde der Effekt auf hämatologische Tumoren untersucht. Papandreou et al. (2011) zeigten eine antitumoröse Wirkung in vitro und in vivo in XenograftModell-Mäusen für das multiple Myelom und Tang et al. (2014) eine tumorprogressionshemmende Wirkung in vivo im Mausmodell der chronisch lymphatischen Leukämie.

Die Hemmung von Chaperonen, wie GRP78 oder HSPB1, stellt eine zweite Strategie zur Hemmung der überlebensfördernden Mechanismen der Zelle dar. In unterschiedlichen Tumoren führte eine hohe GRP78-Expression in vitro zu Resistenz gegenüber Chemotherapie (Reddy et al. 2003; Dong et al. 2005; Pyrko et al. 2007). Die Resistenz bezog sich dabei auf klassische Chemotherapeutika wie Alkylanzien und Topoisomerase-Inhibitoren (Reddy et al. 2003; Pyrko et al. 2007) und Angiogenese-Hemmer (Dong et al. 2005). Die Kombination aus einer Hemmung der GRP78-Expression mit den oben genannten konventionellen Medikamenten führte in vitro und in vivo in unterschiedlichen Tumoren zu einer Steigerung der Effektivität der Therapie (Dong et al. 2005; Pyrko et al. 2007; Han et al. 2015). Bezüglich der Therapie mit Angiogenese-Hemmern wird angenommen, dass durch die Hemmung von GRP78 die Anpassungsfähigkeit der Zelle an den durch verminderte Gefäßneubildung ausgelösten ER-Stress gesenkt wird (Han et al. 2015). Auch HSPB1 wurde mit Chemoresistenz assoziiert (Andrieu et al. 2010; Taba et al. 2010). In in-vitro- und in-vivo-Experimenten konnte das Ansprechen auf Taxane durch eine Regulation von HSPB1 nach unten in unterschiedlichen Tumoren gesteigert werden (Rocchi et al. 2006; Kamada et al. 2007). Die Ergebnisse der präklinischen Experimente waren so vielversprechend, dass sich Hemmstoffe von HSPB1 in der klinischen Erprobung urologischer Tumoren befinden (Chi et al. 2012; Bellmunt et al. 2015). Die Hemmung von Chaperonen könnte in Zukunft also einen neuen Ansatz in der Krebstherapie darstellen.

In der Forschung bezüglich der Therapie des Nierenzellkarzinoms werden ähnliche Ansätze verfolgt. Auch hier konnte der Zelltod durch die Induktion eines hohen Maßes an ER-Stress ausgelöst werden (Jang et al. 2016). In in-vitro-Experimenten löste die Behandlung mit Bortezomib in unterschiedlichen Nierenzellkarzinom-Zelllinien den Zelltod aus (An et al. 2004). Im Rahmen von klinischen Studien war der Effekt von Proteasom-Inhibitoren auf die Tumorerkrankung von Patienten mit metastasiertem Nierenzellkarzinom jedoch enttäuschend. Es zeigten sich nur geringe Ansprechraten von 5\% und 11\%. Der Anteil der Patienten, bei denen unter Therapie der Status quo erhalten werden konnte, lag mit 28\% und 38\% etwas 
höher (Davis et al. 2004; Kondagunta et al. 2004). Diese Datenlage führte dazu, dass Bortezomib in der Therapie des fortgeschrittenen Nierenzellkarzinoms nicht etabliert werden konnte. In weiteren präklinischen Experimenten wurde der Versuch unternommen, das Aus$\mathrm{maß}$ an ER-Stress durch die Kombination von zwei ER-Stress auslösenden Agenzien wie Proteasom-Inhibitoren und Histon-Deacetylase-Inhibitoren noch weiter zu steigern (Sato et al. 2014; Isono et al. 2016). Inhibitoren der Histon-Deacetylase führten zu einer stärkeren Inaktivierung des Chaperons HSP90 und durch Verlust seiner Funktion zu einer Akkumulation ungefalteter Proteine (Bali et al. 2005). In in-vitro-Experimenten mit Nierenzellkarzinom-Zelllinien konnte durch die oben genannte Kombination der zytotoxische Effekt gesteigert werden. Das Auftreten von ER-Stress wurde dabei nachgewiesen (Sato et al. 2014; Isono et al. 2016). Ein weiterer Test bestand in der Kombination zweier unterschiedlicher Inhibitoren des Proteasoms. Auch diese Kombination konnte in in-vitro-Experimenten mit Nierenzellkarzinom-Zelllinien und in in-vivo-Xenograft-Mausmodellen die Effektivität der Therapie steigern (Sato et al. 2012). In anderen in-vitro-Experimenten wurde eine Kombination aus Bortezomib und dem aus der Diabetes-Therapie bekannten peroxisom proliferator-activated Rezeptor-gamma-Liganden (PPAR- $\gamma$ ) Troglitazon erprobt (von Schwarzenberg et al. 2009). Interessanterweise führten Glitazone zu ER-Stress (Weber et al. 2004) und zeigten eine antitumoröse Wirkung in Zellen des Nierenzellkarzinoms. Die Kombination von Glitazonen mit Bortezomib führte zu einem stärkeren Ausmaß an ER-Stress und zu einer Steigerung des zytotoxischen Effekts (von Schwarzenberg et al. 2009).

Ebenso wie in anderen Tumoren wurde auch in Nierenkarzinomzellen die Hemmung des Chaperons GRP78 als experimenteller Therapieansatz verfolgt. Die Induktion von ERStress in Kombination mit einer Hemmung der Expression von GRP78 steigerte in vitro die Effektivität der antitumorösen Behandlung (Matsumura et al. 2014; Han et al. 2015). Zurzeit muss noch evaluiert werden, ob diese größtenteils experimentellen, präklinischen Ansätze auch in klinischen Studien erfolgreich sind. Bisher ist die Nutzung von ER-Stress oder eine Blockade von Teilen der UPR in der Therapie des Nierenzellkarzinoms nicht üblich (Leitlinie Nierenzellkarzinom 2015).

\subsection{Die Proteindisulfidisomerase ERp57}

Endoplasmic reticulum resident protein (ERp) 57, das auch GRP58 oder Proteindisulfidisomerase (PDI) A3 genannt wird, ist ein vor allem im ER gelegenes $57 \mathrm{kDA}$-schweres Protein, das zu der Familie der Proteindisulfidisomerasen gehört (Ferrari und Söling 1999; Turano et al. 2002). Es enthält mehrere Thioredoxin-like Domänen und ist an der Bildung von Disulfidbrücken beteiligt (Ellgaard und Frickel 2003). Im Komplex mit den ER-Chaperonen Calreticulin und Calnexin spielt ERp57 eine wichtige Rolle in der Bildung, der Faltung und der Qualitätskontrolle von Glykoproteinen (Zapun et al. 1998; Oliver et al. 1999; Kang und Cresswell 2002). Außerdem wird ERp57 eine Bedeutung in der Zusammensetzung des MHCKlasse-I-Komplexes in dem ER zugeschrieben (Lindquist et al. 1998; Turano et al. 2002). 
Als Co-Chaperon ist ERp57 zusätzlich Teil der Stressantwort der Zelle (Schröder und Kaufman 2005b; Shishkin et al. 2013). ERp57 wurde in Krebserkrankungen (Kapitel 1.8) und Nierenerkrankungen untersucht. Dabei gab es Hinweise, dass ERp57 an der Progression der Nierenfibrose beteiligt ist (Dihazi et al. 2013).

\subsection{ERp57 und Krebs}

Die Rolle von ERp57 in der Karzinogenese und Therapie von Krebserkrankungen wurde ebenso wie die anderer Chaperone untersucht. Dabei fiel ein auffällig hohes Vorkommen von ERp57 in Tumoren auf. Sowohl in Zellkultur-Analysen des hepatozellulären Karzinoms (Liu et al. 2017), der akuten myeloischen Leukämie (AML) (Trivedi et al. 2016a) und Prostatakarzinomzellen (Basu et al. 2016) als auch in Analysen von Gewebe oder Zellen von Karzinompatienten mit hepatozellulärem Karzinom (Takata et al. 2016; Liu et al. 2017), Ovarialkarzinom (Chay et al. 2010) und dem Adenokarzinom der Lunge (Chen G et al. 2002) konnte im Vergleich zu nicht-tumorösem Gewebe ein erhöhtes Vorkommen von ERp57 nachgewiesen werden. In Gewebeproben von Tumoren des Magens (Leys et al. 2007) und der Zervix (Chung et al. 2013) zeigte sich andererseits nur ein geringes Vorkommen von ERp57.

Weiter wurde der Einfluss von ERp57 auf den Krankheitsprogress sowie sein prognostischer Wert untersucht. Die Proliferation von Zellen des Ovarialkarzinoms wurde in vitro durch ein hohes Vorkommen von ERp57 gesteigert (Zhao et al. 2015). Eine Regulation von ERp57 nach unten führte in vitro zu einer Hemmung der Proliferation von Karzinomzellen gynäkologischer Tumoren (Lwin et al. 2012; Zhao et al. 2015). In einer Auswahl gynäkologischer Tumoren begünstigte das Vorkommen von ERp57 die Metastasierung (Liao et al. 2011; Santana-Codina et al. 2013). Krankheitsprogress und Therapieresistenz des Mammakarzinoms standen ebenfalls in Zusammenhang mit der stärkeren Genexpression von Proteinen des Faltapparats des ERs, wie ERp57 (Wise et al. 2016). In klinischen Studien zum hepatozellulären Karzinom (Liu et al. 2017), zum Larynxkarzinom (Choe et al. 2015) und zum Zervixkarzinom (Liao et al. 2011) wurde eine hohe Expression von ERp57 als prognostisch ungünstig beschrieben. In den Fällen allerdings, in denen in Tumoren nur ein geringes Vorkommen von ERp57 beschrieben wurde, war auch dieses prognostisch ungünstig (Leys et al. 2007; Chung et al. 2013).

ERp57 wurde eine Rolle in der Resistenz gegenüber Chemotherapie (Cicchillitti et al. 2010; Zhao et al. 2015) und Radiotherapie (Choe et al. 2015) zugesprochen. Durch eine Regulation der ERp57-Expression nach unten konnte die Resistenz gegenüber Agenzien überwunden werden, die ER-Stress auslösten. So steigerte die Hemmung der ERp57-Expression mit siRNA das Ansprechen von AML-Zellen in vitro auf eine Shikonin-Behandlung (Trivedi et al. 2016a) und das Ansprechen von Zellen neuroektodermaler Tumoren in vitro auf eine Be- 
handlung mit Fenritinid (Corazzari et al. 2007). Auch das Ansprechen von Zellen des Ovarialkarzinoms auf Taxane wurde in vitro durch eine Hemmung von ERp57 gesteigert und durch eine Regulation nach oben gehemmt (Zhao et al. 2015).

Insgesamt stellt ERp57 also ein Protein dar, das in vielerlei Hinsicht als karzinomfördernd gesehen werden kann. Durch seine potentielle Beteiligung in der Chemoresistenz kann es sich gegebenenfalls als ein geeignetes Target in der zielgerichteten Therapie herausstellen.

\subsection{Zielsetzung der Arbeit}

In der Therapie des fortgeschrittenen Nierenzellkarzinoms besteht weiterhin viel Forschungsbedarf. Insbesondere die Resistenz gegenüber konventionellen und neuen Therapieformen birgt Probleme (Costa und Drabkin 2007; Fischer et al. 2015). Eine Möglichkeit zur Identifizierung von Proteinen, die Chemoresistenz begünstigen, stellen proteomische Analysen dar (Taba et al. 2010; Trivedi et al. 2016b). Die ER-Stressantwort oder UPR, die in Folge von ER-Stress eingeleitet wird, ist ein Mechanismus, der im Zusammenhang mit Tumorentstehung und Tumorprogress untersucht wurde (Tameire et al. 2015; Galmiche et al. 2017). Es gibt Hinweise, dass die Aktivierung der UPR zu einer Resistenz gegenüber unterschiedlichen Therapeutika führt (Reddy et al. 2003; Dong et al. 2005; Pyrko et al. 2007). Ein Beispiel dafür ist Cisplatin, ein klassisches Chemotherapeutikum, für das eine Aktivierung der UPR als Schutzmechanismus vor dem durch Cisplatin ausgelösten Zelltod beschrieben wurde (Jiang et al. 2009; Chen et al. 2011; Shi et al. 2016). Als Chaperon und Teil der UPR wurde die Proteindisulfidisomerase ERp57 im Speziellen mit Krebsentstehung und Chemoresistenz in Verbindung gebracht (Chen G et al. 2002; Cicchillitti et al. 2010; Santana-Codina et al. 2013; Liu et al. 2017). Das Vorkommen von ERp57 zeigte sich als proliferationsfördernd für Karzinomzellen (Lwin et al. 2012; Zhao et al. 2015). In in-vitro-Experimenten konnte durch die Regulation dieses Proteins nach unten die Effizienz der Behandlung mit Chemotherapeutika gesteigert werden (Corazzari et al. 2007; Zhao et al. 2015; Trivedi et al. 2016a). Bezogen auf das Nierenzellkarzinom erwies sich die Regulation von Chaperonen nach unten in vitro als Möglichkeit zur Steigerung des antitumorösen Effekts von Tumorbehandlungen (Matsumura et al. 2014; Han et al. 2015).

Daraus ergaben sich folgende Hypothesen:

Die Vermutung,

- dass durch die proteomische Analyse der mit Cisplatin behandelten NierenzellkarzinomZelllinien Proteine identifiziert werden können, die das Ansprechen auf die Behandlung mit Cisplatin beeinflussen.

- dass in Nierenzellkarzinom-Zellinien durch die Behandlung mit Cisplatin die UPR aktiviert wird.

- dass die ER-Stressantwort in Nierenzellkarzinom-Zelllinien in der Resistenz gegenüber Cisplatin beteiligt ist.

- $\quad$ dass ERp57 im Speziellen an der Resistenz gegenüber Cisplatin beteiligt ist und die Resistenz durch eine Regulation von ERp57 überwunden werden kann. 
- $\quad$ dass ERp57 in Nierenzellkarzinomen die Proliferation der Zellen unterstützt.

Zur Überprüfung dieser Hypothesen wurden in dieser Arbeit zwei etablierte Nierenzellkarzinom-Zelllinien untersucht. Dabei wurden die Auswirkungen einer Behandlung mit Cisplatin auf das Proliferations- und Apoptoseverhalten der Zelllinien betrachtet. Dann wurden signifikante Veränderungen des Proteoms der Zelllinien nach Behandlung mit Cisplatin erfasst, wobei insbesondere die Regulation der Proteindisulfidisomerase ERp57 von Interesse war. Außerdem wurde das Verhalten der Zellen nach einer Expressionsregulation von ERp57 mit und ohne Behandlung mit Cisplatin analysiert. 


\section{Material und Methoden}

\subsection{Material}

\subsubsection{Chemikalien, Kits und Antikörper}

1,4-Dithiothreitol (DTT)

1-Butanol

2-(4-(2-Hydroxyethyl)-1-piperazinyl)ethansulfonsäure (HEPES) (1M)

2-Mercaptoethanol

Acetonitril

Aminosäuren, nicht essentiell (100x)

Ammoniumbikarbonat (Ambic)

Ammoniumperoxidisulfat (APS)

Ampuwa ${ }^{\circledR}$

Bio-Lyte ${ }^{\circledR}$ 3/10 40\%

Bio-Rad Protein Assay Dye Reagent Concentrate

Bromphenolblau

Calciumchlorid $\left(\mathrm{CaCl}_{2}\right)$

CHAPS

Cisplatin

Dulbecco's Modified Eagle Medium (1x) (DMEM)

Dulbecco's Phosphate-Buffered Saline (1x) (DPBS)

Eindeckmedium mit 4',6-Diamidin-2-phenylindol (DAPI)

Essigsäure

Ethanol
Carl Roth GmbH + Co. KG, Karlsruhe Merck KGaA, Darmstadt Gibco $^{\text {TM }}$ by Life Technologies, Grand Island, NY, USA

Sigma-Aldrich, Steinheim Carl Roth $\mathrm{GmbH}+$ Co. KG, Karlsruhe PAA Laboratories GmbH, Pasching, Österreich

Sigma-Aldrich, Steinheim

Sigma-Aldrich, Steinheim

Fresenius Kabi Deutschland GmbH, Bad Homburg

Bio-Rad Laboratories, Hercules, CA, USA

Bio-Rad Laboratories, München

Sigma-Aldrich, Steinheim

Merck KGaA, Darmstadt

Merck KGaA, Darmstadt

EMD chemicals Inc., San Diego, USA

Gibco $^{\text {TM }}$ by Life Technologies, Paisley, UK

Gibco $^{\text {TM }}$ by Life Technologies, Paisley, UK

Vector laboratories, Inc, Burlingame, CA, USA

Carl Roth GmbH + Co. KG, Karlsruhe

Th. Geyer GmbH \& Co. KG, Renningen 
Ethylendiamintetraessigsäure (EDTA)

Flamingo ${ }^{\mathrm{TM}}$ Fluorescent Gel Stain

Fetales Kälberserum (FCS)

Geneticin G418 Sulphate

Glycerol

Glycin

Ziegenserum

Iodoacetamid

Isopropanol

Kupfer(II)-sulfat-Pentahydrat

L-Glutamin

Lipofectamine ${ }^{\circledR} 2000$ Reagent

Magermilchpulver

Methanol

Mineralöl

$\mathrm{N}, \mathrm{N}, \mathrm{N}^{\prime}, \mathrm{N}^{6}$-Tetramethylethylenediamin (TEMED)

Natriumcholrid

Natriumdodecylsulfat (SDS)

Natronlauge

Opti-MEM (1x)

Ponceau S-Lösung

Penicillin/ Streptomycin

Precision Plus Protein ${ }^{\text {TM }}$ Standards Kaleidoscope

Roti ${ }^{-B l u e}$
Merck KGaA, Darmstadt

Bio-Rad Laboratories, Hercules, CA, USA

Invitrogen ${ }^{\mathrm{TM}}$ by Life Technologies, Eugene, Oregon, USA

Gibco $^{\text {TM }}$ by Life Technologies, Paisley, UK

Merck KGaA, Darmstadt

Carl Roth GmbH + Co. KG, Karlsruhe

Sigma-Aldrich, St Louis, MO, USA

Sigma-Aldrich, St Louis, MO, USA

Merck KGaA, Darmstadt

Merck KGaA, Darmstadt

Sigma-Aldrich, Steinheim

Invitrogen $^{\mathrm{TM}}$ by Life Technologies, Carlsbad, USA

Merck KGaA, Darmstadt

Carl Roth GmbH + Co. KG. Karlsruhe

Bio-Rad Laboratories, Hercules, CA, USA

Sigma-Aldrich, Steinheim

Merck KGaA, Darmstadt

Fluka, Steinheim

Merck KGaA, Darmstadt

Gibco $^{\text {TM }}$ by Life Technologies, Grand Island, NY, USA

SERVA Electrophoresis GmbH, Heidelberg

Gibco $^{\mathrm{TM}}$ by Life Technologies, Paisley, UK

Bio-Rad Laboratories, Hercules, CA, USA

Carl Roth GmbH + Co. KG, Karlsruhe 
Rotiphorese ${ }^{\circledR}$ Gel 30, Acrylamidstammlösung mit 0,8 \% Bisacrylamid (37,5:1)

RPMI Medium 1640 1x

Salzsäure

Sequazyme ${ }^{\mathrm{TM}}$ BSA Test Standards

Simethyl-Sulphoxid (DMSO)

Trifluoressigsäure (TFA)

Tris(hydroxymethyl)-aminomethan (Tris)

Tris(hydroxymethyl)-aminomethan

(Tween $\left.{ }^{\circledR} 20\right)$ 0,1\%

Triton X-100, reduziert

Trypsin

Trypsin/Lys-C Mix

Urea

XT MOPS

\section{Kits}

Alexa Fluor 488 Annexin V/ Dead Cell Apoptosis Kit

Cell Proliferation Kit I (MTT)

Nucleic Acid and Protein Purification Kit

\section{Antikörper}

Alexa Fluor 488 Affe anti-Ziege IgG

Alexa Fluor 488 Ziege anti-Kaninchen IgG

Alexa Fluor 555 Ziege anti-Maus IgG

Alexa Fluor 647 Ziege anti-Maus IgG

Anti-Beta-Aktin Maus

Anti-ERp57 Maus

Anti-GRP78 Kaninchen
Carl Roth GmbH + Co. KG, Karlsruhe

Gibco $^{\text {TM }}$ by Life Technologies, Paisley, UK

Merck KGaA, Darmstadt

Applied Biosystems, Foster City, CA, USA

Sigma-Aldrich, Steinheim

Merck KGaA, Darmstadt

Carl Roth $\mathrm{GmbH}+$ Co. KG, Karlsruhe

Carl Roth GmbH + Co. KG, Karlsruhe

Fluka Chemie AG, Buchs, Schweiz

Gibco $^{\text {TM }}$ by Life Technologies, Paisley, UK

Promega Corporation, Madison, WI, USA

Sigma-Aldrich, Steinheim

Bio-Rad Laboratories, Hercules, CA, USA

Molecular probes by Life Technologies, Eugene, Oregon, USA

Roche Diagnostics GmbH, Mannheim

Macherey-Nagel GmbH \& Co. KG, Düren, Deutschland

Invitrogen $^{\mathrm{TM}}$ by Life Technologies, Eugene, Oregon, USA

Invitrogen ${ }^{\mathrm{TM}}$ by Life Technologies, Eugene, Oregon, USA

Life Technologies, Eugene, Oregon, USA

Life Technologies, Eugene, Oregon, USA

Sigma-Aldrich, Steinheim

Enzo life sciences, Lörrach

Sigma-Aldrich, Steinheim 


\subsubsection{Zusammensetzung von Puffern und Lösungen}

Äquilibierpuffer

Bromphenolblau-Lösung

Coomassie-Brilliant-Blau

Elektrophoresepuffer

(5x):

Fixierlösung

G418-Lösung

Lysepuffer

Medium + G418

Medium für A498-Zellen

Medium für Caki-2-Zellen

Milch-Blockpuffer

Probenpuffer (4x)

\section{Rehydratationspuffer}

Sammelgel 4\%

Transferpuffer (1x)

Transferpuffer (5x)

Trenngel 12\%

Triton-X-Lösung
6 M Urea, 30\% (w/v) Glycerol, 2\% (w/v) SDS, 0,05 M Tris- $\mathrm{HCl} \mathrm{pH} 8,8(1,5 \mathrm{M})$

Tris-HCl pH8,8 (1,5 M), 0,25\% (w/v) Bromphenolblau $\mathrm{ddH}_{2} \mathrm{O}, 20 \%$ (v/v) Methanol, 20\% (v/v) Roti®-Blue $30 \mathrm{~g}$ Tris, $144 \mathrm{~g}$ Glycin, $10 \mathrm{~g}$ SDS auf $21 \mathrm{ddH}_{2} \mathrm{O}$

$\mathrm{ddH}_{2} \mathrm{O}, 50 \%$ (v/v) Methanol, $12 \%$ (v/v) Essigsäure 1,6 g G418, 200 ml Medium 9,5M Urea, 2\% (w/v) CHAPS, $1 \%(\mathrm{w} / \mathrm{v})$ DT'T, 2\% (v/v) Bio-Ampholyte Medium für Caki-2 oder A498-Zellen, 6\% G418 (v/v) DMEM-Medium, 10\% (v/v) FCS, 1\% (v/v) Penicillin/ Streptomycin, $1 \%$ (v/v) L-Glutamin (0,2 M)

RPMI1640-Medium, 10\% (v/v) FCS, 2\% (v/v) nicht essentielle Aminosäuren, 1\% (v/v) Penicillin/ Streptomycin, $1 \%$ (v/v) L-Glutamin (0,2 M), 2,5\% (v/v) HEPES

Waschpuffer (1x), 5\% (w/v) Magermilchpulver

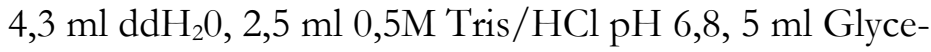
rin, $8 \mathrm{ml} \mathrm{10 \%} \mathrm{SDS,} 200 \mu \mathrm{l} \%$ (v/v) Bromphenolblau, frisch hinzugegeben wurden 2\% (v/v) 2-Mercaptoethanol 8 M Urea, 1\% (w/v) CHAPS, 15 mM DTT und 0,2\% (v/v) Ampholyte, einige Mikroliter Bromphenolblau

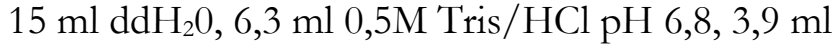
Acrylamid, $125 \mu \mathrm{l} 10 \%$ (w/v) APS, $250 \mu \mathrm{l} 10 \%$ (w/v) SDS, $25 \mu \mathrm{l}$ TEMED

$20 \%$ (v/v) Transferpuffer (5x), 20\% (v/v) Methanol, $\mathrm{ddH}_{2} \mathrm{O}$

30,3 g Tris, $144 \mathrm{~g}$ Glycin, $5 \mathrm{~g}$ SDS auf 2 Liter $\mathrm{ddH}_{2} \mathrm{O}$

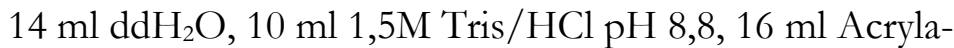
mid, $200 \mu \mathrm{l} 10 \%$ (w/v) APS, $400 \mu \mathrm{l} 10 \%$ (w/v) SDS, $30 \mu \mathrm{l}$ TEMED

DPBS, 0,1\% (v/v) Triton-X 100 
Trypsin/EDTA

Verdaupuffer

Verdaupuffer + Trypsin

Waschpuffer (5x)
0,825 g EDTA, 10\% (v/v) Trypsin (2,5\%), mit DPBS auffüllen auf $500 \mathrm{ml}$ $\mathrm{ddH}_{2} \mathrm{O}, 2,5 \%$ (v/v) Ammoniumbicarbonat (1 M), 0,5\% (v/v) $\mathrm{CaCl}_{2}(1 \mathrm{M})$

Verdaupuffer, $12,5 \%$ (v/v) Trypsin $(0,1 \mu \mathrm{g} / \mu \mathrm{l})$ 12,11 g Tris, 58,44 g NaCl, 10ml Tween ${ }^{\circledR} 20$ auf 11 ddH20, pH 7,4

\subsubsection{Verbrauchsmaterialien}

Cell-scraper $25 \mathrm{~cm}$

Criterion $^{\mathrm{TM}}$ XT Precast Gel

Deckgläser 24 x 60 mm

Filterpapier

Handschuhe

Küvetten $(10 \times 4$ x 45 mm)

Labortücher

Nitrozellulose Blotting Membran

Pasteurpipetten aus Glas

Pipettenspitzen $10 \mu \mathrm{l}$

Pipettenspitzen $1000 \mu \mathrm{l}, 200 \mu \mathrm{l}$

Präzisionswischtücher

ReadyStrip ${ }^{\text {TM }}$ IPG Strips $11 \mathrm{~cm}$, pH 5-8

Reaktionsgefäß 0,6 ml

Reaktionsgefäß $2 \mathrm{ml}$

Reaktionsgefäß $50 \mathrm{ml}, 15 \mathrm{ml}$

Rührspatel $120 \mathrm{~mm}$
Sarstedt AG \& Co, Newton, USA

Bio-Rad Laboratories, Hercules, CA, USA

Menzel-Gläser, Braunschweig

Bio-Rad Laboratories GmbH, München

Rösner-Mautby Meditrade GmbH, Kiefersfelden

Sarstedt AG \& Co, Nümbrecht

Kimberly-Clark Professional, Reigate, UK

GE Healthcare Life Sciences, Freiburg

Brand GmbH + Co., Wertheim

Eppendorf AG, Hamburg

Sarstedt AG \& Co., Nümbrecht

Kimberly-Clark Professional, Reigate,

UK

Bio-Rad Laboratories, Hercules, CA, USA

Biozym Scientific GmbH, Hessisch

Oldendorf

Eppendorf AG, Hamburg

Sarstedt AG \& Co., Nümbrecht

Sarstedt AG \& Co, Nümbrecht 
Rundbodenröhrchen $5 \mathrm{ml}$

Schnelldesinfektionsmittel

Serologische Pipette $20 \mathrm{ml}$

Serologische Pipette $5 \mathrm{ml}, 10 \mathrm{ml}$

Zellkulturflasche, $75 \mathrm{~cm}^{2}$

Zellkulturplatte, 6 Well

Zellkulturplatte, 96 Well

\subsubsection{Geräte}

Biomedizinischer Kühlschrank MDF-U5312

Durchflusszytometer FACS Canto $^{\text {TM }}$ II

Elektrophorese-Set Mini-PROTEAN® 3 Cell

Plattenreader Appliskan@ ${ }^{\circledR}$ Typ 2001

Vlies

Fluoreszenz System Brenner U-RFL-T

Inkubator 3548

Kühlzentrifuge 3-18K

Massenspektrometer Q-TOF Ultima ${ }^{\mathrm{TM}}$

Mikroskop Axiovert 25

Mikroskop IX71 (Fluoreszenz)

Multipette M4

Pipetten 100-1000 $\mu \mathrm{l}, 10-100 \mu \mathrm{l}, 0,5-10 \mu \mathrm{l}$, $50 \mu \mathrm{l}, 100 \mu \mathrm{l}, 200 \mu \mathrm{l}, 1000 \mu \mathrm{l}$

Pipettierhelfer accu-jet ${ }^{\circledR}$ pro

Pipettierhelfer pipetus ${ }^{\circledR}$
BD Falcon ${ }^{\mathrm{TM}}$, Durham, USA

Braun Melsungen AG, Melsungen

Greiner bio-one, Kremsmüns-

ter, Oberösterreich

Sarstedt AG \& Co., Nümbrecht

BD Falcon ${ }^{\mathrm{TM}}$, Durham, USA

Falcon ${ }^{\circledR}$ by Corning incorporated, New York, USA

Sarstedt AG \& Co, Newton, NC, USA

Panasonnic Healthcare, Tokio, Japan

BD Biosciences, Franklin Lakes, USA

Bio-Rad Laboratories GmbH, München

Thermo Scientific, Waltham, Massachusetts, USA

Bio-Rad Laboratories GmbH, München

Olympus Corporation, Hamburg, Deutschland

Forma scientific Inc., Marietta, USA

Sigma Laborzentrifugen GmbH, Osterode

Micromass ${ }^{\circledR}$, Manchester, UK

Carl Zeiss AG, Jena

Olympus Corporation, Hamburg

Eppendorf AG, Hamburg

Eppendorf AG, Hamburg

Brand GmbH + Co, Wertheim

Hirschmann Laborgeräte GmbH \&

Co. KG, Eberstadt 
Protean ${ }^{\circledR}$ IEF Cell

Scanner FLA-5100

Schwenkplatte Polymax2040

Schwenkplatte Typ 3005

Speed Vakuum-Zentrifuge, SVC $10 \mathrm{CH}$

Sterilbank, Gelaire TypBSB4A

Stromquelle für Elektrophorese PS 3002

Tank-Blotting System Criterion ${ }^{\mathrm{TM}}$ Blotter

Thermomixer comfort

Thermo-Schwenkplatte lab-shaker Modell Kühner

Tischkühlzentrifuge 1-15PK

Ultraschallreinigungsbad Sonorex RK 255 H

UV/ VIS Spectrometer Lamda 25

Waage U3800

Wasserbad 1083

Vortexmixer REAX 2000

Zentrifuge 5415 D
Bio-Rad Laboratories, München, Deutschland

Fujifilm life science, Stamford, USA

Heidolph Instruments $\mathrm{GmbH}$ \&

Co.KG, Schwabach

GFL (Gesellschaft für Labortechnik), Burgwedel

Savant, Holbrook, NY, USA

Flow Laboratories, USA

Thermo Fisher Scientific, Carlsbad, USA

Bio-Rad Laboratories GmbH, München

Eppendorf AG, Hamburg

B. Braun Melsungen AG, Melsungen

Sigma Laborzentrifugen GmbH, Osterode

BANDELIN electronic GmbH \& Co. KG, Berlin

PerkinElmer LAS GmbH, Rodgau-Jugesheim

Sartorius AG, Göttingen

GFL (Gesellschaft für Labortechnik), Burgwedel

Heidolph Instruments $\mathrm{GmbH}$ \& Co.KG, Schwabach

Eppendorf AG, Hamburg

\subsubsection{Wissenschaftliche Softwares}

Cell D 3.4

Olympus, Hamburg

Delta 2D Version 4.2 Final 02

DECODON GmbH, Greifswald

Excel 2013 und 2016
Microsoft, Redmond, USA 
FACSDiva $^{\text {TM }}$ Version 6.1.3

iCys ${ }^{\circledR} 3.4 .12$

Image Reader FLA-5000 V3.0

Image J $1.48 \mathrm{v}$

Proteindatenbank „DAVID Bioinformatics Resources" 6.8

Proteindatenbank „Mascot“

Proteindatenbank „UniProt“

SkanIt Software 2.3 for Appliskan

Statistica 13
BD Biosciences, Franklin Lakes, USA

CompuCyte Corporation, Westwood, USA

Fujifilm life science, Stamford, USA

National Institut of Health, USA

https:/ / david.ncifcrf.gov

http://www.matrixscience.com

http://www.uniprot.org

Thermo Scientific, Waltham, USA

Dell Technologies Inc., Round Rock, USA

\subsubsection{Biologisches Material}

\subsubsection{Zelllinien}

Die Zelllinie A498 wurde isoliert und etabliert aus dem Nierenzellkarzinom einer 52 Jahre alten Patientin. In den meisten Fällen wird die Zelllinie als Modell für ein klarzelliges Nierenzellkarzinom genutzt (Brodaczewska et al. 2016). Die Zelllinie Caki-2 wurde aus dem Primärtumor eines klarzelligen Nierenzellkarzinoms eines 69 Jahre alten Patienten isoliert und etabliert. Bei beiden Zelllinien handelt es sich um einschichtig wachsende, adhärente Zellen, die kommerziell vom american tissue culture collection (ATCC) erworben wurden und schon in der Arbeitsgruppe vorhanden waren.

\subsubsection{2 siRNA}

Zur Regulation der Expression von ERp57 nach unten wurden von der Firma Eurofins MWG Operon synthetisierte siRNA-Oligonukleotide verwendet, die in der Arbeitsgruppe, in der diese Arbeit durchgeführt wurde, designend worden waren. Diese hatten folgende Sequenz: 
sense-Strang 5' ACC TCG TCC TTC ACA TCT CAC TAA CAT CAA GAG TGT TAG TGA GAT GTG AAG GACT'T 3“

antisense-Strang 3' CAA AAA GTC CTT' CAC ATC TCA CTA ACA CTC T'TG ATG TTA GTG AGA TGT GAA GGACG 5‘

\subsubsection{Plasmid}

Zur Regulation der Expression von ERp57 nach oben wurde das zuvor gereinigte Plasmid cDNA3.1-ERp57 (freundlicherweise zur Verfügung gestellt von Dr. Neil Bulleid von der Universität in Glasgow) genutzt. Dieses enthielt die Information zur Regulation von ERp57 nach oben und die Information einer Resistenz gegenüber dem Antibiotikum G418, was als Selektionsmarker für erfolgreich transfizierte Zellen diente. Außerdem enthielt das Plasmid die Information über eine Resistenz gegenüber Ampicillin, was für die Resistenz des Bakterienstamms in der Plasmidreinigung von Bedeutung war.

\subsection{Methoden}

\subsubsection{Zellkultur}

Die Zelllinien A498 und Caki-2 wurden in Zellkulturflaschen aus Polystyrol mit einer Polyethylenkappe und einer Grundfläche von $75 \mathrm{~cm}^{2}$ in einem Inkubator bei $37{ }^{\circ} \mathrm{C}$ und $5 \%$ $\mathrm{CO}_{2}$-Begasung sowie in Anwesenheit eines Wasserbads mit gelöstem Kupfersulfat-Pentahydrats aufbewahrt. Als Zellmedium diente für die Caki-2-Zelllinie modifiziertes RPMI1640-Medium und für die A498-Zelllinie modifiziertes Dulbecco's Modified Eagle Medium (DMEM)-Medium. Ein Mediumwechsel wurde alle zwei bis drei Tage durchgeführt. Es erfolgten regelmäßige mikroskopische Kontrollen der Konfluenz und des Zellwachstums sowie die mikroskopische Überprüfung auf Infektionen durch Mikroorganismen.

Um die Zellen vor Kontaminationen zu schützen, wurden alle Arbeitsschritte unter einer Sterilbank mit laminarer Strömung und unter Verwendung von sterilen Materialien durchgeführt.

\subsubsection{Passagieren der Zellen}

Sobald die Zellen Konfluenz erreicht hatten, wurden sie gesplittet, um erneut optimale Wachstumsbedingungen herzustellen und ein Absterben der Zellen zu vermeiden. Hierfür wurde das verbrauchte Medium abgesaugt und der Zellrasen mit vorgewärmten Dulbecco's Phosphate-Buffered Saline (DPBS) gewaschen, um Mediumreste und gegebenenfalls tote Zellen zu entfernen. Dann wurden die Zellen mit $1 \mathrm{ml}$ Trypsin/ Ethylendiamintetraessigsäure (EDTA) benetzt. Dieses wurde abgesaugt und die benetzten Zellen wurden wenige Minuten bei $37^{\circ} \mathrm{C}$ inkubiert. Es folgte eine mikroskopische Überprüfung der morphologi- 
schen Veränderung der Zellen und ein Ablösen durch leichtes Klopfen gegen die Zellkulturflasche. Nun wurde das Trypsin durch mehrmaliges Spülen des Flaschenbodens mit frischem Medium neutralisiert und es wurde eine Zellsuspension erstellt, die dann in gewünschter Verdünnung neu ausgesät wurde.

\subsubsection{Behandlung mit Cisplatin}

Beide Zelllinien wurden jeweils mit einer Konzentration von $50 \mu \mathrm{M}$ Cisplatin behandelt. Zur Orientierung für eine geeigneten Dosis dienten Vorexperimente von Trivedi et al. (2016b). Dort zeigte sich in einer 24-stündigen Behandlung von Caki-2-Zellen in einem Annexin V/ dead cell apoptosis assay mit unterschiedlichen Dosen von Cisplatin für eine Dosis von $50 \mu \mathrm{M}$ eine Apoptoserate von 50\% der gemessenen Zellpopulation.

\subsubsection{Herstellen eines Gesamtzelllysats}

Bei Erreichen von 80-90\% Konfluenz wurden die Zellen geerntet. Zuerst wurde das verbrauchte Medium abgesaugt und die Zellen mit DPBS gewaschen. Dann wurden die Zellen mit Hilfe eines cell-scrapers mechanisch vom Flaschenboden gelöst, in DPBS aufgenommen und in ein Reaktionsgefäß überführt. Das Vorgehen wurde wiederholt, um ein Maximum von Zellen zu ernten. Anschließend wurde die Zellsuspension bei $4{ }^{\circ} \mathrm{C}$ mit $1200 \mathrm{rpm}$ für fünf Minuten zentrifugiert und das Pellet mit DPBS resuspensiert. Nach einer weiteren dreiminutigen Zentrifugation mit $1200 \mathrm{rpm}$ wurde der Überstand verworfen und das Pellet in einer an die Pelletgröße angepassten Menge (20-70 $\mu \mathrm{l}$ ) Lysepuffer gelöst. Die Probe wurde 30 Minuten auf Eis gelegt und in zehnminütigen Abständen mit Hilfe eines Vortexmixers vermischt. Es schloss sich eine Zentrifugation mit $14000 \mathrm{rpm}$ bei $4{ }^{\circ} \mathrm{C}$ für 30 Minuten an. Der Überstand, der die freigewordenen und gelösten Zellbestandteile enthielt, wurde in ein sauberes Reaktionsgefäß überführt und erneut bei gleicher Einstellung zentrifugiert. Der nun gewonnene, von unlöslichen Zellbestandteilen befreite, Überstand bildete das Gesamtzelllysat und wurde bei $-20^{\circ} \mathrm{C}$ gelagert, falls er nicht direkt weiterverwendet wurde.

\subsubsection{Proteinbestimmung nach Bradford}

Zur Bestimmung der Proteinkonzentration des gewonnenen Zelllysats wurde das Protokoll von Bradford verwendet, das eine photometrische Bestimmung der Konzentration ermöglicht (Bradford 1976). Mit einer BSA-Stammlösung (1 mg/ml) wurde zunächst eine Eichkurve erstellt. Hierzu wurde das Bradford-Reagenz im Verhältnis 1:5 mit doppelt destilliertem Wasser $\left(\mathrm{ddH}_{2} \mathrm{O}\right)$ verdünnt, gemäß Tabelle 1 mit BSA-Stammlösung in Küvetten pipettiert und mit Rührstäbchen gut gemischt. Die hergestellte Lösung wurde zehn Minuten bei Raumtemperatur inkubiert. Dann wurde die Extinktion bei $595 \mathrm{~nm}$ in einem Photometer gemessen. 
Tabelle 1: Pipettierschema zur Erstellung einer Eichkurve

\begin{tabular}{ll}
\hline BSA-Stammlösung & Verdünntes Bradford-Reagenz \\
\hline $0 \mu \mathrm{l}$ & $1000 \mu \mathrm{l}$ \\
$2 \mu \mathrm{l}$ & $998 \mu \mathrm{l}$ \\
$4 \mu \mathrm{l}$ & $996 \mu \mathrm{l}$ \\
$6 \mu \mathrm{l}$ & $994 \mu \mathrm{l}$ \\
$8 \mu \mathrm{l}$ & $992 \mu \mathrm{l}$ \\
$10 \mu \mathrm{l}$ & $990 \mu \mathrm{l}$ \\
\hline
\end{tabular}

Nach Erstellen einer geeigneten Eichkurve wurde eine Lösung aus dem Zelllysat in Verdünnungen von 1:10 oder 1:20 und verdünntem Bradford-Reagenz hergestellt (je nach Proteingehalt 2-10 $\mu$ l verdünntes Zelllysat auf 998-990 $\mu$ l verdünntes Bradford-Reagenz) und dann wurde weiter so verfahren wie bereits für die Eichkurve beschrieben. Es wurde eine Doppelbestimmung durchgeführt. Anhand der gemessenen Extinktion sowie mit Hilfe der Eichkurve konnte die Konzentration berechnet werden.

\subsubsection{Western Blot}

Die Western Blots wurden in Anlehnung an das Protokoll von Towbin (Towbin et al. 1979) durchgeführt. Dabei wurden die Proteine der Proben zuerst mit Hilfe einer sodium dodecyl sulfate polyacrylamide gel electrophoresis (SDS-PAGE) nach ihrer Größe aufgetrennt und dann elektrisch von einem Polyacrylamidgel auf eine Membran aus Nitrozellulose übertragen. Das Muster der elektrophoretisch aufgetrennten Proteine blieb bei der Übertragung erhalten. Mit Hilfe von spezifischen Antikörpern wurden in der Folge die zu analysierenden Proteine sichtbar gemacht.

\subsubsection{Vorbereitung der Mini-Gele für die SDS-PAGE}

Die SDS-PAGE wurde nach dem Protokoll nach Laemmli (Laemmli 1970) durchgeführt. Die hierfür benötigten Polyacrylamidgele wurden eigenständig hergestellt und bestanden aus einem Trenngel und aus einem Sammelgel. Das Trenngel wurde als erstes gemischt und für die Polymerisation in eine Haltevorrichtung gegossen. Anschließend wurde auf das noch flüssige Gel gleichmäßig Butanol pipettiert.

Nachdem das Trenngel vollständig polymerisiert war, wurde das Butanol verworfen und die Reste wurden mit Hilfe eines Filterpapiers entfernt. Dann wurde das Sammelgel gemischt und auf das Trenngel aufgetragen. Durch Einsetzen eines Kammes wurden im Sammelgel 
Probetaschen geformt. Luftblasen in den Gelen wurden vermieden. Nach vollständiger Polymerisation des Sammelgels wurden die Gele entweder direkt verwendet oder mit feuchten Tüchern und Alufolie verpackt und bei $4{ }^{\circ} \mathrm{C}$ für wenige Tage gelagert.

\subsubsection{Durchführung der SDS-PAGE}

Die Proben wurden für die SDS-PAGE vorbereitet, indem eine $70 \mu \mathrm{g}$ entsprechende Menge mit Probenpuffer und $\mathrm{ddH}_{2} \mathrm{O}$ auf ein Volumen von $20 \mu \mathrm{l}$ aufgefüllt wurde. Anschließend wurden die Proben für zehn Minuten bei $96{ }^{\circ} \mathrm{C}$ in einem Kochblock erwärmt. Ziele dieser Schritte waren eine Denaturierung und dadurch Linearisierung der Proteine sowie die Herstellung einer konstanten negativen Ladung, was in der nachfolgenden Elektrophorese eine Auftrennung abhängig von der Molekülmasse ermöglichte.

Für die Elektrophorese wurden die Gele in eine Haltevorrichtung innerhalb einer Elektrophorese-Kammer eingespannt, und die Kammer wurde mit 1x Elektrophoresepuffer befüllt. Dann wurden die vorbereiteten Proben in die Taschen des Sammelgels pipettiert. Als Referenz für das entsprechende Molekulargewicht wurde ein Marker in eine eigene Tasche pipettiert. Die Elektrophorese wurde auf Eis durchgeführt und die ersten zehn Minuten mit 150 $\mathrm{V}$ gestartet, um die Probe im oberen Teil des Gels zu sammeln. Dann wurde die Spannung auf 200 V erhöht. Es kam zu einer Wanderung der durch das SDS negativ geladenen Proteine in Richtung der Anode. Hierbei wanderten kleine Proteine schneller und weiter als große. Nach etwa 45 Minuten oder bei Erreichen des Gelendes wurde die Elektrophorese beendet.

\subsubsection{Durchführung des Tankblottings}

In der Vorbereitung wurden Vlies und ein entsprechend der Größe des Gels zurechtgeschnittenes Stück Nitrozellulose-Membran zehn Minuten in gekühltem 1x Transferpuffer eingelegt. Das Gel wurde aus den Haltegläsern entfernt und ein Blot-Sandwich wurde gemäß Abbildung 1 gebaut.

Kathode

Vlies

Filterpapier

Elektrophorese-Gel

Nitrozellulose-Membran

Filterpapier

Vlies

Anode

Abbildung 1: Anordnung des Blot-Sandwich

Abbildung 1 zeigt die korrekte Anordnung des Blot-Sandwich. Dabei liegt die Nitrozellulose-Membran dem Elektrophorese-Gel anodenwärts auf und ermöglicht so bei Anlegen eines senkrecht zum Gel stehenden elektrischen Feldes eine Übertragung der negativ gladdener Proteine von dem Gel auf die Membran. 
Um eine luftfreie Kontaktfläche zwischen Membran und Gel zu gewährleisten, wurde die Schichtung in Transferpuffer vorgenommen und die Membran mit Hilfe einer Rolle an das Gel gedrückt. Anschließend wurde das Blot-Sandwich in die Haltekassette eines Tankblotting-Systems eingespannt und das System mit kaltem Transferpuffer befüllt. Der Proteintransfer wurde 90 Minuten bei $60 \mathrm{~V}$ auf Eis durchgeführt.

\subsubsection{Färbung mit Ponceau S}

Um den Erfolg des Proteintransfers zu überprüfen, wurde die Membran mit Ponceau SLösung angefärbt. Dies ermöglichte eine Darstellung der übertragenen Proteinbanden. Im nächsten Schritt folgte die Entfärbung der Membran in 5\% (v/v) Essigsäure sowie die anschließende Trocknung bei Raumluft.

\subsubsection{Blocken}

Zur Vermeidung von unspezifischen Reaktionen der im Folgenden eingesetzten Antikörper wurden nun noch freie Proteinbindungsstellen durch Milch-Blockpuffer blockiert. Dies geschah durch Inkubation der in Blockpuffer eingelegten Membran für mindestens zwei Stunden unter Schwenken bei $37^{\circ} \mathrm{C}$.

\subsubsection{Proteindetektion durch spezifische Antikörper}

Die Darstellung der Proteine erfolgte durch die Detektion der jeweiligen Proteine mit spezifischen primären Antikörpern. Diese wurden in einem vom Hersteller für Western Blots empfohlenen Verhältnis mit Milch-Blockpuffer gemischt (Tabelle 2) und dann auf die Nitrozellulose-Membran gegeben, so dass diese vollständig bedeckt war. Zunächst wurde eine Stunde bei $37^{\circ} \mathrm{C}$ inkubiert. Dann folgte eine Inkubation über Nacht im Kühlraum. Beide Schritte geschahen auf Schwenkplatten.

Tabelle 2: Empfohlenes Verhältnis für Antikörper im Western Blot

\begin{tabular}{ll}
\hline Antikörper & Verdünnung \\
\hline Primäre Antikörper & \\
Anti-ERp57 Maus & $1: 1000$ \\
Anti-Beta-Aktin Maus & $1: 1000$ \\
Sekundäre Antikörper & \\
Anti-mouse 647 nm Ziege & $1: 2500$ \\
\hline
\end{tabular}

Am nächsten Morgen wurde die Membran drei Mal für jeweils zehn Minuten bei $37^{\circ} \mathrm{C}$ in Waschpuffer geschwenkt. Um die gebundenen, primären Antikörper sichtbar zu machen, 
wurde ein fluoreszenzmarkierter sekundärer Antikörper eingesetzt, der sich gegen herkunftsspezifische Antigene des primären Antikörpers richtete. Der Antikörper wurde in einer vom Hersteller empfohlenen Verdünnung (Tabelle 2) mit Milch-Blockpuffer gemischt und die damit benetzte Nitrozellulose-Membran für zwei Stunden bei $37^{\circ} \mathrm{C}$ inkubiert.

Es schlossen sich drei Waschschritte mit Waschpuffer für jeweils zehn Minuten bei $37^{\circ} \mathrm{C}$ an. Anschließend wurde die Membran getrocknet, lichtgeschützt transportiert und dann mit Hilfe eines Scanners bei der Laserlinie von $635 \mathrm{~nm}$ mit $700 \mathrm{~V}$ entwickelt und digitalisiert.

\subsubsection{Auswertung der Western Blots}

Die Intensität der interessanten Proteinbanden wurde mit dem Programm „Image J“ quantifiziert. Als housekeeping-Protein wurde Beta-Aktin genutzt, dessen Expression in den Zellen gleich bleibt. Beta-Aktin diente als Ladekontrolle und als Kontrolle der Menge an geladenem Protein. Die Intensität der Bande des zu untersuchenden Proteins wurde dann ins Verhältnis zu der Intensität der Bande von Beta-Aktin gesetzt und dieses Verhältnis verglichen. So wurden Intensitätsunterschiede in den untersuchten Banden ausgeschlossen, die durch unterschiedlich geladene Proteinmengen entstanden sind.

\subsubsection{Plasmidreinigung}

Die Plasmidreinigung wurde nach dem Protokoll „NucleoBond®-Isolierung von high-copy Plasmiden“ der Firma Macherey-Nagel durchgeführt. Zunächst wurde in Ampicillin-haltigem LB Medium eine Bakterienkultur von E. coli angesetzt, die Träger des Plasmids waren. Der Zusatz des Antibiotikums war notwendig, um Selektionsdruck für plasmidtragende Bakterien auszuüben. Nur die plasmidtragenden Bakterien trugen die Resistenz gegen das Antibiotikum und ohne Selektionsdruck wäre es im Rahmen der Zellteilung zu dem Verlust des Plasmids gekommen. Bei Erreichen einer ausreichenden Bakteriendichte wurden die Bakterien durch eine Zentrifugation für 15 Minuten bei $4{ }^{\circ} \mathrm{C}$ pelletiert und der Überstand wurde verworfen. Dann wurde das Pellet mit dem Puffer S1 und der Lösung RNase A durch Aufund Abpipettieren resuspensiert. Es folgte die Zelllyse durch Zugabe von Puffer S2 und ein vorsichtiges Mixen durch Invertieren des Gefäßes. Dann wurde bei Raumtemperatur für maximal fünf Minuten inkubiert, wobei sich eine visköse Flüssigkeit bildete. Vorgekühlter (4 $\left.{ }^{\circ} \mathrm{C}\right)$ Puffer S3 wurde zum Zweck der Neutralisation zugefügt, das Gefäß vorsichtig sechs bis acht Mal invertiert und für fünf Minuten auf Eis inkubiert. Es bildete sich ein flockiges, weißes Präzipitat, das gefällte Zellproteine und genomische DNA enthielt. Ein Filter wurde

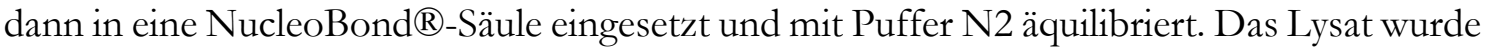
auf den Filter gegeben, was zu einer Klärung des Präzipitats führte. Dann wurde es in die Säule geladen und lief anschließend durch. Um noch verbliebenes Lysat zu gewinnen, wurden im Anschluss der Filter und die Säule mit Puffer N2 gewaschen. Nach Entfernung des Filters wurde die Säule mit Puffer N3 gewaschen. Dies führte zu einem Auswaschen von noch verbliebenen Salzen. Die sich nun in der Membran der Säule befindende Plasmid-DNA wurde durch Zugabe von Puffer N5 eluiert, aufgefangen und durch Zugabe von Isopropanol 
gefällt. Durch Vortexen wurde gründlich gemischt und dann für 30 Minuten bei $4{ }^{\circ} \mathrm{C}$ zentrifugiert. Der Überstand wurde vorsichtig verworfen. Das aus Plasmid-DNA bestehende Pellet wurde mit 70\% (v/v) Ethanol gewaschen, gut gemixt und dann zehn Minuten bei Raumtemperatur zentrifugiert. Der Überstand wurde vorsichtig entfernt und das DNA-Pellet bei Raumtemperatur getrocknet. Zum Abschluss wurde das Pellet in sterilem Wasser gelöst und die Konzentration des gewonnenen Plasmids wurde mit Hilfe eines Photometers bestimmt.

\subsubsection{Transfektion mit Expressionsregulation von ERp57}

Transfektion ist eine Methode, die das Einbringen von genetischem Material in eine Zelle ermöglicht. In der vorliegenden Arbeit wurde die Lipofektion, eine spezielle Form der Transfektion, angewendet. Hier bilden kationische Lipide mit den negativ geladenen Nukleinsäuren Komplexe, die mit der Zellmembran interagieren und durch Fusion mit dieser das genetische Material in die Zelle schleusen (Felgner et al. 1987). Als kationisches Reagenz diente Lipofectamine ${ }^{\circledR}$. Das genetische Material bestand aus einem DNA-Plasmid zur Überexpression von ERp57 und siRNA-Primern zur Hemmung der ERp57-Expression.

Die Transfektion wurde gemäß dem Protokoll des Herstellers mit in unserer Arbeitsgruppe etablierten Modifizierungen durchgeführt. Zum Zeitpunkt der Transfektion hatten die Zellen eine Konfluenz von 70-80\% erreicht. Die Transfektion wurde in $75 \mathrm{~cm}^{2}$ großen Zellkulturflaschen durchgeführt, in denen das Medium eine Stunde vor Transfektion auf $9 \mathrm{ml}$ des Mediums opti-MEM® umgestellt wurde. Anschließend wurden zwei Ansätze gemäß Tabelle 3 hergestellt. Ein Ansatz enthielt opti-MEM ${ }^{\circledR}$ und das genetischen Material, der zweite enthielt opti-MEM® und Lipofectamine $\AA$.

Beide Ansätze wurden bei Raumtemperatur für fünf Minuten inkubiert. Dann wurde jeweils der Ansatz 1 mit dem Ansatz 2 vermischt und das Gemisch wurde nach einer 30-minütigen Inkubation bei Raumtemperatur in die Zellkulturflasche eingetropft und gut verteilt. Die Zellkulturflaschen wurden bei $37^{\circ} \mathrm{C}$ im Inkubator aufbewahrt, und die Transfektion wurde nach sechs bis sieben Stunden durch einen Wechsel auf das jeweilige Standardmedium beendet. Dabei wurden mit dem Plasmid transfizierte Zellen in G418-haltigem Medium kultiviert, um einerseits nicht erfolgreich transfizierte Zellen zu eliminieren und andererseits einen Selektionsdruck zugunsten plasmidtragender Zellen auszuüben. Die Bestätigung der Transfektion erfolgte im Western Blot. 
Tabelle 3: Pipettierschema zur Transfektion

\begin{tabular}{|c|c|c|c|}
\hline Ziel der Transfektion & Zelllinie & Ansatz 1 & Ansatz 2 \\
\hline $\begin{array}{l}\text { Regulation von ERp57 } \\
\text { nach oben }\end{array}$ & A498 & $\begin{array}{l}24 \mu \mathrm{g} \text { Plasmid- } \\
\text { DNA }+500 \mu \mathrm{l}-(24 \\
\mu \mathrm{g} / \mathrm{DNA}-\text { Konzent- } \\
\text { ration) optiMEM® }\end{array}$ & 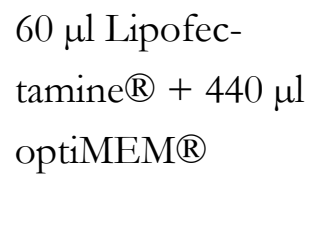 \\
\hline $\begin{array}{l}\text { Regulation von ERp57 } \\
\text { nach oben }\end{array}$ & Caki-2 & $\begin{array}{l}20 \mu \mathrm{g} \text { Plasmid- } \\
\text { DNA }+500 \mu \mathrm{l}-(20 \\
\mu \mathrm{g} / \mathrm{DNA}-\text { Konzent- } \\
\text { ration) optiMEM }{ }^{-}\end{array}$ & $\begin{array}{l}60 \mu \mathrm{l} \text { Lipofec- } \\
\text { tamine } \AA+440 \mu \mathrm{l} \\
\text { optiMEM } \AA\end{array}$ \\
\hline $\begin{array}{l}\text { Regulation von ERp57 } \\
\text { nach unten }\end{array}$ & $\begin{array}{l}\text { A498, } \\
\text { Caki-2 }\end{array}$ & $\begin{array}{l}\text { 2x } 434 \text { pmol siRNA } \\
+500 \mu l-(2 x \text { ( } 434 \\
\text { pmol/siRNA-Kon- } \\
\text { zentration)) opti- } \\
\text { MEM® }\end{array}$ & $\begin{array}{l}43 \mu \text { l Lipofec- } \\
\text { tamine } \AA+457 \mu l \\
\text { optiMEM } \AA\end{array}$ \\
\hline
\end{tabular}

\subsubsection{Indirekte Immunfluoreszenzfärbung}

Die indirekte Immunfluoreszenzfärbung wurde nach einem in unserer Arbeitsgruppe vorliegenden Protokoll durchgeführt. Dabei wurden die zu untersuchenden Proteine zuerst mit einem für das jeweilige Protein spezifischen primären Antikörper markiert, der dann im darauffolgenden Schritt mit einem fluoreszenzmarkierten sekundären Antikörper detektiert wurde. Dies ermöglichte eine fluoreszenzmikroskopische Darstellung des zu untersuchenden Proteins und eine örtliche Zuordnung innerhalb der Zelle.

\subsubsection{Durchführung der Färbung}

Die Zellen wurden am Vorabend der Färbung in nicht zu dichter Konfluenz ausgesät. Am nächsten Tag begann die Färbung mit der Fixierung der Zellen. Hierfür wurden die Zellen zuerst mit DPBS gewaschen und dann für 20 Minuten mit auf $-20{ }^{\circ} \mathrm{C}$ gekühltem Methanol inkubiert. Das Methanol wurde abgesaugt und die Zellen mit DPBS gewaschen. Dann wurden die Zellen mit Triton-X-Lösung benetzt und für 30 Sekunden inkubiert. Dies führte zu einer Permeabilisierung der Zellmembran. Es schloss sich ein weiterer Waschschritt mit DPBS an. Danach wurde für eine Stunde mit 10\% (v/v) Ziegenserum inkubiert, um unspezifische Proteinbindungsstellen zu blocken. Darauf folgte die Inkubation mit den in Ziegenserum verdünnten primären Antikörpern (Tabelle 4), vorerst für eine Stunde bei $37{ }^{\circ} \mathrm{C}$ und dann über Nacht im Kühlraum. Die Inkubation wurde unter Schwenken durchgeführt. Außerdem wurde zeitgleich mit zwei unterschiedlichen primären Antikörpern inkubiert. 
Am nächsten Tag wurden die Zellen mit DPBS gewaschen und mit den für die primären Antikörper spezifischen in Ziegenserum gelösten sekundären Antikörpern für eine Stunde unter Schwenken bei $37^{\circ} \mathrm{C}$ inkubiert (Tabelle 4). Hierbei wurde darauf geachtet, dass beide sekundären Antikörper bei unterschiedlichen Wellenlängen fluoreszieren, um eine Unterscheidung bei der folgenden mikroskopischen Darstellung zu ermöglichen. Es folgte ein weiterer Waschschritt und die Vorbereitung der Objektträger, bei der die Kerne mit einem 4',6Diamidin-2-phenylindol (DAPI)-haltigen Eindeckmedium angefärbt wurden. Die gefärbten Zellen wurden luftdicht mit einem Deckgläschen verschlossen.

Tabelle 4: Empfohlenes Verhältnis für Antikörper in Immunofluoreszenzfärbungen

\begin{tabular}{ll}
\hline Antikörper & Verdünnung \\
\hline Primäre Antikörper & \\
Anti-ERp57 Maus & $1: 100$ \\
Anti-GRP 78 Kaninchen & $1: 50$ \\
Sekundäre Antikörper & \\
Anti-Maus $555 \mathrm{~nm}$ & $1: 500$ \\
Anti-Kaninchen $488 \mathrm{~nm}$ & $1: 500$ \\
\hline
\end{tabular}

\subsubsection{Mikroskopie und Auswertung}

Die Aufnahme der Bilder erfolgte mit einem Fluoreszenzmikroskop und unter Verwendung der Programme „Icys“ und „CellD“. Hierbei wurden die bei unterschiedlichen Wellenlängen aufgenommenen Bilder farblich unterlegt, wobei die bei $555 \mathrm{~nm}$ (entsprechend an ERp57 gebundene Antikörper) aufgenommenen Bilder rot, die bei $488 \mathrm{~nm}$ (entsprechend an GRP78 gebundene Antikörper) aufgenommenen Bilder grün und die mit DAPI gefärbten bei 358 $\mathrm{nm}$ aufgenommenen Kerne blau unterlegt wurden. Alle drei gefärbten Einzelbilder wurden in ein Bild zusammengeführt und dann wurde die Lokalisation der Proteine verglichen. Dabei diente GRP78 als Protein, das vor allem im ER vorkommt (Casas 2017), als Orientierung für die Lage des ERs in der Zelle.

\subsubsection{MTT-Assay}

Der MTT-Assay wurde in Anlehnung an das Protokoll von Mosman (Mosmann 1983) und das Protokoll des Herstellers des Zellproliferations-Kits durchgeführt. Der Assay ist eine Methode zur kolorimetrischen Darstellung der Zellviabilität und Zellproliferation. Durch die Zugabe von wasserlöslichem gelben 3-(4,5-Dimethylthiazol-2-yl)-2,5-diphenyltetrazoliumbromid (MTT), das durch mitochondriale und endoplasmatische Enzyme und Nicotinamidadenindinukleotidphosphat (NADP) zu wasserunlöslichem blau-violetten Formazan reduziert wird, ist es möglich, durch die Intensität der Verfärbung auf die Menge lebendiger, 
metabolisch aktiver Zellen zu schließen, da nur diese im Stande sind, die Reduktion durchzuführen. Zur Quantifizierung der Verfärbung wurde die Extinktion mit einem Plattenreader gemessen.

Zu Beginn erfolgte die Aussaat der transfizierten Zellen und der Kontrollzellen auf eine 96Well-Platte. Jede Gruppe („Kontrolle“/ „mit dem Plasmid transfizierte Zellen“ / „mit siRNA transfizierte Zellen") wurde in doppelter Menge ausgesät, um für jede in Folge mit Cisplatin behandelte Zellgruppe ein nicht behandeltes Pendant zu haben. Innerhalb einer Platte wurden acht bis zehn Replikate ausgesät. Hierbei wurde beachtet, dass die Konfluenz der Zellen ausreichend dünn war, um einen Proliferationsstop durch zu hohe Konfluenz zu vermeiden. Außerdem war die Anzahl ausgesäter Zellen pro Well für jede Zellgruppe gleich, um eine Vergleichbarkeit der Messungen zu gewährleisten. Am Folgetag wurde ein Mediumwechsel durchgeführt sowie die Behandlung der Zellen innerhalb eines Wells mit $50 \mu \mathrm{M}$ Cisplatin.

Nach 24, 48 und 72 Stunden wurde die Behandlung und Beobachtung der Proliferation für jeweils eine Platte beendet, und die Zellen wurden für die Messung vorbereitet.

Nach Ablauf des gewünschten Zeitraums wurden pro Well $10 \mu \mathrm{l}$ MT'T labeling reagent hinzugegeben. Die Zellen wurden hiermit vier Stunden im Inkubator gelagert. Nach Ablauf dieser Zeit ließ sich die blau-violette Verfärbung durch die Bildung des Formazans beobachten. Die unlöslichen Formazan-Kristalle wurde durch die Zugabe von $100 \mu$ l solubilization solution gelöst und die Platten mit einem Plattenreader bei $570 \mathrm{~nm}$ vermessen.

Insgesamt ergaben sich 33-35 Messwerte für jede Gruppe. Der Mittelwert der Extinktionswerte und das 95\%-Konfidenzintervall jeder Gruppe wurden bestimmt und im Zeitverlauf mit Hilfe des Programms „Statistica“ graphisch dargestellt. Die Werte wurden auf die zweite Nachkommastelle gerundet. Um signifikante Unterschiede zwischen den einzelnen Gruppen zu berechnen, wurde der Bonferroni-Test angewandt. In der Auswertung der Werte der mit Cisplatin behandelten Zellgruppen wurde der Mittelwert aus den Verhältnissen der Extinktion der behandelten Zellen zu der Kontrolle der betroffenen Zellgruppe berechnet (Beispiel: Extinktion der Zellen, die mit dem Plasmid transfiziert und mit Cisplatin behandelt wurden/Extinktion der Zellen, die mit dem Plasmid transfiziert wurden zum gleichen Zeitpunkt). Die Standardabweichung wurde berechnet und ein Unterschied zwischen den transfizierten Zellen und den nicht transfizierten Zellen zu dem Zeitpunkt 24 Stunden, 48 Stunden und 72 Stunden mit Hilfe des t-Tests festgestellt. Hierbei galt $\mathrm{p}<0,05$ als signifikant.

\subsubsection{Annexin V/ dead cell apoptosis assay}

Die Analyse der sterbenden Zellen wurde mit dem Alexa Fluor 488 Annexin V/ Dead Cell Apoptosis Kit nach dem Protokoll des Herstellers durchgeführt. Diese Methode macht sich den Umstand zu Nutze, dass apoptotische Zellen in der frühen Phase der Apoptose Phosphatidylserin (PS), ein eigentlich nur auf der intrazellulären Seite der Plasmamembran vor- 
kommendes Molekül, auf der extrazelluläre Seite exprimieren, ohne die Integrität der Membran zu verlieren. Annexin V hat eine hohe Bindungsaffinität zu PS und kann somit PS exprimierende Zellen markieren (van Engeland et al. 1996). Nukleinsäuren können durch Propidium Iodid (PI) markiert werden. Eine Bindung an Nukleinsäuren der Zellen ist nur bei toten Zellen möglich, die die Membranintegrität im Prozess des Zelltods verloren haben. Dies ermöglicht die Differenzierung innerhalb einer Zellpopulation (Tabelle 5).

Tabelle 5: Schema zur Interpretation der Ergebnisse des Annexin V/ dead cell apoptosis assay

\begin{tabular}{lll}
\hline Label der Zelle & Bedeutung des Labels & $\begin{array}{l}\text { Entspricht in dem Dia- } \\
\text { gramm der Auswertung }\end{array}$ \\
\hline Annexin V - / PI - & Lebende Zelle & Q3 \\
Annexin V + / PI - & Früh-apoptotische Zelle & Q4 \\
Annexin V + / PI + & Tote Zelle in später & Q2 \\
& Apoptose oder Nekrose & \\
\hline
\end{tabular}

Da sowohl Annexin V als auch PI unterschiedlich fluoreszenzmarkiert sind, kann eine Sortierung der Zellen mit einem fluorescence-activated cell sorting (FACS)-Gerät vorgenommen werden.

Für die Durchführung des Assays wurden die Zellen auf 6-Well-Platten in etwa 60-70\% Konfluenz ausgesät. Am Folgetag erfolgte ein Mediumwechsel und die Behandlung der Zellen mit $50 \mu \mathrm{M}$ Cisplatin pro Well. Zu jeder behandelten Zellgruppe gab es eine unbehandelte Kontrollgruppe. Nach 42 Stunden Behandlung der A498 Ziellinie mit Cisplatin und 24 Stunden Behandlung der Caki-2-Zelllinie wurde das Medium abgesaugt und für nicht mit Cisplatin behandelte Zellen verworfen. Das Medium der mit Cisplatin behandelten Zellen wurde getrennt in dafür vorgesehenen Reaktionsgefäßen aufgefangen. Nachdem die Zellen gewaschen, durch Trypsin vom Plattenboden gelöst und in Medium suspendiert wurden, wurden die gleichartig behandelten Zellen in dafür vorgesehenen Reaktionsgefäße gefüllt, so dass Zellen mehrerer Wells in einem Rektionsgefäß zu liegen kamen. Dann folgte eine kurze Zentrifugation mit $1100 \mathrm{rpm}$ und ein einmaliges Waschen mit DPBS.

Die Chemikalien des Alexa Fluor 488 Annexin V/ Dead Cell Apoptosis Kits wurden vorbereitet. Hierfür wurde 5 x Annexin-Binde Puffer mit $\mathrm{ddH}_{2} \mathrm{O}$ auf 1 x Annexin-Binde-Puffer verdünnt. Weiter wurde PI im Verhältnis 1:10 mit 1x Annexin-Binde-Puffer gemischt. Anschließend wurden die gewaschenen Zellen erneut zentrifugiert und die Pellets mit jeweils $100 \mu \mathrm{l}$ 1x Annexin-Binde-Puffer resuspensiert und in dafür vorgesehene FACS-Röhrchen überführt. Es folgte die Zugabe von jeweils $5 \mu$ Alexa Fluor 488 Annexin V und $1 \mu$ der zuvor hergestellten PI-Lösung zu jedem Röhrchen. Als Negativ- und Positivkontrolle wurde ein Röhrchen ohne Zusatz belassen und in zwei weitere Röhrchen wurde jeweils nur ein 
Zusatz (PI oder AnnexinV) hinzugefügt. Nach 15 Minuten Inkubation in abgedunkelten Verhältnissen bei Raumtemperatur wurde zu jedem Röhrchen $200 \mu$ l Annexin-Binde-Puffer gegeben und leicht gemischt. Dann wurden die Röhrchen auf Eis gelagert. Nun konnte die Analyse mit einem FACS-Gerät stattfinden. Insgesamt wurde das Experiment für Caki-2Zellen drei Mal wiederholt, für A498-Zellen zwei Mal.

Die Analyse der Ergebnisse erfolgte mit Hilfe des Programms „FACSDiva Version 6.1.3“ und anhand Tabelle 5. In der Analyse des Programms „FACSDiva“" wurde quantifiziert, welcher Anteil der gemessenen Zellpopulation in welchem Quadranten lokalisiert war. Ein besonderes Augenmerk lag dabei auf der Fraktion der früh apoptotischen Zellen (Q4). Für die mit der Caki-2-Zelllinie durchgeführten Experimente lagen jeweils drei bis vier Werte vor, aus denen der Mittelwert und die Standardabweichung berechnet wurden. Für die mit der A489 Zelllinie durchgeführten Experimente lagen lediglich zwei Werte vor, aus denen der Mittelwert gebildet wurde.

\subsubsection{D-Gelelektrophorese}

Die 2D-Gelelektrophorese wurde in Anlehnung an die Protokolle von O'Farrell (O'Farrell 1975) und Klose (Klose 1975) und an in der Arbeitsgruppe vorliegenden Protokollen durchgeführt. Sie ist eine Methode, die die isoelektrische Fokussierung, eine Auftrennung von Proteinen gemäß ihrem isoelektrischen Punkt, und die SDS-PAGE vereint. Durch die Auftrennung der Proteine in zwei Dimensionen ist eine Analyse des gesamten Proteoms der Zellen möglich.

\subsubsection{Die erste Dimension: Isoelektrische Fokussierung}

Für die isoelektrische Fokussierung wurden zuerst fertige immobilisierte pH-Gradient (IPG)-Streifen aufgetaut, auf denen sich ein Polyacrylamidgel mit einem eingearbeiteten Gradienten von pH 5-8 befand. Dann wurde der Rehydratationspuffer mit einer $150 \mu \mathrm{g}$ entsprechenden Menge der Probe so gemischt, dass ein Gesamtvolumen von $175 \mu$ l entstand. Jede Probe wurde in eine Kammer des Fokussiergeräts gegeben, die zuvor ordentlich mit Ethanol gereinigt und getrocknet worden war. Dann wurde der IPG-Streifen mit der Gelseite zur Flüssigkeit weisend blasenfrei und gemäß der vorgegebenen Ausrichtung von Anode und Kathode in die Kammer gelegt. Nach 30-45 Minuten Inkubation wurde jeder Streifen mit 2 $\mathrm{ml}$ Mineralöl benetzt und dann abgedeckt in das Fokussiergerät gestellt. Das Fokussierprogramm lief entsprechend Tabelle 6 . 
Tabelle 6: Fokussierprogramm

\begin{tabular}{ll}
\hline Rehydratation & 11 Stunden \\
$200 \mathrm{~V}$ & 1 Stunde \\
$500 \mathrm{~V}$ & 1 Stunde \\
$1000 \mathrm{~V}$ & 1 Stunde \\
$2000 \mathrm{~V}$ & 1 Stunde \\
$8000 \mathrm{~V}$ & 50000 Stunde \\
\hline
\end{tabular}

Durch das Anlegen der elektrischen Spannung kam es zu einer Wanderung der Proteine, die vom Ladungszustand bei unterschiedlichen $\mathrm{pH}$-Werten abhängig war. Bei Erreichen ihres isoelektrischen Punktes trugen die Proteine in Summe keine Ladung mehr und wanderten nicht mehr in dem elektrischen Feld. Nach der Fokussierung wurden die Streifen entweder direkt weiterverarbeitet oder bei $-20{ }^{\circ} \mathrm{C}$ gelagert.

\subsubsection{2 Äquilibrierung}

Vor der Durchführung der zweiten Dimension der 2D-Elektrophorese fand die Äquilibrierung statt. Sie diente der Linearisierung und der negativen Beladung der Proteine, äquivalent zur Vorbereitung der Proben für die bereits in 2.2.6.2 beschriebene SDS-PAGE. Die Streifen wurden zuerst mit Äquilibrierpuffer benetzt, wovon zuvor $10 \mathrm{ml}$ mit $100 \mathrm{mg}$ 1,4-Dithiothreitol (DTT) und $50 \mu \mathrm{l}$ Bromphenolblau versetzt worden waren, und dann für 20 Minuten unter Schwenken inkubiert. Währenddessen wurde zu $10 \mathrm{ml}$ Äquilibrierpuffer 400 mg Iodacetamid und $50 \mu \mathrm{l}$ Bromphenolblau hinzugefügt. Die Streifen wurden nach Abkippen des zuerst genutzten Puffers wieder benetzt und für weitere 20 Minuten unter Schwenken inkubiert.

\subsubsection{Die zweite Dimension: SDS-PAGE}

Zur Durchführung der SDS-PAGE wurden bereits fertig gegossene Gele verwendet. Das Gel wurde in die Elektrophoresekammer eingespannt und der fokussierte und äquilibrierte IPG-Streifen wurde vorsichtig in die Halterung eingesetzt. Außerdem wurde ein Marker für unterschiedliche Molekulargewichte in die dafür vorgesehene Tasche gefüllt. Die Elektrophoresekammer wurde mit MOPS-Puffer befüllt und die Elektrophorese bei $200 \mathrm{~V}$ durchgeführt.

Anschließend erfolgte eine Fixierung der aufgetrennten Proteine im Gel für ein bis zwei Stunden in einer Fixierlösung. 


\subsubsection{Darstellung der Proteine}

Zur Darstellung der Proteine wurden die Gele mit einem fluoreszierenden Proteinfarbstoff (Flamingo $^{\mathrm{TM}}$ ) über Nacht abgedunkelt inkubiert. Am Folgetag wurden die markierten Proteine mit einem Scanner mit der Laserlinie von $532 \mathrm{~nm}$ und $700 \mathrm{~V}$ sichtbar gemacht und digitalisiert. Dann erfolgte die Färbung mit Coomassie-Brillant-Blau. Dies führte dazu, dass die Proteinspots in den Gelen für das bloße Auge sichtbar gemacht wurden.

\subsubsection{Auswertung der Gele}

Die Auswertung der Gele erfolgte mit Hilfe des Programms „Delta 2D“. Von beiden Zelllinien wurden sowohl von mit Cisplatin behandelten Zellen als auch von Zellen, die nicht behandelt wurden, in drei unabhängigen Versuchen Zelllysate und 2D-Gele hergestellt, um die Reproduzierbarkeit der Ergebnisse zu gewährleisten. Dabei wurden Caki-2-Zellen 24 Stunden und A498-Zellen 48 Stunden mit Cisplatin behandelt. Die Auswertung mit dem Programm „Delta 2D“ erfolgte nach dem workflow des Programms. Nachdem die drei Replikate einer Zellgruppe (Sortiert nach Zelllinien und innerhalb einer Zelllinie nach Kontrollgruppe und Behandlung mit Cisplatin) hochgeladen wurden und im project setup als eine Gruppe definiert worden waren, folgte das image warping. In diesem Schritt wurden alle Bilder einer Zelllinie netzartig miteinander verknüpft, indem die gleichen Spots von jeweils zwei Bildern übereinandergelegt wurden. Dies ermöglichte im Folgenden den Vergleich aller Bilder einer Zelllinie und der einzelnen Proteinspots untereinander, da nun gewährleistet war, dass zum Beispiel durch unterschiedliche Laufbedingungen aufgetretene Verschiebungen von einzelnen Spots nicht mehr zum Tragen kamen. Im nächsten Schritt wurden die einzelnen Spots markiert und quantifiziert. Hierzu wurde von „Delta2D“ ein fusioniertes Bild aus allen vernetzten Bildern einer Zelllinie kreiert und anhand dieses Bildes die Größe des Spots festgelegt. Nach einer zunächst automatischen Spoterkennung wurden manuelle Änderungen vorgenommen, wie zum Beispiel die Entfernung von fälschlicherweise als Spot markierten Flächen. Als Beispiel hierfür zeigt Abbildung 2 ein fusioniertes Bild mit manuell bearbeiteter Spotentdeckung. 


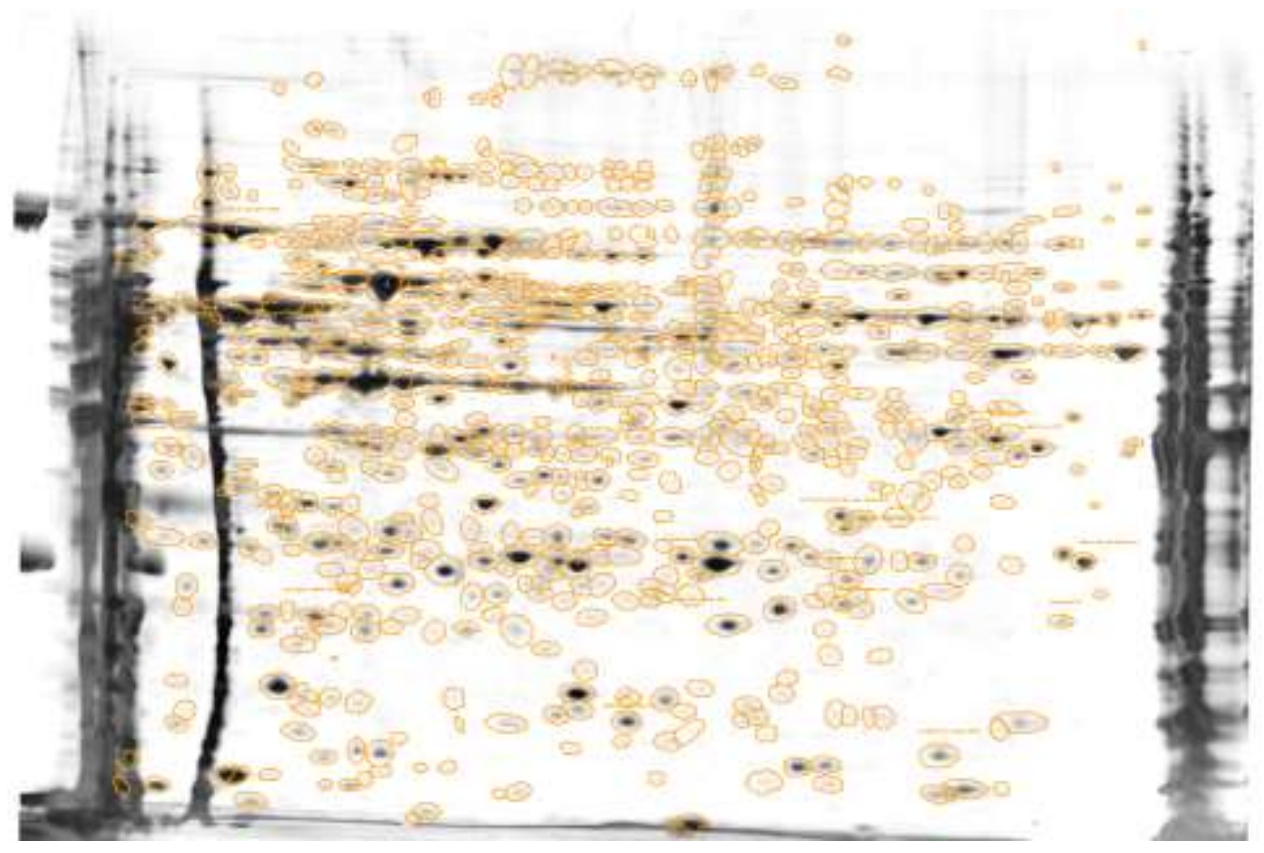

Abbildung 2: Beispiel für ein fusioniertes Bild mit Spotentdeckung mit dem Programm „Delta2D“

Nachdem die markierten Spots durch das Programm auf jedes Bild der Zelllinie übertragen worden waren, wurden die Spots quantifiziert und statistisch ausgewertet. Dabei wurde folgende Parameter errechnet: Mittelwert der relativen Spotintensität der Spots einer definierten Zellgruppe, das Verhältnis des Mittelwerts der relativen Spotintensität der Gruppe „behandelt mit Cisplatin“ zu dem Mittelwert der relativen Spotintensität der Gruppe „Kontrolle“ („Ratio“), die relative Standardabweichung der Werte einer Zellgruppe, der p-Wert. Aus der relativen Standardabweichung wurde manuell die Standardabweichung bestimmt. Ein pWert unter 0,05 galt als signifikant.

\subsubsection{Proteinidentifizierung}

Die Proteinidentifizierung wurde durch eine massenspektrometrische Analyse von zuvor mit Trypsin zurecht geschnittenen Peptiden der interessanten Proteinspots der 2D-Gele und durch einen Abgleich dieser Daten mit einer Proteindatenbank ermöglicht.

\subsubsection{In-Gel-Verdau}

Zur Vorbereitung der Proteinproben für die massenspektrometrische Analyse wurde der InGel-Verdau in Anlehnung an das Protokoll von Rosenfeld und Kollegen (Rosenfeld et al. 1992) mit in der Arbeitsgruppe vorhandenen Protokollen durchgeführt. Durch mehrere Verarbeitungsschritte kam es zur proteolytischen Spaltung am Carboxyende der Aminosäuren Arginin und Lysin durch das Enzym Trypsin und zur Gelextraktion der Proteinbestandteile. Zuerst wurden die zu analysierenden Proteinspots aus dem mit Coomassie-Brilliant-Blau gefärbten 2D-Gelen ausgestochen und einzeln in Eppendorf-Reaktionsgefäße gegeben. Es 
wurde darauf geachtet, jeden Schritt mit Handschuhen durchzuführen, um eine Verunreinigung durch körpereigenes Keratin zu vermeiden. Dann wurden die Spots drei Mal mit $\mathrm{ddH}_{2} \mathrm{O}$ gewaschen und im Folgenden mit acetonitrilhaltiger Lösung entfärbt. Hierfür wurden die Spots zunächst mit einer 50\%igen Lösung bedeckt und 15 Minuten inkubiert. Nach Entfernung der Lösung folgte eine Bedeckung und Inkubation für eine Stunde mit 100\%iger Acetonitril-Lösung. Nachdem der Spot entfärbt war, wurde die Lösung entfernt und zu jedem Spot wurde für fünf Minuten $10 \mu 100$ mM Ammoniumbikarbonat gegeben. Dieses wurde entfernt und die Spots wurden für 15 Minuten getrocknet. In der Zwischenzeit wurde der Verdaupuffer angesetzt. Dann folgte die Mischung von Verdaupuffer und Trypsin und die Zugabe von $8 \mu \mathrm{l}$ zu jedem Gelspot. Nach einer 45-minütigen Inkubation auf Eis wurde der Überschuß an Trypsinlösung verworfen, die Gelstücke wurden mit Verdaupuffer bedeckt und über Nacht bei $37^{\circ} \mathrm{C}$ inkubiert. Dies führte zu einer durch das Trypsin katalysierten enzymatischen Spaltung der Proteine in Peptide.

Am nächsten Morgen folgte die Extraktion der Peptide aus der Gelmatrix. Hierfür wurde zuerst der über Nacht mit dem Gel inkubierte Verdaupuffer aufgefangen und in ein für jeden Spot markiertes neues Eppendorf-Reaktionsgefäß überführt. Dann wurde zu den Gelstücken zuerst $20 \mu$ l einer Lösung aus 30\% Acetonitril und $70 \%$ Trifluoressigsäure (0,1\% (v/v)) gegeben, und die Reaktionsgefäße wurden für 30 Minuten in einem Ultraschallbad inkubiert. Dies ermöglichte die Herauslösung der Peptide aus dem Gel. Die Flüssigkeit, in der sich nun ein Teil der aus dem Gel gelösten Peptide befand, wurde in das für den jeweiligen Spot markierte Reaktionsgefäß überführt. Es folgte die Zugabe von $20 \mu \mathrm{l}$ einer Lösung aus 60\% Acetonitril und 40\% Trifluoressigsäure sowie eine weitere Inkubation im Ultraschallbad. Nach dem Hinzufügen der zuletzt gewonnenen peptidhaltigen Flüssigkeit in das zugehörige Gefäß wurden die Proben in einer speed vacuum-Zentrifuge getrocknet und bis zur weiteren Verarbeitung bei $-20{ }^{\circ} \mathrm{C}$ gelagert.

\subsubsection{Massenspektrometrische Analyse mit Q-TOF}

Die Massenspektrometrie (MS) ist ein Verfahren, das die Bestimmung der Masse von Molekülen ermöglicht. Jede massenspektrometrische Analyse teilt sich prinzipiell in drei Schritte. Zuerst werden die zu untersuchenden Moleküle ionisiert. Dann werden sie dem Analysator zugeführt, in dem sie nach ihrem Masse-zu-Ladung-Verhältnis $(\mathrm{m} / \mathrm{z})$ sortiert werden. Zuletzt werden die sortierten Moleküle von einem Detektor erfasst. Als Ergebnis wird ein Massenspektrum generiert, ein Diagramm, auf dem die Signalintensität auf der Ordinate und $\mathrm{m} / \mathrm{z}$ auf der Abszisse dargestellt wird (Abbildung 3) (Gross 2013).

In der hier vorliegenden Arbeit wurde die Analyse mit einem Tandem-Massenspektrometer (auch als MS/MS bezeichnet), dem quadrupole-time-of-flight-Massenspektrometer (Q-TOFMS), durchgeführt. Das Q-TOF-MS kombiniert mehrere massenspektrometrische Analysen und steigert den Informationsgewinn über die zu untersuchende Substanz. So ermöglicht die Analyse nicht nur eine Sortierung der Peptide nach ihrem $\mathrm{m} / \mathrm{z}$-Verhältnis, sondern auch eine 
Sequenzierung der Peptide (Richter 2003). Für die Ionisation nutzt das Gerät die Elektrospray-Ionisation (ESI). Zur Ionentrennung enthält das Q-TOF-MS zwei unterschiedliche Methoden, einen Quadrupol-Analysator und einen Flugzeit-Analysator. Im Quadrupol-Analysator werden die Ionen durch ein Feld aus vier in einem Quadrat angeordneten Stabelektroden geleitet. Eine durch das Anlegen von elektrischer Spannung wirkende Kraft führt zu einer Art Filter, da nur Ionen mit einem bestimmten $\mathrm{m} / \mathrm{z}$-Verhältnis den Quadrupol durchqueren können. Das Prinzip der Flugzeitanalyse basiert darauf, dass Ionen, die zeitgleich durch einen definierten Raum geschickt werden, den Detektor bei unterschiedlichem $\mathrm{m} / \mathrm{z}$ Verhältnis zu einem unterschiedlichen Zeitpunkt erreichen. So erreichen leichte Ionen den Detektor früher als schwere (Gross 2013). Nach einer ersten Messung schließt sich in dem Q-TOF-MS eine zweite Messphase an. Hierfür werden nur Peptide mit einem bestimmten $\mathrm{m} / \mathrm{z}$ - Verhältnis durch den Quadrupol-Analysator hindurch gelassen. In einer nachgeschalteten Stoßzelle kollidieren diese Peptide mit Gasmolekülen, was zu einer Fragmentierung durch Aufbrechen der Peptidbindungen führt und als collisionally induces decay (CID) bezeichnet wird. Das Massenspektrum der dabei entstehenden Fragmente wird in der Flugzeitanalyse bestimmt. Dieses ermöglicht durch die Abstände zwischen den gemessenen Peaks Rückschlüsse auf die Aminosäuresequenz des untersuchten Peptids (Richter 2003).

In dieser Arbeit wurden die Analysen in Zusammenarbeit mit dem Q-TOF-MS-Labor unter der Leitung von Prof. Dr. Asif durchgeführt. Die verdauten, getrockneten Proteine wurden in einer je nach Spotdicke festgelegten Menge 0,1 \% (v/v) Ameisensäure gelöst und analysiert.

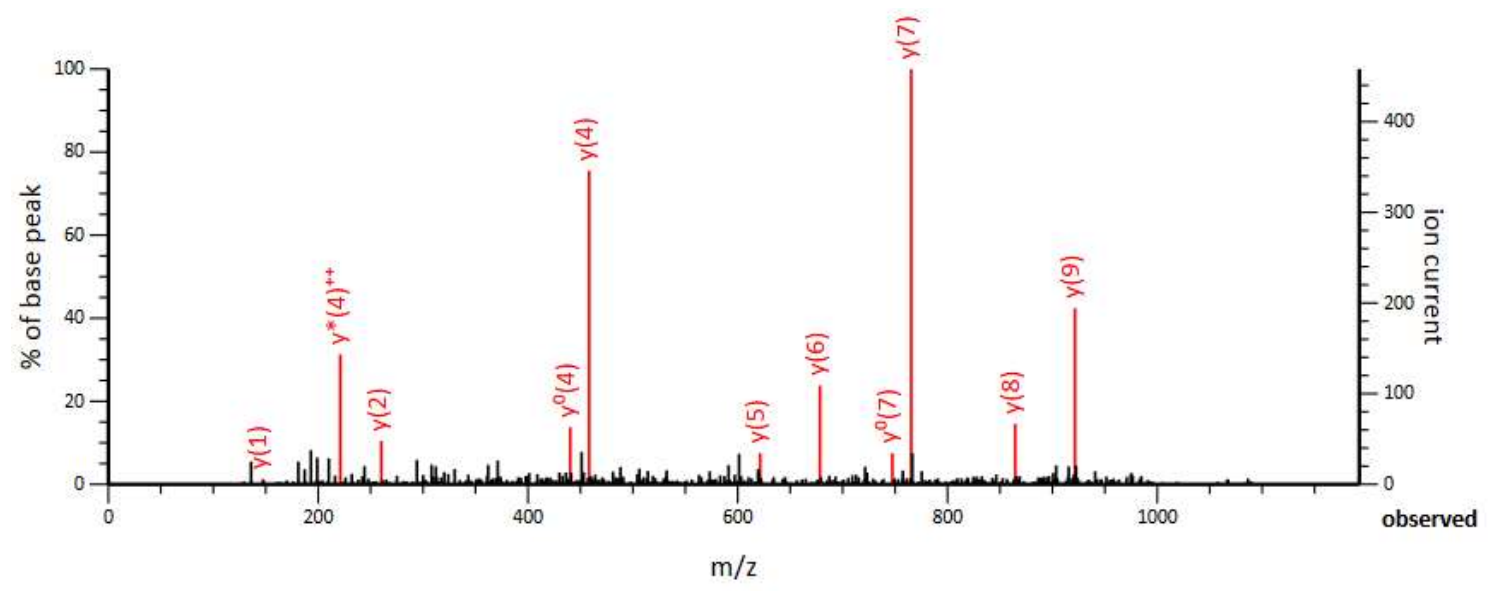

Abbildung 3: Beispiel für das MS/MS-Spektrum des Peptids YGVSGYPTLK eines Spots des Proteins ERp57

\subsubsection{Auswertung der Ergebnisse}

Nach dem enzymatischen Verdau des unbekannten Proteins und der Fragmentierung der dabei entstandenen Peptide in dem Q-TOF-MS, wurden die Peptidmassenspektren des Proteins gemessen. Diese ermöglichten die Sequenzierung mehrerer Peptide des untersuchten Proteins. In der Suchmaske der MS/MS-Ionensuche der Datenbank „Mascot“ konnten die 
Ergebnisse der Q-TOF-Analyse als Datei mit dem Format „.pkl“ hochgeladen werden. Die Sucheinstellungen wurden gemäß Tabelle 7 vorgenommen. Die Ergebnisse dieser Arbeit beziehen sich auf die Datenbanksuche, die im Dezember 2015 durchgeführt wurde.

Tabelle 7: Einstellungen für die MS/MS-Ionensuche mit der Datenbank „Mascot“

\begin{tabular}{ll}
\hline Datenbank & SwissProt \\
Enzym & Trypsin \\
Variable Modifikationen & Carbamidomethyl \\
& Oxidation \\
Peptid-Toleranz & $+/-0,5$ Dalton \\
MS/MS-Toleranz & $+/-0,5$ Dalton \\
Peptid-Ladung & $2+, 3+$, und $4+$ \\
\hline
\end{tabular}

Das Programm führte die Suche nach Übereinstimmungen der Peptidsequenzen des unbekannten untersuchten Proteins mit in der Datenbank hinterlegten MS/MS-Daten bekannter Proteine durch. Optimalerweise wurde das untersuchte Protein einem in der Datenbank gespeicherten Protein zugeordnet und somit identifiziert. Um die Wahrscheinlichkeit einer korrekten Identifizierung beurteilen zu können, wurde in den Ergebnissen der Mascot-Score angezeigt. Dieser gab Aufschluss darüber, ob die ermittelten Übereinstimmungen lediglich als zufällig zu bewerten waren. Ein Mascot-Score von über 29 galt dabei als signifikant. Je höher der Score, desto verlässlicher war die Identifizierung. Weiter ergab die Suche für jedes identifizierte Protein folgende Parameter: den Namen in der Proteindatenbank „Swiss-Prot“, den Gennamen, die Masse in Dalton, den errechneten isoelektrischen Punkt (pI) und den Prozentsatz der übereinstimmenden Peptidsequenzen (Abbildung 4). Durch diese Parameter konnte außerdem durch Betrachten des 2D-Gels die Plausibilität der Identifizierung überprüft werden. 

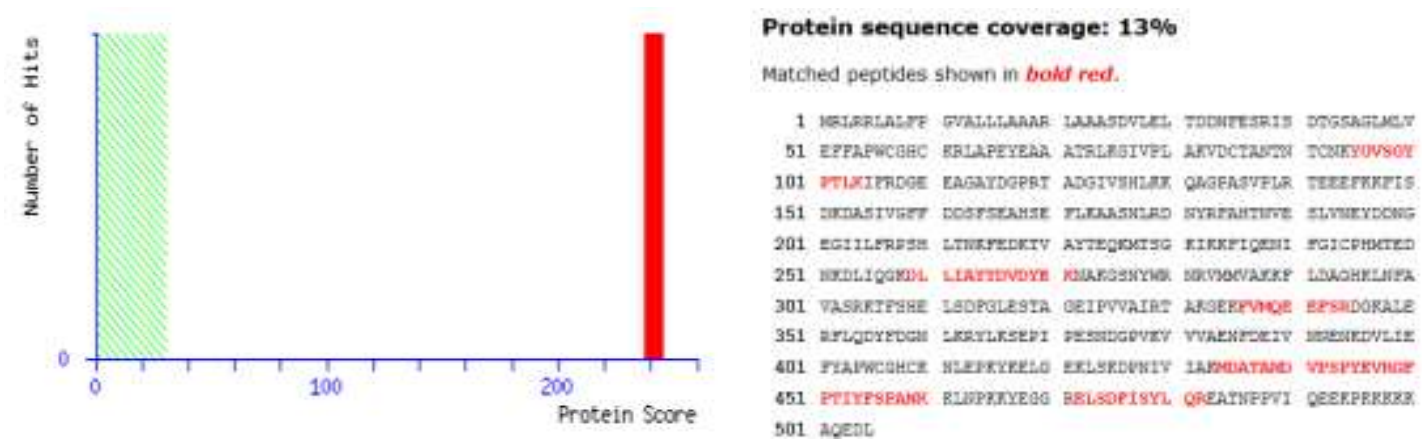

Abbildung 4: Beispiel der Ergebnisse einer Suche mit der Datenbank „Mascot“

Auf der linken Seite ist beispielhaft die graphische Darstellung des Mascot-Scores zu sehen. Der grün schraffierte Bereich markiert den Score-Bereich, der als nicht signifikant angesehen wird $(<29)$. In diesem Bereich lokalisierte Treffer sind statistisch gesehen nur zufällig zustande gekommen. Auf der rechten Seite ist beispielaft dargestellt, wie viel Prozent der Peptide in der Probe mit denen der Datenbank übereinstimmen. Übereinstimmende Peptide sind rot dargestellt.

Nachdem die Proteine identifiziert und den Spots zugeordnet worden waren, erfolgte eine Gruppierung der differenziell exprimierten Proteine in weit gefasste Gruppen nach ihrer biologischen Funktion mit Hilfe der Datenbank „DAVID“ und der Proteindatenbank „Uniprot“. 


\section{Ergebnisse}

\subsection{Auswirkungen der Behandlung mit Cisplatin auf das Überleben der Nierenzellkarzinom-Zelllinien}

Zur Erfassung der Auswirkung der Behandlung mit Cisplatin auf das Überleben beider Zelllinien wurde sowohl die Zellviabilität als auch der Anteil an apoptotischen Zellen untersucht.

\subsection{Auswirkung der Behandlung mit Cisplatin auf die Zellviabilität der Nierenzellkarzinom-Zelllinien}

Zur Analyse der Auswirkung der Behandlung mit Cisplatin auf die Zellviabilität und Proliferation beider Zelllinien wurde ein MT'T-Assay durchgeführt, in dem zum einen nicht behandelte Zellen und mit Cisplatin behandelte Zellen der jeweiligen Zelllinie untersucht wurden.

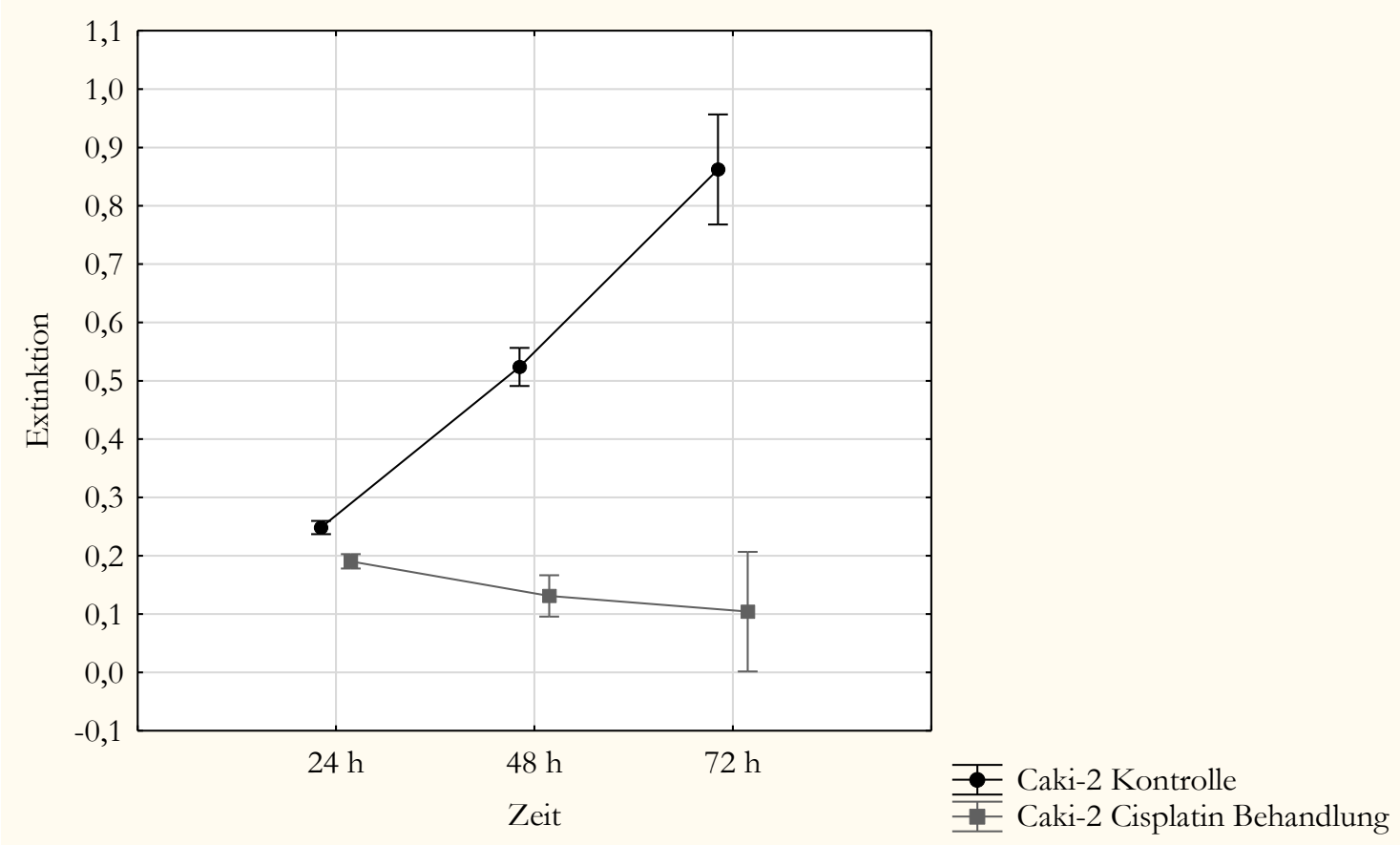

Abbildung 5: Diagramm der Ergebnisse des MTT-Assays für nicht behandelte Caki-2-Zellen und mit Cisplatin behandelte Caki-2-Zellen

Das Diagramm zeigt den errechneten Mittelwert nach 24, 48 und 72 Stunden der gemessenen Extinktion für Caki-2-Kontrollzellen und mit Cisplatin behandelten Caki-2-Zellen nach Durchführung des MTT-Assay. Die Extinktion, dargestellt auf der Ordinate, gilt als ein Maß für das Vorhandensein von metabolisch aktiven Zellen und somit als ein Maß für die Zellviabilität und Proliferation. Die Abszisse zeigt die Zeitabstände der Messintervalle. Die vertikalen Striche zeigen das 95\%-Konfidenzintervall an. 
Die Kontrollzellen der Caki-2-Zelllinie zeichneten sich dadurch aus, dass kontinuierlich eine Zunahme der Extinktion gemessen wurde. Die Extinktion wurde, wie schon in 2.2.10 erläutert, als Maß für die Zellviabilität und Proliferation gesehen. Innerhalb von 48 Stunden stieg der Mittelwert der gemessenen Extinktion von 0,25 (Standardabweichung 0,03) auf 0,86 (Standardabweichung 0,36) und multiplizierte sich innerhalb des ersten und letzten Messzeitpunkts um den Faktor 3,4. In den mit Cisplatin behandelten Zellen wurde kontinuierlich eine Abnahme der Extinktion nachgewiesen. Der Mittelwert sank innerhalb des Messzeitraums von 0,18 (Standardabweichung 0,03) auf 0,10 (Standardabweichung 0,07). Im Verlauf des Experiments unterschieden sich mit Cisplatin behandelte Caki-2-Zellen immer ausgeprägter von den Caki-2-Kontrollzellen (Abbildung 5).

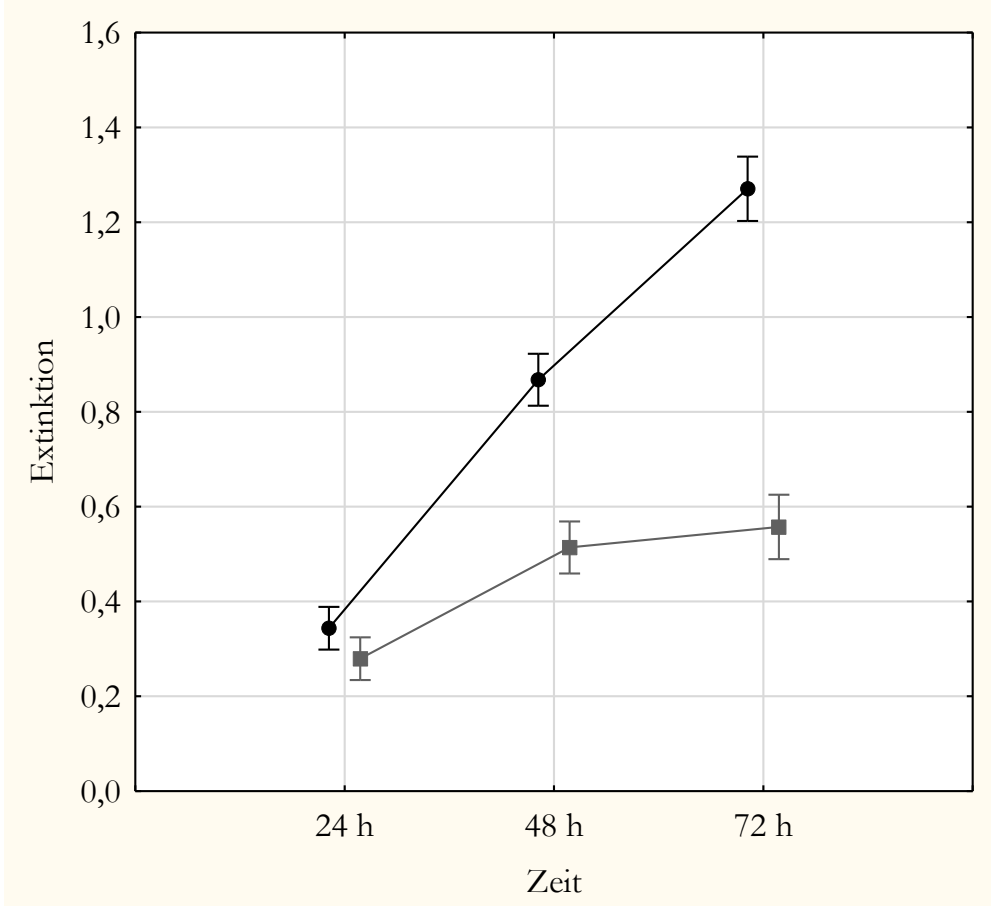

A498 Kontrolle A498 Cisplatin Behandlung

Abbildung 6: Diagramm der Ergebnisse des MTT-Assays für nicht behandelte A498-Zellen und mit Cisplatin behandelte A498-Zellen

Das Diagramm zeigt den errechneten Mittelwert nach 24, 48 und 72 Stunden der gemessenen Extinktion für A498-Kontrollzellen und mit Cisplatin behandelten A498-Zellen nach Durchführung des MTT-Assay. Die Extinktion, dargestellt auf der Ordinate, gilt als ein Maß für das Vorhandensein von metabolisch aktiven Zellen und somit als ein Maß für die Zellviabilität und Proliferation. Die Abszisse zeigt die Zeitabstände der Messintervalle. Die vertikalen Striche zeigen das 95\%-Konfidenzintervall an.

Sowohl A498-Kontrollzellen als auch mit Cisplatin behandelte A498-Zellen zeigten eine Zunahme der Extinktion und somit der Zellviabilität im Zeitverlauf (Abbildung 6). Der Mittelwert der gemessenen Extinktionswerte für die Kontrollzellen stieg im Messzeitraum von 0,34 (Standardabweichung 0,14) auf 1,27 (Standardabweichung 0,18), was einer Multiplikation um den Faktor 3,7 entspricht. Die mit Cisplatin behandelten A498-Zellen zeigten einen Anstieg 
des Mittelwerts der gemessenen Extinktion von 0,28 (Standardabweichung 0,13) auf 0,56 (Standardabweichung 0,22), was einer Multiplikation um den Faktor 1,9 entspricht. Nach 24 Stunden zeigte sich zunächst nur ein geringer Unterschied zwischen mit Cisplatin behandelten A498-Zellen und A498-Kontrollzellen. Im Verlauf des Experiments wurde dieser jedoch deutlicher.

\subsubsection{Auswirkung der Behandlung mit Cisplatin auf die Apoptoseinduktion in Nierenzellkarzinom-Zelllinien}

Um nachzuvollziehen, ob die Behandlung mit Cisplatin zum Zelltod führte, wurde der Annexin V/dead cell apoptosis assay für beide Zelllinien durchgeführt und gemäß Tabelle 5 analysiert. Abbildung 8 und Abbildung 9 zeigen die Auswirkungen der Behandlung mit Cisplatin auf beide Zelllinien im Vergleich zu den Kontrollzellen.

Der Mittelwert des Anteils der nicht behandelten Caki-2-Zellen, die sich in der apoptotischen Fraktion (Q4) befanden, lag bei 4,5\% (Standardabweichung 0,9), während er für die mit Cisplatin behandelten Caki-2-Zellen bei 35,6\% (Standardabweichung 2,1) lag.

In der A498-Zelllinie lagen von den nicht behandelten A498-Zellen im Mittel 0,2\% der Zellpopulation in der apoptotischen Zellfraktion (Q4). Nach 42 Stunden Behandlung mit Cisplatin betrug der Anteil im Mittel 22,6\%.

Hieraus ergab sich, dass der Anteil der apoptotischen Zellen nach einer Behandlung mit Cisplatin in der A498-Zelllinie signifikant kleiner war als in Caki-2-Zellen ( $p=0,03$ ) (Abbildung 7).

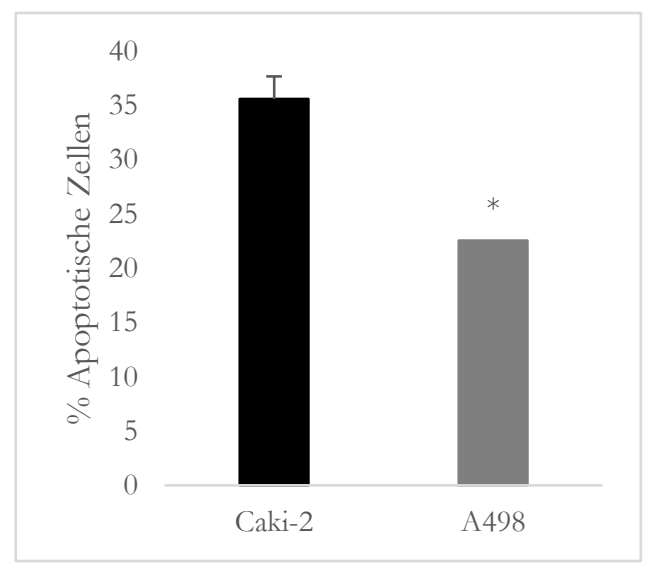

Abbildung 7: Diagramm der apoptotischen Zellfraktion nach Behandlung mit Cisplatin in der Caki-2-Zelllinie und der A498-Zelllinie

Das Diagramm zeigt die Ergebnisse des Annexin V/dead cell apoptosis assay der Caki-2-Zelllinie und der A498-Zelllinie. Die gefärbten Balken stehen für den Mittelwert des Anteils der apoptotischen Zellfraktion nach Behandlung mit Cisplatin für Caki-2- und für A498-Zellen. Der vertikale Strich zeigt für Caki-2-Zellen die Standardabweichung. Für A498-Zellen wurde bei nur 2 Werten keine Standardabweichung berechnet. Der Stern markiert einen signifikanten Unterschied zwischen beiden Zelllinien, wobei als signifikant galt ${ }^{*}=\mathrm{p}<0,05$. 

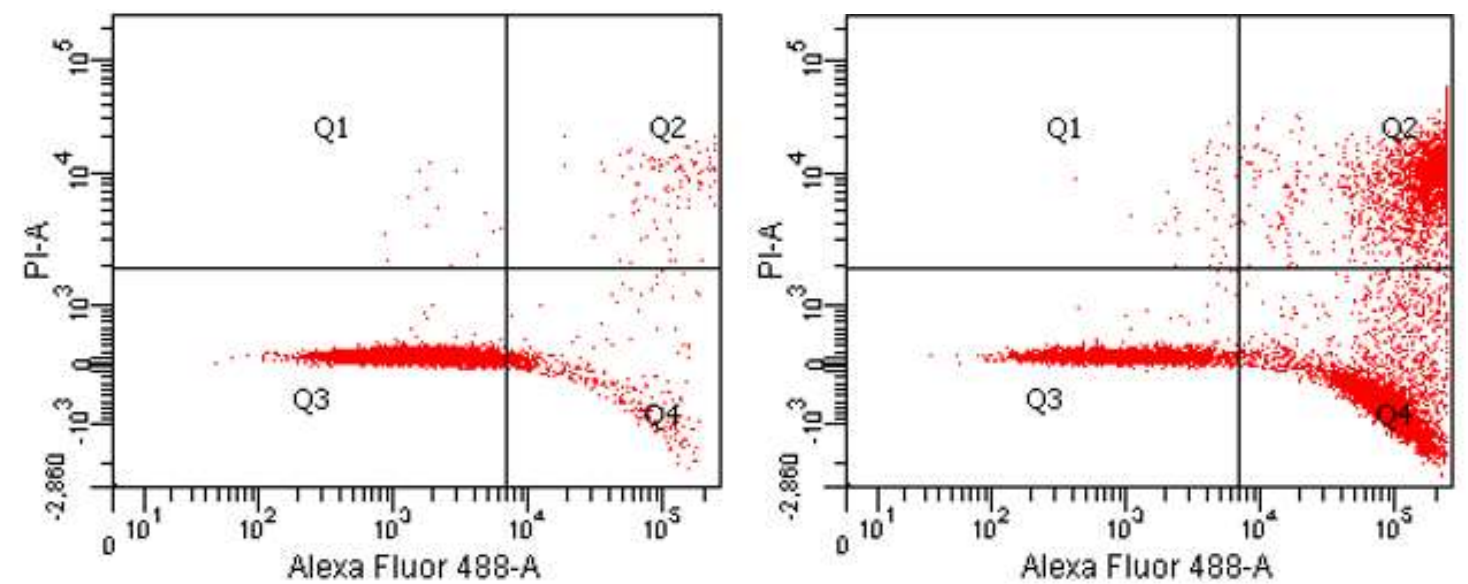

Abbildung 8: Diagramm des Annexin V/dead cell apoptosis assay mit Annexin V-/PI-Markierung von Caki-2-Kontrollzellen (links) und mit Cisplatin behandelten Caki-2-Zellen (rechts)
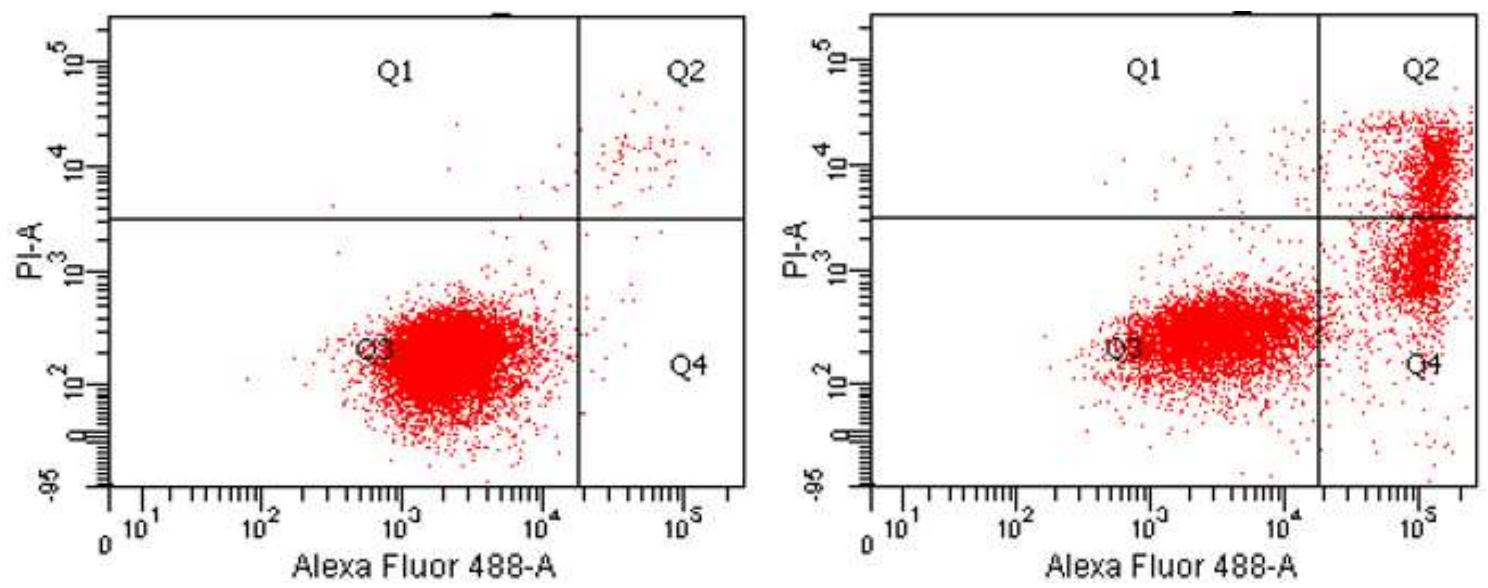

Abbildung 9: Diagramm des Annexin V/dead cell apoptosis assay mit Annexin V-/PI-Markierung von A498-Kontrollzellen (links) und mit Cisplatin behandelten A498-Zellen (rechts)

Abbildung 8 und Abbildung 9 zeigen beispielhaft die graphische Auswertung des Annexin V/ dead cell apoptosis assay in beiden Zelllinien. Es werden jeweils Kontrollzellen und mit Cisplatin behandelte Zellen gegenübergestellt. Die Ordninate stellt die Markierung mit dem DNA-Marker PI dar. Die Abszisse spiegelt die Markierung mit Annexin V. Die gemessene Zellpopulation stellt sich als eine Ansammlung roter Punkte dar. Das Diagramm ist in vier Quadranten geteilt, um die Sortierung der Zellen zu ermöglichen. Dabei stellt der Quadrant Q4 die Zellen dar, die mit Annexin V markiert wurden, jedoch nicht mit PI. Dies entspricht Zellen, die sich in früher Apoptose befinden.

\subsection{Auswirkung der Behandlung mit Cisplatin auf das Proteom der Nierenzellkarzinom-Zelllinien}

Zur Untersuchung der Veränderungen auf Proteinebene, die in beiden Zelllinien durch eine Behandlung mit Cisplatin entstanden waren, wurden, wie in 2.2.12 und 2.2.13 beschrieben, vergleichende 2D-Gele beider Zelllinien angefertigt und auffallende Spots mittels Massenspektrometrie identifiziert sowie in den Gelen quantifiziert. 


\subsubsection{Zweidimensionale Proteinprofile ohne und nach Behandlung mit Cisplatin}

2D-Gelelektrophoresen wurden von Kontrollzellen und von mit Cisplatin behandelten Zellen angefertigt. Die Veränderungen des Proteoms sollten mögliche Erklärungsansätze für die Chemoresistenz oder -sensibilität ergeben. Abbildung 10 bis Abbildung 13 zeigen repräsentative Beispiele für die durchgeführten 2D-Gelelektrophoresen.

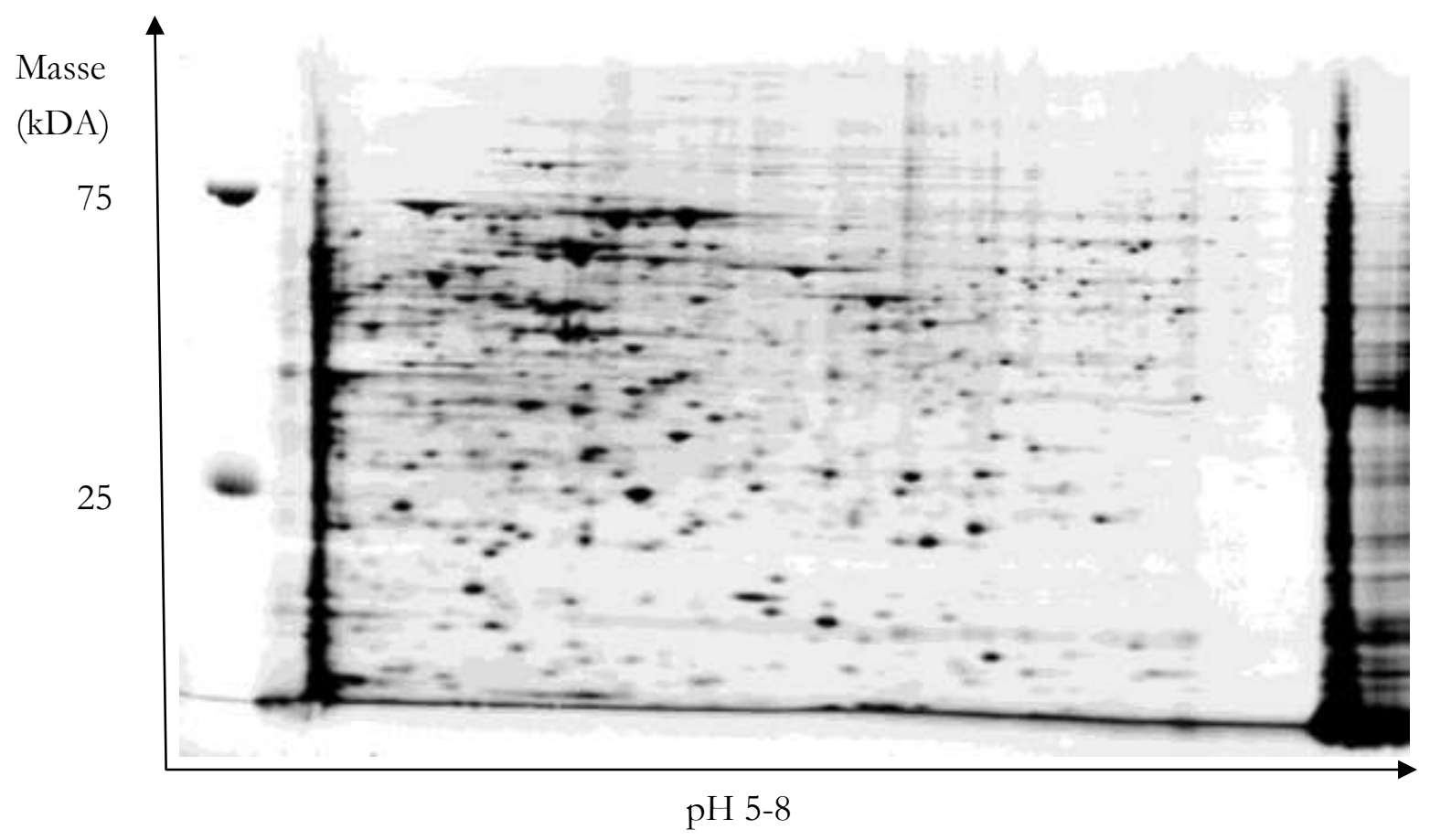

Abbildung 10: 2D-Gelelektrophorese von Caki-2-Kontrollzellen

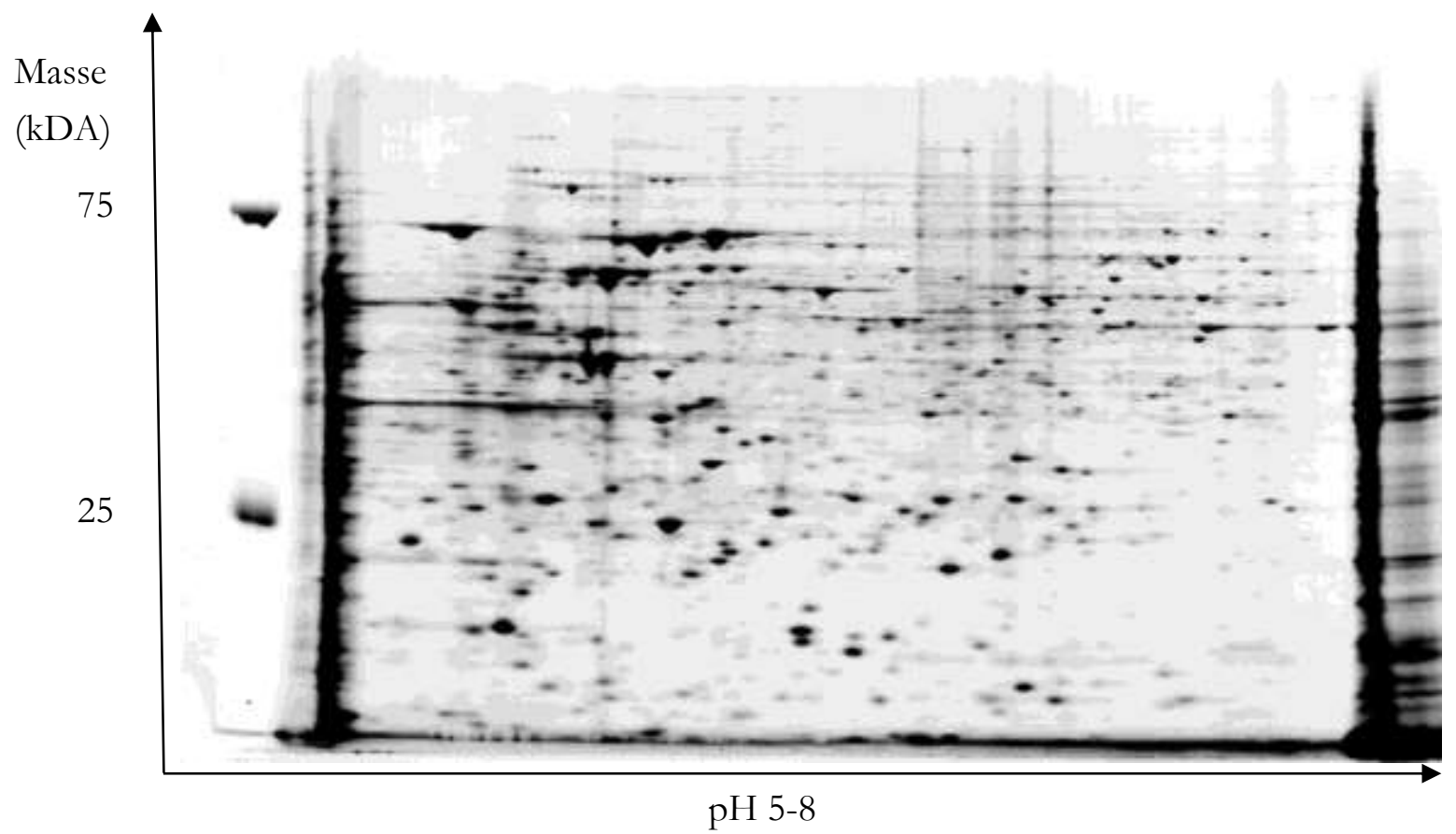

Abbildung 11: 2D-Gelelektrophorese von mit Cisplatin behandelten Caki-2-Zellen 


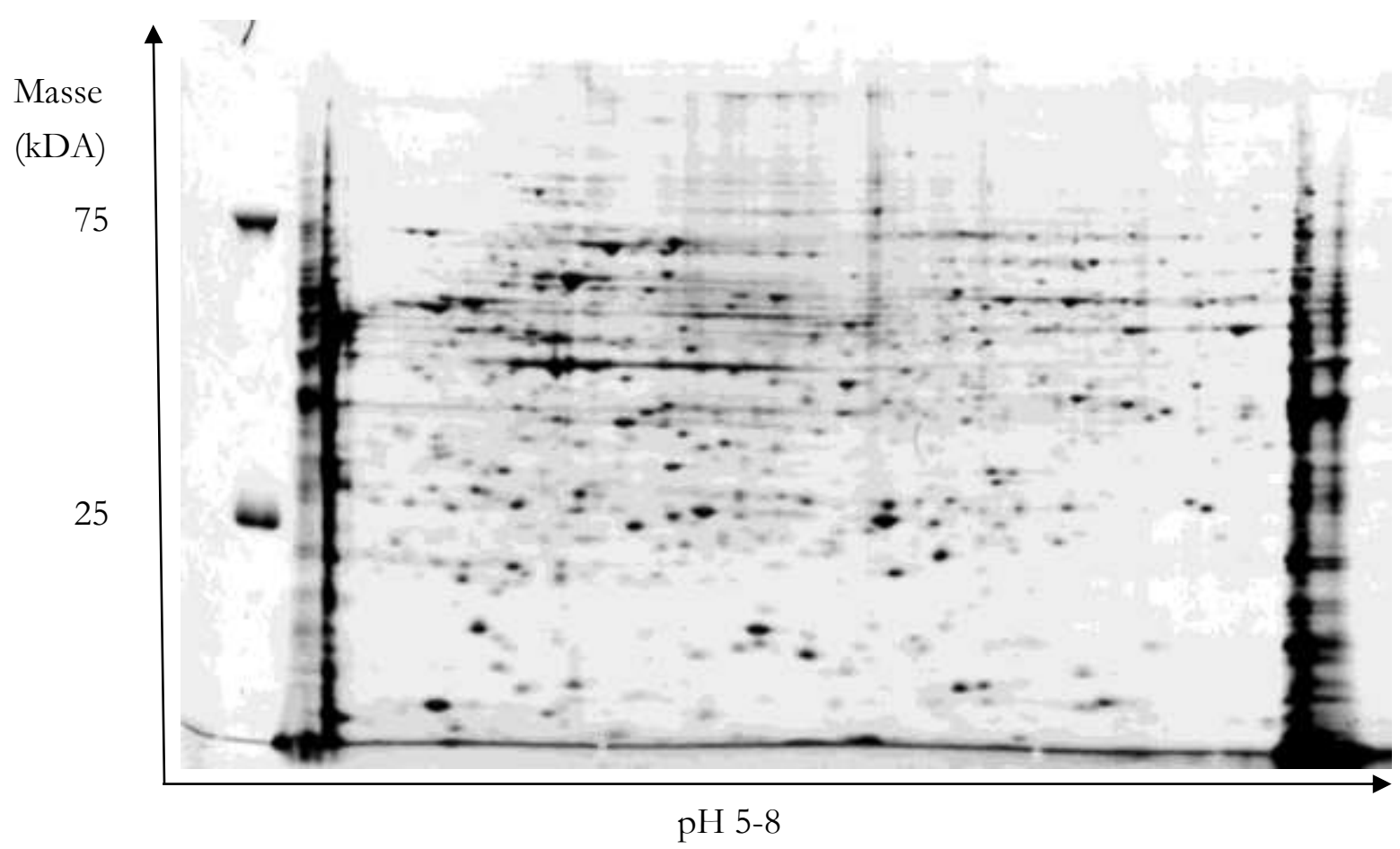

Abbildung 12: 2D-Gelelektrophorese von A498-Kontrollzellen

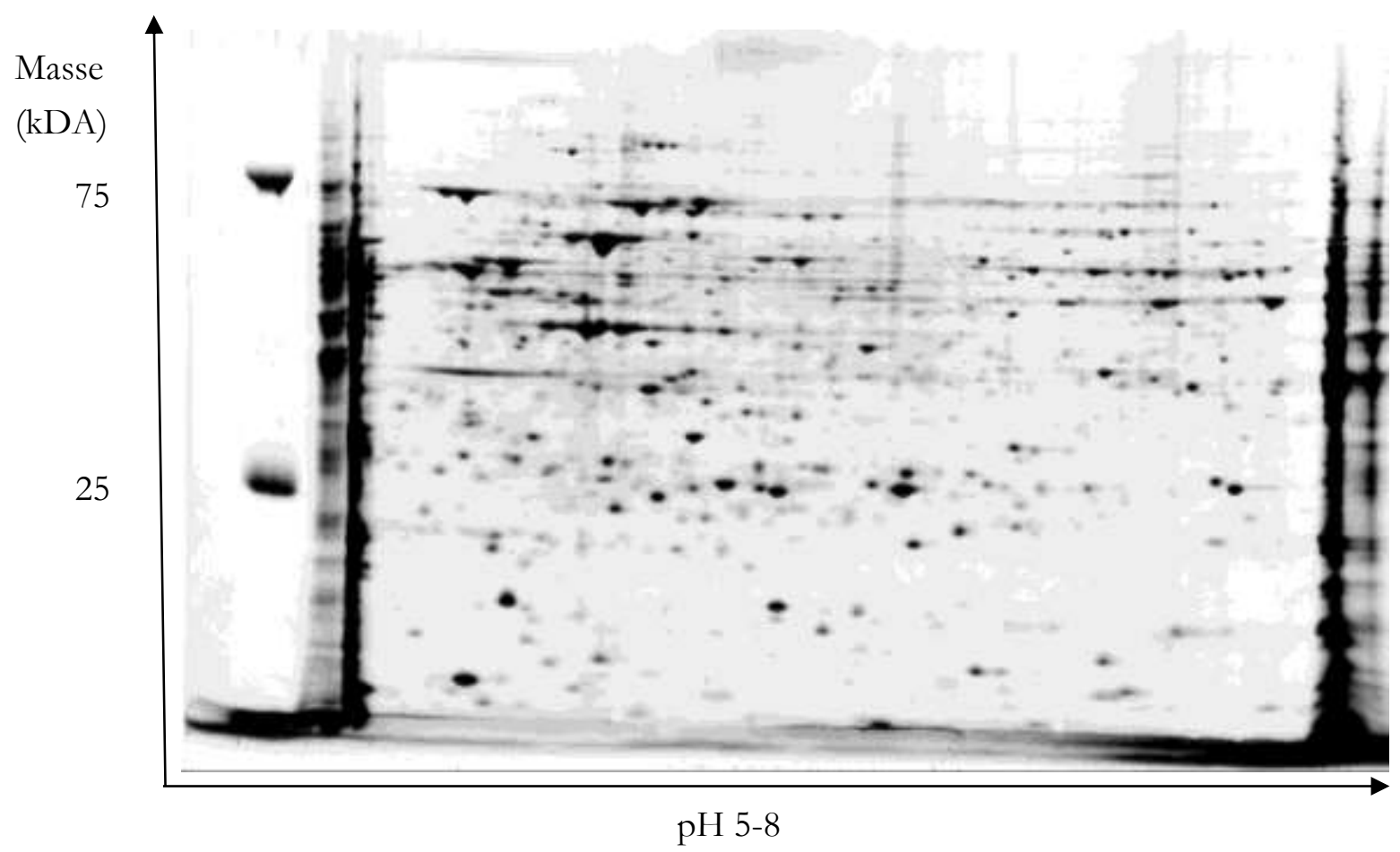

Abbildung 13: 2D-Gelelektrophorese von mit Cisplatin behandelten A498-Zellen

Schon mit dem bloßen Auge waren sowohl in Caki-2-Zellen als auch in A498-Zellen Veränderungen in dem Proteom nach Behandlung mit Cisplatin zu erkennen. 


\subsubsection{Analyse des Expressionsprofils einzelner Spots und Proteinidentifizierung}

Auffallende Spots wurden mit Hilfe der Massenspektrometrie und Datenbanksuche identifiziert. Für eine detaillierte Auswertung des Expressionsprofils der identifizierten Spots und für die Quantifizierung der einzelnen Spots wurde die Auswertung mit dem Programm „Delta 2D“ durchgeführt. So konnte untersucht werden, ob und in welchem Maße die identifizierten Proteine nach Behandlung mit Cisplatin reguliert wurden, und ob diese Regulation signifikant war.

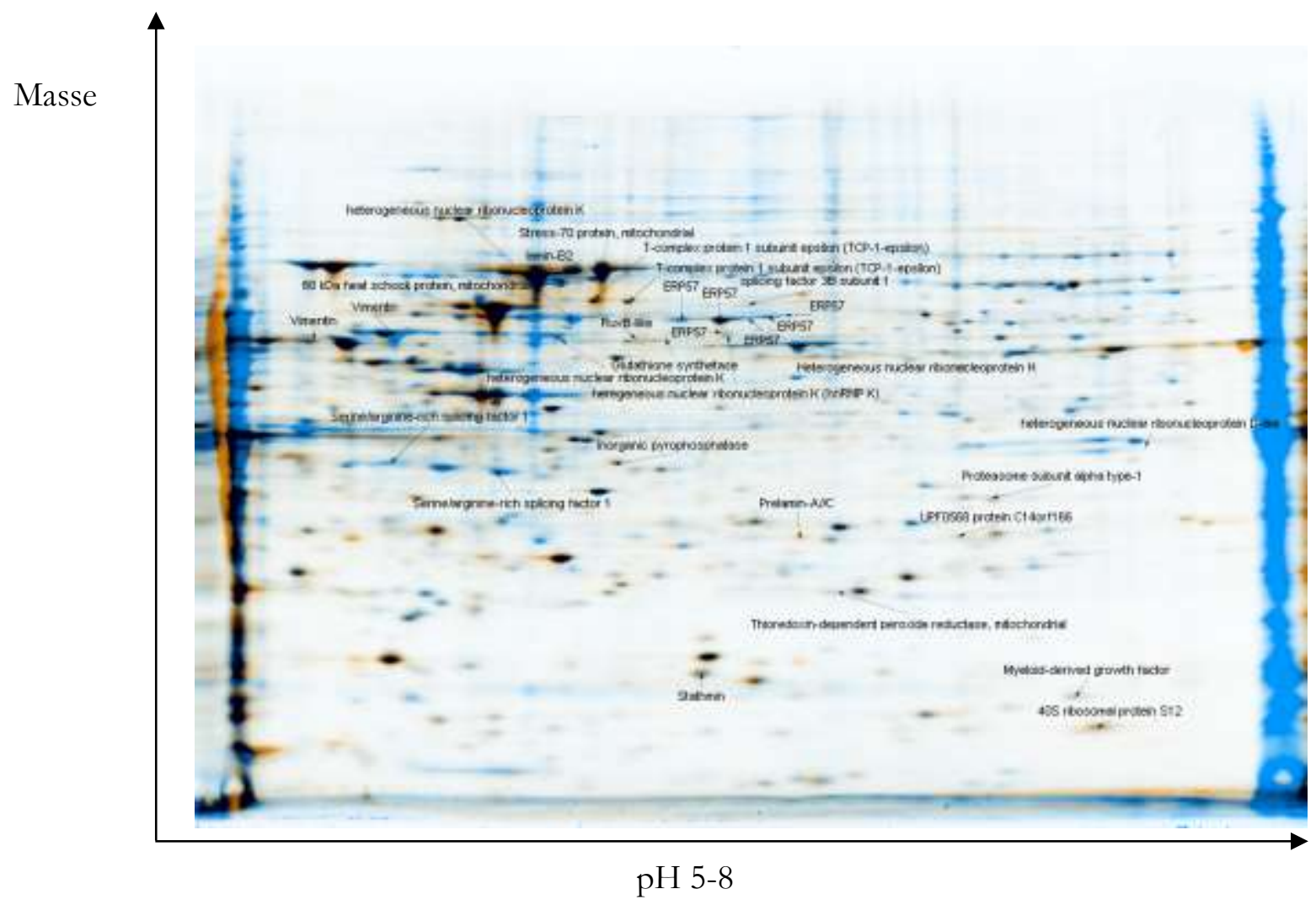

Abbildung 14: Identifizierte Proteine der Caki-2-Zelllinie in einem übereinandergelegten Bild

Die Abbildung zeigt ein übereinandergelegtes Bild (entsprechend dem zweiten Schritt der Analyse mit dem Programm „Delta 2D“) von einer 2D-Gelelektrophorese von Caki-2-Kontrollzellen und von mit Cisplatin behandelten Caki-2-Zellen. Das Gel der Kontrollzellen ist in dem kombinierten Bild blau dargestellt, das Gel der mit Cisplatin behandelten Zellen gelb. In horizontaler Achse zeigt sich der pH-Gradient von $\mathrm{pH}$ 5-8. In vertikaler Achse zeigt sich das Molekulargewicht, wobei schwere Proteine weiter oben im Bild verortet sind. Anhand der Spots des fusionierten Gesamtbildes erfolgte die Beschriftung der durch die Analyse mit dem Q-TOF-Massenspektrometer und durch den Datenbankvergleich identifizierten Proteine und wurde auf das Beispielbild übertragen. 
Tabelle 8: Liste der identifizierten Proteine der Caki-2-Zelllinie und Ratio der Expression der Spots

\begin{tabular}{|c|c|c|c|c|c|c|c|c|}
\hline & Proteinname & $\begin{array}{c}\text { Nr. in Swiss-Prot } \\
\text { Datenbank }\end{array}$ & Genname & $\begin{array}{l}\text { Masse } \\
\text { (in Da) }\end{array}$ & $\mathrm{pI}$ & Mascot-Score & Sequenz & Ratio \\
\hline 1 & $40 S$ ribosomal protein $S 12$ & RS12_HUMAN & RPS12 & 14505 & 6,81 & 31 & $17 \%$ & 2,92993 \\
\hline 2 & $\begin{array}{l}60 \mathrm{kD} \text { a beat shock protein, mitochond- } \\
\text { rial }\end{array}$ & CH60_HUMAN & HSPD1 & 61016 & 5,70 & 217 & $14 \%$ & 1,06015 \\
\hline 3 & Glutathion Synthetase & GSHB_HUMAN & GSS & 52352 & 5,67 & 30 & $5 \%$ & 0,81652 \\
\hline 4 & $\begin{array}{l}\text { Heterogeneous nuclear ribonucleoprotein } \\
\text { D-like }\end{array}$ & HNRDL_HUMAN & HNRNPDL & 46409 & 9,59 & 45 & $3 \%$ & 0,59956 \\
\hline 5 & Heterogeneous nuclear ribonucleoprotein & HNRH1_HUMAN & HNRNPH1 & 49198 & 5,89 & 74 & $3 \%$ & 0,81471 \\
\hline 6 & $\begin{array}{l}\text { Heterogeneous nuclear ribonucleoprotein } K \\
\text { (hnRNP K) }\end{array}$ & HNRPK_HUMAN & $H N R N P K$ & 50944 & 5,39 & 38 & $1 \%$ & 0,41792 \\
\hline 7 & $\begin{array}{l}\text { Heterogeneous nuclear ribonucleoprotein } K \\
\text { (hnRNP K) }\end{array}$ & HNRPK_HUMAN & $H N R N P K$ & 50944 & 5,39 & 55 & $7 \%$ & 0,43472 \\
\hline 8 & $\begin{array}{l}\text { Heterogeneous nuclear ribonucleoprotein } K \\
\text { (hnRNP K) }\end{array}$ & HNRPK_HUMAN & HNRNPK & 50944 & 5,39 & 191 & $21 \%$ & 0,74122 \\
\hline 9 & Inorganic pyrophosphatase & IPYR_HUMAN & $P P A 1$ & 32639 & 5,54 & 117 & $26 \%$ & 1,57379 \\
\hline 10 & Lamin-B2 & LMNB2_HUMAN & $L M N B 2$ & 3990 & 5,50 & 101 & $8 \%$ & 0,43001 \\
\hline 11 & Myeloid-derived growth factor & MYDGF_HUMAN & MYDGF & 18783 & 6,20 & 47 & $15 \%$ & 1,44971 \\
\hline 12 & Prelamin-A/C & LMNA_HUMAN & $L M N A$ & 74095 & 6,57 & 59 & $6 \%$ & 8,1023 \\
\hline 13 & Proteasome subunit alpha type-1 & PSA1_HUMAN & PSMA1 & 29537 & 6,15 & 45 & $6 \%$ & 3,35246 \\
\hline 14 & $\begin{array}{l}\text { Proteindisulfidisomerase A3 } \\
\text { (ERP57) }\end{array}$ & PDIA3_HUMAN & PDIA3 & 56747 & 5,98 & 549 & $35 \%$ & 0,8068 \\
\hline
\end{tabular}


Proteindisulfidisomerase A3
15 (ERP57)
Proteindisulfidisomerase A3
16 (ERP57)
17 RuvB-like
18 Serine/ arginine-rich splicing factor 1
19 Serine/ arginine-rich splicing factor 1
20 Splicing factor $3 B$ subunit 1
21 Stathmin
22 Stress-70 protein, mitochondrial T-complex protein 1 subunit epsilon
23 (TCP-1-epsilon)
T-complex protein 1 subunit epsilon
24 (TCP-1-epsilon)
Thioredoxin-dependent peroxide reduc-
25 tase, mitochondrial
26 UPF0568 protein C14orf166
27 Vimentin
28 Vimentin

\begin{tabular}{lcccccc} 
PDIA3_HUMAN & PDIA3 & 56747 & 5,98 & 550 & $43 \%$ & 0,9946 \\
PDIA3_HUMAN & PDIA3 & 56747 & 5,98 & 264 & $25 \%$ & 0,79112 \\
RUVB2_HUMAN & RUVBL2 & 51125 & 5,49 & 426 & $28 \%$ & 1,21561 \\
SRSF1_HUMAN & SRSF1 & 27728 & 10,37 & 40 & $14 \%$ & 0,46471 \\
SRSF1_HUMAN & SRSF1 & 27728 & 10,37 & 46 & $14 \%$ & 0,34303 \\
SF3B1_HUMAN & SF3B1 & 145738 & 6,65 & 45 & $2 \%$ & 0,50059 \\
STMN1_HUMAN & STMN1 & 17292 & 5,76 & 54 & $22 \%$ & 1,42298 \\
GRP75_HUMAN & HSPA9 & 73635 & 5,87 & 50 & $8 \%$ & 1,06321 \\
TCPE_HUMAN & CCT5 & 59633 & 5,45 & 135 & $15 \%$ & 1,4749 \\
TCPE_HUMAN & CCT5 & 59633 & 5,45 & 259 & $17 \%$ & 1,952 \\
PRDX3_HUMAN & PRDX3 & 27675 & 7,67 & 42 & $6 \%$ & 0,52359 \\
CN166_HUMAN & C14orf166 & 28051 & 6,19 & 34 & $9 \%$ & 2,49992 \\
VIME_HUMAN & VIM & 53619 & 5,06 & 124 & $23 \%$ & 0,70401 \\
VIME_HUMAN & VIM & 53619 & 5,06 & 501 & $46 \%$ & 1,05046 \\
\hline
\end{tabular}

Die Tabelle fasst alle 28 Proteine zusammen, die für die Caki-2-Zelllinie identifiziert wurden. Die Tabelle enthält Informationen über jedes Protein und die Ergebnisse der Datenbanksuche, die Aufschluss über die Zuverlässigkeit der Identifizierung gab, sowie das mit „Delta 2D“ ermittelte Verhältnis aus mittlerer Spotintensität in den Gelen von mit Cisplatin behandelten Zellen zu der mittleren Spotintensität in Gelen von Caki-2-Kontrollzellen (Ratio). Außerdem zeigt die Tabelle den Proteinnamen, die dazugehörige Bezeichnung in der Datenbank „Swiss-Prot“, den Namen des zugehörigen Gens, die Molekularmasse des Proteins, den errechneten isoelektrischen Punkt (pI), den Mascot Score, für den ein Wert über 29 als signifikant galt, und den Anteil an übereinstimmenden Peptidsequenzen der Probe mit der Datenbank. 
Für die Zelllinie Caki-2 sind die Ergebnisse in Abbildung 14 und Tabelle 8 dargestellt. Insgesamt wurden 28 Spots identifiziert.

Die detaillierten Ergebnisse für die Zelllinie A498 zeigen Abbildung 15 und Tabelle 9. Hier wurden 26 Spots identifiziert.

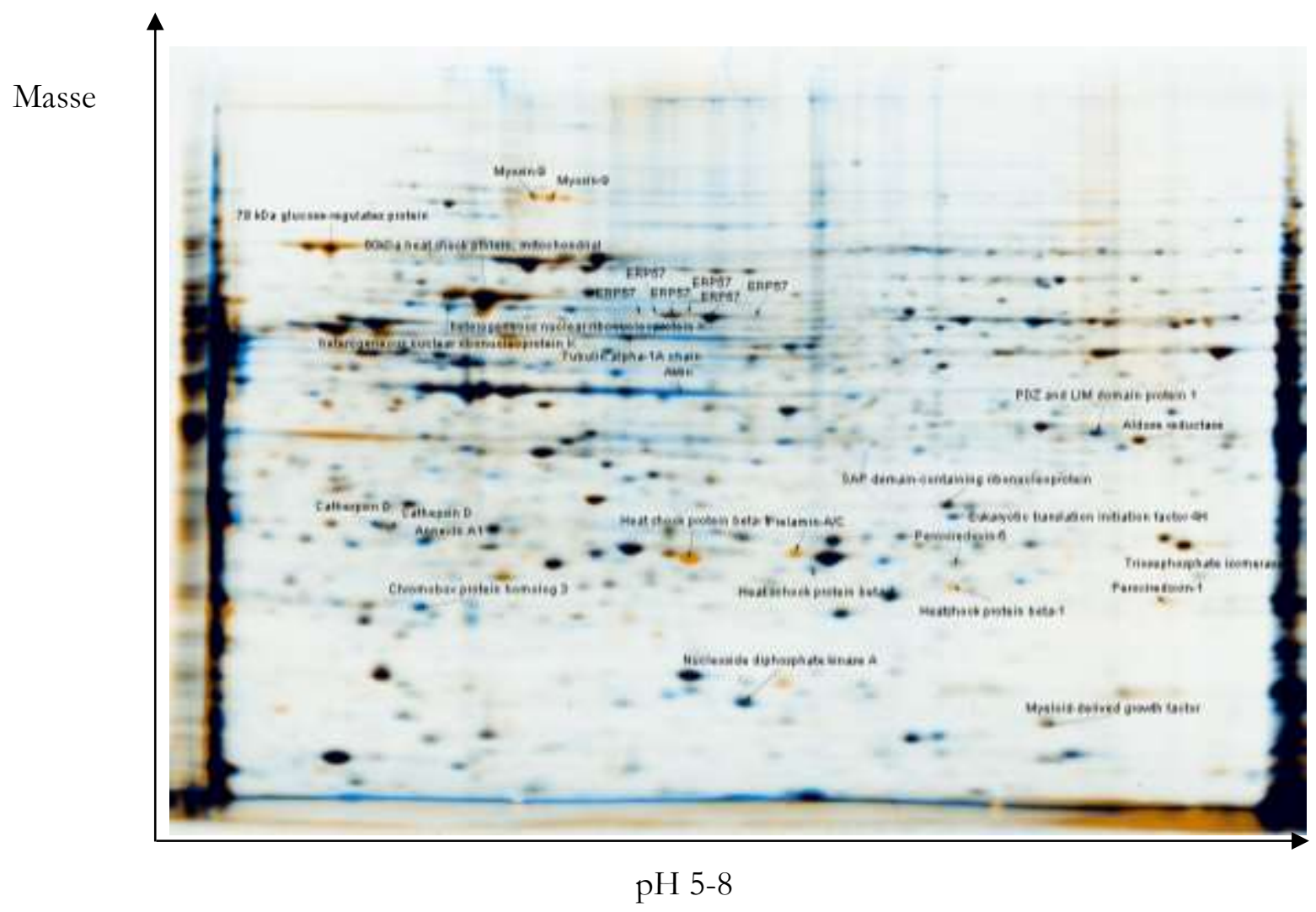

Abbildung 15: Identifizierte Proteine der A498-Zelllinie in einem übereinandergelegten Bild

Die Abbildung zeigt ein übereinandergelegtes Bild (entsprechend dem zweiten Schritt der Analyse mit dem Programm „Delta 2D“) von einer 2D-Gelelektrophorese von A498-Kontrollzellen und von mit Cisplatin behandelten A498-Zellen. Das Gel der Kontrollzellen ist in dem kombinierten Bild blau dargestellt, das Gel der mit Cisplatin behandelten Zellen gelb. Das Gel der Kontrollzellen ist in dem kombinierten Bild blau dargestellt, das Gel der mit Cisplatin behandelten Zellen gelb. In horizontaler Achse zeigt sich der $\mathrm{pH}-\mathrm{Gradient}$ von $\mathrm{pH}$ 5-8. In vertikaler Achse zeigt sich das Molekulargewicht, wobei schwere Proteine weiter oben im Bild verortet sind. Anhand der Spots des fusionierten Gesamtbildes erfolgte die Beschriftung der durch die Analyse mit dem Q-TOF-Massenspektrometer und durch den Datenbankvergleich identifizierten Proteine und wurde auf das Beispielbild übertragen. 
Tabelle 9: Liste der identifizierten Proteine der A498-Zellinie und Ratio der Expression der Spots

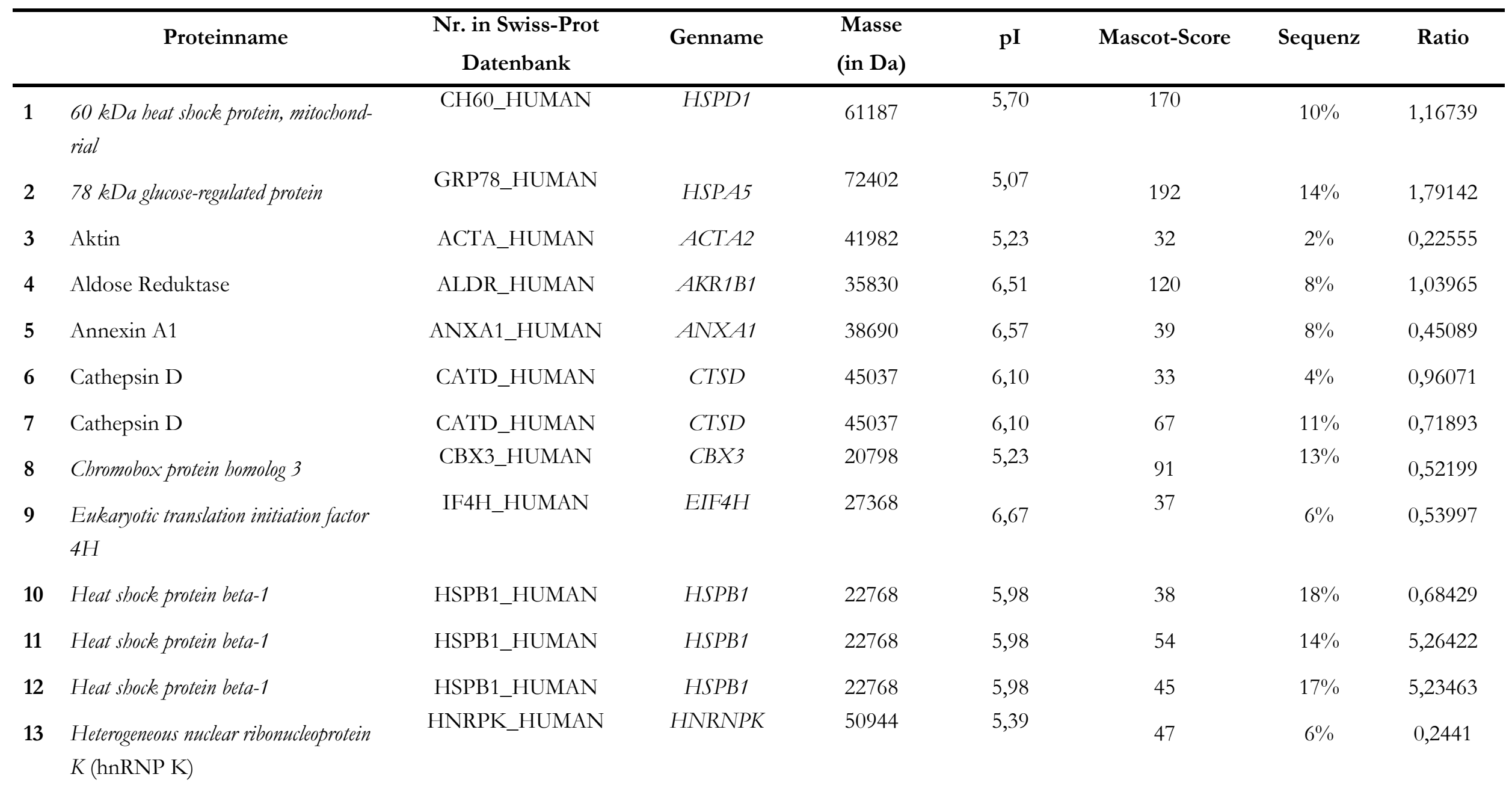




\begin{tabular}{|c|c|c|c|c|c|c|c|c|}
\hline 14 & $\begin{array}{l}\text { Heterogeneous nuclear ribonucleoprotein } \\
K(\mathrm{hnRNP} \mathrm{K})\end{array}$ & HNRPK_HUMAN & HNRNPK & 50944 & 5,39 & 41 & $4 \%$ & 0,30316 \\
\hline 15 & Myeloid-derived growth factor & MYDGF_HUMAN & MYDGF & 18783 & 6,20 & 72 & $12 \%$ & 2,38241 \\
\hline 16 & Myosin-9 & MYH9_HUMAN & MYH9 & 226392 & 5,50 & 59 & $1 \%$ & 9,2898 \\
\hline 17 & Myosin-9 & MYH9_HUMAN & МYH9 & 226392 & 5,50 & 106 & $2 \%$ & 25,47297 \\
\hline 18 & Nucleoside diphosphate kinase $A$ & NDKA_HUMAN & NME1 & 17138 & 5,83 & 86 & $26 \%$ & 1,22139 \\
\hline 19 & PDZ and LIM domain protein 1 & PDLI1_HUMAN & PDLIM1 & 36049 & 6,56 & 44 & $4 \%$ & 0,95472 \\
\hline 20 & Peroxiredoxin-1 & PRDX1_HUMAN & PRDX1 & 22096 & 8,27 & 49 & $12 \%$ & 4,76888 \\
\hline 21 & Peroxiredoxin-6 & PRDX6_HUMAN & PRDXG & 25019 & 6,00 & 35 & $6 \%$ & 1,06844 \\
\hline 22 & Prelamin-A/C & LMNA_HUMAN & $L M N A$ & 74095 & 6,57 & 133 & $5 \%$ & 5,31912 \\
\hline 23 & $\begin{array}{l}\text { Proteindisulfidisomerase A3 } \\
\text { (ERp57) }\end{array}$ & PDIA3_HUMAN & $P D L A 3$ & 56747 & 5,98 & 100 & $5 \%$ & 1,17168 \\
\hline 24 & $\begin{array}{l}\text { SAP domain-containing ribonucleopro- } \\
\text { tein }\end{array}$ & SARNP_HUMAN & $S A R N P$ & 23656 & 6,10 & 36 & $8 \%$ & 1,27954 \\
\hline 25 & Triosephosphate isomerase & TPIS_HUMAN & TPI1 & 30772 & 5,65 & 46 & $9 \%$ & 1,18605 \\
\hline 26 & Tubulin alpha-1 $A$ chain & TBA1A_HUMAN & $T U B A 1 A$ & 50104 & 4,94 & 36 & $2 \%$ & 1,04829 \\
\hline
\end{tabular}

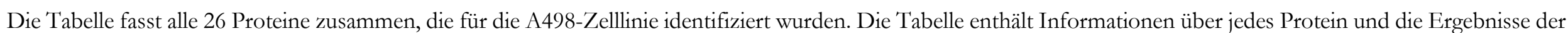

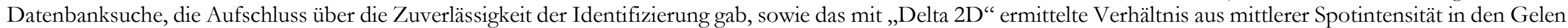

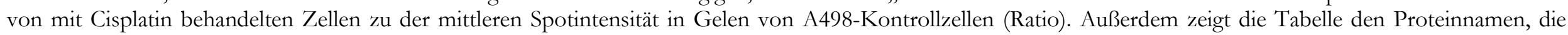

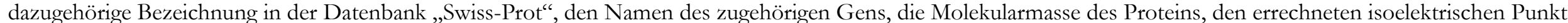
(pI), den Mascot Score, für den ein Wert über 29 als signifikant galt, und den Anteil an übereinstimmenden Peptidsequenzen der Probe mit der Datenbank. 


\subsubsection{Differenziell unterexprimierte Proteine nach Behandlung mit Cisplatin}

Von besonderem Interesse waren Spots von Proteinen, bei denen die Behandlung mit Cisplatin zu einer signifikanten Regulation nach unten führte. Hierfür wurden die Spots der identifizierten Proteine betrachtet, die eine Ratio unter oder gleich 0,5 aufwiesen.

In beiden Zelllinien wurden jeweils fünf Proteine identifiziert, die eine Ratio von unter oder gleich 0,5 zeigten (Abbildung 16, Abbildung 17). Der Unterschied zwischen Caki-2-Kontrollzellen und mit Cisplatin behandelten Caki-2-Zellen war für drei Proteine signifikant $(\mathrm{p}<0,05)$, und zwar für serine/arginine-rich splicing factor 1 (SRSF1), heterogeneous nuclear ribonucleoprotein K (hnRNP K) und splicing factor 3B subunit 1 (SF3B1) (Abbildung 16). In der A498Zelllinie war das Ergebnis lediglich für zwei Spots des Proteins hnRNP K signifikant $(\mathrm{p}<0,01)$ (Abbildung 17).

In Tabelle 10 sind die Proteine entsprechend der Recherche mit den Datenbanken „DAVID Bioinformatics“ und „Uniprot“ in Gruppen sortiert und gemäß ihrer biologischen Funktion zusammengefasst.

Tabelle 10: Zuordnung der differenziell unterexprimierten Proteine in Gruppen entsprechend ihrer biologischen Funktion

\begin{tabular}{lll}
\hline & Caki-2 & A498 \\
\hline mRNA-Prozessierung, Proteinbiosynthese & hnRNP K, SRSF1, & EIF4H, hnRNP K \\
& SF3B1 & \\
Redox-Homöostase & PDIA3, PRDX3 & \\
Proteinfaltung & PDIA3 & \\
Organisation des Zytoskeletts, der Zellkontakte & LMNB2 & ANXA1, CBX3, \\
und des Chromatins & & hnRNP K, EIF4H, \\
& & ACTA \\
Negative Regulation der Apoptose & hnRNP K & ANXA1, hnRNP K \\
\hline
\end{tabular}

Die benutzten Abkürzungen bezeichnen SRSF1 = serine/ arginine-rich splicing factor 1, LMNB2=Lamin$\mathrm{B} 2, \mathrm{SF} 3 \mathrm{~B} 1=$ splicing factor $3 \mathrm{~B}$ subunit $1, \mathrm{PRDX} 3=$ thioredoxin-dependent peroxide reductase, $\mathrm{h} n \mathrm{RNP} \mathrm{K}=$ beterogeneous nuclear ribonucleoprotein $\mathrm{K}, \mathrm{ACTA}=\mathrm{Aktin}, \mathrm{ANXA} 1=\mathrm{Annexin} \mathrm{A} 1, \mathrm{CBX} 3=$ chromobox protein homolog 3, EIF4H=enkaryotic translation initiation factor $4 \mathrm{H}$. 


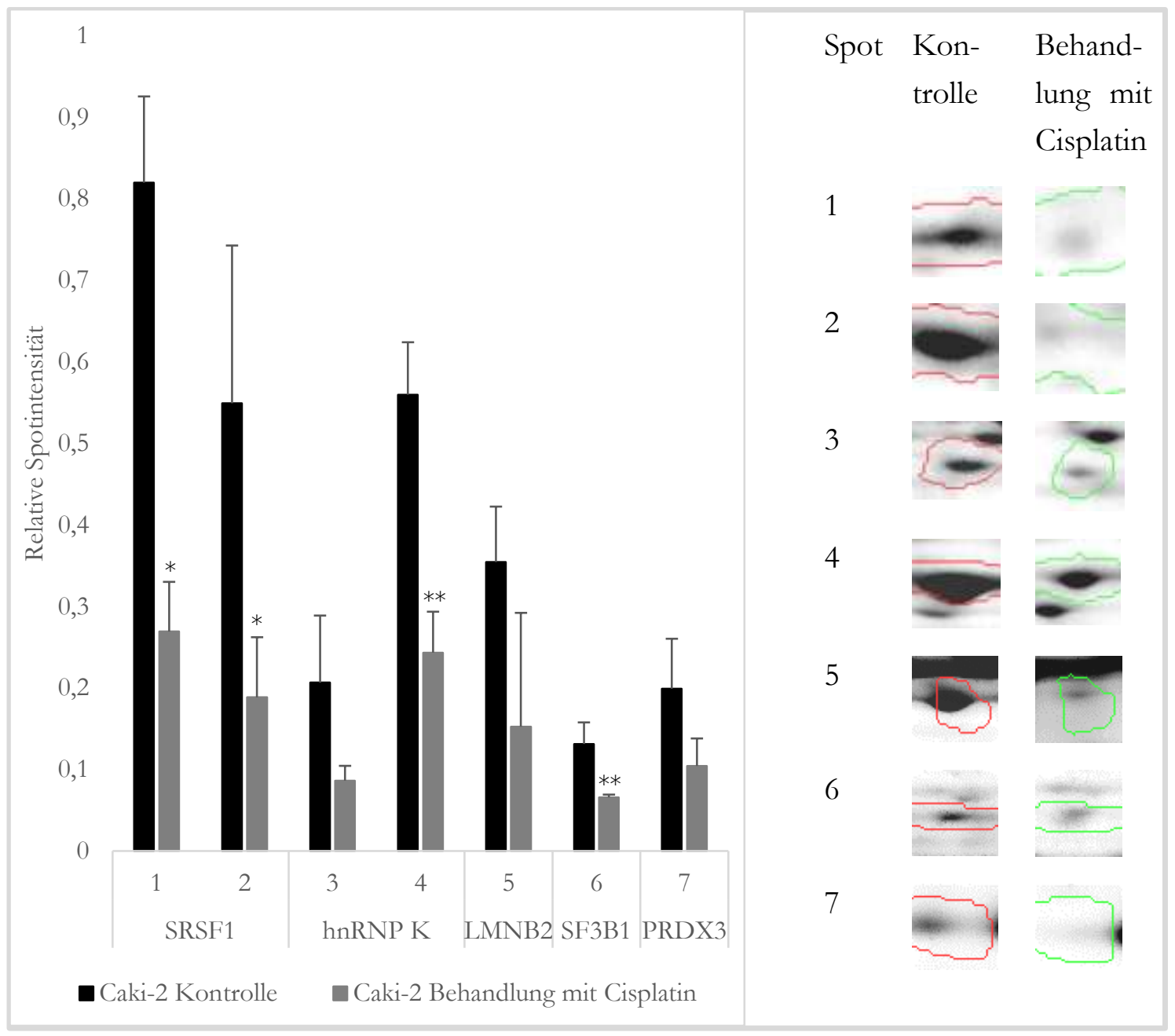

Abbildung 16: Übersicht über die Spotintensität der unterexprimierten Proteine nach Behandlung mit Cisplatin für Caki-2-Zellen

Das Diagramm (links) zeigt die mit dem Programm „Delta2D“ aus drei unabhängigen Experimenten errechneten Mittelwerte der Spotintensitäten von sieben Spots, in denen es nach einer Behandlung mit Cisplatin zu einer Regulation nach unten mit einer Ratio von unter oder gleich 0,5 gekommen war. Die gefärbten Balken symbolisieren den Mittelwert einer Gruppe für jeden Spot. Auf der Ordinate steht die relative Spotintensität. Die Abszisse separiert die einzelnen Spots und, wenn ein Protein durch mehrere Spots dargestellt wurde, die unterschiedlichen Proteine voneinander. Dabei sind die Proteine mit Abkürzungen wie folgt bezeichnet: SRSF1 = serine/arginine-rich splicing factor 1, hnRNP $\mathrm{K}=$ beterogeneous nuclear ribonucleoprotein $\mathrm{K}, \mathrm{LMNB} 2=\mathrm{Lamin}-\mathrm{B} 2, \mathrm{SF} 3 \mathrm{~B} 1=$ splicing factor $3 \mathrm{~B}$ subunit 1 , PRDX3 = thioredoxin-dependent peroxide reductase, mitochondrial. Die vertikalen Striche zeigen die Standardabweichung an. Gruppiert sind jeweils die Balken der Gele der Gruppe „Caki-2 Kontrolle“ und der Gruppe „Caki-2 behandelt mit Cisplatin“ des gleichen Spots. Durch die Sterne wird ein mit dem t-Test berechneter signifikanter Unterschied zwischen der Kontrollgruppe und der mit Cisplatin behandelten Gruppe angezeigt. Hierbei galt ${ }^{*}=\mathrm{p}<0,05$ als signifikant und ${ }^{* *}=\mathrm{p}<0,01$ als hoch signifikant. Repräsentativ für alle Gele einer Gruppe sind auf der rechten Seite der Abbildung die zu den im Diagramm dargestellten Spots zugehörigen Gelausschnitte präsentiert. 


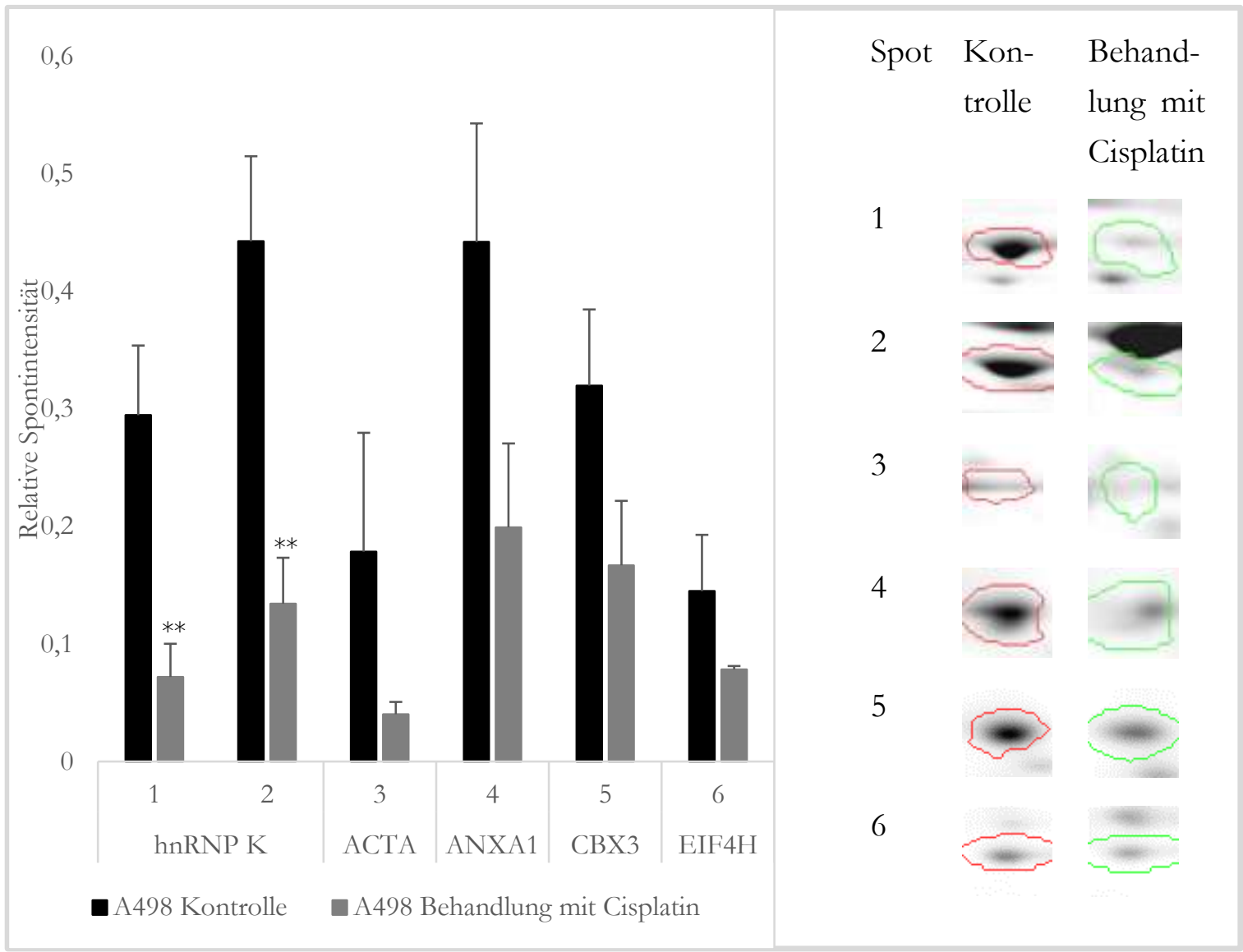

Abbildung 17: Übersicht über die Spotintensität der unterexprimierten Proteine nach Behandlung mit Cisplatin für A498-Zellen

Das Diagramm (links) zeigt die mit dem Programm „Delta2D“ aus drei unabhängigen Experimenten errechneten Mittelwerte der Spotintensitäten von sechs Spots, in denen es nach einer Behandlung mit Cisplatin zu einer Regulation nach unten mit einer Ratio von unter oder gleich 0,5 gekommen war. Die gefärbten Balken symbolisieren den Mittelwert einer Gruppe für jeden Spot. Auf der Ordinate steht die relative Spotintensität. Die Abszisse separiert die einzelnen Spots und, wenn ein Protein durch mehrere Spots dargestellt wurde, die unterschiedlichen Proteine voneinander. Dabei sind die Proteine mit Abkürzungen wie folgt bezeichnet: hnRNP $\mathrm{K}=$ heterogeneous nuclear ribonucleoprotein $K$, $\mathrm{ACTA}=$ Aktin, $\mathrm{ANXA1}=$ Annexin A1, CBX3=chromobox protein bomolog 3, EIF4H=eukaryotic translation initiation factor $4 H$. Die vertikalen Striche zeigen die Standardabweichung an. Gruppiert sind jeweils die Balken der Gele der Gruppe „A498 Kontrolle“ und der Gruppe „A498 behandelt mit Cisplatin" des gleichen Spots. Durch die Sterne wird ein mit dem t-Test berechneter signifikanter Unterschied zwischen der Kontrollgruppe und der mit Cisplatin behandelten Gruppe angezeigt. Hierbei galt ${ }^{* *}=\mathrm{p}<0,01$ als hoch signifikant. Repräsentativ für alle Gele einer Gruppe sind auf der rechten Seite der Abbildung die zu den im Diagramm dargestellten Spots zugehörigen Gelausschnitte präsentiert.

\subsubsection{Differenziell überexprimierte Proteine nach Behandlung mit Cisplatin}

Ein weiteres Augenmerk lag auf Spots von Proteinen, bei denen die Behandlung mit Cisplatin zu einer signifikanten Regulation nach oben führte. Hierfür wurden alle Spots betrachtet, die eine Ratio über oder gleich 2 aufwiesen. Für die Caki-2-Zelllinie wurden fünf Proteine identifiziert, für die eine Behandlung mit Cisplatin zu einer Regulation mit einer Ratio von 
über oder gleich 2 führte (Abbildung 18). Ein signifikanter Unterschied $(\mathrm{p}<0,05)$ zeigte sich für das Protein Prelamin A/C (LMNA) und UPF0568 protein C14orf166 (CGI-99).

In der A498-Zelllinie fielen fünf Proteine auf, die nach einer Behandlung mit Cisplatin mit einer Ratio von über oder gleich 2 hochreguliert waren (Abbildung 19). Davon war der Unterschied bei vier Proteinen signifikant $(\mathrm{p}<0,05)$. Hierzu zählte, wie auch schon bei Caki-2Zellen, LMNA und außerdem HSPB1, Myosin-9 (MYH-9) und myeloid-derived growth factor (MYDGF).

Tabelle 11 fasst die identifizierten überexprimierten Proteine entsprechend der Zuordnung mit den Proteindatenbanken „DAVID Bioinformatics“ und „Uniprot“ in Gruppen sortiert und gemäß ihrer biologischen Funktion zusammen.

Tabelle 11: Zuordnung der differenziell überexprimierten Proteine in Gruppen nach ihrer biologischen Funktion

\begin{tabular}{lll}
\hline & Caki-2 & A498 \\
\hline mRNA-Prozessierung, Proteinbiosynthese & CGI-99, RS12 & \\
Redox-Homöostase & & PDIA3, PRDX1 \\
Proteinfaltung & TCP-1 epsilon & PDIA3 \\
Negative Regulation der Apoptose & & HSPB1, MYDGF \\
(IRE1-vermittelte) UPR und Zellhomöostase & LMNA, PSA1 & LMNA, HSPB1, \\
& & MYDGF \\
$\begin{array}{l}\text { Organisation des Zytoskeletts, der Zellkon- } \\
\text { takte und des Chromatins }\end{array}$ & MYH9 \\
\hline
\end{tabular}

Die benutzten Abkürzungen bezeichnen CGI-99=UPF0568 protein C14orf166, LMNA=Prelamin $\mathrm{A} / \mathrm{C}, \mathrm{PSA} 1=$ proteasome subunit alpha type- $1, \mathrm{RS} 12=40$ S ribosomal protein $\mathrm{S12}, \mathrm{TCP}-1 \mathrm{epsilon}=\mathrm{T}-$ complex protein 1 subuinit epsilon, HSPB1 = heat shock protein beta-1, MYH9=Myosin-9, LMNA=Prelamin A/C, MYDGF = myeloid-derived growth factor, PRDX1=Peroxiredoxin-1. 


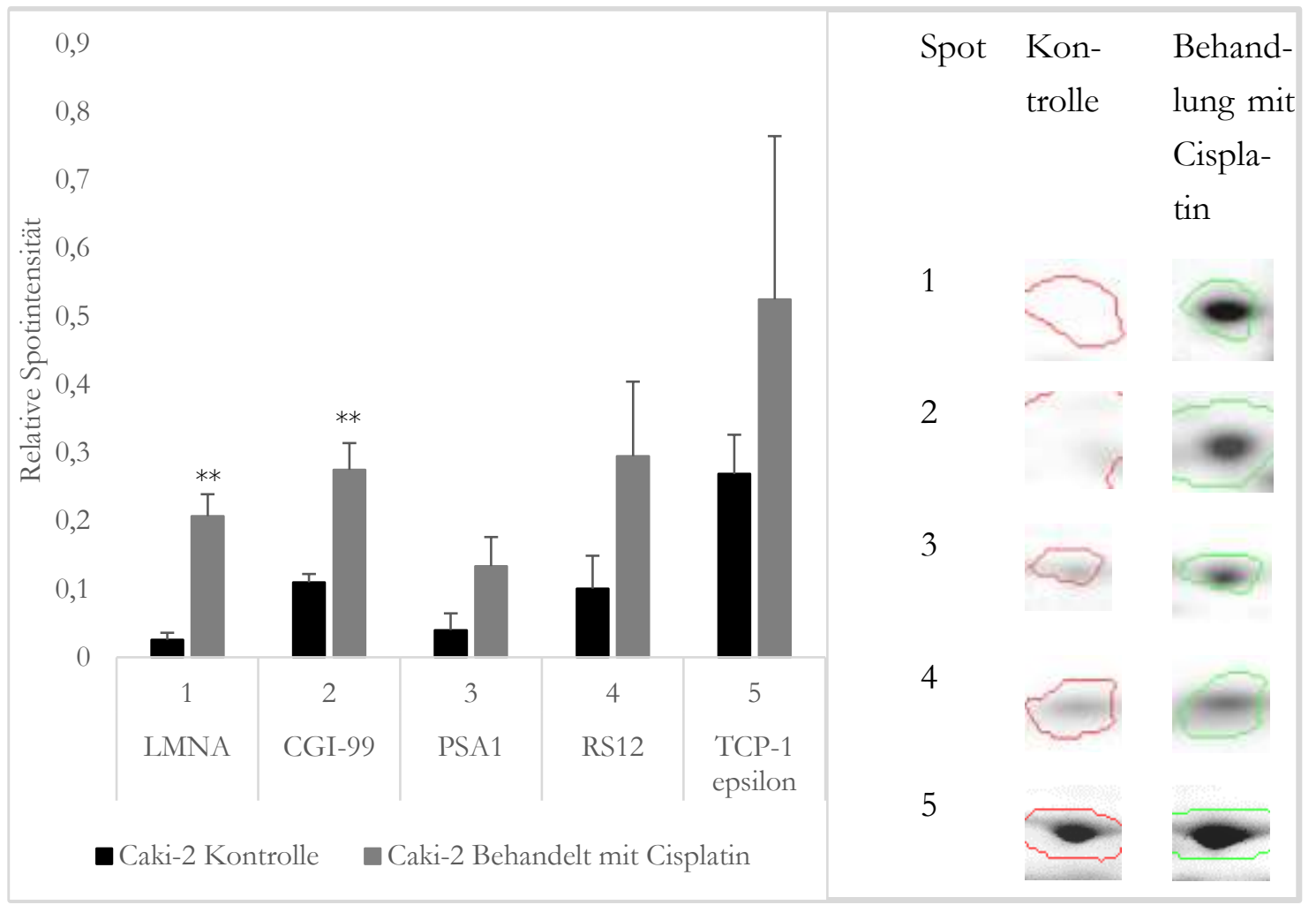

Abbildung 18: Übersicht über die Spotintensität der überexprimierten Proteine nach Behandlung mit Cisplatin für Caki-2-Zellen

Das Diagramm (links) zeigt die mit dem Programm „Delta2D“ aus drei unabhängigen Experimenten errechneten Mittelwerte der Spotintensitäten von fünf Spots, in denen es nach einer Behandlung mit Cisplatin zu einer Regulation nach oben mit einer Ratio von unter oder gleich 2 gekommen war. Die gefärbten Balken symbolisieren den Mittelwert einer Gruppe für jeden Spot. Auf der Ordinate steht die relative Spotintensität. Die Abszisse separiert die einzelnen Spots und, wenn ein Protein durch mehrere Spots dargestellt wurde, die unterschiedlichen Proteine voneinander. Dabei sind die Proteine mit Abkürzungen wie folgt bezeichnet: LMNA=Prelamin A/C, CGI-99= UPF0568 protein 14orf166, PSA1 = proteasome subunit alpha type-1, RS12 $=40$ S ribosomal protein S12, TCP-1 epsilon $=\mathrm{T}$-complex protein 1 subuinit epsilon. Die vertikalen Striche zeigen die Standardabweichung an. Gruppiert sind jeweils die Balken der Gele der Gruppe „Caki-2 Kontrolle“ und der Gruppe „Caki-2 behandelt mit Cisplatin“ des gleichen Spots. Durch die Sterne wird ein mit dem t-Test berechneter signifikanter Unterschied zwischen der Kontrollgruppe und der mit Cisplatin behandelten Gruppe angezeigt. Hierbei galt $* *=p<0,01$ als hoch signifikant. Repräsentativ für alle Gele einer Gruppe sind auf der rechten Seite der Abbildung die zu den im Diagramm dargestellten Spots zugehörigen Gelausschnitte präsentiert. 


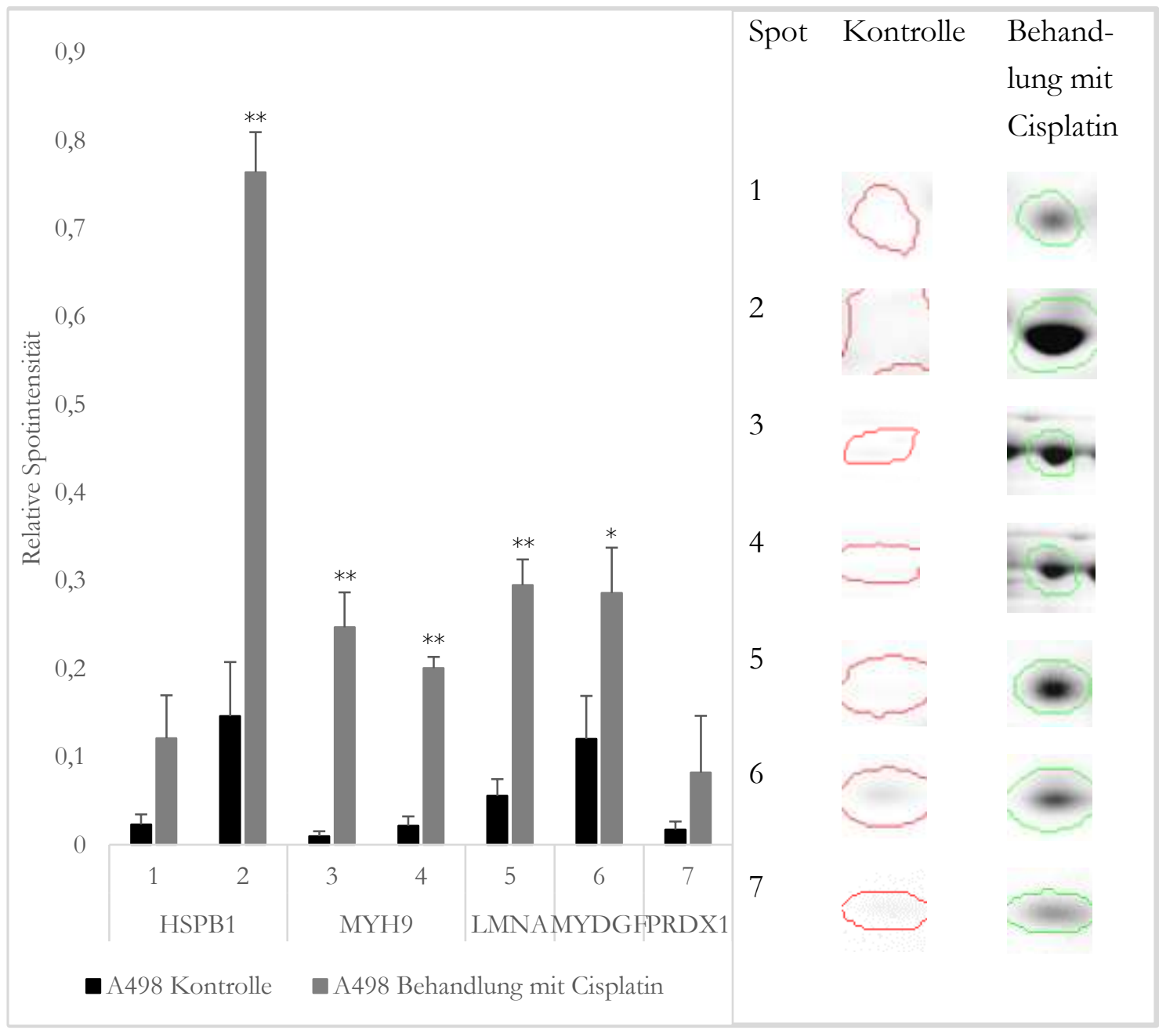

Abbildung 19: Übersicht über die Spotintensität der überexprimierten Proteine nach Behandlung mit Cisplatin für A498-Zellen

Das Diagramm (links) zeigt die mit dem Programm „Delta2D“ aus drei unabhängigen Experimenten errechneten Mittelwerte der Spotintensitäten von sieben Spots, in denen es nach einer Behandlung mit Cisplatin zu einer Regulation nach oben mit einer Ratio von unter oder gleich 2 gekommen war. Die gefärbten Balken symbolisieren den Mittelwert einer Gruppe für jeden Spot. Auf der Ordinate steht die relative Spotintensität. Die Abszisse separiert die einzelnen Spots und, wenn ein Protein durch mehrere Spots dargestellt wurde, die unterschiedlichen Proteine voneinander. Dabei sind die Proteine mit Abkürzungen wie folgt bezeichnet: HSPB1 = heat shock protein beta-1, MYH9=Myosin-9, $\mathrm{LMNA}=$ Prelamin A/C, MYDGF = myeloid-derived growth factor, PRDX1=Peroxiredoxin -1 . Die vertikalen Striche zeigen die Standardabweichung an. Gruppiert sind jeweils die Balken der Gele der Gruppe „A498 Kontrolle“ und der Gruppe „A498 behandelt mit Cisplatin“ des gleichen Spots. Durch die Sterne wird ein mit dem t-Test berechneter signifikanter Unterschied zwischen der Kontrollgruppe und der mit Cisplatin behandelten Gruppe angezeigt. Hierbei galt $*=p<0,05$ als signifikant und ${ }^{* *}=\mathrm{p}<0,01$ als hoch signifikant. Repräsentativ für alle Gele einer Gruppe sind auf der rechten Seite der Abbildung die zu den in dem Diagramm dargestellten Spots zugehörigen Gelausschnitte präsentiert. 


\subsection{Auswirkung der Behandlung mit Cisplatin auf ER-Stressproteine in Nierenzellkarzinom-Zelllinien am Beispiel der Proteindisulfidisomerase ERp57}

Aus den differenziell über- oder unterexprimierten Proteinen ging hervor, dass die Behandlung mit Cisplatin die Expression der ER-Stressproteine beeinflusste. Um die Rolle der ERStressproteine in der Zellantwort auf die Behandlung mit Cisplatin zu untersuchen, wurde exemplarisch für die ER-Stressproteine das Protein ERp57 betrachtet.

\subsubsection{Auswirkung der Behandlung mit Cisplatin auf Spots des ER-Stressproteins ERp57 in 2D-Gelen der Nierenzellkarzinom-Zelllinien}

Zunächst wurden die Spots in den 2D-Gelen beider Zelllinien genauer betrachtet, die das Protein ERp57 darstellen. Hierfür wurden auch Spots, die nicht in dieser Arbeit identifiziert wurden, jedoch zuvor in unserer Arbeitsgruppe identifiziert worden waren, benannt und quantifiziert (Abbildung 14 und Abbildung 15). Somit war eine vollständigere Auswertung des Expressionsprofils von ERp57 mit dem Programm „Delta2D“ möglich. 


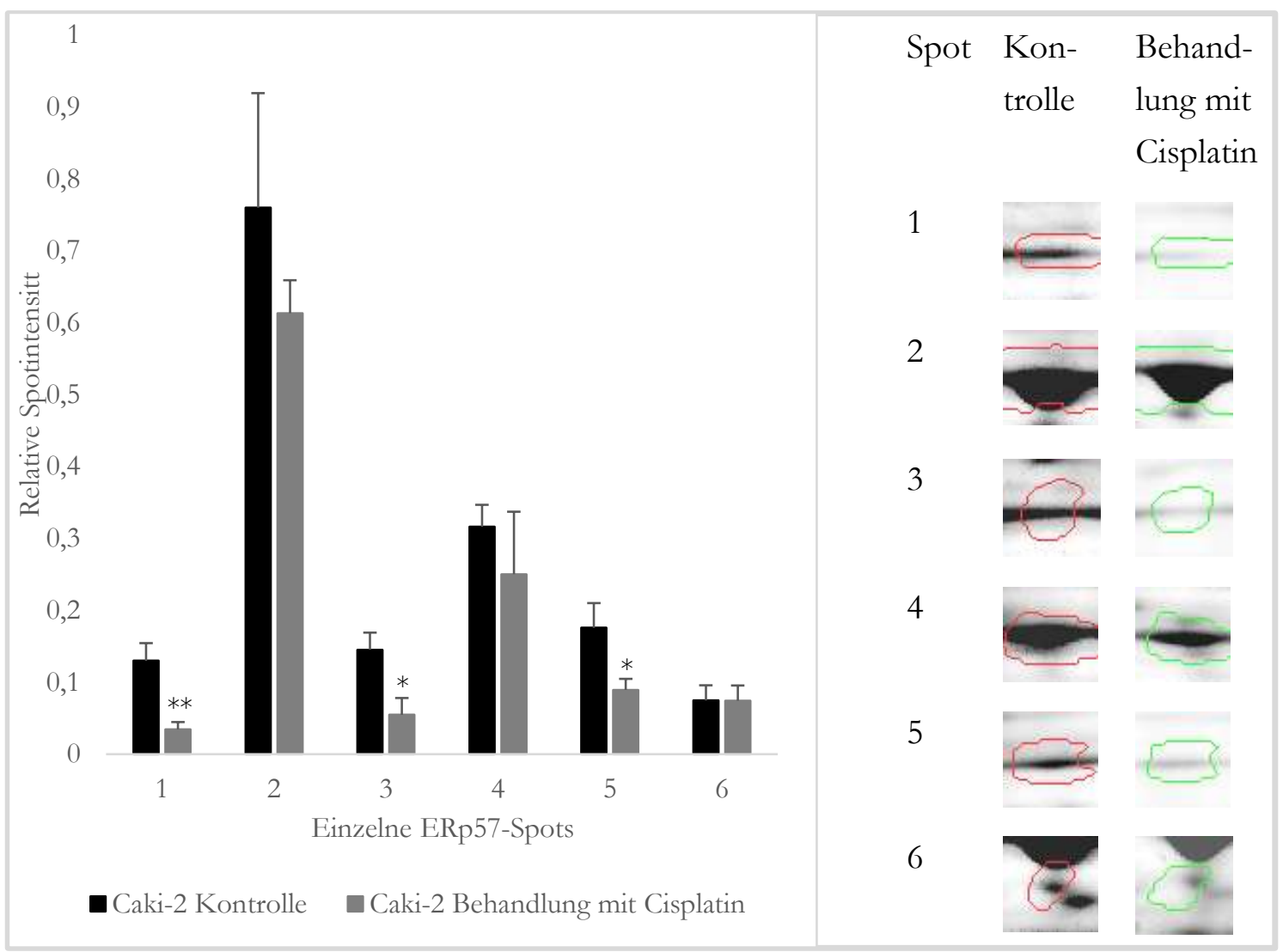

Abbildung 20: Übersicht der Spotintensität der einzelnen ERp57-Spots für Caki-2-Zellen im Vergleich

Das Diagramm (links) zeigt die mit dem Programm „Delta2D“ aus drei unabhängigen Experimenten errechneten Mittelwerte der Spotintensitäten von sechs Spots, in denen sich das Protein ERp57 darstellt. Die gefärbten Balken symbolisieren den Mittelwert einer Gruppe für jeden Spot. Auf der Ordinate steht die relative Spotintensität. Die Abszisse separiert die einzelnen Spots voneinander. Die vertikalen Striche zeigen die Standardabweichung an. Gruppiert sind jeweils die Balken der Gele der Gruppe „Caki-2 Kontrolle“ und der Gruppe „Caki-2 behandelt mit Cisplatin“ des gleichen Spots. Durch die Sterne wird ein mit dem t-Test berechneter signifikanter Unterschied zwischen der Kontrollgruppe und der mit Cisplatin behandelten Gruppe angezeigt. Hierbei galt $*=\mathrm{p}<0,05$ als signifikant und ${ }^{* *}=\mathrm{p}<0,01$ als hoch signifikant. Repräsentativ für alle Gele einer Gruppe sind auf der rechten Seite der Abbildung die zu den im Diagramm dargestellten Spots zugehörigen Gelausschnitte präsentiert.

Bei der Auswertung der Spots zeigte sich für drei relativ kleine Spots ein signifikanter Unterschied $(\mathrm{p}<0,05)$, einer davon hoch signifikant $(\mathrm{p}<0,01)$, zwischen den Caki-2-Kontrollzellen und den mit Cisplatin behandelten Caki-2-Zellen (Spot 1, 3 und 5, Abbildung 20). Für zwei dieser drei Spots betrug das Verhältnis des Mittelwerts der Spotintensität der mit Cisplatin behandelten Caki-2-Zellen zu den Caki-2-Kontrollzellen („Ratio“) unter 0,5. Dies entsprach einer Spotintensität, die im Mittel um mehr als die Hälfte gesunken war. Für den Spot mit der Nummer 5 wurde eine Ratio von 0,51 berechnet. Für die weiteren drei dargestellten Spots betrug die Ratio zwischen 0,5 und 1 (Spot 2,4 und 6, Abbildung 20). 


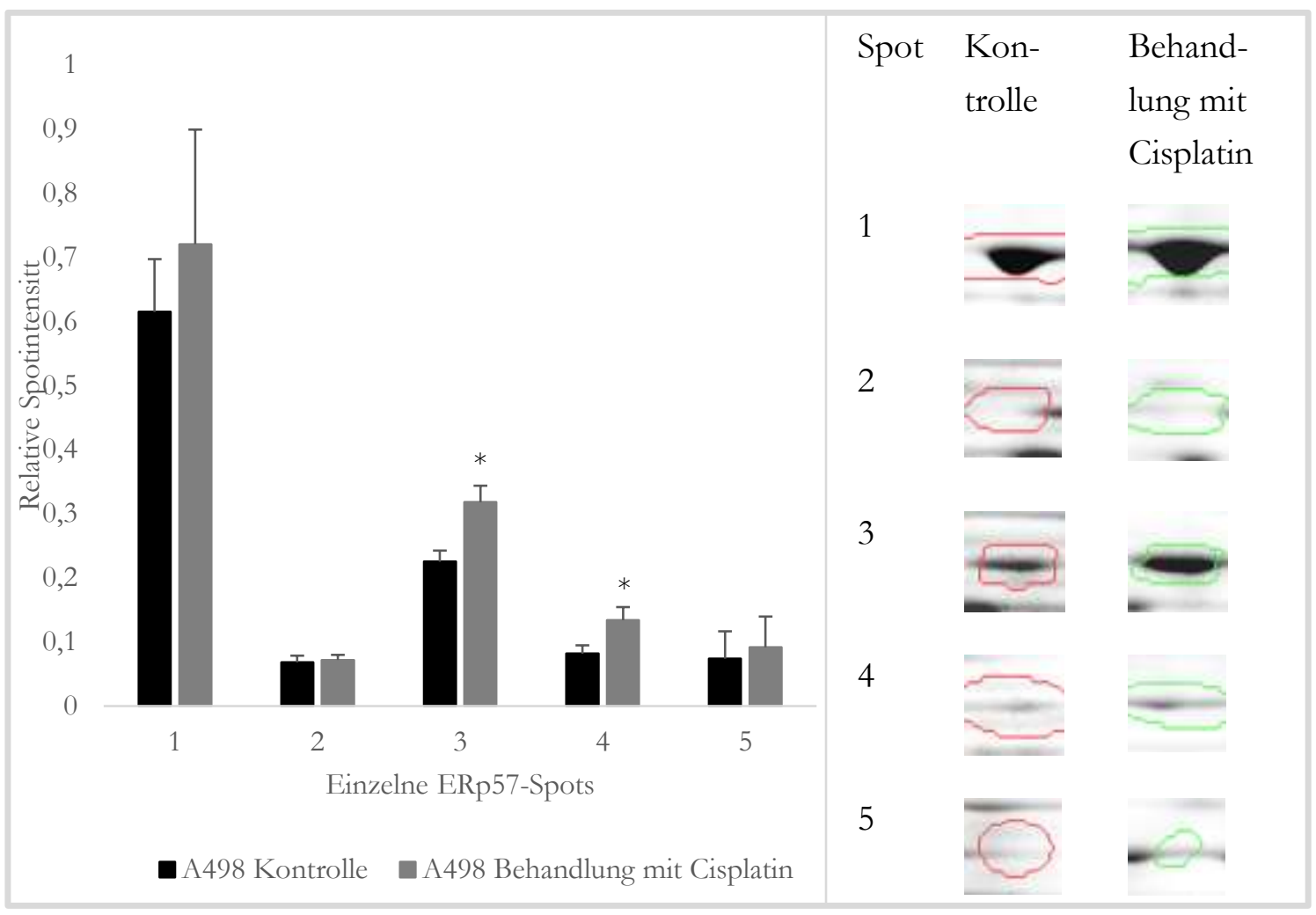

Abbildung 21: Übersicht der Spotintensität der einzelnen ERp57-Spots für A498-Zellen im Vergleich

Das Diagramm (links) zeigt die mit dem Programm „Delta2D“ aus drei unabhängigen Experimenten errechneten Mittelwerte der Spotintensitäten von fünf Spots, in denen sich das Protein ERp57 darstellt. Die gefärbten Balken symbolisieren den Mittelwert einer Gruppe für jeden Spot. Auf der Ordinate steht die relative Spotintensität. Die Abszisse separiert die einzelnen Spots voneinander. Die vertikalen Striche zeigen die Standardabweichung an. Gruppiert sind jeweils die Balken der Gele der Gruppe „A498 Kontrolle“ und der Gruppe „A498 behandelt mit Cisplatin“ des gleichen Spots. Durch die Sterne wird ein mit dem t-Test berechneter signifikanter Unterschied zwischen der Kontrollgruppe und der mit Cisplatin behandelten Gruppe angezeigt. Hierbei galt $*=\mathrm{p}<0,05$ als signifikant. Repräsentativ für alle Gele einer Gruppe sind auf der rechten Seite der Abbildung die zu den im Diagramm dargestellten Spots zugehörigen Gelausschnitte präsentiert.

Für Spots des Proteins ERp57 in der Zelllinie A498 zeigte sich in zwei Fällen (Spot 3 und Spot 4, Abbildung 21) ein signifikanter Unterschied zwischen den A498-Kontrollzellen und den mit Cisplatin behandelten A498-Zellen. Das Verhältnis aus Mittelwert der Spotintensität der mit Cisplatin behandelten Zellen und der A498-Kontrollzellen („Ratio“) blieb unter 2. Für Spot Nummer 3 betrug die Ratio 1,41, für Spot Nummer 4 1,64. Somit war es im Mittel nicht zu einer Verdopplung der Intensität gekommen. Für die anderen Spots (Spot 1, Spot 2 und Spot 5, ) zeigte sich kein signifikanter Unterschied. Die Ratio lag für diese drei Spots zwischen 1,05 und 1,27. 


\subsubsection{Auswirkung der Behandlung mit Cisplatin auf die Expression des ER- Stressproteins ERp57 in Nierenzellkarzinom-Zelllinien im Western Blot}

Zur Verfizierung der in der proteomischen Analyse gewonnenen Daten wurde dann die Expression von ERp57 im Zeitverlauf nach einer Behandlung mit Cisplatin im Western Blot betrachtet.

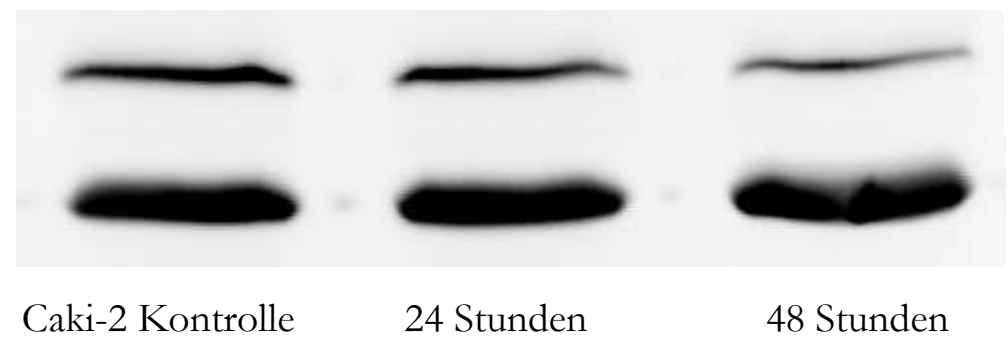

Abbildung 22: ERp57- (oben) und Beta-Aktin- (unten) Expression im zeitlichen Verlauf nach Behandlung mit Cisplatin in Caki-2-Zellen im Western Blot

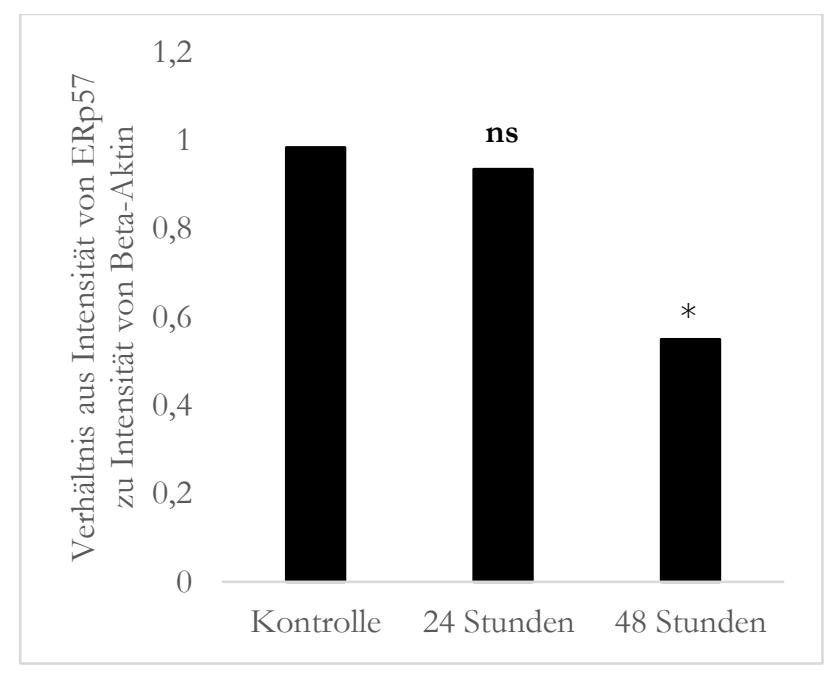

Abbildung 23: Diagramm des Verhältnisses der ERp57-Expression zu der Beta-Aktin-Expression in Caki-2-Zellen im zeitlichen Verlauf nach Behandlung mit Cisplatin

Die schwarzen Balken des Diagramms zeigen den Mittelwert des Verhältnisses der gemessenen Intensität der Bande für ERp57 zu der Intensität der Bande von Beta-Aktin im Western Blot. Dieses Verhältnis ist auf der Ordinate abgebildet. Beta-Aktin wurde als housekeeping-Protein genutzt und fungierte so zum einen als Ladekontrolle und zum anderen zur Kontrolle dafür, dass die gleiche Menge an Protein geladen war. Durch die Berechnung des Verhältnisses wurden Intensitätsunterschiede in der ERp57-Bande ausgeschlossen, die durch eine unterschiedliche Menge an geladenem Protein entstanden waren. Die Beta-Aktin-Expression in den Zellen bleibt gewöhnlich gleich. Die Abszisse separiert die Zeitintervalle der Behandlung. Das Signifikanzniveau wurde im Vergleich zu der Kontrolle mit Hilfe des t-Tests ermittelt. Dabei galt $*=p<0,05$ als signifikant und ns $=\mathrm{p}>0,05$ als nicht signifikant.

Nach Behandlung mit Cisplatin zeigte sich im Zeitverlauf in Caki-2-Zellen eine Regulation der Proteindisulfidisomerase ERp57 nach unten. Zunächst unterschied sich das Level der 
ERp57-Expression nur unwesentlich von der der Kontrolle ( $>>0,05)$. Nach zweitägiger Behandlung mit Cisplatin war das Verhältnis von ERp57-Expression zu Beta-Aktin-Expression im Mittel um den Faktor 0,6 gesunken (Abbildung 22, Abbildung 23). Der Unterschied zwischen der Kontrollgruppe und den für 48 Stunden behandelten Caki-2-Zellen war signifikant $(\mathrm{p}<0,05)$.

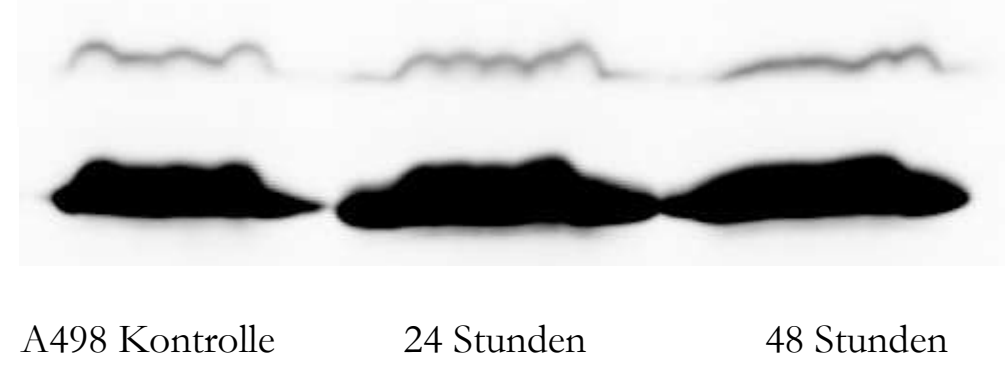

Abbildung 24: ERp57- (oben) und Beta-Aktin- (unten) Expression im zeitlichen Verlauf nach Behandlung mit Cisplatin in A498-Zellen im Western Blot

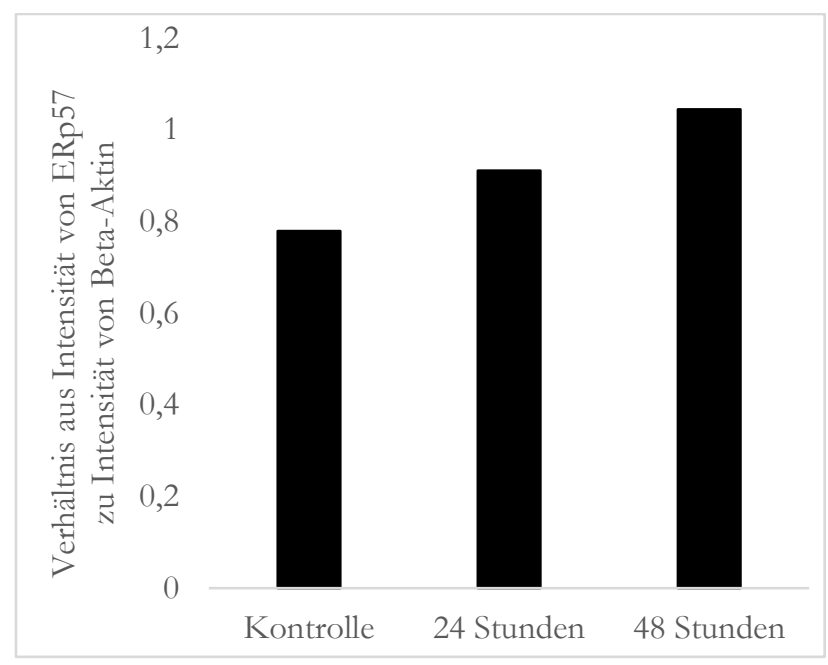

Abbildung 25: Diagramm des Verhältnisses der ERp57-Expression zu der Beta-Aktin-Expression in A498-Zellen im zeitlichen Verlauf nach Behandlung mit Cisplatin

Die schwarzen Balken des Diagramms zeigen das Verhältnis der gemessenen Intensität der Bande für ERp57 zu der Intensität der Bande von Beta-Aktin im Western Blot. Dieses Verhältnis ist auf der Ordinate abgebildet. Beta-Aktin wurde als housekeeping-Protein genutzt und fungierte so zum einen als Ladekontrolle und zum anderen zur Kontrolle dafür, dass die gleiche Menge an Protein geladen war. Durch die Berechnung des Verhältnisses wurden Intensitätsunterschiede ausgeschlossen, die durch eine unterschiedliche Menge an geladenem Protein entstanden war. Die Beta-Aktin-Expression in den Zellen bleibt gewöhnlich gleich. Die Abszisse separiert die Zeitintervalle der Behandlung.

In der A498-Zelllinie zeigte sich nach Behandlung mit Cisplatin im Zeitverlauf eine Regulation von ERp57 nach oben. Diese prägte sich bei längerer Behandlungsdauer weiter aus. Das Verhältnis von ERp57-Expression zu Beta-Aktin-Expression stieg nach 48 Stunden nur leicht um den Faktor 1,3 (Abbildung 24, Abbildung 25). 


\subsection{Expressionsregulation von ERp57 in Caki-2- und A498-Zelllinien: siRNA-Herunterregulation und Plasmid-Hochregulation}

Die Rolle des ER-Stress Proteins ERp57 war von besonderem Interesse. Es konnte gezeigt werden, dass ERp57 in der Pathogenese unterschiedlicher Krankheitsbilder wie Krebserkrankungen und Nierenfibrose beteiligt ist. In den durchgeführten proteomischen Analysen und Western Blots zeigte sich nach Behandlung mit Cisplatin in beiden Zelllinien eine gegenläufige Regulation von ERp57. Es entstand die Annahme, dass ERp57 eine Rolle in der Resistenz gegenüber Cisplatin in Nierenzellkarzinom-Zelllinien spielt und die Proliferation der untersuchten Zelllinien positiv beeinflusst.

Zur Untersuchung dieser Hypothesen erfolgte zunächst eine Expressionsregulation von ERp57 durch Transfektion der beiden Zelllinien, wie sie in 2.2.8 beschrieben wird. Dadurch sollte die Expression von ERp57 einerseits durch siRNA herunterreguliert und andererseits durch ein Plasmid, das das ERp57 Gen trägt, hochreguliert werden.

\subsubsection{Bestätigung durch Western Blot}

Zur Verifizierung des Erfolgs der Transfektion und Expressionsregulation von ERp57 erfolgten Western Blots.

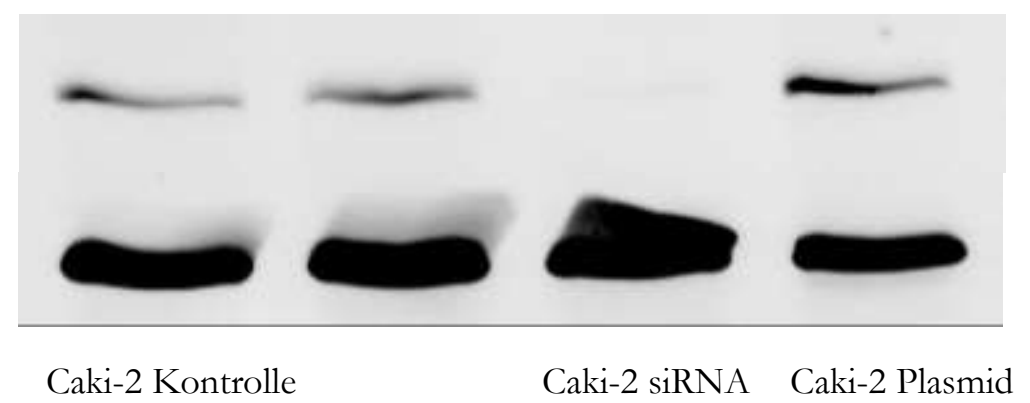

Abbildung 26: ERp57- (oben) und Beta-Aktin- (unten) Expression in der Kontrolle und nach Transfektion in Caki-2-Zellen im Western Blot

Abbildung 26 zeigt exemplarisch einen nach Transfektion von Caki-2-Zellen durchgeführten Western Blot. Hier führte die Transfektion mit siRNA zu einem kompletten Fehlen der Bande für ERp57, bei korrekter Ladung der Probe. Somit wurde für mit siRNA transfizierte Caki-2-Zellen die Expression von ERp57 komplett gehemmt und die Transfektion mit siRNA war erfolgreich. Für mit dem Plasmid transfizierte Zellen galt das Gegenteil. Die Bande für ERp57 zeigte sich hier in einer stärkeren Intensität als in der Kontrolle. Die BetaAktin-Banden deuteten auf eine ähnliche Menge an Proteinladung hin. Diese war in mit dem Plasmid transfizierten Zellen schlanker als die der Kotrollzellen bei trotzdem stärkerer Intensität der Bande für ERp57, so dass die Transfektion und die daraus resultierende Expressionsregulation als erfolgreich angesehen wurde. 


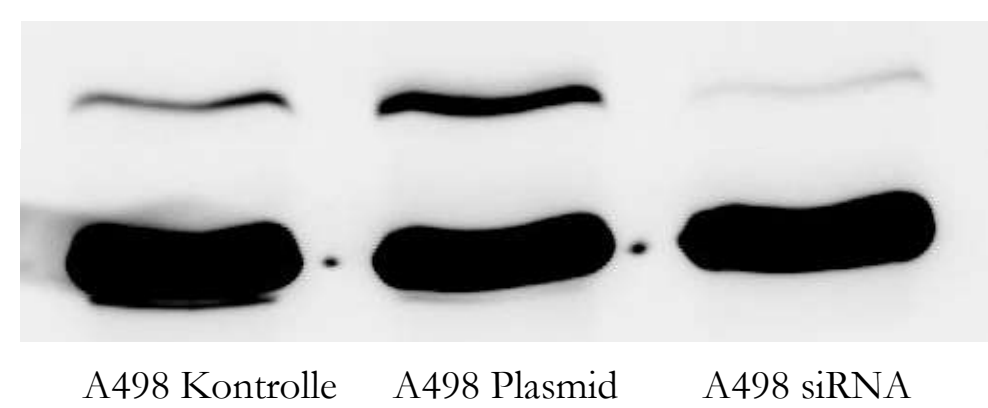

Abbildung 27: ERp57- (oben) und Beta-Aktin- (unten) Expression in der Kontrolle und nach Transfektion in A498-Zellen im Western Blot

Abbildung 27 zeigt exemplarischen einen Western Blot nach Transfektion in A498-Zellen. Auch hier zeigte sich für mit dem Plasmid transfizierte Zellen eine stärkere Intensität der Bande von ERp57 sowie eine deutlich schwächere Intensität der Bande, die das Vorkommen von ERp57 in den mit siRNA transfizierten Zellen widerspiegelte. Die Banden für BetaAktin stellten sich in beiden transfizierten Zellen ähnlich breit dar. Die Beta-Aktin-Bande der A498-Kontrollzellen war etwas breiter. Insgesamt war aber auch in A498-Zellen der Erfolg der Transfektion mit Expressionsregulation von ERp57 deutlich zu sehen.

Aufgrund des augenscheinlichen Erfolgs der Transfektion in beiden Zelllinien wurde auf eine Quantifizierung der Banden verzichtet und die Expressionsregulation wurde durch den Western Blot als bestätigt gesehen.

\subsubsection{Bestätigung durch indirekte Immunfluoreszenzfärbung}

Als nächstes stellte sich die Frage, ob sich das Vorkommen des nach Hochregulation gebildeten ERp57s in der Zelle von dem der Kontrollzellen unterschied. Wie schon in 1.7 erwähnt, handelt es sich bei ERp57 um ein in physiologischer Weise vor allem im ER vorkommendes Protein. Die indirekte Immunfluoreszenzfärbung der Kontrollzellen und der mit dem Plasmid transfizierten Zellen wurde, wie bereits in 2.2.9 erläutert, durchgeführt, um ERp57 in der Zelle zu lokalisieren. 


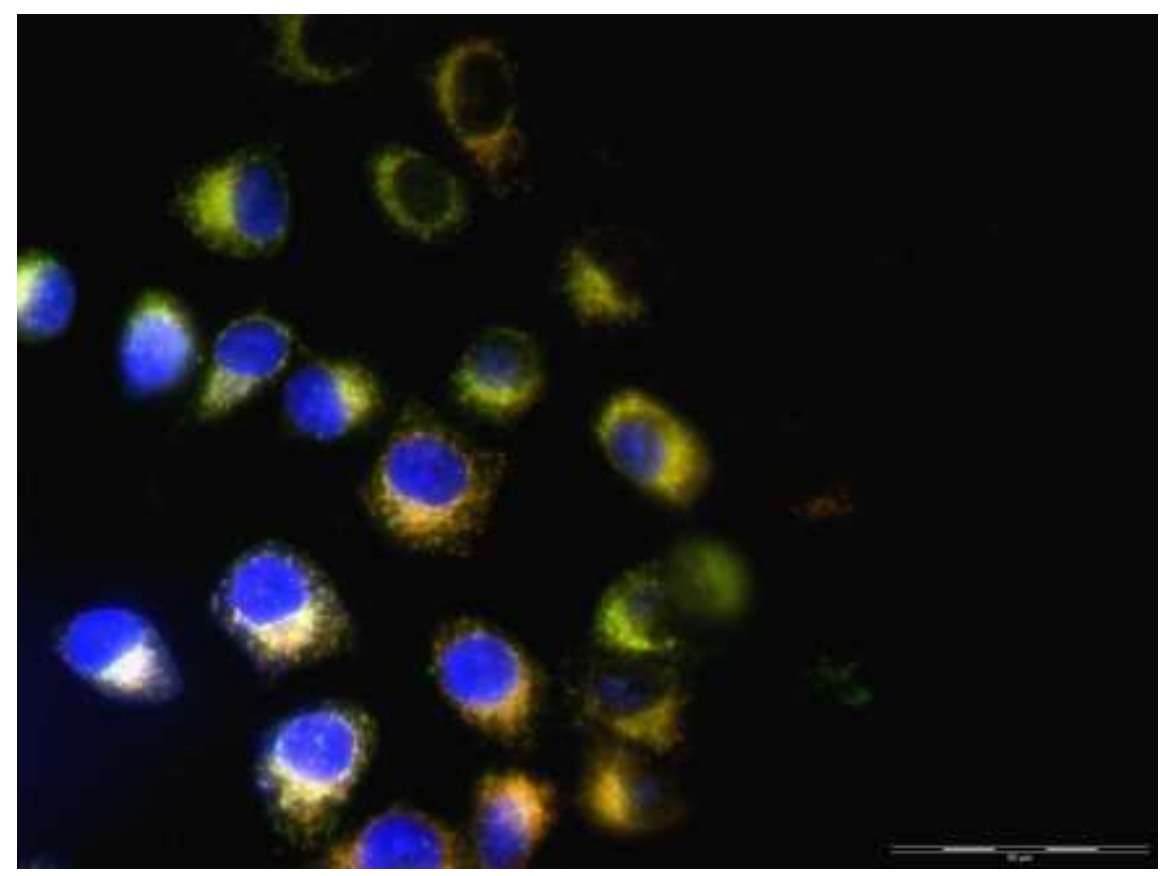

Abbildung 28: Indirekte Immunfluoreszenzfärbung von Caki-2-Kontrollzellen

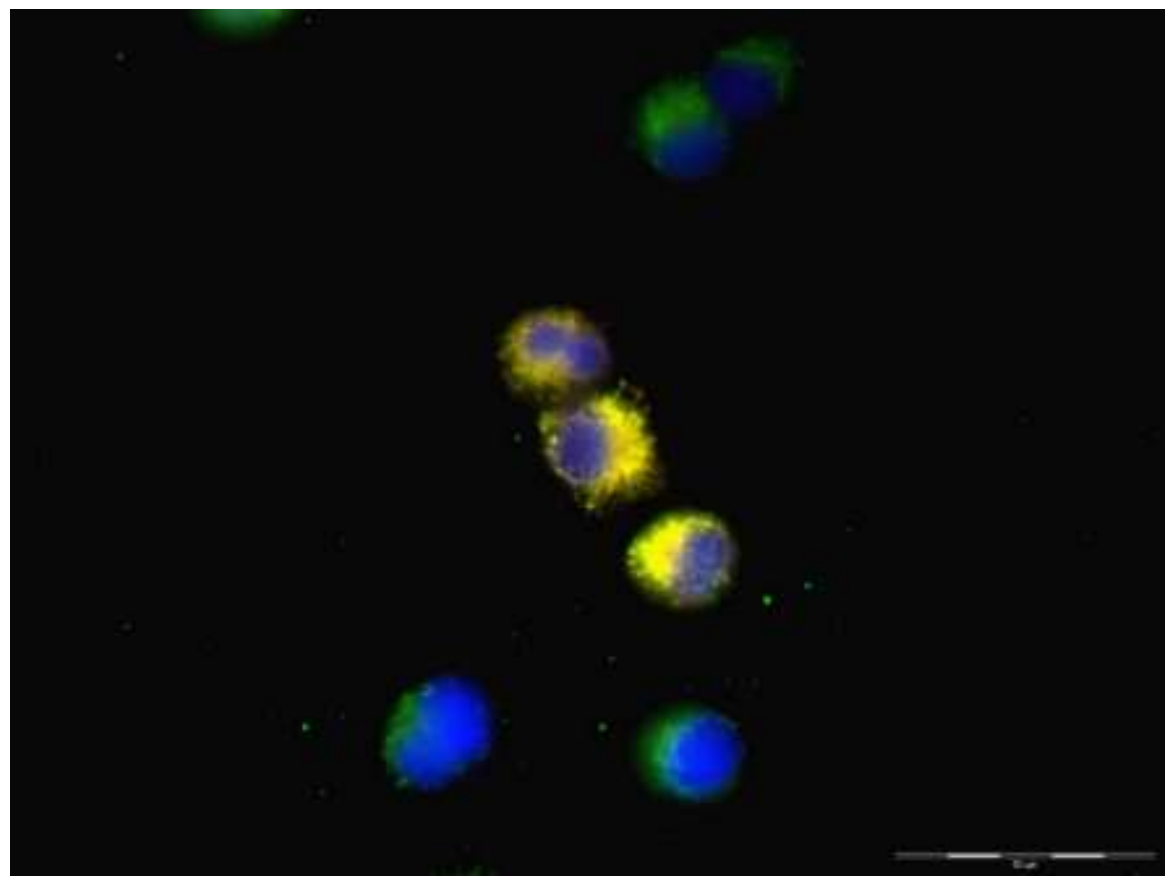

Abbildung 29: Indirekte Immunfluoreszenzfärbung von mit dem Plasmid transfizierten Caki-2-Zellen

Zu Abbildung 28 und Abbildung 29: Die Zellen sind in vierzigfacher Vergrößerung dargestellt. An ERp57 gebundene Antikörper wurden nach Markierung mit einem bei $555 \mathrm{~nm}$ fluoreszierenden sekundären Antikörper in der Nachbearbeitung rot dargestellt. An GRP78 gebundene Antikörper wurden nach Markierung mit einem bei $488 \mathrm{~nm}$ fluoreszierenden sekundären Antikörper in der Nachbearbeitung grün dargestellt. Die mit DAPI gefärbten Zellkerne wurden blau dargestellt. Eine Überlappung von ERp57 und GRP78 ergibt sich somit in dem übereinandergelegten Bild als gelb. 


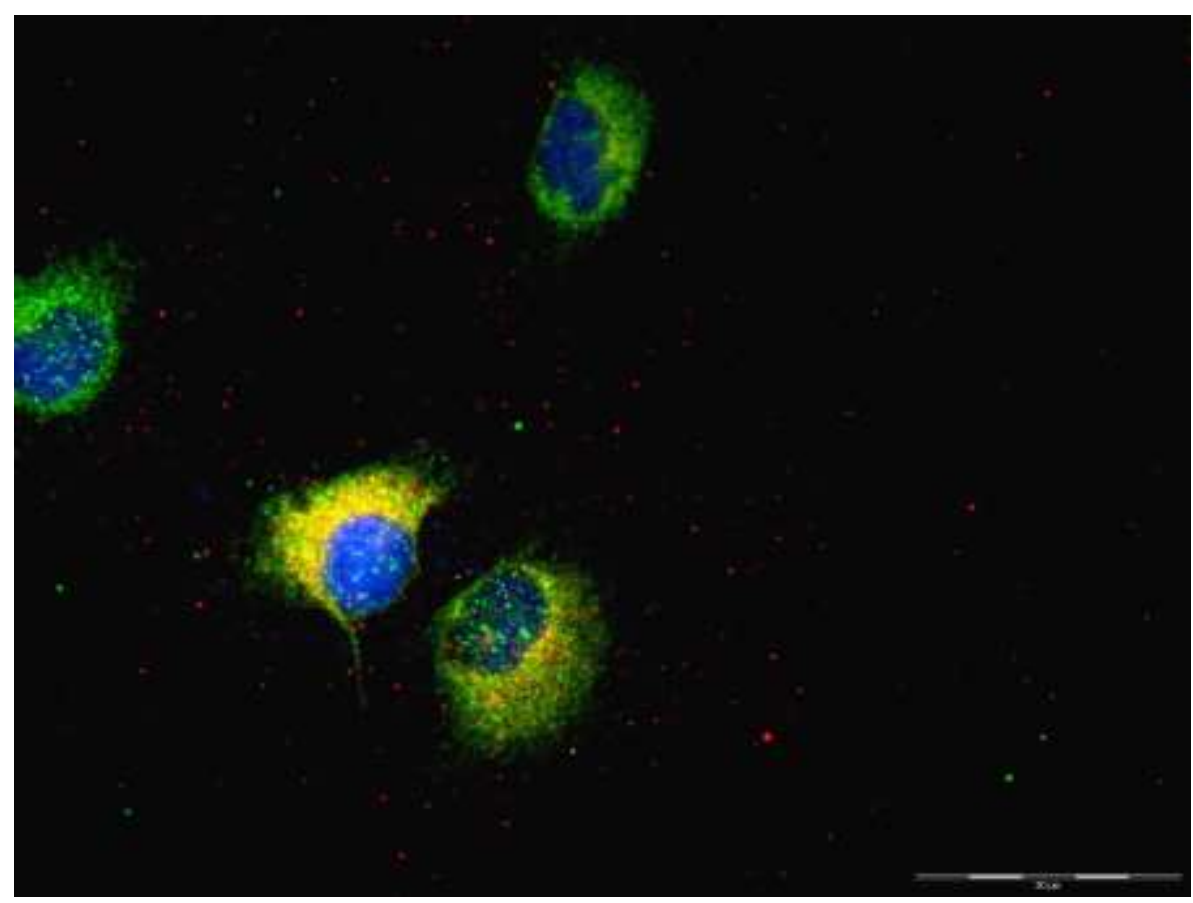

Abbildung 30: Indirekte Immunfluoreszenzfärbung von A498-Kontrollzellen

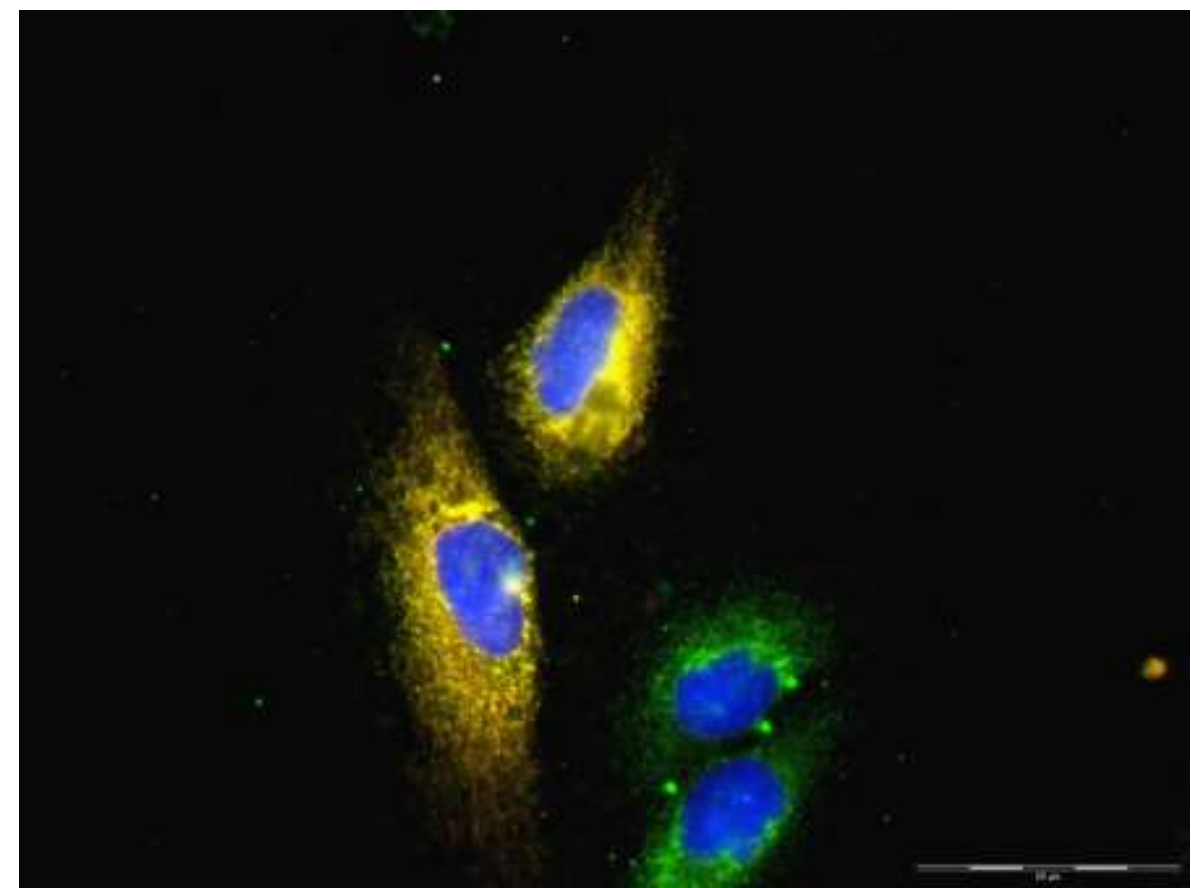

Abbildung 31: Indirekte Immunfluoreszenzfärbung von mit dem Plasmid transfizierten A498-Zellen

Zu Abbildung 30 und Abbildung 31: Die Zellen sind in vierzigfacher Vergrößerung dargestellt. An ERp57 gebundene Antikörper wurden nach Markierung mit einem bei $555 \mathrm{~nm}$ fluoreszierenden sekundären Antikörper in der Nachbearbeitung rot dargestellt. An GRP78 gebundene Antikörper wurden nach Markierung mit einem bei $488 \mathrm{~nm}$ fluoreszierenden sekundären Antikörper in der Nachbearbeitung grün dargestellt. Die mit DAPI gefärbten Zellkerne wurden blau dargestellt. Eine Überlappung von ERp57 und GRP78 ergibt sich somit in dem übereinandergelegten Bild als gelb. 
In Caki-2-Kontrollzellen zeigt sich die Gelbfärbung, die für eine Überlappung des markierten und gefärbten ERp57s und GRP78s sprach, kompakt in Nachbarschaft zu dem blau gefärbten Zellkern (Abbildung 28). Die gelbgefärbten Anteile der Zelle zeigen eine retikuläre Struktur. Wie schon im Methodenteil erwähnt, galt GRP78 als Orientierung für die Lage des ERs. In den Zellen, in denen eine Gelbfärbung zu sehen war, zeigten sich keine Anteile, in denen es nur zu Rot- oder Grünfärbung gekommen war. Allerdings waren Zellen zu sehen, an denen es perinukleär lediglich zu einer Grünfärbung gekommen war, entsprechend einer Markierung von GRP78. Die in Abbildung 29 dargestellten Zellen, die mit dem Plasmid transfiziert worden waren, zeigten im Vergleich zu den Kontrollzellen keine Veränderungen der Zellmorphologie, beziehungsweise der Morphologie des Zellkerns oder des ERs, soweit dies beurteilt werden kann. Auch hier zeigten Zellen mit gelbgefärbten Anteilen keine ausschließlich grün- oder rotgefärbten Flächen. Auffällig war die stärkere Intensität der Gelbfärbung in einer Beispielzelle.

Abbildung 30 zeigt A498-Kontrollzellen. Perinukleär stellte sich eine retikuläre, gelbe Struktur dar, die sich ausladender darstellte als die der in Abbildung 28 in gleicher Vergrößerung abgebildeten Caki-2-Kontrollzellen. Auch in der A498 Zellline gab es Zellen, die sich nur grün färbten. In den Zellen, die gelb dargestellt wurden, überlappte der grün gefärbte Anteil der Zellen sich mit dem rot gefärbten Anteil vollständig und stellte sich als gelb dar. Für die in Abbildung 31 dargestellten mit dem Plasmid transfizierten A498-Zellen gilt dasselbe. In den mit Antikörpern gegen ERp57 und GRP78 gefärbten gelben Zellen überlappten sich die gefärbten Anteile ebenfalls vollständig. In den hier beispielhaft gezeigten mit dem Plasmid transfizierten Zellen war das ER ausladender als in den A498-Kontrollzellen.

Für sowohl Caki-2-transfizierte als auch für A498-transfizierte Zellen gab es nach den Färbungen keinen Anhaltspunkt dafür, dass das nach Plasmidtransfektion gebildete ERp57 auBerhalb des ERs zu liegen kam. Somit befand es sich in seinem physiologischen Zellkompartiment.

\subsection{Einfluss der ERp57-Expressionsregulation auf die Zellviabilität und Zellproliferation der Nierenzellkarzinom-Zelllinien}

Nach Bestätigung der erfolgreichen Transfektion mit Expressionsregulation von ERp57 wurden die Auswirkungen der Regulation von ERp57 auf die Zellviabilität und Zellproliferation in einem Zeitraum von 72 Stunden mittels MTT'-Assay untersucht. 


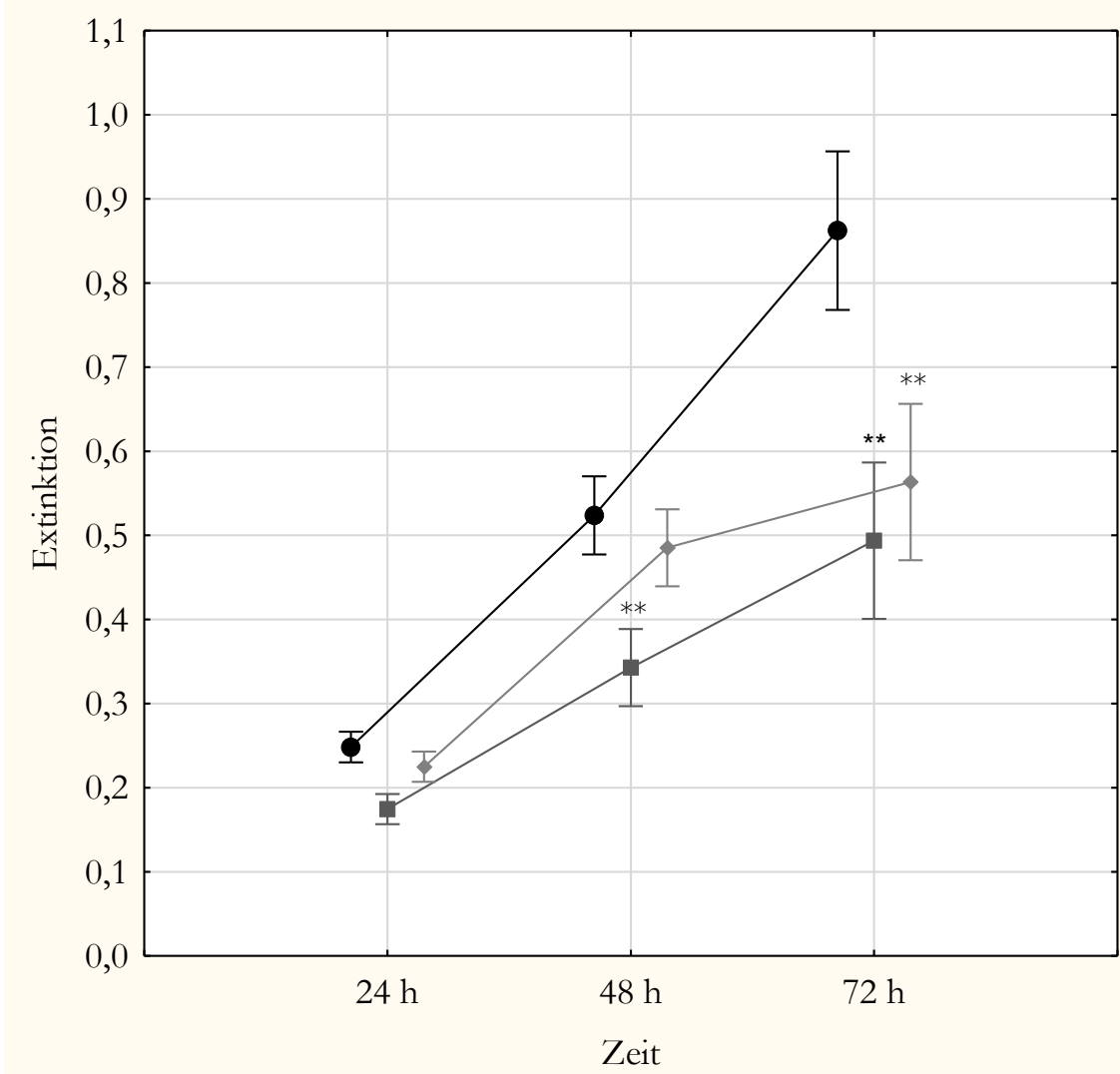

Caki-2 Kontrolle

Caki-2 Plasmid

Caki-2 siRNA

Abbildung 32: Diagramm des MTT-Assays für Caki-2-Kontrollzellen und transfizierte Caki2-Zellen

Das Diagramm zeigt den errechneten Mittelwert nach 24, 48 und 72 Stunden der gemessenen Extinktion für Caki-2-Kontrollzellen, für mit dem Plasmid transfizierte Caki-2-Zellen und für mit siRNA transfizierte Caki-2-Zellen nach Durchführung des MTT-Assay. Die Extinktion, dargestellt auf der Ordinate, gilt als ein Maß für das Vorhandensein von metabolisch aktiven Zellen und somit als ein Maß für die Zellviabilität und Proliferation. Die Abszisse zeigt die Zeitabstände der Messintervalle. Die vertikalen Striche zeigen das 95\%-Konfidenzintervall an. Die Sterne kennzeichnen einen signifikanten Unterschied der transfizierten Zellen zu den Kontrollzellen am markierten Zeitpunkt. Dabei galt als signifikant ${ }^{*}=\mathrm{p}<0,05$ und als hoch signifikant ${ }^{* *}=\mathrm{p}<0,01$. Die Signifikanz wurde mit Hilfe des Bonferroni Test ermittelt.

Abbildung 32 zeigt die Entwicklung der Zellviabilität und Proliferation für Caki-2-Kontrollzellen und transfizierte Caki-2-Zellen. In der ersten Messung nach 24 Stunden ließ sich zunächst kein Unterschied zwischen Kontroll- und transfizierten Zellen erkennen. Nach 48 Stunden fiel auf, dass sich die mit dem Plasmid transfizierten Zellen hoch signifikant von den Kontrollzellen unterschieden $(p<0,01)$. Nach 72 Stunden bestand dann ein hoch signifikanter Unterschied zwischen Kontrollzellen und beiden transfizierten Zellgruppen (für beide $\mathrm{p}<0,01$ ). Insgesamt ließ sich für alle Zellgruppen im Messzeitraum ein Anstieg des Mittelwertes der Extinktion nachweisen. Während die gemessene Extinktion der Kontrollzellen innerhalb des Messzeitraums im Mittel um den Faktor 3,4 anstieg, betrug der Faktor für die mit dem Plasmid transfizierten Zellen im Mittel nur 2,9 und für die mit siRNA transfizierten Zellen 2,5. 


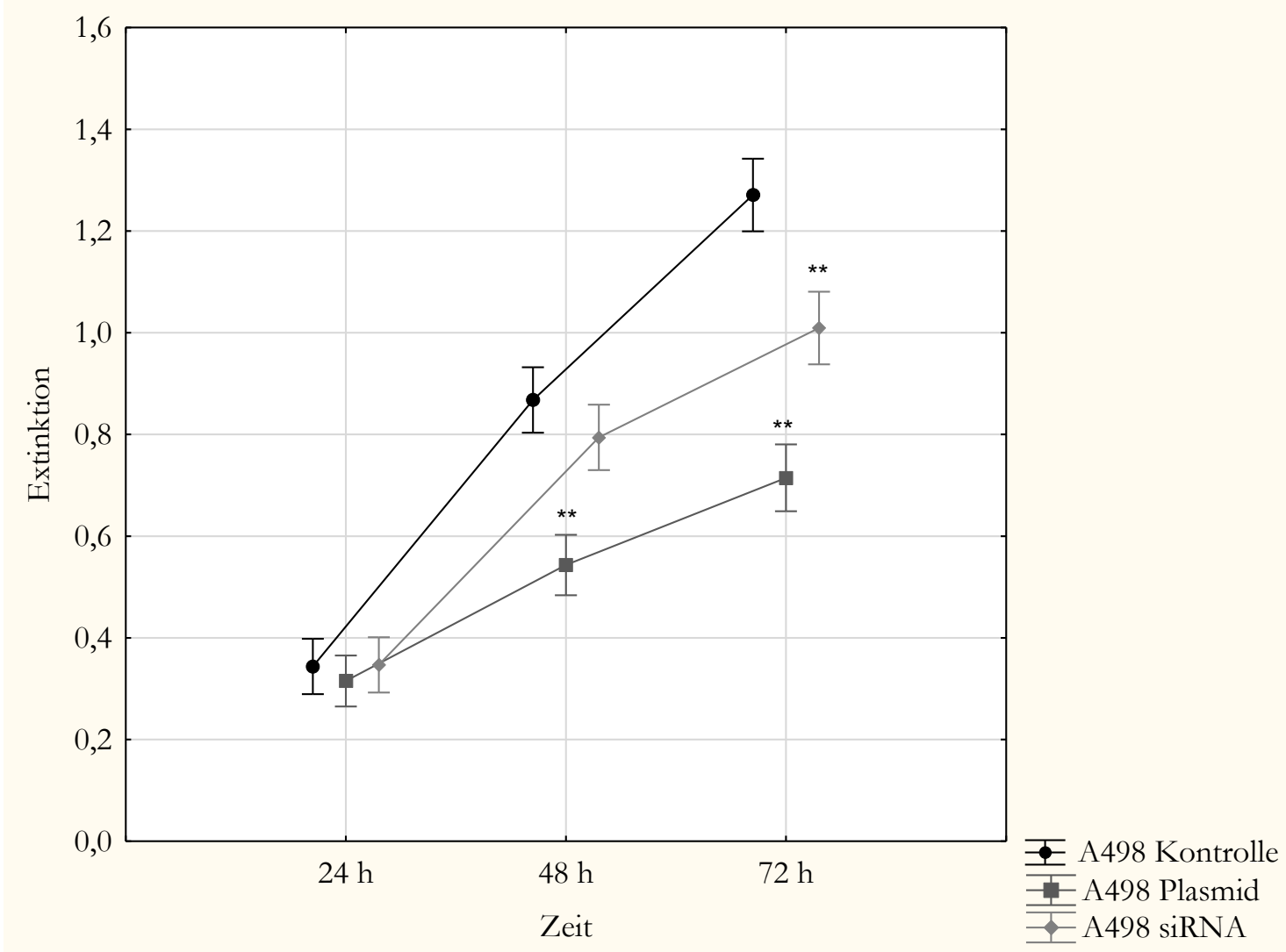

Abbildung 33: Diagramm des MTTT-Assays für A498-Kontrollzellen und transfizierte A498Zellen

Das Diagramm zeigt den errechneten Mittelwert nach 24, 48 und 72 Stunden der gemessenen Extinktion für A498-Kontrollzellen, für mit dem Plasmid transfizierte A498-Zellen und für mit siRNA transfizierte A498-Zellen nach Durchführung des MTT-Assay. Die Extinktion, dargestellt auf der Ordinate, gilt als ein $\mathrm{Ma} \beta$ für das Vorhandensein von metabolisch aktiven Zellen und somit als ein $\mathrm{Ma}$ für die Zellviabilität und Proliferation. Die Abszisse zeigt die Zeitabstände der Messintervalle. Die vertikalen Striche zeigen das 95\%-Konfidenzintervall an. Die Sterne kennzeichnen einen signifikanten Unterschied der transfizierten Zellen zu den Kontrollzellen am markierten Zeitpunkt. Dabei galt als signifikant ${ }^{*}=\mathrm{p}<0,05$ und als hoch signifikant ${ }^{* *}=\mathrm{p}<0,01$. Die Signifikanz wurde mit Hilfe des Bonferroni Test ermittelt.

Wie in Abbildung 33 veranschaulicht, zeigte sich für A498-Zellen nach 24 Stunden kein Unterschied zwischen den Kontroll- und den transfizierten Zellen. Obwohl in jeder Zellgruppe ein Anstieg des Mittelwerts der Extinktion zu sehen war, unterschieden sich nach 48 Stunden die mit dem Plasmid transfizierten A498-Zellen von den Kontrollzellen hoch signifikant $(p<0,01)$. Zum Zeitpunkt 72 Stunden bestand ein hoch signifikanter Unterschied zwischen beiden transfizierten Zellgruppen und der Kontrollgruppe (für beide $\mathrm{p}<0,01$ ). Innerhalb des Messzeitraums stieg der Mittelwert der Extinktion für A498-Kontrollzellen um den Faktor 3,7. Für die mit dem Plasmid transfizierten Zellen betrug der Faktor lediglich 2,2 und für die mit siRNA transfizierten Zellen 2,9.

Der zunächst geringe Unterschied zwischen nicht transfizierten und transfizierten Zellen wurde im Zeitverlauf in beiden Zelllinien deutlicher. 


\subsection{Einfluss der ERp57-Expressionsregulation auf das Überleben der Nierenzellkarzinom-Zelllinien nach Behandlung mit Cisplatin}

Der Einfluss der Regulation von ERp57 wurde dann auf das Verhalten der beiden Zelllinien nach einer Behandlung mit Cisplatin im Vergleich zu den Kontrollzellen untersucht. Hierzu wurde zum einen die Entwicklung der Zellviabilität und -proliferation der Kontrollzellen sowie der transfizierten Zellen im Zeitverlauf nach Behandlung mit Cisplatin mittels MTTAssay beobachtet. Zum anderen wurde mit dem Annexin V/dead cell apoptosis assay gemessen, inwieweit die Apoptoseinduktion nach Behandlung mit Cisplatin durch die Regulation von ERp57 beeinflusst wurde.

\subsubsection{Einfluss der ERp57-Expressionsregulation auf die Zellviabilität in Nierenzellkarzinom-Zelllinien nach Behandlung mit Cisplatin}

Da für beide transfizierte Zellgruppen gezeigt werden konnten, dass die Proliferation und Zellviabilität schon durch die Transfektion beeinflusst wurde, wurde für jeden Zeitpunkt der Messintervalle ein Verhältnis aus mit Cisplatin behandelten Zellen zu den jeweiligen Kontrollzellen berechnet und so die prozentuale Zellviabilität ermittelt. 


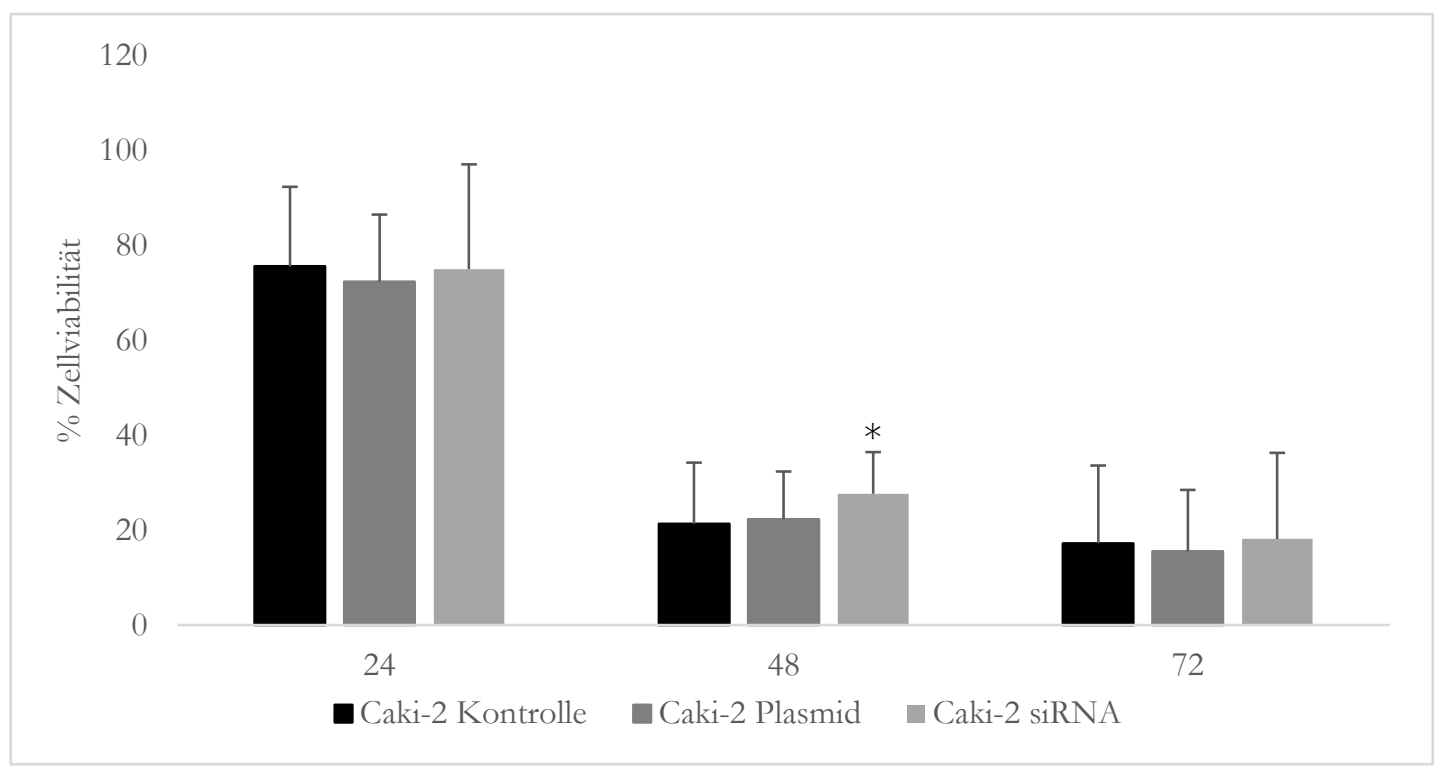

Abbildung 34: Diagramm der prozentualen Zellviabilität für Caki-2-Kontrollzellen und transfizierte Caki-2-Zellen nach Behandlung mit Cisplatin

Die Balken im Diagramm zeigen den errechneten Mittelwert des Verhältnisses der Extinktion der mit Cisplatin behandelten Zellen zu den dazugehörigen unbehandelten Kontrollzellen nach Durchführung des MTT-Assay für unbehandelte Caki-2-Zellen, für mit dem Plasmid transfizierte Caki-2Zellen und für mit siRNA transfizierte Caki-2-Zellen im Zeitverlauf. Die Ordinate zeigt die prozentuale Zellviabilität, die den Anteil der metabolisch aktiven Zellen nach Behandlung mit Cisplatin widerspiegelt. Die Abszisse zeigt die Zeitabstände der Messintervalle. Die vertikalen Striche kennzeichnen die Standardabweichung der errechneten Mittelwerte. Die Sterne kennzeichnen einen signifikanten Unterschied der transfizierten Zellen zu den Kontrollzellen am markierten Zeitpunkt. Dabei galt als signifikant $*=\mathrm{p}<0,05$.

Für Caki-2-Kontrollzellen zeigte sich ebenso wie für mit dem Plasmid transfizierte Caki-2Zellen und für mit siRNA transfizierte Caki-2-Zellen im Zeitverlauf eine Abnahme der prozentualen Zellviabilität. Besonders auffällig war in allen drei Zellgruppen die starke Abnahme zwischen dem Zeitpunkt 24 Stunden und dem Zeitpunkt 48 Stunden. Im Vergleich der Gruppen untereinander ließ sich für Zellen, die mit dem Plasmid transfiziert worden waren, zu Caki-2-Kontrollzellen kein nennenswerter Unterschied in der prozentualen Zellviabilität nach einer Behandlung mit Cisplatin erkennen. Für mit siRNA transfizierte Caki-2-Zellen ergab sich nach 48 Stunden Behandlung mit Cisplatin eine signifikant höhere prozentuale Zellviabilität als in den Caki-2-Kontrollzellen $(p<0,05)$. Nach 72 Stunden Behandlung ließ sich kein Unterschied mehr erkennen (Abbildung 34). 


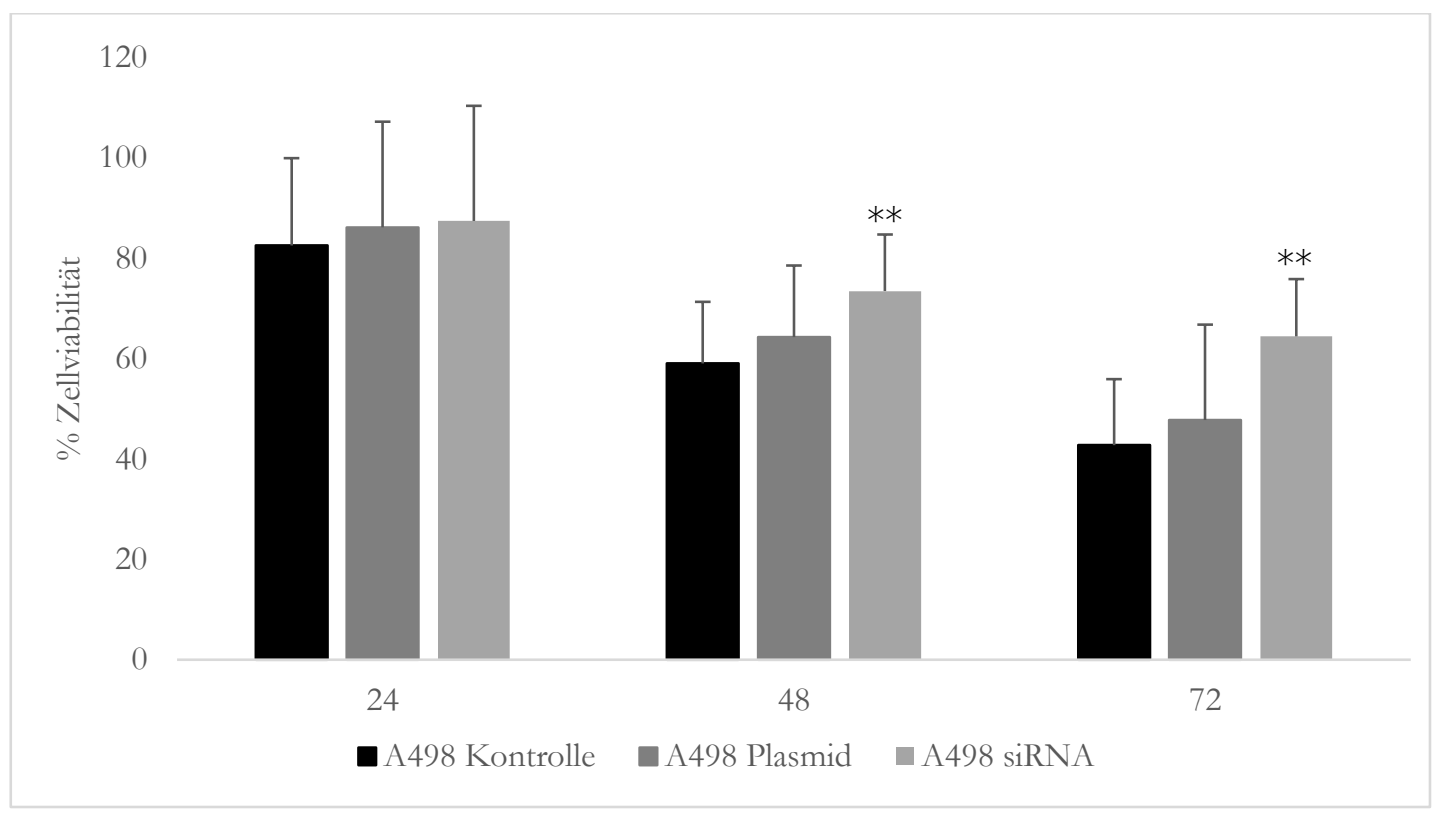

Abbildung 35: Diagramm der prozentualen Zellviabilität für A498-Kontrollzellen und transfizierte A498-Zellen nach Behandlung mit Cisplatin

Die Balken im Diagramm zeigen den errechneten Mittelwert des Verhältnisses der Extinktion der mit Cisplatin behandelten Zellen zu den dazugehörigen unbehandelten Kontrollzellen nach Durchführung des MTT-Assay für unbehandelte A498-Zellen, für mit dem Plasmid transfizierte A498Zellen und für mit siRNA transfizierte A498-Zellen im Zeitverlauf. Die Ordinate zeigt die prozentuale Zellviabilität, die den Anteil der metabolisch aktiven Zellen nach Behandlung mit Cisplatin widerspiegelt. Die Abszisse zeigt die Zeitabstände der Messintervalle. Die vertikalen Striche kennzeichnen die Standardabweichung der errechneten Mittelwerte. Die Sterne kennzeichnen einen signifikanten Unterschied der transfizierten Zellen zu den Kontrollzellen am markierten Zeitpunkt. Dabei galt als hoch signifikant $* *=\mathrm{p}<0,01$.

Für die A498-Zelllinie fiel ebenfalls in allen drei Gruppen auf, dass es im zeitlichen Verlauf zu einem Abfall der prozentualen Zellviabilität kam. Mit dem Plasmid transfizierte A498Zellen unterschieden sich im gesamten Beobachtungszeitraum nicht nennenswert von den Kontrollzellen. Tendenziell war die prozentuale Zellviabilität jedoch höher als in den Kontrollzellen. Für die mit siRNA transfizierten Zellen zeigte sich sowohl zum Zeitpunkt 48 Stunden als auch zum Zeitpunkt 72 Stunden ein hoch signifikanter Unterschied zu den Kontrollzellen $(p<0,01)$. Dabei war die prozentuale Zellviabilität höher als in den Kontrollzellen (Abbildung 35). Im Vergleich mit der Caki-2-Zelllinie fiel auf, dass die prozentuale Zellviabilität für Caki-2-Zellen zu den Zeitpunkten 24 Stunden und 48 Stunden deutlich niedriger war als in der A498-Zelllinie. 
3.7.2 Einfluss der ERp57-Expressionsregulation auf die Apoptoseinduktion in Nierenzellkarzinom-Zelllinien nach Behandlung mit Cisplatin
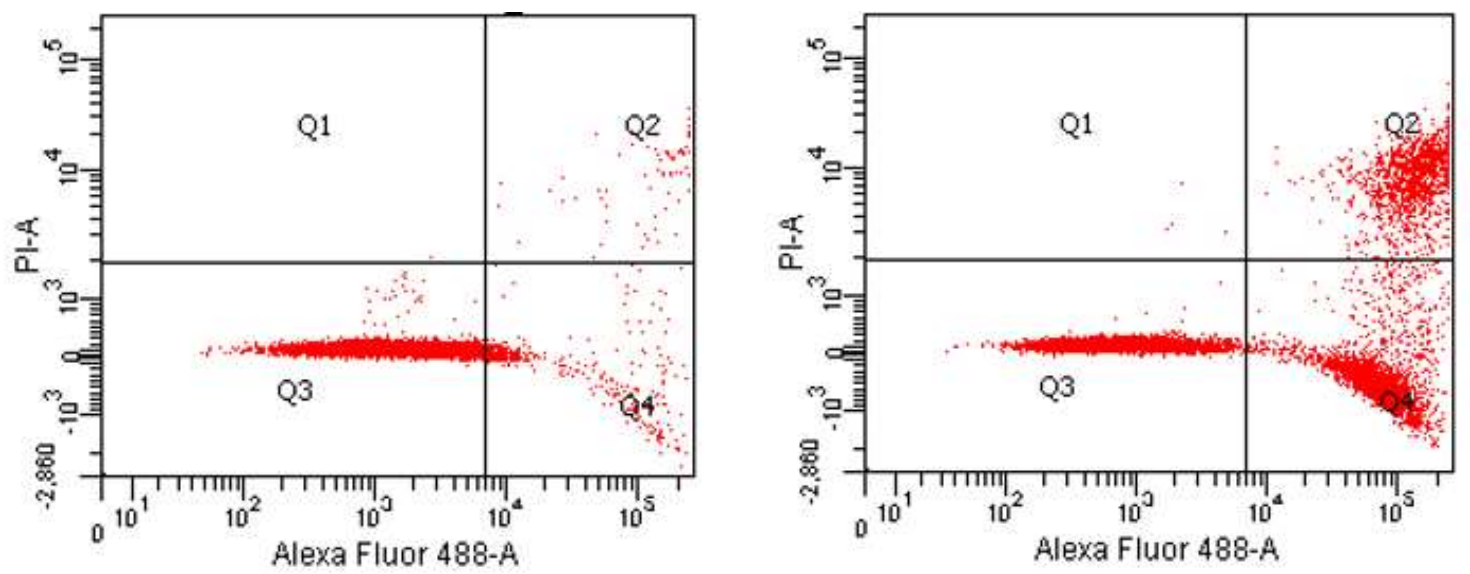

Abbildung 36: Diagramm des Annexin V/dead cell apoptosis assay von mit dem Plasmid transfizierten Caki-2-Zellen (links) und von mit Cisplatin behandelten und mit dem Plasmid transfizierten Caki-2-Zellen (rechts)
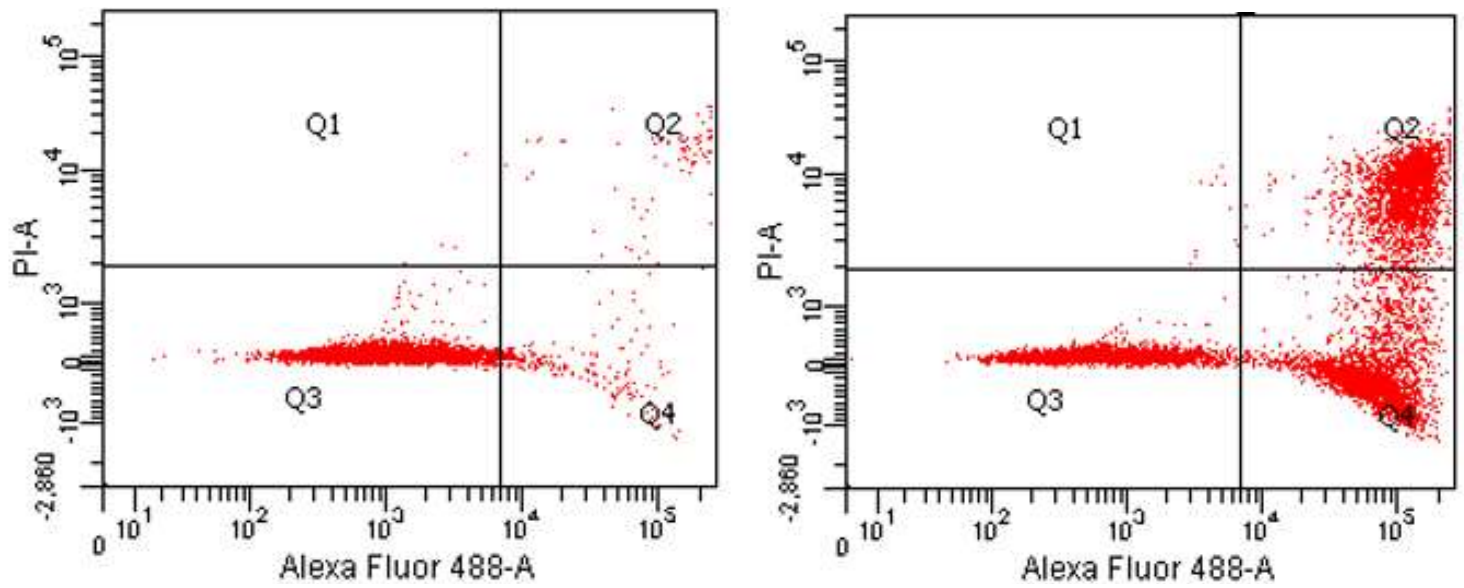

Abbildung 37: Diagramm des Annexin V/dead cell apoptosis assay von mit siRNA transfizierten Caki-2-Zellen (links) und von mit Cisplatin behandelten und mit siRNA transfizierten Caki-2Zellen (rechts)

Zu Abbildung 36 und Abbildung 37: Es werden jeweils Kontrollzellen und mit Cisplatin behandelte Zellen gegenübergestellt. Die Ordninate stellt die Markierung mit dem DNA-Marker PI dar. Die Abszisse spiegelt die Markierung mit Annexin V. Die gemessene Zellpopulation stellt sich als eine Ansammlung roter Punkte dar. Das Diagramm ist in vier Quadranten geteilt, um die Sortierung der Zellen zu ermöglichen. Dabei stellt der Quadrant Q4 die Zellen dar, die mit Annexin V markiert wurden, jedoch nicht mit PI. Dies entspricht Zellen, die sich in früher Apoptose befinden. 


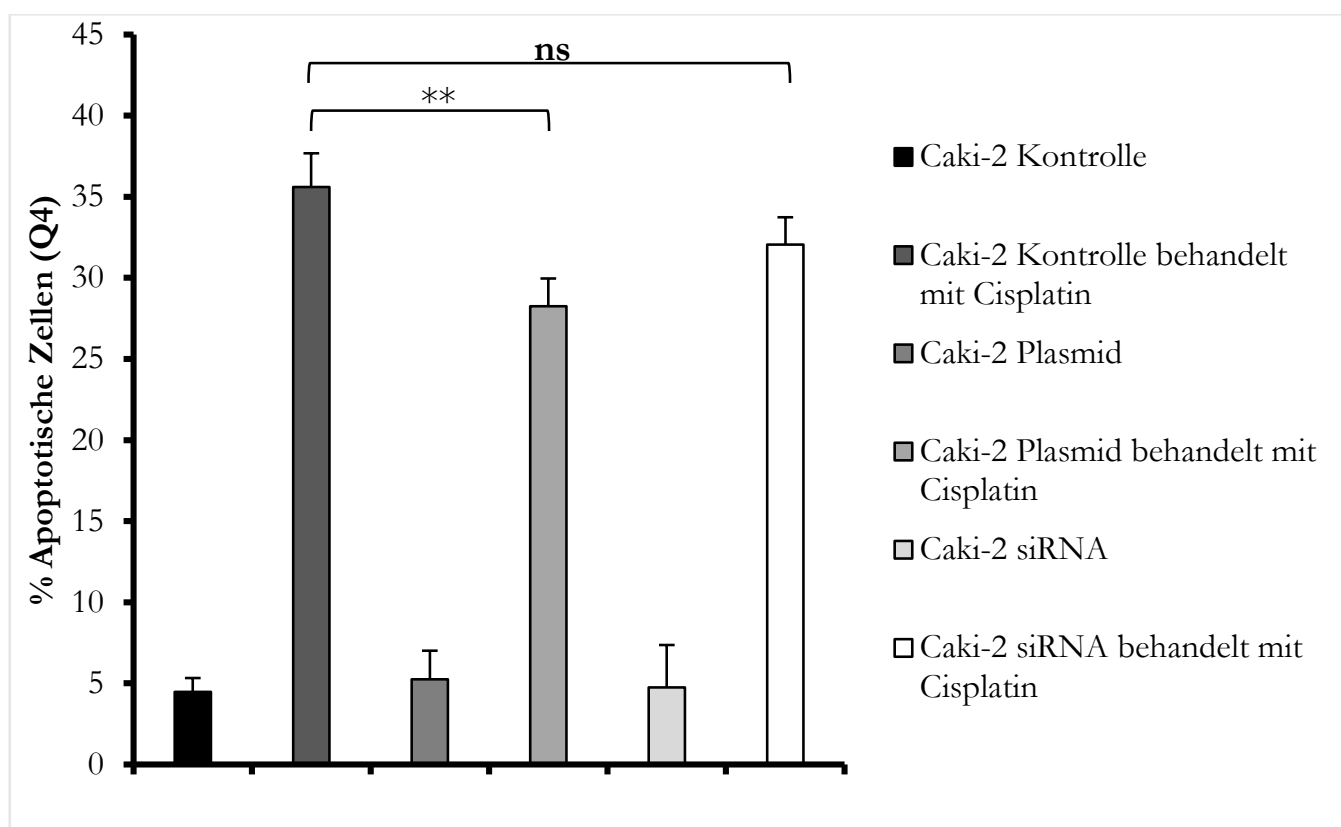

Abbildung 38: Diagramm der mit dem Annexin V/dead cell apoptosis assay ermittelten apoptotischen Zellfraktion von Caki-2-Kontrollzellen und transfizierten Caki-2-Zellen

Das Diagramm zeigt zusammenfassend die Ergebnisse der mit Caki-2-Zellen durchgeführten Annexin V/dead cell apoptosis assays. Die gefärbten Balken zeigen den Mittelwert der mit dem Programm „FACSDiva“ ermittelten apoptotischen Zellfraktion (Q4). Die Ordinate stellt den Prozentsatz an apoptotischen Zellen dar. Die Abszisse separiert die unterschiedlichen Zellgruppen. Es sind sowohl mit Cisplatin behandelte Zellen als auch nicht behandelte Kontrollzellen der jeweiligen Zellgruppe dargestellt. Die vertikalen Striche zeigen die Standardabweichung der Mittelwerte an. Die Ergebnisse der mit Cisplatin behandelten Kontrollzellen und der mit Cisplatin behandelten transfizierten Zellen wurden mit Hilfe des t-Tests untereinander verglichen. Dabei ergab sich $* *=p<0,01$ als hoch signifikant und $n s=p>0,05$ als nicht signifikant.

Wie in den Abbildung 8 und Abbildung 36 bis Abbildung 38 veranschaulicht, fiel für jede Zellgruppe der Caki-2-Zelllinie auf, dass der Anteil der apoptotischen Zellfraktion durch eine Behandlung mit Cisplatin deutlich zunahm. In den nicht mit Cisplatin behandelten Zellgruppen war der Anteil der apoptotischen Zellen nur sehr gering. Im Vergleich der mit Cisplatin behandelten Zellgruppen untereinander zeigte sich ein hoch signifikanter Unterschied zwischen den Caki-2-Kontrollzellen und den mit dem Plasmid transfizierten Caki-2-Zellen $(\mathrm{p}<0,01)$. Für Caki-2-Kontrollzellen betrug der Mittelwert des Anteils an apoptotischen Zellen 35,6\% (Standardabweichung 2,1), für die mit dem Plasmid transfizierten Zellen lediglich 28,3\% (Standardabweichung 1,7). Die mit Cisplatin behandelten und mit siRNA transfizierten Zellen unterschieden sich mit einem Mittelwert der apoptotischen Zellfraktion von $32,1 \%$ (Standardabweichung 1,7) nicht signifikant von den mit Cisplatin behandelten Kontrollzellen ( $p>0,05)$. 

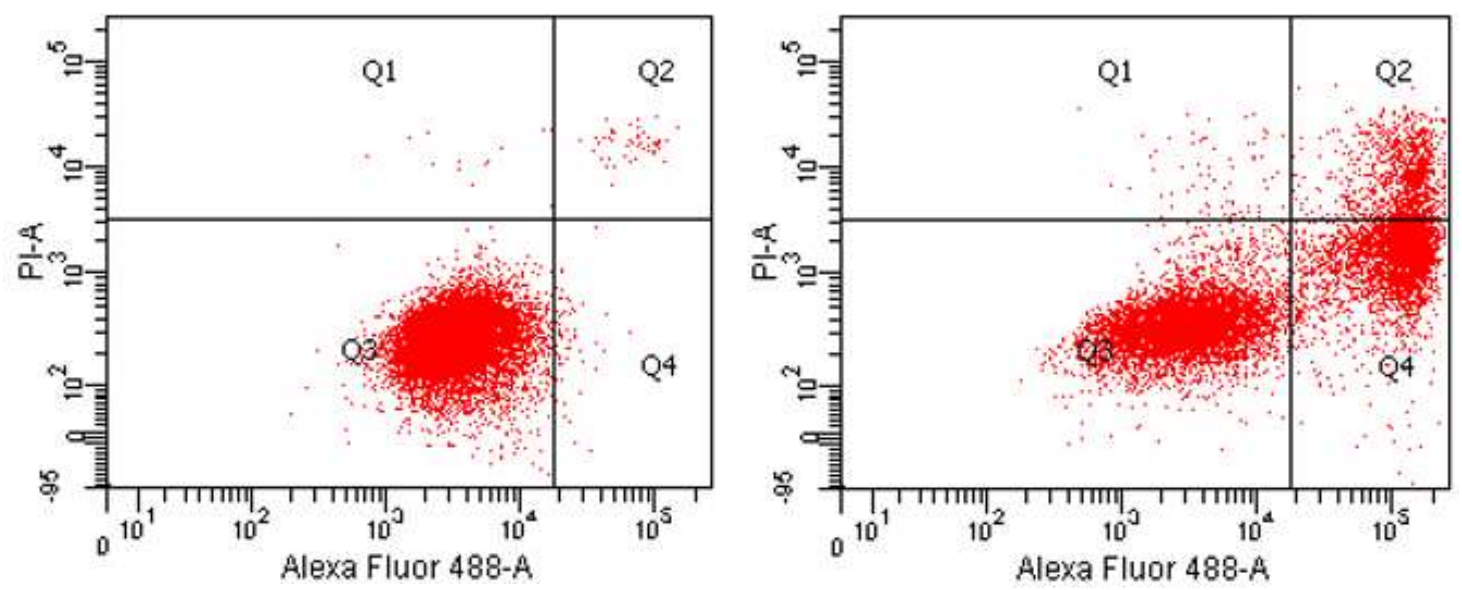

Abbildung 39: Diagramm des Annexin V/ dead cell apoptosis assay von mit dem Plasmid transfizierten A498-Zellen (links) und von mit Cisplatin behandelten und mit dem Plasmid transfizierten A498-Zellen (rechts)
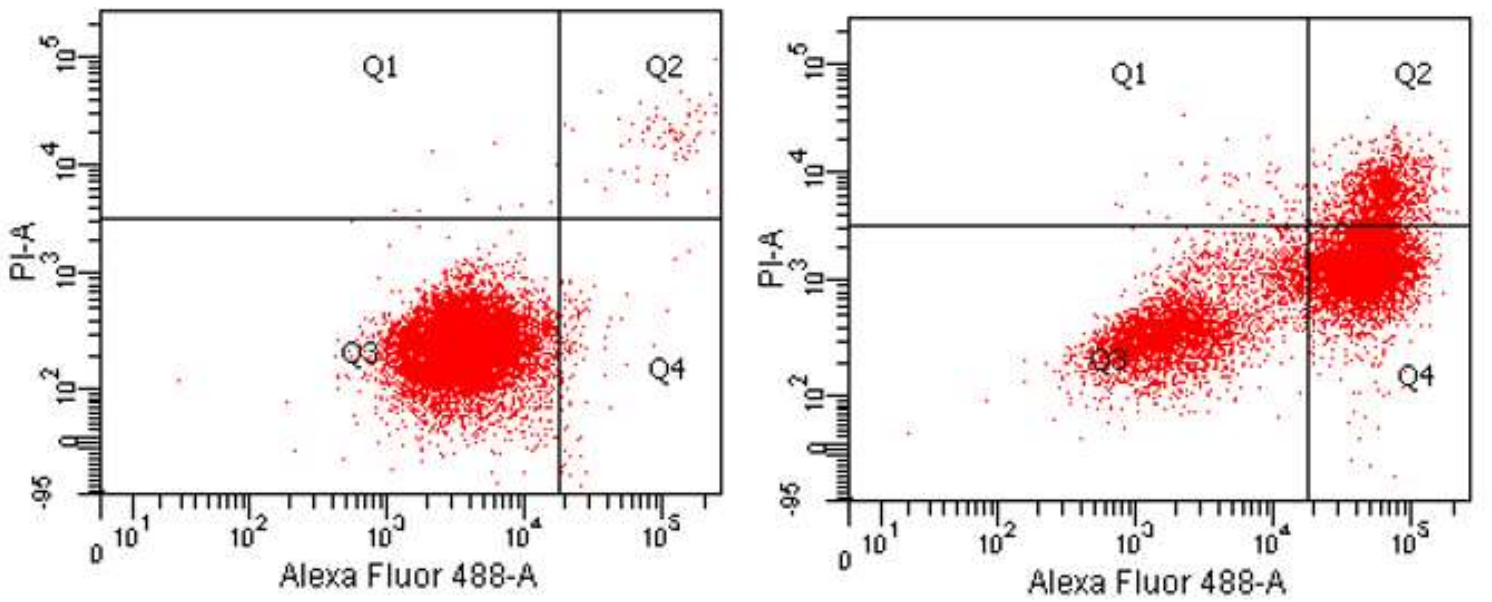

Abbildung 40: Diagramm des Annexin V/dead cell apoptosis assay von mit siRNA transfizierten A498-Zellen (links) und von mit Cisplatin behandelten und mit siRNA transfizierten A498-Zellen (rechts)

Zu Abbildung 39 und Abbildung 40: Es werden jeweils Kontrollzellen und mit Cisplatin behandelte Zellen gegenübergestellt. Die Ordninate stellt die Markierung mit dem DNA-Marker PI dar. Die Abszisse spiegelt die Markierung mit Annexin V. Die gemessene Zellpopulation stellt sich als Ansammlung roter Punkte dar. Das Diagramm ist in vier Quadranten geteilt, um die Sortierung der Zellen zu ermöglichen. Dabei stellt der Quadrant Q4 die Zellen dar, die mit Annexin V markiert wurden, jedoch nicht mit PI. Dies entspricht Zellen, die sich in früher Apoptose befinden. 


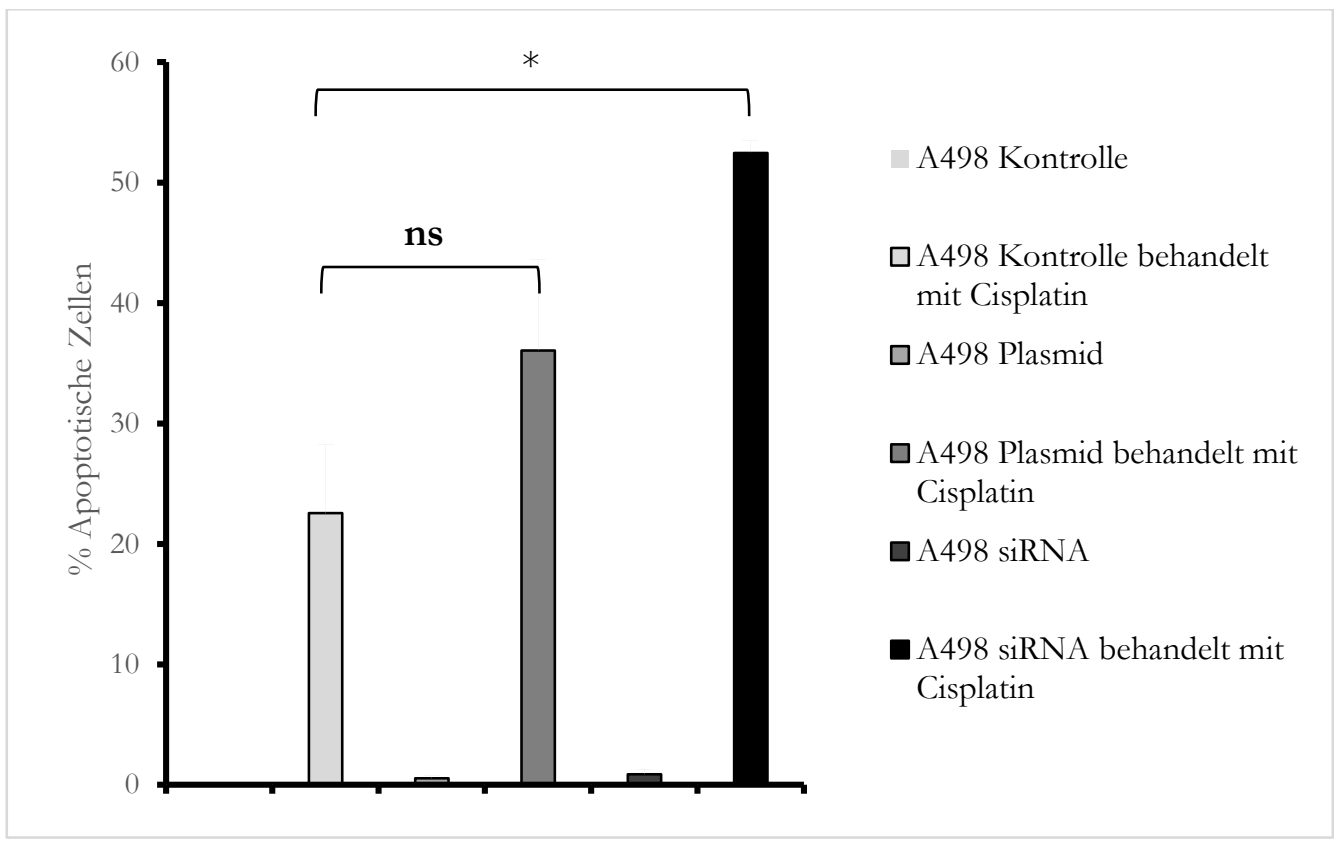

Abbildung 41: Diagramm der mit dem Annexin V/dead cell apoptosis assay ermittelten apoptotischen Zellfraktion von A498-Kontrollzellen und transfizierten A498-Zellen

Das Diagramm zeigt zusammenfassend die Ergebnisse der mit A498-Zellen durchgeführten Annexin $\mathrm{V} /$ dead cell apoptosis assays. Die gefärbten Balken zeigen den Mittelwert der mit dem Programm „FACSDiva“ ermittelten apoptotischen Zellfraktion (Q4). Die Ordinate stellt den Prozentsatz an apoptotischen Zellen dar. Die Abszisse trennt die unterschiedlichen Zellgruppen. Es sind sowohl mit Cisplatin behandelte Zellen als auch nicht behandelte Kontrollzellen der jeweiligen Zellgruppe dargestellt. Die Ergebnisse der mit Cisplatin behandelten Kontrollzellen und der mit Cisplatin behandelten transfizierten Zellen wurden mit Hilfe des t-Tests untereinander verglichen. Dabei ergab sich ${ }^{*}=\mathrm{p}<0,05$ als hoch signifikant und $n s=p>0,05$ als nicht signifikant.

Für A498-Kontrollzellen und transfizierte A498-Zellen zeigte sich ebenfalls eine Zunahme des Mittelwerts der apoptotischen Zellfraktion (Abbildung 9, Abbildung 39 bis Abbildung 41). Der Anteil an apoptotischen Zellen nach Behandlung mit Cisplatin war sowohl für die mit dem Plasmid transfizierten als auch für die mit siRNA transfizierten Zellen höher als für A498-Kontrollzellen. Der Unterschied zwischen den mit Cisplatin behandelten Zellen war für die mit dem Plasmid transfizierten Zellen im Vergleich zu den A498-Kontrollzellen nicht signifikant $(\mathrm{p}>0,05)$. Mit siRNA transfizierte Zellen unterschieden sich mit einem Mittelwert der apoptotischen Zellfraktion von 52,45\% signifikant von den A498-Kontrollzellen, in denen die apoptotische Zellfraktion lediglich $22,6 \%$ betrug $(\mathrm{p}<0,05)$. 


\section{Diskussion}

\subsection{Auswahl der Zelllinien und des zytotoxischen Agens}

Die Therapie des fortgeschrittenen Nierenzellkarzinoms stellt die Medizin weiterhin vor Herausforderungen. Die Resistenz gegenüber klassischer Chemotherapie hat zu der Etablierung neuerer Therapiemöglichkeiten wie VEGF-Inhibitoren geführt (Stadler 2005). Bisher sind die Ergebnisse dieser Behandlungsoptionen jedoch nicht zufriedenstellend (Fischer et al. 2015). Häufig ist das Ansprechen der Tumoren nur unvollständig oder nur von kurzer Dauer (Costa und Drabkin 2007). Zur Untersuchung der Therapieresistenz wurden Experimente mit zwei etablierten Nierenzellkarzinom-Zelllinien, A498 und Caki-2, durchgeführt. Beide wurden in der Forschung als Modell für das klarzellige Nierenzellkarzinom eingesetzt, wobei es für die Caki-2-Zelllinie Hinweise darauf gab, dass es sich um Zellen eines papilläres Karzinoms handelt (Brodaczewska et al. 2016). Als zytotoxisches Agens fiel die Entscheidung auf das klassische Chemotherapeutikum Cisplatin. Cisplatin ist ein potentes Medikament, das in der Behandlung unterschiedlichster Tumoren eingesetzt wird. Die Wirkung von Cisplatin besteht unter anderem in der Bindung an Purinbasen der DNA der Zelle, was zu intra- und interstrang-Vernetzungen führt (Jamieson und Lippard 1999). Der durch die Behandlung resultierende Zelltod kann durch Apoptose oder Nekrose ausgelöst werden (Pestell et al. 2000; Wang und Lippard 2005). Für Caki-2-Zellen war bereits zuvor beschrieben worden, dass durch eine Behandlung mit Cisplatin die Apoptose ausgelöst werden kann (Trivedi et al. 2016b). Auch in den Experimenten dieser Arbeit zeigte sich, dass der Zelltod durch eine Behandlung mit Cisplatin in beiden Zelllinien sowohl durch Apoptose als auch durch Nekrose ausgelöst wurde (Abbildung 9, Tabelle 5). Von besonderem Interesse waren vor allem die Zellen, in denen die Apoptose ausgelöst wurde. Unter diesen ließ sich ein deutlicher Unterschied im Ansprechen auf die Behandlung mit Cisplatin zwischen den beiden Zelllinien erkennen. Der Anteil an apoptotischen Zellen war in der Caki-2-Zelllinie nach einer Behandlung mit Cisplatin signifikant höher als in der A498-Zelllinie (Abbildung 7), obwohl die A498-Zellen etwa 20 Stunden länger mit Cisplatin behandelt worden waren. Während in Caki-2-Zellen die Proliferation unter Behandlung mit Cisplatin abnahm (Abbildung 5), kam es in A498-Zellen unter Behandlung mit Cisplatin lediglich zu einem geringeren Anstieg der Proliferation im Zeitverlauf (Abbildung 6). Somit war es trotz der zytotoxischen Behandlung nicht zu einer Reduktion der proliferierenden Zellpopulation, sondern zu einem weiteren Wachstum der A498-Zellen gekommen. Diese Ergebnisse führten dazu, dass die Caki-2Zelllinie als ein Modell für chemosensible Zellen des Nierenzellkarzinoms und die A498Zelllinie als ein Modell für chemoresistente Zellen angesehen wurden. 


\subsection{Veränderungen des Proteoms der Nierenzellkarzinom-Zelllinien nach Behandlung mit Cisplatin}

Zur weiterführenden Analyse von Faktoren, die die Reaktion der sensiblen Caki-2-Zellen und der resistenten A498-Zellen auf eine Behandlung mit Cisplatin beeinflussten, wurden die differenziell regulierten Proteine nach der Behandlung mit Cisplatin in 2D-Gelelektrophoresen beider Zelllinien betrachtet. Für die Validierung der gesamten Ergebnisse der Proteomanalyse sollten sich noch weitere Validierungsmethoden anschließen, die im Rahmen dieser Arbeit nicht durchgeführt wurden. Im Folgenden werden nur die Proteine diskutiert, bei denen der Unterschied von Kontrollzellen zu mit Cisplatin behandelten Zellen signifikant war. Die Diskussion der Regulation der Proteindisulfidisomerase ERp57 schließt sich im darauffolgenden Kapitel an.

\subsubsection{Unterexprimierte Proteine nach Behandlung mit Cisplatin}

In der Caki-2-Zelllinie waren die drei Proteine SRSF1, hnRNP K und SF3B1 signifikant mit einer Ratio von unter oder gleich 0,5 herunterreguliert (Abbildung 16). Alle drei Proteine spielen eine Rolle im Prozess des Spleißens (Tabelle 10). Das Spleißen ist Teil der posttranskriptionalen RNA-Modifizierung, in deren Rahmen aus einer prä-mRNA, die nicht kodierende Introns und kodierende Exons enthält, durch das Mitwirken des Spleißosoms die für die Translation reife, nur Exons enthaltende mRNA generiert wird (Matera und Wang 2014). Das Spleißosom besteht dabei aus einer Ansammlung von small nuclear ribonucleoprotein particles (snRNPs) und Spleißfaktoren (Das et al. 1999). Der DNA-Schaden, der durch eine Behandlung mit Cisplatin entsteht, führt zu einer generellen Hemmung der Transkription und der kompletten Proteinbiosynthese (Vichi et al. 1997). Somit scheint es sinnvoll, dass auch die in der Proteinbiosynthese involvierten Spleißfaktoren in der Caki-2-Zelllinie herunterreguliert waren. Eine Hemmung der Proteinbiosynthese muss allerdings nicht zwingend in eine geringere Expression von Spleißfaktoren münden. Die Regulation von Spleißfaktoren ist weitaus komplexer (Shkreta und Chabot 2015).

SRSF1 und hnRNP K gehören zu den wichtigsten Familien von Spleißfaktoren. Durch das Binden an regulierende Elemente der mRNA führen sie dazu, dass bestimmte Regionen durch das Spleißosom erkannt werden und das Spleißen einer Region gefördert oder verhindert wird. Sie sind besonders wichtig für den Vorgang des alternativen Spleißens, in dessen Rahmen aus einer prä-mRNA verschiedene Isoformen reifer mRNAs mit unterschiedlichen Funktionen entstehen können (Gonçalves und Jordan 2015). Durch die Therapie mit zytotoxischen Substanzen kann alternatives Spleißen eingeleitet werden. Das veränderte Spleißen fördert dann die Bildung von proapoptotischen mRNA-Isoformen (Shkreta et al. 2008; Gabriel et al. 2015). SRSF1 wurde intensiv bezüglich seiner Rolle in Tumoren untersucht. Dabei wurde ein auffällig hohes Vorkommen in unterschiedlichen Tumoren und eine die Tumorgenese fördernde Wirkung beschrieben (Hayes et al. 2007; Anczuków et al. 2012; Gout et al. 2012). Außerdem ergaben sich Hinweise, dass ein hohes Level an SRSF1 mit Chemoresistenz 
einhergeht (Hayes et al. 2007; Gout et al. 2012). Ein Grund hierfür könnte in der Apoptoseregulierenden Funktion von SRSF1 liegen. Ein Verlust oder eine Regulation von SRSF1 nach unten führte zu einem Zellzyklusstopp, der die Einleitung der Apoptose zur Folge hatte (Li et al. 2005; Moore et al. 2010). Außerdem konnte durch eine Regulation von SRSF1 nach unten in vitro eine geringere Expression von antiapoptotischen Genen erreicht werden (Yadav et al. 2014). Entsprechend dem guten Ansprechen der Caki-2-Zellen auf Cisplatin zeigte sich eine signifikante Regulation von SRSF1 nach unten. Vermutlich war diese in der Induktion der in Caki-2-Zellen ausgelösten Apoptose beteiligt. In der A498-Zelllinie lagen keine Daten für SRSF1 vor. Es wäre interessant, ob es in dieser Zelllinie auch zu einer Regulation nach unten oder gar zu einer Regulation nach oben gekommen war. Dies würde weitere Vermutungen bezüglich der Rolle dieses Proteins in dem Ansprechen auf die Behandlung mit Cisplatin in Zellen des Nierenzellkarzinoms zulassen.

Auch hnRNP $\mathrm{K}$ ist an der Regulation von Prozessen beteiligt, die Apoptose auslösen (Venables et al. 2008). Ein geringes Vorkommen von hnRNP K führte in vitro dazu, dass das Gleichgewicht des alternativen Spleißens der mRNA des Apoptose-regulierenden Proteins Bcl-x in Richtung der proapoptotischen Isoform Bcl-xs verlagert wurde (Revil et al. 2009). Für mehrere Nierenzellkarzinom-Zelllinien, darunter auch die hier untersuchte Zelllinie A498, wurde ein hohes Vorkommen von hnRNP K beschrieben. Die Regulation von hnRNP K nach unten löste in A498-Zellen in vitro auch ohne zytotoxische Behandlung die Apoptose aus (Otoshi et al. 2015). Ebenso wie in den Caki-2-Zellen zeigte sich in A498Zellen nach der Behandlung mit Cisplatin eine signifikante Regulation von hnRNP K nach unten (Abbildung 17). Obwohl der Anteil der Zellen, in denen durch die Behandlung mit Cisplatin der Zelltod ausgelöst wurde, in der A498-Zelllinie nur gering war (Abbildung 7), gab es auch in dieser Zelllinie Mechanismen, die zu dem Ansprechen auf die Behandlung geführt hatten. Einer davon könnte die Regulation von hnRNP K nach unten sein. Da die signifikante Regulation dieses Spleißfaktors in beiden Zellinien auffiel, entstand die allgemeinere Vermutung, dass die Regulation dieses Spleißfaktors eine entscheidende Rolle in der Apoptose von Zellen des Nierenzellkarzinoms spielt.

Das dritte in der Caki-2-Zelllinie signifikant herunterregulierte Protein SF3B1 ist Teil des Spleißosoms (Gozani et al. 1998). Auch die Regulation dieses Faktors nach unten begünstigte das Spleißen der proapoptotischen Isoform von Bcl-x. Als Folge davon kam es zu einem gesteigerten Ansprechen auf eine Behandlung mit einem Chemotherapeutikum in einer Zelllinie des Adenokarzinoms der Lunge (Massiello et al. 2006). In Zelllinien des kleinzelligen Lungenkarzinoms konnte kein Effekt auf das Spleißen von Bcl-x nachgewiesen werden. Allerdings führte die Hemmung von SF3B1 zu einer Verlagerung in Richtung der proapoptotischen Isoform des Faktors Mcl-1 (Gao und Koide 2013).

Insgesamt ergab sich also für die in beiden Zelllinien signifikant nach unten regulierten Proteine, dass die Regulation nach unten mit einer Verlagerung des Gleichgewichts der Zelle in 
Richtung Apoptoseinduktion einherging. Weitere diese Proteine betreffende Versuche könnten ihre Relevanz in Zellen des Nierenzellkarzinoms untersuchen und Hinweise darüber geben, ob sie sich als potentielles Target in der Behandlung eignen.

\subsection{2 Überexprimierte Proteine nach Behandlung mit Cisplatin}

In der Caki-2-Zelllinie wurde eine signifikante Regulation nach oben mit einer Ratio von über 2 für zwei Proteine, LMNA und CGI-99, nachgewiesen. LMNA ist der Vorläufer der reifen Lamine Lamin A und C. Diese entstehen durch alternatives Spleißen aus dem gleichen Gen. Sie gehören zu den Intermediärfilamenten, die sich in der inneren Membran des Zellnukleus befinden und an der Organisation des Zellkerns, des Chromatins und der DNAReplikation und Transkription beteiligt sind (Dechat et al. 2008; Worman et al. 2009). Während der Apoptose kommt es zu Veränderungen der Zelle, die durch Caspasen eingeleitet werden (Slee et al. 2001). Der Zellkern verliert dabei seine Struktur, es findet eine Kondensation des Chromatins und eine Fragmentierung der DNA statt (Rao et al. 1996). Damit dieser Schritt adäquat vollzogen werden kann, ist die Proteolyse der Lamine durch Caspasen notwendig (Rao et al. 1996; Slee et al. 2001; Ruchaud et al. 2002). In den Analysen dieser Arbeit zeigte sich für einen Spot, der als LMNA identifiziert worden war, sowohl in Caki-2Zellen als auch in A498-Zellen eine Regulation nach oben (Abbildung 18, Abbildung 19). Bei Betrachtung der 2D-Gele fällt auf, dass sich die oben genannten Spots in der Höhe eines Molekulargewichts von etwa $25 \mathrm{kDa}$ befinden (Abbildung 11, Abbildung 13), obwohl das Molekulargewicht des identifizierten Proteins laut Tabelle 8 und Tabelle 9 etwa 74 kDa beträgt. Es lässt sich somit vermuten, dass es zu einer Fragmentierung des Proteins gekommen war und sich bloß ein Fragment als die oben erwähnten Spots präsentierte. Folglich handelte es sich in den hier durchgeführten Experimenten nicht tatsächlich um eine Regulation des Proteins nach oben, sondern nur um die durch die Spaltung des Proteins bedingte Präsentation des Spots an einer anderen Stelle in der 2D-Gelelektrophorese. Dieses Ergebnis kann als Indikator für den regelhaften Ablauf der Apoptose in den mit Cisplatin behandelten Zellen beider Zelllinien verstanden werden.

CGI-99 wurde als Teil des Komplexes um die humane tRNA-Spleiß-Ligase beschrieben (Popow et al. 2011). RNA-Ligasen wurden mehrere Funktionen zugeordnet, wie eine Beteiligung in der RNA-Reparatur (Nandakumar et al. 2008) oder eine Rolle bei der Reifung der tRNA für die Translation (Laski et al. 1983). Die Funktion des Proteins CGI-99 in dem Komplex ist im Detail ungeklärt. CGI-99 unterstützt jedoch die Funktion der tRNA-Ligase (Popow et al. 2014) und nimmt während der Transkription modulierenden Einfluss auf die Funktion der RNA-Polymerase II (Pérez-González et al. 2006). Weiter zeigte sich eine Beteiligung in der Organisation des Zytoskeletts während der Mitose (Brobeil et al. 2012). Diese Funktionen führten zu der Vermutung, dass CGI-99 an der Karzinogenese von Tumoren beteiligt sein könnte (Howng et al. 2004). Untersuchungen ergaben ein hohes Vorkommen von CGI99 in unterschiedlichen Karzinomen (Howng et al. 2004; Guo et al. 2009; Chen et al. 2016). Außerdem wurde ein Zusammenhang von CGI-99 und einer den Zellzyklus antreibenden 
Wirkung beschrieben (Chen et al. 2016). Die Regulation dieses Proteins nach oben wirkt bei den oben genannten biologischen Funktionen in Anbetracht des großen Ausmaßes an Apoptose (Abbildung 8) und dem Rückgang der Zellproliferation (Abbildung 5) in den Caki2-Zellen nach Behandlung mit Cisplatin paradox. Trivedi et al. (2016b) wiesen in mit Cisplatin behandelten Caki-2-Zellen keine Regulation von CGI-99 nach oben nach. Somit stellt sich die Frage der Reproduzierbarkeit des Ergebnisses. Daten für die A498-Zelllinie bezüglich dieses Proteins lagen nicht vor, da das Protein nicht identifiziert worden war. Weiterführende Western Blots könnten klären, ob tatsächlich und wenn ja, in welche Richtung eine Regulation stattgefunden hat.

Das in der A498-Zelllinie ebenfalls nur anscheinend hochregulierten Protein LMNA wurde oben bereits diskutiert. Außerdem waren die Proteine Myosin-9, HSPB1 und MYDGF signifikant mit einer Ratio von über 2 hochreguliert (Abbildung 19). Myosin-9 bildet die schwere Kette des nicht muskulären Myosins IIA (Conti und Adelstein 2008). Dieses besteht aus zwei schweren und vier leichten Ketten (Bresnick 1999). Typ-II-Myosine lassen sich in drei Isoformen unterteilen, die sich in ihren schweren Ketten unterscheiden (Ouderkirk und Krendel 2014). Myosin IIA nimmt durch die Interaktion mit Aktin eine regulierende Funktion in Zellmigration, Zelladhäsion und in der Dynamik des Zytoskeletts ein (Even-Ram et al. 2007; Vicente-Manzanares et al. 2009). Auch im Ablauf der Apoptose spielen Myosin-IIIsoformen eine Rolle. Der erste Schritt der Apoptose umfasst die Umstrukturierung des Zytoskeletts, die die Ablösung der Zelle von der Umgebung, die Schrumpfung und Veränderung der Zellform zur Folge hat (Ndozangue-Touriguine et al. 2008). Für die erfolgreiche Durchführung dieser morphologischen Veränderungen werden die schweren Ketten des nicht muskulären Myosins IIA fragmentiert (Suarez-Herta et al. 2000; Kato et al. 2005; Solinet und Vitale 2008). In Folge entstehen ein 95-97 kDa (Suarez-Herta et al. 2000; Kato et al. 2005), ein $125 \mathrm{kDa}$ und ein 204 kDa schweres Fragment (Kato et al. 2005). Im Vergleich des zweidimensionalen Proteinprofils von mit Cisplatin behandelten A498-Zellen und A498Kontrollzellen wurden zwei Spots als Myosin-9 identifiziert, die nur in mit Cisplatin behandelten Zellen sichtbar waren (Spot 3, Spot 4, Abbildung 19). Das Molekulargewicht des vollständigen Proteins Myosin-9 betrug in der Datenbanksuche etwa 226 kDa (Tabelle 9). In dem 2D-Gel befanden sich die oben genannten Spots jedoch nur auf der Höhe eines Molekulargewichts von ein wenig über $75 \mathrm{kDa}$. Ein dritter sich in unmittelbarer Nachbarschaft befindender Spot konnte nicht identifiziert werden (Abbildung 14, Abbildung 15). Es liegt nahe, dass es sich bei den Spots um die 95 kDa schweren Spaltprodukte von Myosin-9 handelte. Ob der dritte Spot ebenfalls ein Spaltprodukt darstellte, bleibt unklar. Die Darstellung in unterschiedlichen Spots kann durch Veränderungen bedingt worden sein, die zu einer Verschiebung des isoelektrischen Punkts führten. Auch in Caki-2-Zellen fielen im Vergleich zu den Kontrollzellen im 2D-Gel der mit Cisplatin behandelten Zellen drei neu aufgetreten Spots an ähnlicher Stelle auf wie im Gel der A498-Zellen (Abbildung 10, Abbildung 11). Keiner der drei Spots konnte identifiziert werden. Es ist jedoch wahrscheinlich, dass es sich 
hierbei ebenfalls um die Spaltprodukte von Myosin-9 handelte. Die Fragmentierung von Myosin-9 während der Apoptose ist abhängig von Caspasen (Suarez-Herta et al. 2000; Solinet und Vitale 2008). Dabei waren Caspase-3 und -7 von besonderer Bedeutung (Kato et al. 2005). In der durch Cisplatin ausgelösten Apoptose wurde ebenfalls eine entscheidende Rolle für Caspase-3 beschrieben (Wang und Lippard 2005), so dass das Auftreten der Spaltprodukte als Folge der durch Cisplatin ausgelösten Apoptose gesehen werden kann. Dementsprechend ist es auch für Myosin-9, ebenso wie für LMNA, nicht zu einer Regulation der Proteinexpression nach oben, sondern lediglich zu der Darstellung des Proteinspots an einer anderen Stelle im 2D-Gel gekommen. Die Fragmentierung von Myosin-9 ist als Indiz für den regelrechten Ablauf der Apoptose nach zytotoxischer Behandlung in der A498-Zelllinie zu sehen. Resistenzmechanismen, die die Fragmentierung des Zytoskeletts betreffen, schienen in der A498-Zelllinie bei regelhafter Fragmentierung der Elemente des Zytoskeletts keine entscheidende Rolle zu spielen.

HSPB1 ist ein Protein, das unter anderem eine Funktion als Chaperon einnimmt und, wie oben schon erwähnt, einen Teil der Stressantwort auf un- oder fehlgefaltete Proteine darstellt (Mathew et al. 1998). Dabei senkt sein Vorkommen ER-Stress unter anderem dadurch, dass durch HSPB1 die Effizienz der Degradierung von fehlgefalteten Proteinen durch das Proteasom gesteigert wird (Parcellier et al. 2003; Gan et al. 2010). HSPB1 wurde allgemein als zytoprotektiv und antiapoptotisch beschrieben (Rocchi 2004; Garrido et al. 2006). Diese Eigenschaften führten zu Untersuchungen im Zusammenhang mit malignen Erkrankungen. In Patientenproben von unterschiedlichen Karzinomen (Souza et al. 2009; Huang et al. 2010) und in Nierenzellkarzinom-Zelllinien (Atkins et al. 2005) zeigte sich ein hohes Vorkommen von HSPB1. Die Behandlung mit Chemotherapeutika führte in unterschiedlichen Tumoren in vitro und in vivo zu einem Anstieg des Vorkommens dieses Proteins (Kase et al. 2009; Nadin et al. 2014). Dies betraf insbesondere das Vorkommen von HSPB1 in dem Nukleus der Zelle (Castro et al. 2015). HSPB1 wurde außerdem mit Chemoresistenz assoziiert (Andrieu et al. 2010; Taba et al. 2010). Es wurde angenommen, dass durch eine Regulation von HSPB1 nach unten die Effektivität von Chemotherapeutika gesteigert werden konnte. Dies bestätigte sich in vitro und in vivo in unterschiedlichen Tumoren durch den Einsatz von siRNA oder von antisense-Oligonukleotiden (Rocchi et al. 2006; Kamada et al. 2007; Matsui et al. 2009). HSPB1 spielt auch speziell in Bezug auf eine Resistenz gegenüber Cisplatin eine Rolle (Yamamoto et al. 2001; Zhang und Shen 2007; Chen et al. 2011). In A498-Zellen zeigte sich nach einer Behandlung mit Cisplatin eine signifikante Regulation von HSPB1 nach oben (Abbildung 19). Zum einen war dies ein Hinweis für die Induktion der Antwort auf fehl- und ungefaltete Proteine in den behandelten A498-Zellen (Mathew et al. 1998). HSPB1 beeinflusst durch seine biologische Funktion das Stressniveau der Zelle, was sich darin zeigte, dass eine Regulation nach unten ER-Stress zur Folge hatte (Kumano et al. 2012). Somit entstand die Vermutung, dass HSPB1 das Stressniveau der A498-Zellen senken kann. Zum anderen wurde angenommen, dass die Regulation von HSPB1 nach oben durch die antiapoptotische Wirkung dieses Proteins an der Chemoresistenz beteiligt war. Die antiapoptotische Funktion 
von HSPB1 bestand unter anderem in der Hemmung der Aktivierung von Caspase-3 (Pandey et al. 2000; Voss et al. 2007). Es wäre interessant, Daten für die Expression des Proteins nach einer Behandlung mit Cisplatin für die Caki-2-Zelllinie zu erheben. Dies könnte Hinweise darauf geben, ob die Resistenz in Zellen des Nierenzellkarzinoms durch HSPB1 bedingt war. Weiterführende Experimente könnten prüfen, ob HSPB1 ein potentielles Target zur Überwindung dieser Resistenz in der Behandlung des Nierenzellkarzinoms darstellt. Tatsächlich ist HSPB1 ein Protein, das bereits im Sinne der zielgerichteten Therapie adressiert wird. Das antisense-Oligonukleotid OGX-427 („Apatorsen“), das die HSPB1 Expression hemmt, wurde bereits erfolgreich in Phase-II-Studien in Bezug auf Tumoren der Prostata (Chi et al. 2012) und der Blase (Bellmunt et al. 2015) getestet.

MYDGF gehört zu der Familie der Zytokine und wurde insbesondere im Zusammenhang mit immunologisch bedingten Erkrankungen beschrieben. Sein Vorkommen wurde in Epithelzellen von Lunge und Leber sowie in Zellen des Immunsystems nachgewiesen (Xu und Dong 2017). Es handelt sich dabei um ein sekretorisches Protein (Sunagozaka et al. 2011). Auch in Patientenproben des Mammakarzinoms (Mombelli et al. 2015) und des hepatozellulären Karzinoms (Sunagozaka et al. 2011) wurde im Vergleich zu nicht malignem Gewebe ein höheres Vorkommen von MYDGF gezeigt. In Caki-2-Zellen konnte im Gegensatz zu den A498-Zellen nach einer Behandlung mit Cisplatin keine signifikante Regulation von MYDGF nach oben nachgewiesen werden (Tabelle 8). Mombelli et al. (2015) beschrieben, dass eine Vorbehandlung mit MYDGF in vitro einen protektiven Effekt gegenüber zytotoxischen Substanzen hatte. Diese Assoziation mit Chemoresistenz lässt vermuten, dass auch A498-Zellen durch die Regulation von MYDGF nach oben vor dem Zelltod durch Cisplatin geschützt waren. Weiter spricht die fehlende Regulation nach oben in Caki-2-Zellen dafür, dass MYDGF einen Anteil an der Resistenz der A498-Zellen haben könnte. Dies ist allerdings lediglich eine Hypothese, die durch weiterführende Untersuchungen geprüft werden muss. A498-Zellen überraschten zudem insofern, als trotz einer Behandlung mit Cisplatin eine Zunahme der Proliferation zu beobachten war (Abbildung 7). In den Experimenten von Sunagozaka et al. (2011) wurde die Proliferation von Tumorzellen des hepatozellulären Karzinoms in vitro durch eine Regulation von MYDGF nach oben gefördert. Ob dies auch in Zellen des Nierenzellkarzinoms der Fall ist, muss überprüft werden. Dies könnte einen Einflussfaktor identifizieren, der die Proliferation der A498-Zellen trotz zytotoxischer Therapie begünstigte.

Von besonderem Interesse für die Analyse der Chemoresistenz des Nierenzellkarzinoms ergeben sich nach Literaturrecherche also die beiden in der A498-Zelllinie hochregulierten Proteine HSPB1 und MYDGF. Dabei bildet HSPB1 einen Teil der UPR und lässt die Vermutung entstehen, dass dieser Mechanismus tatsächlich an der Resistenz des Nierenzellkarzinoms beteiligt ist. 


\subsection{Rolle der UPR in Nierenzellkarzinom-Zelllinien nach Behandlung mit Cisplatin}

Das ER ist das Zellorganell, in dem Proteinbiosythese, Proteinfaltung und Proteinmodifikation stattfinden (Bravo et al. 2013). ER-Stress entsteht, wenn die Faltkapazität des ERs überstiegen wird und sich für die Zelle toxische, ungefaltete Proteine in dem ER-Lumen sammeln (Boyce und Yuan 2006). Zur Wiederherstellung der Homöostase der Zelle wird eine ERStressantwort, die UPR, eingeleitet, die entweder zu einer Anpassung der Zelle an die Bedingungen führt oder, wenn dies nicht möglich ist, in die Apoptose mündet. ER-Stress kann also entweder einen Überlebensmechanismus oder einen Weg in den Zelltod darstellen (Schröder und Kaufman 2005a; Hetz 2012). Als Folge einer Behandlung mit zytotoxisch wirkenden Medikamenten wurde in Zelllinien unterschiedlicher Tumoren beschrieben, dass ER-Stress und als Antwort darauf die UPR ausgelöst wurde (Rahmani et al. 2007; Panaretakis et al. 2009; Yadunandam et al. 2012). So auch nach Behandlung mit Cisplatin. Eine Aktivierung der UPR zeigte sich in vitro in Zelllinien unterschiedlicher Karzinome als Reaktion auf die Behandlung mit Cisplatin (Mandic et al. 2003; Jiang et al. 2009; Chen et al. 2011; Xu et al. 2012; Shi et al. 2016). Dies konnte unter anderem durch einen Anstieg des Vorkommens des Chaperons GRP78 nachgewiesen werden. Es ist bekannt, dass GRP78 bei einer Akkumulation von ungefalteten Proteinen hochreguliert wird (Kozutsumi et al. 1988). Xu et al. (2012) untersuchten außerdem noch das Vorkommen von Proteindisulfidisomerasen. Die Vermutung entstand, dass die Behandlung mit Cisplatin auch in den hier untersuchten Zelllinien zu ER-Stress und zu einer Aktivierung der UPR führte.

Zur Untersuchung dieser Hypothese wurde die Ratio der Proteinspots der identifizierten Chaperone in der Auswertung der 2D-Gele betrachtet. In der Caki-2-Zelllinie konnte keine Regulation der identifizierten Chaperone 60 kDa heat shock protein und GRP75 nachgewiesen werden (Tabelle 8). Von den differenziell nach oben regulierten Proteinen wurden zwei Proteine, LMNA und proteasome subunit alpha type-1, gemäß ihrer biologischen Funktion in eine Gruppe sortiert, die einen Teil der UPR umfasst (Tabelle 11). Hiervon war nur die Regulation von LMNA signifikant, was in Kapitel 4.2.2 diskutiert wird. In zuvor in unserer Arbeitsgruppe durchgeführten Analysen konnte für Caki-2-Zellen nach einer Behandlung mit Cisplatin auch keine Regulation von GRP78, ERp57 oder 60 kDa beat shock protein nachgewiesen werden. Dabei wurde ERp57 allerdings nur in einem Spot erfasst. Lediglich die Proteindisulfidisomerase war hochreguliert (Trivedi et al. 2016b). Aufgrund der fehlenden Induktion der meisten identifizierten Chaperone der ER-Stressantwort wurde in Caki-2-Zellen kein Hinweis auf eine umfassende Aktivierung der UPR nach einer Behandlung mit Cisplatin gesehen. In der A498-Zelllinie konnte zwar für das Chaperon 60 kDa heat shock protein keine Regulation nachgewiesen werden, jedoch zeigte sich für GRP78 und das HSPB1 eine Regulation nach oben (Tabelle 9). Diese war für GRP78 in der Auswertung nicht signifikant ( $>>0,05)$ und zeigte mit einer Ratio von 1,7 keine Verdopplung. Für HSPB1 wurde eine deutliche signifi- 
kante Regulation nachgewiesen (Abbildung 19). HSPB1 ist, wie auch schon in 4.2.2 besprochen, ebenfalls ein Chaperon, das Teil der Stressantwort auf un- oder fehlgefaltete Proteine darstellt (Mathew et al. 1998). Drei der signifikant nach oben regulierten Proteine wurden nach Datenbankrecherchen in eine Gruppe einsortiert, die einen Teil der UPR umfasst (Tabelle 11). Eines davon ist das oben erwähnte HSPB1. Dieses und die beiden noch nicht erwähnten Proteine LMNA und myeloid-derived growth factor wurden in Kapitel 4.2.2 diskutiert.

Repräsentativ für ER-Stressproteine wurde in dieser Arbeit die Expression der Proteindisulfidisomerase ERp57 nach Behandlung mit Cisplatin intensiver untersucht. Im Rahmen der ER-Stressantwort war eine Regulation der Expression von ERp57 nach oben beschrieben worden (Shishkin et al. 2013; Yu et al. 2014). In den hier gewonnenen Ergebnissen zeigte sich für die A498-Zelllinie und für die Caki-2-Zelllinie eine gegenläufige Regulation von ERp57. Die proteomischen Analysen der Caki-2-Zellen zeigten nach 24 Stunden Behandlung mit Cisplatin eine signifikante Regulation von ERp57 nach unten (Abbildung 20). Im Gegensatz dazu zeigte sich in A498-Zellen nach 48 Stunden Behandlung mit Cisplatin eine Regulation von ERp57 nach oben (Abbildung 21). Im Western Blot war es in Caki-2-Zellen ebenfalls zu einer sich im Zeitverlauf verstärkenden Regulation nach unten gekommen (Abbildung 22, Abbildung 23). In der A498-Zelllinie kam es zu einer, wenn auch nur geringen, Regulation nach oben (Abbildung 24, Abbildung 25). Die im Western Blot gewonnenen Ergebnisse sind bei einem Mangel an auswertbaren Replikaten isoliert betrachtet kritisch zu sehen. In Zusammenschau mit den proteomischen Daten, die in drei unabhängigen Versuchen gewonnen wurden, stellen sie jedoch eine Bestätigung der proteomischen Analyse dar. Durch diese Ergebnisse wurde angenommen, dass es im Gegensatz zu der Caki-2-Zelllinie in der A498-Zelllinie zu Aktivierung der UPR gekommen war.

\subsection{Rolle des ER-Stressproteins ERp57 in der Chemoresistenz von Nierenzellkarzinom-Zelllinien gegenüber einer Behandlung mit Cisplatin}

Wie oben erwähnt stellt die Chemoresistenz des Nierenzellkarzinoms die medikamentöse Therapie dieser malignen Erkrankung vor Herausforderungen und bedarf die Entdeckung neuer, die Resistenz überwindender Strategien (Fischer et al. 2015). Eine Vielzahl von Mechanismen wurde im Zusammenhang mit Chemoresistenz beschrieben (Galluzzi et al. 2012). Einer davon ist die UPR (Rahmani et al. 2007; Salaroglio et al. 2017), wobei die hohe Expression von Chaperonen, wie von GRP78 (Reddy et al. 2003; Pyrko et al. 2007) oder ERp57 (Cicchillitti et al. 2010) eine Rolle spielt. Durch die Hemmung der Expression von Teilen der UPR, wie von GRP78, konnte die Resistenz gegenüber klassischen Chemotherapeutika, wie Alkylanzien und Topoisomerase-Inhibitoren (Pyrko et al. 2007; Martin et al. 2010), aber auch gegenüber Angiogenese-Hemmern (Dong et al. 2005; Han et al. 2015) in vitro und in vivo zum Teil überwunden werden. In der Resistenz gegenüber Cisplatin im Speziellen wurde ebenfalls eine Beteiligung der UPR beschrieben (Chen et al. 2011; Feng et al. 2011; Lin et al. 2011). 
Deren Hemmung führte in Kombination mit einer Cisplatin-Behandlung in vitro zu einer Steigerung des Zelltods in Karzinomzellen unterschiedlicher Tumoren und stellte folglich die Überwindung eines zuvor bestehenden Resistenzmechanismus dar (Jiang et al. 2009; Shi et al. 2016). Dabei kombinierten Jiang et al. (2009) die Behandlung mit Cisplatin mit Inhibitoren der Expression von GRP78, Shi et al. (2016) mit ER-Stress Inhibitoren. In weiteren Experimenten wurde allerdings auch durch die Induktion von ER-Stress in Kombination mit einer Behandlung mit Cisplatin der apoptotische Effekt der Behandlung gesteigert $(\mathrm{Xu}$ et al. 2012), so dass insbesondere eine moderate Aktivierung der UPR zytoprotektiv zu sein scheint.

Da sich in den hier durchgeführten Experimenten beide Zelllinien sowohl im Ansprechen auf die Behandlung mit Cisplatin als auch in der Aktivierung der UPR unterschieden, führte dies zu der Annahme, dass das schlechte Ansprechen der A498-Zelllinie mit der Aktivierung der UPR zusammenhing. Die nur geringe Induktion der UPR in der Caki-2-Zelllinie ließ vermuten, dass hierdurch eine Resistenz verhindert und das bessere Ansprechen auf die Behandlung ermöglicht wurde. In Patientenproben und Nierenzellkarzinom-Zelllinien wurde im Vergleich zu nicht entarteten Nierenzellen eine Aktivierung der UPR nachgewiesen (Fu et al. 2010). Vermutlich nimmt die UPR also eine Funktion in dieser Tumorerkrankung ein. Die Proteindisulfidisomerase ERp57 stellt einen Teil der UPR dar und wurde bereits zuvor im Zusammenhang mit unterschiedlichen Krebserkrankungen und Chemoresistenz assoziiert (Chay et al. 2010; Cicchillitti et al. 2010; Trivedi et al. 2016a; Liu et al. 2017). Nach einer Behandlung mit Cisplatin zeigte sich in beiden untersuchten Zelllinien eine gegenläufige Regulation von ERp57 (Abbildung 23, Abbildung 25). Für die weiteren Experimente dieser Arbeit wurde vermutet, dass ERp57 eine entscheidende Rolle für das unterschiedliche Ansprechen der Zelllinien auf die Behandlung mit Cisplatin spielt. Die folgenden Untersuchungen sollten klären, ob durch die Regulation von ERp57 das Ansprechen auf die Behandlung beeinflusst und die Resistenz der A498-Zelllinie überwunden werden könnte.

Die Expression von ERp57 wurde also reguliert und das Verhalten beider Zelllinien nach einer Behandlung mit Cisplatin wurde bezüglich Proliferation und Zellviabilität sowie Apoptose beobachtet. In der Caki-2-Zelllinie zeigte sich nach Regulation von ERp57 nach unten lediglich 48 Stunden nach Behandlung mit Cisplatin ein signifikanter Unterschied in der Abnahme der prozentualen Zellviabilität im Vergleich zu den Kontrollzellen. Dieser ließ sich im nächsten Messintervall nicht mehr nachweisen und hatte somit keine weitreichende Konsequenz (Abbildung 34). Der Anteil der apoptotischen Zellen unterschied sich ebenfalls nicht signifikant von den mit Cisplatin behandelten und nicht-transfizierten Caki-2-Zellen (Abbildung 37, Abbildung 38). Zuvor war beschrieben worden, dass das Ansprechen von Karzinomzellen auf Therapeutika, die zu einer Regulation von ERp57 nach unten führten, in vitro durch eine vor der Behandlung vorgenommenen Regulation von ERp57 nach unten gesteigert werden konnte (Hafiza und Latifah 2014; Trivedi et al. 2016a). Dies wurde in den Experimenten dieser Arbeit für die ohnehin schon gut ansprechende Caki-2-Zelllinie nicht 
bestätigt, da sich in den gemessenen Parametern kein Unterschied im Ansprechen auf die Behandlung durch die Regulation von ERp57 nach unten zeigen ließ.

Für Caki-2-Zellen, in denen ERp57 nach oben reguliert wurde, ergab sich über den ganzen Messzeitraum kein signifikanter Unterschied in der Abnahme der prozentualen Zellviabilität im Vergleich zu den Caki-2-Kontrollzellen (Abbildung 34). Der Anteil an apoptotischen Zellen war signifikant kleiner als in Caki-2-Kontrollzellen (Abbildung 38). Das Ansprechen auf die Behandlung mit Cisplatin war in den mit dem Plasmid transfizierten Zellen also geringer. Dies deckt sich mit den Ergebnissen der bereits erwähnten Studie von Trivedi et al. (2016a), in der durch eine Regulation von ERp57 nach oben das Ansprechen auf die Behandlung mit dem zytotoxischen Agens in vitro vermindert werden konnte. Zwar wurde der Anteil der apoptotischen Zellen nach der Regulation von ERp57 nach oben in der Caki-2-Zelllinie signifikant gesenkt, durch die Regulation nach unten ergab sich jedoch nicht der gegenteilige Effekt. Das Ansprechen auf die Behandlung mit Cisplatin war in den mit dem Plasmid transfizierten und mit Cisplatin behandelten Caki-2-Zellen weiterhin höher als in nicht transfizierten und mit Cisplatin behandelten, relativ resistenten A498-Zellen (Abbildung 38, Abbildung 41). Außerdem lag die prozentuale Zellviabilität, trotz des kleineren Anteils an apoptotischen Zellen nach 24 Stunden Behandlung mit Cisplatin, in mit dem Plasmid transfizierten Caki-2Zellen im Zeitverlauf ähnlich wie in Caki-2-Kontrollzellen lediglich bei etwa 20\% (Abbildung 34). Diese geringe Zellviabilität spricht für ein gutes Ansprechen auf die Behandlung mit Cisplatin und deutlich gegen die Entstehung eines resistenten Zelltyps durch die Regulation von ERp57 nach oben. Es zeigte sich also keine Schlüsselrolle für ERp57 in dem Ansprechen auf eine Behandlung mit Cisplatin in der Caki-2-Zelllinie.

In der A498-Zelllinie wurde vermutet, dass die Regulation von ERp57 nach oben als Folge der Behandlung mit Cisplatin zu dem geringen Ansprechen auf dieselbe beitrug. Schon in früheren Experimenten konnte durch die Regulation von ERp57 nach unten der zytotoxische Effekt von ER-Stress auslösenden Agentien in vitro gesteigert und eine Resistenz überwunden werden (Corazzari et al. 2007; Zhao et al. 2015). Eine Regulation nach oben hatte den gegenteiligen Effekt und verstärkte die Resistenz gegenüber dem verwendeten Agens (Zhao et al. 2015). In den im Rahmen dieser Arbeit durchgeführten Experimenten ergab sich für eine Regulation von ERp57 nach unten ein signifikanter Anstieg des Anteils an A498Zellen, in denen nach Behandlung mit Cisplatin die Apoptose induziert wurde (Abbildung 40, Abbildung 41). Die prozentuale Zellviabilität unterschied sich ebenfalls hoch signifikant von den A498-Kontrollzellen. Allerdings war der Anteil der proliferierenden Zellen trotz einer Behandlung mit Cisplatin deutlich größer als in den nicht transfizierten A498-Zellen (Abbildung 35). Diese Ergebnisse entsprächen einem Zelltyp, der durch die Behandlung mit Cisplatin nicht wesentlich in der Proliferation eingeschränkt wurde, obwohl in einem Großteil der Zellen der Zelltod ausgelöst wurde. Hieraus ergab sich die Frage, wie der Vorteil bezüglich der Zellproliferation für mit Cisplatin behandelte und mit siRNA transfizierte Zellen trotz deutlichem Nachteil in Bezug auf die apoptotischen Zellen zustande kam. Dies erklärte sich umso weniger, da die Transfektion mit Expressionsregulation von ERp57 an 
sich bereits einen negativen Einfluss auf die Proliferation und Zellviabilität darstellte (Abbildung 33). Die Ergebnisse können so interpretiert werden, dass die bereits durch die Transfektion mit Expressionsregulation von ERp57 eingeschränkte Proliferation der Zelle durch die Behandlung mit Cisplatin nur zu einem geringen Teil weiter eingeschränkt wurde. Weiter wurde vermutet, dass die alleinige Transfektion mit siRNA die Apoptose ausgelöst hatte und der hohe Anteil an apoptotischen Zellen nach einer Behandlung mit Cisplatin nicht nur durch die Behandlung mit Cisplatin, sondern auch durch die Transfektion an sich bedingt war. Da der Überstand der lediglich mit siRNA transfizierten Zellen im Annexin V/ dead cell apoptosis assay verworfen worden war, kann diese Vermutung anhand der vorliegenden Ergebnisse jedoch nicht bestätigt werden. Neben dem Mangel an Replikaten für die Experimente mit der A498-Zelllinie stellt dies eine Schwäche der durchgeführten Experimente in beiden Zelllinien dar. Dass die Regulation von ERp57 nach unten ausreicht, um die Apoptose auszulösen, war bereits für Zelllinien des Kolonkarzinoms und des Mammakarzinoms beschrieben worden (Hussmann et al. 2015). Folglich konnte die Regulation von ERp57 nach unten an sich zu Zelltod geführt und nicht das Ansprechen auf die Behandlung mit Cisplatin im Speziellen gesteigert haben. Dementsprechend war auch der Effekt der zusätzlichen Behandlung mit Cisplatin in Bezug auf die Zellproliferation gering.

Die prozentuale Zellviabilität in Zellen, in denen ERp57 hochreguliert wurde, unterschied sich nicht signifikant von der der Kontrollzellen (Abbildung 35). Der Anteil der apoptotischen Zellen nach einer Behandlung mit Cisplatin war in A498-Zellen, in denen ERp57 hochreguliert wurde, größer als in A498-Kontrollzellen, die mit Cisplatin behandelt wurden. Dieser Unterschied war allerdings nicht signifikant und ist bei einem Mangel an Replikaten kritisch zu sehen (Abbildung 41). Die mit dem Plasmid transfizierten A498-Zellen unterschieden sich also weder in Proliferation noch in Zelltod nach einer Behandlung mit Cisplatin signifikant von den A498-Kontrollzellen. Schlussfolgernd wurde ERp57 auch in dieser Zelllinie keine Schlüsselrolle in dem Ansprechen auf Cisplatin zugesprochen. Es entstand jedoch die Vermutung, dass durch eine Regulation von ERp57 nach unten eine Destabilisierung der Homöostase der A498-Zellen erreicht worden war. Zur Bestätigung dieser Vermutung wären allerdings weitere Experimente notwendig. Diese könnten ERp57 als wichtigen Überlebensfaktor für Zellen des Nierenzellkarzinoms im Allgemeinen und nicht speziell in Bezug auf eine Resistenz gegenüber Cisplatin identifizieren.

\subsection{Rolle des ER-Stressproteins ERp57 in der Proliferation von Nierenzellkarzinom-Zelllinien}

In unseren Experimenten fiel auf, dass die Expressionsregulation von ERp57 sich auf die Zellviabilität und Proliferation der Nierenzellkarzinom-Zelllinien auswirkte (Abbildung 32, Abbildung 33). In der Vergangenheit wurde bereits ein Einfluss von ERp57 auf die Proliferation von Zellen beschrieben. Sowohl in nicht entarteten Keratinozyten (Kim et al. 2015) als auch in Zelllinien von gynäkologischen Tumoren (Lwin et al. 2012; Zhao et al. 2015) 
beeinflusste die Regulation von ERp57 nach unten die Proliferation der Zellen in vitro negativ. Dies bestätigte sich in den durchgeführten Experimenten. Sowohl in der Caki-2-Zelllinie als auch in der A498-Zelllinie zeigte sich im Zeitverlauf in Zellen, in denen ERp57 herunterreguliert wurde, im Vergleich zu den Kontrollzellen ein geringerer Anstieg der Proliferation und Zellviabilität. Dieser war nach 72 Stunden Wachstum hoch signifikant $(p<0,01)$ (Abbildung 32, Abbildung 33). Dies könnte zum einen durch einen Zellzyklusstopp bedingt sein, der nach einer Regulation von ERp57 nach unten beschrieben wurde (Lwin et al. 2012; Hussmann et al. 2015). Zum anderen ist bekannt, dass in schnell proliferierenden Zellen wie Karzinomzellen ein größeres $\mathrm{Maß}$ an Proteinbiosynthese stattfindet und hierfür eine größere Faltkapazität des ERs als in nicht entarteten Zellen benötigt wird (Tameire et al. 2015). Durch die Regulation von ERp57 nach unten ist diese zumindest zum Teil eingeschränkt.

In der A498-Zellline war es trotz Behandlung mit Cisplatin weiterhin zu einer Steigung der Zellproliferation gekommen (Abbildung 6). Es entstand die Vermutung, dass die Regulation von ERp57 nach oben (Abbildung 25) nach Behandlung mit Cisplatin zu diesem Ergebnis beitrug. Allerdings zeigte sich für Zellen, in denen ERp57 durch das Plasmid hochreguliert wurde, in beiden Zelllinien ein noch geringerer Anstieg der Proliferation und Zellviabilität als in den Kontrollzellen und den mit siRNA transfizierten Zellen (Abbildung 32, Abbildung 33). Der Unterschied zu den Kontrollzellen war ab dem Zeitpunkt 48 Stunden in beiden Zelllinien hoch signifikant $(\mathrm{p}<0,01)$. Somit proliferierten die mit dem Plasmid transfizierten Zellen im Vergleich zu den Kontrollzellen am geringsten. Dieses Ergebnis steht im Widerspruch zu dem von Zhao et al. (2015) und Ramirez-Rangel et al. (2011). In diesen Studien wurde die Proliferation von Zellen durch eine mittels Plasmidtransfektion erreichte Regulation von ERp57 nach oben in vitro gesteigert. Auch in der Untersuchung von Tumorgewebe von hepatozellulären Karzinomen zeigte sich ein Zusammenhang zwischen einem hohen Vorkommen von ERp57 und einem hohen Proliferationsindex (Takata et al. 2016). Eine Erklärung der proliferationsfördernden Wirkung von ERp57 stellte die Beteiligung dieses Proteins an der Aktivierung des die Proliferation-regulierenden Faktors mTOR1 dar (Ramirez-Rangel et al. 2011). Es stellte sich die Frage, ob das nach Plasmidtransfektion gebildete ERp57 die gleiche Funktion wie das endogen gebildete ERp57 einnahm. Nach Plasmidtransfektion wurde ERp57 im ER nachgewiesen (Abbildung 29, Abbildung 31), dem Zellkompartiment, in welchem dieses Protein physiologischerweise größtenteils vorkommt (Ferrari und Söling 1999). Bei physiologischer Lage wurde davon ausgegangen, dass dieses zusätzlich gebildete ERp57 auch seine biologische Funktion erfüllte. Aus welchem Grund sich die Regulation von ERp57 nach oben in den in dieser Arbeit durchgeführten Experimenten konträr zu den in der Literatur beschriebenen Ergebnissen negativ auf die Proliferation und die Zellviabilität auswirkte, bleibt unklar. Dadurch, dass der Überstand der lediglich mit dem Plasmid transfizierten Zellen im Annexin V/ dead cell apoptosis assay verworfen worden war, kann nicht nachvollzogen werden, ob die Transfektion mit dem Plasmid an sich zu Zelltod geführt hat und dies eine Ursache für den geringen Anstieg der Zellviabilität darstellt. Weiter bleibt unklar, ob die Transfektion mit dem Plasmid an sich, das keine Information zur Regulation von 
ERp57 enthielt, einen negativen Einfluss auf die Proliferation der Zellen oder einen positiven Effekt auf die Apoptoseinduktion hat. Für eine Zelllinie der AML wurde gezeigt, dass die Transfektion mit dem „leeren“ Plasmidvektor des in dieser Arbeit verwendeten Plasmids keinen Einfluss auf die Apoptoseinduktion hatte (Trivedi et al. 2016a).

Da sich die Regulation von ERp57 nach oben in beiden Zelllinien negativ auf die Proliferation auswirkte, konnte kein proliferationsfördernder Effekt von ERp57 auf die untersuchten Nierenzellkarzinom-Zelllinien festgestellt werden. Tatsächlich stellte sich die Plasmidtransfektion mit Regulation von ERp57 nach oben als der Faktor dar, der die Proliferation am deutlichsten negativ beeinflusste. Auch die Transfektion mit siRNA und die damit einhergehende Regulation von ERp57 nach unten führte zu einem geringeren Anstieg der Proliferation als in den Kontrollzellen. Somit zeigte sich lediglich, dass sich die Transfektion an sich und die damit gekoppelte Veränderung der ERp57-Expression in beide Richtungen negativ auf die Proliferation und Zellviabilität auswirkte. 


\section{$5 \quad$ Zusammenfassung}

Im Rahmen dieser Arbeit wurden zwei etablierte Nierenzellkarzinom-Zelllinien, Caki-2 und A498, bezüglich ihres Ansprechens auf eine Behandlung mit Cisplatin untersucht. Im Annexin $\mathrm{V} /$ dead cell apoptosis assay und im MTT-Assay zeigte sich ein deutlicher Unterschied im Ansprechen auf die Behandlung in beiden Zelllinien. A498 stellte eine relativ resistente Zelllinie dar, während Caki-2-Zellen gut ansprachen. Zunächst wurden Veränderungen des Proteoms beider Zelllinien nach Cisplatinbehandlung analysiert. Diese ergaben in der Caki-2Zelllinie drei Proteine, SRSF1, hnRNP K und SF3B1, und in der A498-Zelllinie ein Protein, hnRNP K, die nach der Behandlung signifikant herunterreguliert waren. Die Regulation dieser drei Proteine nach unten verlagert laut Literaturrecherche das Gleichgewicht der Zelle in Richtung Apoptose und stellt so vermutlich einen wichtigen Aspekt für den Zelltod der untersuchten Zellen des Nierenzellkarzinoms nach Behandlung dar. Als signifikant hochreguliert wurden in der Caki-2-Zelllinie zwei Proteine identifiziert, LMNA und CGI-99, und in der A498-Zelllinie vier Proteine, LMNA, Myosin-9, HSPB1 und MYDGF. Dabei waren LMNA und Myosin-9 nur anscheinend reguliert. Tatsächlich präsentierten sie sich durch eine Fragmentierung während der Apoptose lediglich als ein zuvor nicht vorhandener Spot. Eine Assoziation zu Karzinogenese und Chemoresistenz besteht laut Literaturrecherche zu HSPB1 und MYDGF. Inhibitoren von HSPB1 werden aktuell bereits in klinischen Studien urologischer Tumoren getestet und könnten in Zukunft eine Rolle in der Krebstherapie spielen. $\mathrm{Ob}$ die Chemoresistenz des Nierenzellkarzinoms durch die Inhibition von HSPB1 oder MYDGF überwunden werden kann, muss weiter überprüft werden.

Weiter fiel in der Analyse von 2D-Gelen und Western Blots nach Behandlung mit Cisplatin auf, dass sich in A498-Zellen eine Aktivierung der ER-Stressantwort (UPR) beobachtet ließ, was sich in der Regulation von Chaperonen wie ERp57 nach oben zeigte. Im Gegensatz dazu war ERp57 in Caki-2-Zellen herunterreguliert worden, so dass eine Beteiligung der UPR und von ERp57 an der Resistenz der A498-Zellen vermutetet wurde. Zur Überprüfung dieser Annahme wurde die Expression von ERp57 durch die Transfektion mit einem Plasmid und mit siRNA reguliert. Nach Bestätigung der Transfektion im Western Blot und in der indirekten Immunfluoreszenzfärbung wurde untersucht, ob das Ansprechen auf die Behandlung mit Cisplatin durch die Regulation von ERp57 verändert werden konnte. In beiden Zelllinien ergaben sich keine Hinweise, dass ERp57 eine Schlüsselrolle in dem Ansprechen auf die Behandlung mit Cisplatin spielt. Allerdings führte die Regulation von ERp57 nach unten in der A498-Zelllinie zu einem Anstieg des Zelltods, so dass die Vermutung entstand, dass dieses Protein für die Zellhomöostase im Allgemeinen von Bedeutung ist. Gegebenenfalls könnte so die Regulation von ERp57 nach unten Zellen des Nierenzellkarzinoms destabilisieren. Weitere Analysen müssten sich zur Bestätigung dieser Hypothese jedoch anschließen. Die Transfektion sowohl mit dem Plasmid als auch mit siRNA hatte zudem einen negativen Einfluss auf die Proliferation der Zellen beider Zelllinien, wobei die Plasmidtransfektion den größten Nachteil darstellte. Somit war ERp57 nicht proliferationsfördernd. 


\section{$6 \quad$ Literaturverzeichnis}

Ameri K (2004): Anoxic induction of ATF-4 through HIF-1-independent pathways of protein stabilization in human cancer cells. Blood 103, 1876-1882

An J, Sun Y, Fisher M, Rettig MB (2004): Maximal apoptosis of renal cell carcinoma by the proteasome inhibitor bortezomib is nuclear factor-kappaB dependent. Mol Cancer Ther $\underline{3}$, $727-736$

Anczuków O, Rosenberg AZ, Akerman M, Das S, Zhan L, Karni R, Muthuswamy SK, Krainer AR (2012): The splicing factor SRSF1 regulates apoptosis and proliferation to promote mammary epithelial cell transformation. Nat Struct Mol Biol $\underline{19}$, 220-228

Andrieu C, Taieb D, Baylot V, Ettinger S, Soubeyran P, De-Thonel A, Nelson C, Garrido C, So A, Fazli L, et al. (2010): Heat shock protein 27 confers resistance to androgen ablation and chemotherapy in prostate cancer cells through eIF4E. Oncogene 29, 1883-1896

Andruska N, Zheng X, Yang X, Helferich WG, Shapiro DJ (2015): Anticipatory estrogen activation of the unfolded protein response is linked to cell proliferation and poor survival in estrogen receptor [alpha]-positive breast cancer. Oncogene $\underline{34}$, 3760-3769

Atkins C, Liu Q, Minthorn E, Zhang S-Y, Figueroa DJ, Moss K, Stanley TB, Sanders B, Goetz A, Gaul N, et al. (2013): Characterization of a novel PERK kinase inhibitor with antitumor and antiangiogenic activity. Cancer Res $\underline{73}$, 1993-2002

Atkins D, Lichtenfels R, Seliger B (2005): Heat shock proteins in renal cell carcinomas. Contrib Nephrol 148, 35-56

Bagratuni T in., Wu P, Gonzalez de Castro D, Davenport EL, Dickens NJ, Walker BA, Boyd K, Johnson DC, Gregory W, Morgan GJ, Davies FE (2010): XBP1s levels are implicated in the biology and outcome of myeloma mediating different clinical outcomes to thalidomidebased treatments. Blood 116, 250-253

Bahar E, Kim H, Yoon H (2016): ER stress-mediated signaling: action potential and ca2+ as key players. Int J Mol Sci $\underline{17}, 1558$

Baldewijns MM, van Vlodrop IJ, Vermeulen PB, Soetekouw PM, van Engeland M, de Bruïne AP (2010): VHL and HIF signalling in renal cell carcinogenesis. J Pathol 221, 125-138

Bali P, Pranpat M, Bradner J, Balasis M, Fiskus W, Guo F, Rocha K, Kumaraswamy S, Boyapalle S, Atadja P, et al. (2005): Inhibition of histone deacetylase 6 acetylates and distupts the chaperone function of heat shock protein 90: a novel basis for antileukemia activity of histone deacetylase inhibitors. J Biol Chem 280, 26729-26734

Bates SE, Bakke S, Kang M, Robey RW, Zhai S, Thambi P, Chen CC, Patil S, Smith T, Steinberg SM, et al. (2004): A phase I/II study of infusional vinblastine with the P-glycoprotein antagonist valspodar (PSC 833) in renal cell carcinoma. Clin Cancer Res 10, 4724-4733

Baytekin F, Tuna B, Mungan U, Aslan G, Yorukoglu K (2011): Significance of P-glycoprotein, p53, and survivin expression in renal cell carcinoma. Urol Oncol Semin Orig Investig $\underline{29}, 502$ 507

Bellmunt J, Eigl BJ, Senkus-Konefka E, Loriot Y, Twardowski P, Castellano DE, Blais N, Sridhar SS, Sternberg CN, Retz M, et al. (2015): First-line randomized phase II study of gemcitabine/cisplatin plus apatorsen or placebo in patients with advanced bladder cancer: The International Borealis-1 trial. J Clin Oncol $\underline{33}$, 4503-4503 
Bertolotti A, Zhang Y, Hendershot LM, Harding HP, Ron D (2000): Dynamic interaction of BiP and ER stress transducers in the unfolded-protein response. Nat Cell Biol $2,326-332$

Bi M, Naczki C, Koritzinsky M, Fels D, Blais J, Hu N, Harding H, Novoa I, Varia M, Raleigh J, et al. (2005): ER stress-regulated translation increases tolerance to extreme hypoxia and promotes tumor growth. EMBO J 24, 3470-3481

Blais JD, Addison CL, Edge R, Falls T, Zhao H, Wary K, Koumenis C, Harding HP, Ron D, Holcik M, Bell JC (2006): PERK-dependent translational regulation promotes tumor cell adaptation and angiogenesis in response to hypoxic stress. Mol Cell Biol 26, 9517-9532

Boyce M, Yuan J (2006): Cellular response to endoplasmic reticulum stress: a matter of life or death. Cell Death Differ 13, 363-373

Bradford MM (1976): A rapid and sensitive method for the quantitation of microgram quantities of protein utilizing the principle of protein-dye binding. Anal Biochem $\underline{72}, 248-254$

Bravo R, Parra V, Gatica D, Rodriguez AE, Torrealba N, Paredes F, Wang ZV, Zorzano A, Hill JA, Jaimovich E, et al. (2013): Endoplasmic reticulum and the unfolded protein response: dynamics and metabolic integration. Int Rev Cell Mol Biol $\underline{301}$, 215-290

Bresnick AR (1999): Molecular mechanisms of nonmuscle myosin-II regulation. Curr Opin Cell Biol 11, 26-33

Brobeil A, Graf M, Eiber M, Wimmer M (2012): Interaction of PTPIP51 with tubulin, CGI-99 and Nuf2 during cell cycle progression. Biomolecules 2 , 122-142

Brodaczewska KK, Szczylik C, Fiedorowicz M, Porta C, Czarnecka AM (2016): Choosing the right cell line for renal cell cancer research. Mol Cancer $\underline{15}, 83$

Buszczak M, Signer RAJ, Morrison SJ (2014): Cellular differences in protein synthesis regulate tissue homeostasis. Cell 159, 242-251

Carbonaro M, Escuin D, O’Brate A, Thadani-Mulero M, Giannakakou P (2012): Microtubules regulate hypoxia-inducible factor- 1 protein trafficking and activity: implications for taxane therapy. J Biol Chem 287, 11859-11869

Casas C (2017): GRP78 at the centre of the stage in cancer and neuroprotection. Front Neurosci $\underline{11,177}$

Castro GN, Cayado-Gutiérrez N, Zoppino FCM, Fanelli MA, Cuello-Carrión FD, Sottile M, Nadin SB, Ciocca DR (2015): Effects of temozolomide (TMZ) on the expression and interaction of heat shock proteins (HSPs) and DNA repair proteins in human malignant glioma cells. Cell Stress Chaperones 20, 253-265

Chay D, Cho H, Lim BJ, Kang ES, Oh YJ, Choi SM, Kim BW, Kim YT (2010): ER-60 (PDIA3) is highly expressed in a newly established serous ovarian cancer cell line, YDOV-139. Int J Oncol $\underline{37}$, 399-412

Chen G, Gharib TG, Huang C-C, Thomas DG, Shedden KA, Taylor JMG, Kardia SLR, Misek DE, Giordano TJ, Iannettoni MD, et al. (2002): Proteomic analysis of lung adenocarcinoma. Clin Cancer Res $\underline{8}, 2298-2305$

Chen J, Ding Z, Peng Y, Pan F, Li J, Zou L, Zhang Y, Liang H (2014): HIF-1 $\alpha$ inhibition reverses multidrug resistance in colon cancer cells via downregulation of MDR1/P-glycoprotein. PLoS ONE $\underline{9}$, e98882 
Chen M, Ye Y, Zou B, Guo S, Zhou F, Lu K, Liu J, Xu Z, Han H, Liu Z, et al. (2016): C14orf166 is a high-risk biomarker for bladder cancer and promotes bladder cancer cell proliferation. J Transl Med 14, 55

Chen R, Dai RY, Duan CY, Liu YP, Chen SK, Yan DM, Chen CN, Wei M, Li H (2011): Unfolded protein response suppresses cisplatin-induced apoptosis via autophagy regulation in human hepatocellular carcinoma cells. Folia Biol (Praha) $\underline{57}$, 87-95

Chen X, Shen J, Prywes R (2002): The luminal domain of ATF6 senses endoplasmic reticulum (ER) stress and causes translocation of ATF6 from the ER to the golgi. J Biol Chem 277 , 13045-13052

Chi KN, Hotte SJ, Ellard S, Gingerich JR, Joshua AM, Kollmannsberger CK, Yu EY, Gleave ME (2012): A randomized phase II study of OGX-427 plus prednisone versus prednisone alone in patients with chemotherapy-naive metastatic castration-resistant prostate cancer. J Clin Oncol 30, 121-121

Chitnis NS, Pytel D, Bobrovnikova-Marjon E, Pant D, Zheng H, Maas NL, Frederick B, Kushner JA, Chodosh LA, Koumenis C, et al. (2012): MiR-211 is a prosurvival microRNA that regulates CHOP expression in a PERK-dependent manner. Mol Cell 4ㅇ, 353-364

Choe MH, Min JW, Jeon HB, Cho D-H, Oh JS, Lee HG, Hwang S-G, An S, Han Y-H, Kim J-S (2015): ERp57 modulates STAT3 activity in radioresistant laryngeal cancer cells and serves as a prognostic marker for laryngeal cancer. Oncotarget $\underline{6}, 2654-2666$

Chow W-H, Gridley G, Fraumeni Jr JF, Järvholm B (2000): Obesity, hypertension, and the risk of kidney cancer in men. N Engl J Med $\underline{343}, 1305-1311$

Chung H, Cho H, Perry C, Song J, Ylaya K, Lee H, Kim J-H (2013): Downregulation of ERp57 expression is associated with poor prognosis in early-stage cervical cancer. Biomarkers $\underline{18}$, $573-579$

Cicchillitti L, Della Corte A, Di Michele M, Donati MB, Rotilio D, Scambia G (2010): Characterisation of a multimeric protein complex associated with ERp57 within the nucleus in paclitaxel-sensitive and -resistant epithelial ovarian cancer cells: The involvement of specific conformational states of $\beta$-actin. Int J Oncol 37, 445-454

Ciechanover A, Schwartz AL (1998): The ubiquitin-proteasome pathway: the complexity and myr-

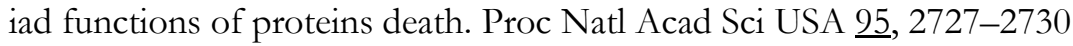

Ciocca DR, Arrigo AP, Calderwood SK (2013): Heat shock proteins and heat shock factor 1 in carcinogenesis and tumor development: an update. Arch Toxicol 87, 19-48

Conti MA, Adelstein RS (2008): Nonmuscle myosin II moves in new directions. J Cell Sci $\underline{121}, 11-$ 18

Corazzari M, Lovat PE, Armstrong JL, Fimia GM, Hill DS, Birch-Machin M, Redfern CPF, Piacentini M (2007): Targeting homeostatic mechanisms of endoplasmic reticulum stress to increase susceptibility of cancer cells to fenretinide-induced apoptosis: the role of stress proteins ERdj5 and ERp57. Br J Cancer 96, 1062-1071

Costa LJ, Drabkin HA (2007): Renal cell carcinoma: new developments in molecular biology and potential for targeted therapies. The Oncologist 12, 1404-1415

Croft A, Tay KH, Boyd SC, Guo ST, Jiang CC, Lai F, Tseng H-Y, Jin L, Rizos H, Hersey P, Zhang XD (2014): Oncogenic activation of MEK/ERK primes melanoma cells for adaptation to endoplasmic reticulum stress. J Invest Dermatol 134, 488-497 
Cubillos-Ruiz JR, Bettigole SE, Glimcher LH (2017): Tumorigenic and immunosuppressive rffects of endoplasmic reticulum stress in cancer. Cell $\underline{168}, 692-706$

Daneshmand S, Quek ML, Lin E, Lee C, Cote RJ, Hawes D, Cai J, Groshen S, Lieskovsky G, Skinner DG, et al. (2007): Glucose-regulated protein GRP78 is up-regulated in prostate cancer and correlates with recurrence and survival. Hum Pathol $\underline{38}, 1547-1552$

Das BK, Xia L, Palandjian L, Gozani O, Chyung Y, Reed R (1999): Characterization of a protein complex containing spliceosomal proteins SAPs 49, 130, 145, and 155. Mol Cell Biol 19, 6796-6802

Davies MP, Barraclough DL, Stewart C, Joyce KA, Eccles RM, Barraclough R, Rudland PS, Sibson DR (2008): Expression and splicing of the unfolded protein response gene XBP-1 are significantly associated with clinical outcome of endocrine-treated breast cancer. Int J Cancer $\underline{123}, 85-88$

Davis NB, Taber DA, Ansari RH, Ryan CW, George C, Vokes EE, Vogelzang NJ, Stadler WM (2004): Phase II trial of PS-341 in patients with renal cell cancer: a university of chicago phase II consortium study. J Clin Oncol 22, 115-119

Dechat T, Pfleghaar K, Sengupta K, Shimi T, Shumaker DK, Solimando L, Goldman RD (2008): Nuclear lamins: major factors in the structural organization and function of the nucleus and chromatin. Genes Dev 22, 832-853

Dihazi H, Dihazi GH, Bibi A, Eltoweissy M, Mueller CA, Asif AR, Rubel D, Vasko R, Mueller GA (2013): Secretion of ERP57 is important for extracellular matrix accumulation and progression of renal fibrosis, and is an early sign of disease onset. J Cell Sci 126, 3649-3663

Dong D, Ko B, Baumeister P, Swenson S, Costa F, Markland F, Stiles C, Patterson JB, Bates SE, Lee AS (2005): Vascular targeting and antiangiogenesis agents induce drug resistance effector GRP78 within the tumor microenvironment. Cancer Res $\underline{65}$, 5785-5791

Duensing S, Dallmann I, Grosse J, Buer J, Lopez Hänninen E, Deckert M, Störkel S, Kirchner H, Poliwoda H, Atzpodien J (1994): Immunocytochemical detection of P-glycoprotein: initial expression correlates with survival in renal cell carcinoma patients. Oncology $\underline{51}$, 309-313

Ellgaard L, Frickel E-M (2003): Calnexin, calreticulin, and ERp57. Cell Biochem Biophys 39, 223247

Ellgaard L, Molinari M, Helenius A (1999): Setting the standards: quality control in the secretory pathway. Science $\underline{286}, 1882-1888$

Even-Ram S, Doyle AD, Conti MA, Matsumoto K, Adelstein RS, Yamada KM (2007): Myosin IIA regulates cell motility and actomyosin-microtubule crosstalk. Nat Cell Biol 2, 299-309

Fawcett TW, Martindale JL, Guyton KZ, Hai T, Holbrook NJ (1999): Complexes containing activating transcription factor (ATF)/cAMP-responsive-element-binding protein (CREB) interact with the CCAAT/enhancer-binding protein (C/EBP)-ATF composite site to regulate Gadd153 expression during the stress response. Biochem J 339, 135-141

Felgner PL, Gadek TR, Holm M, Roman R, Chan HW, Wenz M, Northrop JP, Ringold GM, Danielsen M (1987): Lipofection: a highly efficient, lipid-mediated DNA-transfection procedure. Proc Natl Acad Sci U S A $\underline{84}, 7413-7417$

Feng R, Zhai WL, Yang HY, Jin H, Zhang QX (2011): Induction of ER stress protects gastric cancer cells against apoptosis induced by cisplatin and doxorubicin through activation of p38 MAPK. Biochem Biophys Res Commun 406, 299-304 
Feng Y, Sokol ES, Del Vecchio CA, Sanduja S, Claessen JHL, Proia TA, Jin DX, Reinhardt F, Ploegh HL, Wang Q, Gupta PB (2014): Epithelial-to-mesenchymal transition activates PERK-eIF2 $\alpha$ and sensitizes cells to endoplasmic reticulum stress. Cancer Discov 4,702 715

Ferguson RE, Jackson SM, Stanley AJ, Joyce AD, Harnden P, Morrison EE, Patel PM, Phillips RM, Selby PJ, Banks RE (2005): Intrinsic chemotherapy resistance to the tubulin-binding antimitotic agents in renal cell carcinoma. Int J Cancer $\underline{115}, 155-163$

Ferrari DM, Söling H-D (1999): The protein disulphide-isomerase family: unravelling a string of folds. Biochem J $\underline{339}, 1-10$

Fischer S, Gillessen S, Rothermundt C (2015): Sequence of treatment in locally advanced and metastatic renal cell carcinoma. Transl Androl Urol 4, 310-325

Friedenberg WR, Rue M, Blood EA, Dalton WS, Shustik C, Larson RA, Sonneveld P, Greipp PR (2006): Phase III study of PSC-833 (valspodar) in combination with vincristine, doxorubicin, and dexamethasone (valspodar/VAD) versus VAD alone in patients with recurring or refractory multiple myeloma (E1A95): A trial of the eastern cooperative oncology group. Cancer 106, 830-38

Friedlander R, Jarosch E, Urban J, Volkwein C, Sommer T (2000): A regulatory link between ERassociated protein degradation and the unfolded-protein response. Nat Cell Biol 2, 379384

Fu W, Wu X, Li J, Mo Z, Yang Z, Huang W, Ding Q (2010): Upregulation of GRP78 in renal cell carcinoma and its significance. Urology $\underline{75}$, 603-607

Gabriel M, Delforge Y, Deward A, Habraken Y, Hennuy B, Piette J, Klinck R, Chabot B, Colige A, Lambert C (2015): Role of the splicing factor SRSF4 in cisplatin-induced modifications of pre-mRNA splicing and apoptosis. BMC Cancer $\underline{15}, 227$

Galluzzi L, Senovilla L, Vitale I, Michels J, Martins I, Kepp O, Castedo M, Kroemer G (2012): Molecular mechanisms of cisplatin resistance. Oncogene $\underline{31}, 1869-1883$

Galmiche A, Sauzay C, Chevet E, Pluquet O (2017): Role of the unfolded protein response in tumor cell characteristics and cancer outcome. Curr Opin Oncol 29, 41-47

Gan N, Wu Y-C, Brunet M, Garrido C, Chung F-L, Dai C, Mi L (2010): Sulforaphane activates heat shock response and enhances proteasome activity through up-regulation of HSP27. J Biol Chem 285, 35528-35536

Gao H, Niu Y, Li M, Fang S, Guo L (2017): Identification of DJ-1 as a contributor to multidrug resistance in human small-cell lung cancer using proteomic analysis. Int J Exp Pathol $\underline{98}, 67-$ 74

Gao Y, Koide K (2013): Chemical perturbation of mcl-1 pre-mRNA splicing to induce apoptosis in cancer cells. ACS Chem Biol $\underline{8}, 895-900$

Garrido C, Brunet M, Didelot C, Zermati Y, Schmitt E, Kroemer G (2006): Heat shock proteins 27 and 70: anti-apoptotic proteins with tumorigenic properties. Cell Cycle $\underline{5}, 2592-2601$

Gonçalves V, Jordan P (2015): Posttranscriptional regulation of splicing factor SRSF1 and its role in cancer cell biology. BioMed Res Int 2015, 287048

Gorospe M, Egan JM, Zbar B, Lerman M, Geil L, Kuzmin I, Holbrook NJ (1999): Protective function of von hippel-lindau protein against impaired protein processing in renal carcinoma cells. Mol Cell Biol 19, 1289-1300 
Gout S, Brambilla E, Boudria A, Drissi R, Lantuejoul S, Gazzeri S, Eymin B (2012): Abnormal expression of the pre-mRNA splicing regulators SRSF1, SRSF2, SRPK1 and SRPK2 in non small cell lung carcinoma. PLoS ONE $\underline{7}$, e46539

Gozani O, Potashkin J, Reed R (1998): A potential role for U2AF-SAP 155 interactions in recruiting U2 snRNP to the branch site. Mol Cell Biol $\underline{18}$, 4752-4760

Greenberg PL, Lee SJ, Advani R, Tallman MS, Sikic BI, Letendre L, Dugan K, Lum B, Chin DL, Dewald G, et al. (2004): Mitoxantrone, Etoposide, and Cytarabine with or without valspodar in patients with relapsed or refractory acute myeloid leukemia and high-risk myelodysplastic syndrome: a phase III trial (E2995). J Clin Oncol 22, 1078-1086

Gross JH: Massenspektrometrie: ein Lehrbuch. Springer Spektrum, Berlin Heidelberg 2013

Guo J, Wang W, Liao P, Lou W, Ji Y, Zhang C, Wu J, Zhang S (2009): Identification of serum biomarkers for pancreatic adenocarcinoma by proteomic analysis. Cancer Sci 100, 2292-2301

Hafiza WA, Latifah SY (2014): Potential implications of GRP58 expression and susceptibility of cervical cancer to cisplatin and thymoquinone-based therapy. OncoTargets Ther $7,1375-$ 1387

Han KS, Li N, Raven PA, Fazli L, Frees S, Ettinger S, Park KC, Hong SJ, Gleave ME, So AI (2015): Inhibition of endoplasmic reticulum chaperone protein glucose-regulated protein 78 potentiates anti-angiogenic therapy in renal cell carcinoma through inactivation of the PERK/eIF2 $\alpha$ pathway. Oncotarget $\underline{6}, 34818-34830$

Hart LS, Cunningham JT, Datta T, Dey S, Tameire F, Lehman SL, Qiu B, Zhang H, Cerniglia G, Bi M, et al. (2012): ER stress-mediated autophagy promotes Myc-dependent transformation and tumor growth. J Clin Invest 122, 4621-4634

Hayes GM, Carrigan PE, Miller LJ (2007): Serine-arginine protein kinase 1 overexpression is associated with tumorigenic imbalance in mitogen-activated protein kinase pathways in breast, colonic, and pancreatic carcinomas. Cancer Res $\underline{67}, 2072-2080$

Herold G: Innere Medizin. Gerd Herold (Verlag), Köln 2014

Hetz C (2012): The unfolded protein response: controlling cell fate decisions under ER stress and beyond. Nat Rev Mol Cell Biol 13, 89-102

Hodorová I, Rybárová S, Solár P, Vecanová J, Mihalik J, Bohus P, Mellová Y, Kluchová D (2008): Multidrug resistance proteins in renal cell carcinoma. Folia Biol (Praha) $\underline{54}$, 187-192

Hofmockel G, Bassukas ID, Wittmann A, Dammrich J (1997): Is the expression of multidrug resistance gene product a prognostic indicator for the clinical outcome of patients with renal cancer? Br J Urol $\underline{80}, 11-7$

Hollien J, Weissman JS (2006): Decay of endoplasmic reticulum-localized mRNAs during the unfolded protein response. Science $\underline{313}, 104-107$

Howng S-L, Hsu H-C, Cheng T-S, Lee Y-L, Chang L-K, Lu P-J, Hong Y-R (2004): A novel nineininteraction protein, CGI-99, blocks ninein phosphorylation by GSK3 $\beta$ and is highly expressed in brain tumors. FEBS Lett $\underline{566}, 162-168$

Hsu W-M, Hsieh F-J, Jeng Y-M, Kuo M-L, Tsao P-N, Lee H, Lin M-T, Lai H-S, Chen C-N, Lai DM, Chen W-J (2005): GRP78 expression correlates with histologic differentiation and favorable prognosis in neuroblastic tumors. Int J Cancer $\underline{113}$, 920-927 
Huang Q, Ye J, Huang Q, Chen W, Wang L, Lin W, Lin J, Lin X (2010): Heat shock protein 27 is over-expressed in tumor tissues and increased in sera of patients with gastric adenocarcinoma. Clin Chem Lab Med 노, 263-269

Huber A-L, Lebeau J, Guillaumot P, Pétrilli V, Malek M, Chilloux J, Fauvet F, Payen L, Kfoury A, Renno T, et al. (2013): p58IPK-mediated attenuation of the proapoptotic PERK-CHOP pathway allows malignant progression upon low glucose. Mol Cell 49, 1049-1059

Hunt JD, van der Hel OL, McMillan GP, Boffetta P, Brennan P (2005): Renal cell carcinoma in relation to cigarette smoking: Meta-analysis of 24 studies. Int J Cancer 114, 101-108

Hussmann M, Janke K, Kranz P, Neumann F, Mersch E, Baumann M, Goepelt K, Brockmeier U, Metzen E (2015): Depletion of the thiol oxidoreductase ERp57 in tumor cells inhibits proliferation and increases sensitivity to ionizing radiation and chemotherapeutics. Oncotarget $\underline{6}, 39247-39261$

Isono M, Sato A, Okubo K, Asano T, Asano T (2016): Ritonavir interacts with belinostat to cause endoplasmic reticulum stress and histone acetylation in renal cancer cells. Oncol Res $\underline{24}$, $327-335$

Isono T, Chano T, Kitamura A, Yuasa T (2014): Glucose deprivation induces G2/M transition-arrest and cell death in N-GlcNAc2-modified protein-producing renal carcinoma cells. PLoS ONE $\underline{9}$, e96168

Izquierdo MA, Scheffer GL, Flens MJ, Giaccone G, Broxterman HJ, Meijer CJ, Van der Valk P, Scheper RJ (1996): Broad distribution of the multidrug resistance-related vault lung resistance protein in normal human tissues and tumors. Am J Pathol 148, 877-887

Jamieson ER, Lippard SJ (1999): Structure, recognition, and processing of cisplatin-DNA adducts. Chem Rev $\underline{\text { 99, }}$,2467-2498

Jang JH, Min K, Kim S, Park J-W, Kwon TK (2016): RU486 induces pro-apoptotic endoplasmic reticulum stress through the induction of $\mathrm{CHOP}$ expression by enhancing $\mathrm{C} / \mathrm{EBP} \delta$ expression in human renal carcinoma caki cells. J Cell Biochem 117, 361-369

Jiang CC, Mao ZG, Avery-Kiejda KA, Wade M, Hersey P, Zhang XD (2009): Glucose-regulated protein 78 antagonizes cisplatin and adriamycin in human melanoma cells. Carcinogenesis $\underline{30}, 197-204$

Kabaria R, Klaassen Z, Terris MK (2016): Renal cell carcinoma: links and risks. Int J Nephrol Renov Dis $\underline{9}, 45-52$

Kalluri R, Weinberg RA (2009): The basics of epithelial-mesenchymal transition. J Clin Invest 119 , $1420-1428$

Kamada M, So A, Muramaki M, Rocchi P, Beraldi E, Gleave M (2007): Hsp27 knockdown using nucleotide-based therapies inhibit tumor growth and enhance chemotherapy in human bladder cancer cells. Mol Cancer Ther $\underline{6}, 299-308$

Kane RC, Bross PF, Farrell AT, Pazdur R (2003): Velcade®: U.S. FDA approval for the treatment of multiple myeloma progressing on prior therapy. Oncologist $\underline{8}, 508-513$

Kang S-J, Cresswell P (2002): Calnexin, calreticulin, and ERp57 cooperate in disulfide bond formation in human CD1d heavy chain. J Biol Chem $\underline{277}$, 44838-44844

Kase S, Parikh JG, Rao NA (2009): Expression of heat shock protein 27 and alpha-crystallins in human retinoblastoma after chemoreduction. Br J Ophthalmol 93, 541-544 
Kato M, Fukuda H, Nonaka T, Imajoh-Ohmi S (2005): Cleavage of nonmuscle myosin heavy chain-A during apoptosis in human Jurkat T cells. J Biochem (Tokyo) 137, 157-166

Kaufman RJ (1999): Stress signaling from the lumen of the endoplasmic reticulum: coordination of gene transcriptional and translational controls. Genes Dev $\underline{13}, 1211-1233$

Kellner U: Nierentumoren. In: Krams M, Frahm SO, Mawrin C, Kellner U (Hrsg.): Kurzlehrbuch Pathologie. Thieme, Stuttgart 2010, 316-319

Kim B-K, Yoo H-I, Choi K, Yoon SK (2015): miR-330-5p inhibits proliferation and migration of keratinocytes by targeting Pdia3 expression. FEBS J 282, 4692-4702

Kim I, Xu W, Reed JC (2008): Cell death and endoplasmic reticulum stress: disease relevance and therapeutic opportunities. Nat Rev Drug Discov 7, 1013-1030

Klose J (1975): Protein mapping by combined isoelectric focusing and electrophoresis of mouse tissues. Humangenetik 26, 231-243

Kondagunta GV, Drucker B, Schwartz L, Bacik J, Marion S, Russo P, Mazumdar M, Motzer RJ (2004): Phase II trial of bortezomib for patients with advanced renal cell carcinoma. J Clin Oncol 22, 3720-3725

Koumenis C, Wouters BG (2006): “Translating” tumor hypoxia: unfolded protein response (UPR)dependent and UPR-independent pathways. Mol Cancer Res 4, 423-436

Kozutsumi Y, Segal M, Normington K, Gething M-J, Sambrook J (1988): The presence of malfolded proteins in the endoplasmic reticulum signals the induction of glucose-regulated proteins. Nature $\underline{332}, 462-464$

Krebs in Deutschland 2011/2012. 10. Ausgabe. Robert Koch-Institut (Hrsg) und die Gesellschaft der epidemiologischen Krebsregister in Deutschland e.V. (Hrsg). Berlin, 2015

Kumano M, Furukawa J, Shiota M, Zardan A, Zhang F, Beraldi E, Wiedmann RM, Fazli L, Zoubeidi A, Gleave ME (2012): Cotargeting stress-activated Hsp27 and autophagy as a combinatorial strategy to amplify endoplasmic reticular stress in prostate cancer. Mol Cancer Ther 11, 1661-1671

Kuroda K, Horiguchi A, Asano T, Ito K, Asakuma J, Sato A, Yoshii H, Hayakawa M, Sumitomo M, Asano T (2011): Glucose-regulated protein 78 positivity as a predictor of poor survival in patients with renal cell carcinoma. Urol Int $\underline{87}, 450-456$

Laemmli U (1970): Cleavage of structural proteins during the assembly of the head of bacteriophage T4. Nature 227, 680-685

Laski FA, Fire AZ, RajBhandary UL, Sharp PA (1983): Characterization of tRNA precursor splicing in mammalian extracts. J Biol Chem $\underline{258}, 11974-11980$

Leys CM, Nomura S, LaFleur BJ, Ferrone S, Kaminishi M, Montgomery E, Goldenring JR (2007): Expression and prognostic significance of prothymosin- $\alpha$ and ERp57 in human gastric cancer. Surgery $\underline{141}, 41-50$

Lhommé C, Joly F, Walker JL, Lissoni AA, Nicoletto MO, Manikhas GM, Baekelandt MM, Gordon AN, Fracasso PM, Mietlowski WL, et al. (2008): Phase III study of valspodar (PSC 833) combined with paclitaxel and carboplatin compared with paclitaxel and carboplatin alone in patients with stage IV or suboptimally debulked stage III epithelial ovarian cancer or primary peritoneal cancer. J Clin Oncol 26, 2674-2682 
Li X, Wang J, Manley JL (2005): Loss of splicing factor ASF/SF2 induces G2 cell cycle arrest and apoptosis, but inhibits internucleosomal DNA fragmentation. Genes Dev 19, 2705-2714

Liao C-J, Wu T-I, Huang Y-H, Chang T-C, Wang C-S, Tsai M-M, Lai C-H, Liang Y, Jung S-M, Lin $\mathrm{K}-\mathrm{H}$ (2011): Glucose-regulated protein 58 modulates cell invasiveness and serves as a prognostic marker for cervical cancer. Cancer Sci 102, 2255-2263

Lin Y, Wang Z, Liu L, Chen L (2011): Akt is the downstream target of GRP78 in mediating cisplatin resistance in ER stress-tolerant human lung cancer cells. Lung Cancer $\underline{71}, 291-297$

Lindquist JA, Jensen ON, Mann M, Hämmerling GJ (1998): ER-60, a chaperone with thiol-dependent reductase activity involved in MHC class I assembly. EMBO J 17, 2186-2195

Ling V. (1997): Multidrug resistance: molecular mechanisms and clinical relevance. Cancer Chemother Pharmacol 40 Suppl, S3-S8

Liu M, Du L, He Z, Yan L, Shi Y, Shang J, Tang H (2017): Increased ERp57 expression in HBVrelated hepatocellular carcinoma: possible correlation and prognosis. BioMed Res Int 2017, $\underline{1252647}$

Lwin ZM, Yip GW, Chew FT, Bay BH (2012): Downregulation of ER60 protease inhibits cellular proliferation by inducing G1/S arrest in breast cancer cells in vitro. Anat Rec 295, 410-416

Ma Y, Hendershot LM (2004): The role of the unfolded protein response in tumour development: friend or foe? Nat Rev Cancer 4, 966-977

Mandic A, Hansson J, Linder S, Shoshan MC (2003): Cisplatin induces endoplasmic reticulum stress and nucleus-independent apoptotic signaling. J Biol Chem 278, 9100-9106

Martin S, Hill DS, Paton JC, Paton AW, Birch-Machin MA, Lovat PE, Redfern CPF (2010): Targeting GRP78 to enhance melanoma cell death. Pigment Cell Melanoma Res $\underline{23}$, 675-682

Massiello A, Roesser JR, Chalfant CE (2006): SAP155 binds to ceramide-responsive RNA cis-element 1 and regulates the alternative 5' splice site selection of Bcl-x pre-mRNA. FASEB J $\underline{20}, 1680-1682$

Matera AG, Wang Z (2014): A day in the life of the spliceosome. Nat Rev Mol Cell Biol 15, 108121

Mathew A, Mathur SK, Morimoto RI (1998): Heat shock response and protein degradation: regulation of HSF2 by the ubiquitin-proteasome pathway. Mol Cell Biol 18, 5091-5098

Matsui Y, Hadaschik BA, Fazli L, Andersen RJ, Gleave ME, So AI (2009): Intravesical combination treatment with antisense oligonucleotides targeting heat shock protein-27 and HTI-286 as a novel strategy for high-grade bladder cancer. Mol Cancer Ther $\underline{8}, 2402-2411$

Matsumura K, Sakai C, Kawakami S, Yamashita F, Hashida M (2014): Inhibition of cancer cell growth by GRP78 siRNA lipoplex via activation of unfolded protein response. Biol Pharm Bull $\underline{37}$, 648-653

Mei Y, Thompson MD, Cohen RA, Tong X (2013): Endoplasmic reticulum stress and related pathological processes. J Pharmacol Biomed Anal 1, 1000107

Meister S, Schubert U, Neubert K, Herrmann K, Burger R, Gramatzki M, Hahn S, Schreiber S, Wilhelm S, Herrmann M, et al. (2007): Extensive immunoglobulin production sensitizes myeloma cells for proteasome inhibition. Cancer Res $\underline{67}, 1783-1792$ 
Mignogna C, Staibano S, Altieri V, De Rosa G, Pannone G, Santoro A, Zamparese R, D’Armiento M, Rocchetti R, Mezza E, et al. (2006): Prognostic significance of multidrug-resistance protein (MDR-1) in renal clear cell carcinomas: a five year follow-up analysis. BMC Cancer $\underline{6}$, 293

Mombelli S, Cochaud S, Merrouche Y, Garbar C, Antonicelli F, Laprevotte E, Alberici G, Bonnefoy N, Eliaou J-F, Bastid J, et al. (2015): IL-17A and its homologs IL-25/IL-17E recruit the c-RAF/S6 kinase pathway and the generation of pro-oncogenic LMW-E in breast cancer cells. Sci Rep $\underline{5}, 11874$

Moore MJ, Wang Q, Kennedy CJ, Silver PA (2010): An alternative splicing network links cell-cycle control to apoptosis. Cell 142, 625-636

Mori K (2015): The unfolded protein response: the dawn of a new field. Proc Jpn Acad Ser B Phys Biol Sci $\underline{11}, 469-480$

Mosmann T (1983): Rapid colorimetric assay for cellular growth and survival: application to proliferation and cytotoxicity assays. J Immunol Methods $\underline{65}, 55-63$

Nadin SB, Sottile ML, Montt-Guevara MM, Gauna GV, Daguerre P, Leuzzi M, Gago FE, Ibarra J, Cuello-Carrión FD, Ciocca DR, Vargas-Roig LM (2014): Prognostic implication of HSPA (HSP70) in breast cancer patients treated with neoadjuvant anthracycline-based chemotherapy. Cell Stress Chaperones $\underline{19}$, 493-505

Nagelkerke A, Bussink J, Mujcic H, Wouters BG, Lehmann S, Sweep FC, Span PN (2013): Hypoxia stimulates migration of breast cancer cells via the PERK/ATF4/LAMP3-arm of the unfolded protein response. Breast Cancer Res $\underline{15}$, R2

Nakagawa T, Zhu H, Morishima N, Li E, Xu J, Yankner BA, Yuan J (2000): Caspase-12 mediates endoplasmic-reticulum-specific apoptosis and cytotoxicity by amyloid-[beta]. Nature $\underline{403}$, 98-103

Nandakumar J, Schwer B, Schaffrath R, Shuman S (2008): RNA repair: an antidote to cytotoxic eukaryal RNA damage. Mol Cell $\underline{31}, 278-286$

Ndozangue-Touriguine O, Hamelin J, Bréard J (2008): Cytoskeleton and apoptosis. Biochem Pharmacol $\underline{76}, 11-18$

Niu Z, Wang M, Zhou L, Yao L, Liao Q, Zhao Y (2015): Elevated GRP78 expression is associated with poor prognosis in patients with pancreatic cancer. Sci Rep $\underline{5}, 16067$

Normington K, Kohno K, Kozutsumi Y, Gething M-J, Sambrook J (1989): S. cerevisiae encodes an essential protein homologous in sequence and function to mammalian BiP. Cell $\underline{57}, 1223$ 1236

Obeng EA, Carlson LM, Gutman DM, Harrington WJ, Lee KP, Boise LH (2006): Proteasome inhibitors induce a terminal unfolded protein response in multiple myeloma cells. Blood 107, 4907-4916

O’Connor R (2007): The pharmacology of cancer resistance. Anticancer Res $\underline{27}$, 1267-1272

O'Farrell PH (1975): High resolution two-dimensional electrophoresis of proteins. J Biol Chem 250, 4007-4021

Oliver JD, Roderick HL, Llewellyn DH, High S (1999): ERp57 functions as a subunit of specific complexes formed with the ER lectins calreticulin and calnexin. Mol Biol Cell $\underline{10}, 2573$ 2582 
Otoshi T, Tanaka T, Morimoto K, Nakatani T (2015): Cytoplasmic accumulation of heterogeneous nuclear ribonucleoprotein $\mathrm{K}$ strongly promotes tumor invasion in renal cell carcinoma cells. PloS One $\underline{10}$, e0145769

Ouderkirk JL, Krendel M (2014): Non-muscle myosins in tumor progression, cancer cell invasion, and metastasis: non-muscle myosins and cancer. Cytoskeleton $\underline{71}, 447-463$

Oyadomari S, Mori M (2004): Roles of CHOP/GADD153 in endoplasmic reticulum stress. Cell Death Differ 11, 381-389

Ozawa K, Kondo T, Hori O, Kitao Y, Stern DM, Eisenmenger W, Ogawa S, Ohshima T (2001): Expression of the oxygen-regulated protein ORP150 accelerates wound healing by modulating intracellular VEGF transport. J Clin Invest 108, 41-50

Panaretakis T, Kepp O, Brockmeier U, Tesniere A, Bjorklund A-C, Chapman DC, Durchschlag M, Joza N, Pierron G, Van Endert P, et al. (2009): Mechanisms of pre-apoptotic calreticulin exposure in immunogenic cell death. EMBO J 28, 578-590

Pandey P, Farber R, Nakazawa A, Kumar S, Bharti A, Nalin C, Weichselbaum R, Kufe D, Kharbanda S (2000): Hsp27 functions as a negative regulator of cytochrome c-dependent activation of procaspase-3. Oncogene $\underline{19}, 1975-1981$

Papandreou I, Denko NC, Olson M, Van Melckebeke H, Lust S, Tam A, Solow-Cordero DE, Bouley DM, Offner F, Niwa M, Koong AC (2011): Identification of an Ire1alpha endonuclease specific inhibitor with cytotoxic activity against human multiple myeloma. Blood $\underline{117}, 1311-1314$

Parcellier A, Schmitt E, Gurbuxani S, Seigneurin-Berny D, Pance A, Chantome A, Plenchette S, Khochbin S, Solary E, Garrido C (2003): HSP27 is a ubiquitin-binding protein involved in I-kappaBalpha proteasomal degradation. Mol Cell Biol $\underline{23}, 5790-5802$

Pérez-González A, Rodriguez A, Huarte M, Salanueva IJ, Nieto A (2006): hCLE/CGI-99, a human protein that interacts with the influenza virus polymerase, is a mRNA transcription modulator. J Mol Biol $\underline{362}, 887-900$

Pestell KE, Hobbs SM, Titley JC, Kelland LR, Walton MI (2000): Effect of p53 status on sensitivity to platinum complexes in a human ovarian cancer cell line. Mol Pharmacol $\underline{57}, 503-511$

Popow J, Englert M, Weitzer S, Schleiffer A, Mierzwa B, Mechtler K, Trowitzsch S, Will CL, Lührmann R, Söll D, Martinez J (2011): HSPC117 is the essential subunit of a human tRNA splicing ligase complex. Science $\underline{331}, 760-764$

Popow J, Jurkin J, Schleiffer A, Martinez J (2014): Analysis of orthologous groups reveals archease and DDX1 as tRNA splicing factors. Nature $\underline{511}, 104-107$

Pyrko P, Schönthal AH, Hofman FM, Chen TC, Lee AS (2007): The unfolded protein response regulator GRP78/BiP as a novel target for increasing chemosensitivity in malignant gliomas. Cancer Res 67, 9809-9816

Qiu B, Ackerman D, Sanchez DJ, Li B, Ochocki JD, Grazioli A, Bobrovnikova-Marjon E, Diehl JA, Keith B, Simon MC (2015): HIF- $2 \alpha$ dependent lipid storage promotes endoplasmic reticulum homeostasis in clear cell renal cell carcinoma. Cancer Discov $\underline{5}, 652-667$

Rahmani M, Davis EM, Crabtree TR, Habibi JR, Nguyen TK, Dent P, Grant S (2007): The kinase inhibitor sorafenib induces cell death through a process involving induction of endoplasmic reticulum stress. Mol Cell Biol 27, 5499-5513 
Ramirez-Rangel I, Bracho-Valdes I, Vazquez-Macias A, Carretero-Ortega J, Reyes-Cruz G, Vazquez-Prado J (2011): Regulation of mTORC1 complex assembly and signaling by GRp58/ERp57. Mol Cell Biol 31, 1657-1671

Rao L, Perez D, White E (1996): Lamin proteolysis facilitates nuclear events during apoptosis. J Cell Biol 135, 1441-1455

Rao RV, Hermel E, Castro-Obregon S, del Rio G, Ellerby LM, Ellerby HM, Bredesen DE (2001): Coupling endoplasmic reticulum stress to the cell death program: Mechanism of caspase activation. J Biol Chem 276, 33869-33874

Reddy RK, Mao C, Baumeister P, Austin RC, Kaufman RJ, Lee AS (2003): Endoplasmic reticulum chaperone protein GRP78 protects cells from apoptosis induced by topoisomerase inhibitors: role of ATP binding site in suppression of caspase-7 activation. J Biol Chem $\underline{278}$, 20915-20924

Revil T, Pelletier J, Toutant J, Cloutier A, Chabot B (2009): Heterogeneous nuclear ribonucleoprotein $\mathrm{K}$ represses the production of pro-apoptotic Bcl-xS splice isoform. J Biol Chem $\underline{284}$, 21458-21467

Richter G: Praktische Biochemie: Grundlagen und Techniken. Thieme, Stuttgart 2003

Robert Koch-Institut, Gesellschaft der epidemiologischen Krebsregiser in Deutschland (Hrsg.): Krebs in Deutschland 2011/2012. 10. Ausgabe; Berlin 2015

Rocchi P (2004): Heat shock protein 27 increases after androgen ablation and plays a cytoprotective role in hormone-refractory prostate cancer. Cancer Res $\underline{64}, 6595-6602$

Rocchi P, Jugpal P, So A, Sinneman S, Ettinger S, Fazli L, Nelson C, Gleave M (2006): Small interference RNA targeting heat-shock protein 27 inhibits the growth of prostatic cell lines and induces apoptosis via caspase-3 activation in vitro. BJU Int $\underline{98}$, 1082-1089

Ron D, Walter P (2007): Signal integration in the endoplasmic reticulum unfolded protein response. Nat Rev Mol Cell Biol $\underline{8}, 519-529$

Rosenfeld J, Capdevielle J, Guillemot JC, Ferrara P (1992): In-gel digestion of proteins for internal sequence analysis after one-or two-dimensional gel electrophoresis. Anal Biochem $\underline{203}$, 173-179

Ruchaud S, Korfali N, Villa P, Kottke TJ, Dingwall C, Kaufmann SH, Earnshaw WC (2002): Caspase- 6 gene disruption reveals a requirement for lamin A cleavage in apoptotic chromatin condensation. EMBO J 21, 1967-1977

Salaroglio IC, Panada E, Moiso E, Buondonno I, Provero P, Rubinstein M, Kopecka J, Riganti C (2017): PERK induces resistance to cell death elicited by endoplasmic reticulum stress and chemotherapy. Mol Cancer $\underline{16}, 91$

Santana-Codina N, Carretero R, Sanz-Pamplona R, Cabrera T, Guney E, Oliva B, Clezardin P, Olarte OE, Loza-Alvarez P, Méndez-Lucas A, et al. (2013): A transcriptome-proteome integrated network identifies endoplasmic reticulum thiol oxidoreductase (ERp57) as a hub that mediates bone metastasis. Mol Cell Proteomics MCP 12, 2111-2125

Sato A, Asano T, Ito K, Asano T (2012): Ritonavir interacts with bortezomib to enhance protein ubiquitination and histone acetylation synergistically in renal cancer cells. Urology $\underline{79}$, 966.e13-966.e21 
Sato A, Asano T, Isono M, Ito K, Asano T (2014): Panobinostat synergizes with bortezomib to induce endoplasmic reticulum stress and ubiquitinated protein accumulation in renal cancer cells. BMC Urol 14, 71

Scheffer GL, Schroeijers AB, Izquierdo MA, Wiemer EA c., Scheper RJ (2000): Lung resistancerelated protein/major vault protein and vaults in multidrug-resistant cancer. Curr Opin Oncol 12 , 550-556

Schröder M (2008): Endoplasmic reticulum stress responses. Cell Mol Life Sci 65, 862-894

Schröder M, Kaufman RJ (2005a): ER stress and the unfolded protein response. Mutat Res Mol Mech Mutagen $\underline{569}, 29-63$

Schröder M, Kaufman RJ (2005b): The mammalian unfolded protein response. Annu Rev Biochem 74, 739-789

Shapiro JA, Williams MA, Weiss NS, Stergachis A, LaCroix AZ, Barlow WE (1999): Hypertension, antihypertensive medication use, and risk of renal cell carcinoma. Am J Epidemiol $\underline{149}$, $521-530$

Shi S, Tan P, Yan B, Gao R, Zhao J, Wang J, Gua J, Li N, Ma Z (2016): ER stress and autophagy are involved in the apoptosis induced by cisplatin in human lung cancer cells. Oncol Rep $\underline{35}, 2606-2614$

Shimizu A, Kaira K, Yasuda M, Asao T, Ishikawa O (2016): Clinical and pathological significance of ER stress marker (BiP/GRP78 and PERK) expression in malignant melanoma. Pathol Oncol Res 1-6

Shishkin SS, Eremina LS, Kovalev LI, Kovaleva MA (2013): AGR2, ERp57/GRP58, and some other human protein disulfide isomerases. Biochem Mosc $\underline{78}, 1415-1430$

Shkreta L, Chabot B (2015): The RNA splicing response to DNA damage. Biomolecules $\underline{5}, 2935$ 2977

Shkreta L, Froehlich U, Paquet ER, Toutant J, Elela SA, Chabot B (2008): Anticancer drugs affect the alternative splicing of $\mathrm{Bcl}-\mathrm{x}$ and other human apoptotic genes. Mol Cancer Ther $\underline{7}$, 1398-1409

Shuda M, Kondoh N, Imazeki N, Tanaka K, Okada T, Mori K, Hada A, Arai M, Wakatsuki T, Matsubara O, et al. (2003): Activation of the ATF6, XBP1 and grp78 genes in human hepatocellular carcinoma: a possible involvement of the ER stress pathway in hepatocarcinogenesis. J Hepatol $\underline{38}, 605-614$

Slee EA, Adrain C, Martin SJ (2001): Executioner caspase-3, -6, and -7 perform distinct, non-redundant roles during the demolition phase of apoptosis. J Biol Chem $\underline{276}, 7320-7326$

Solinet S, Vitale ML (2008): Isoform B of myosin II heavy chain mediates actomyosin contractility during TNF-induced apoptosis. J Cell Sci $\underline{121}, 1681-1692$

Song MS, Park YK, Lee J-H, Park K (2001): Induction of glucose-regulated protein 78 by chronic hypoxia in human gastric tumor cells through a protein kinase C- epsilon /ERK/AP-1 signaling cascade. Cancer Res $\underline{61}, 8322-8330$

Souza AP, Albuquerque C, Torronteguy C, Frasson A, Maito F, Pereira L, Duval da Silva V, Zerwes F, Raynes D, Guerriero V, Bonorino C (2009): HspBP1 levels are elevated in breast tumor tissue and inversely related to tumor aggressiveness. Cell Stress Chaperones 14, 301-310 
Stadler WM (2005): Targeted agents for the treatment of advanced renal cell carcinoma. Cancer 104, 2323-2333

Suarez-Herta N, Lecocq R, Mosselmanst R, Galand P, Dumont JE, Robaye B (2000): Myosin heavy chain degradation during apoptosis in endothelial cells. Cell Prolif $\underline{33}, 101-114$

Sunagozaka H, Honda M, Yamashita T, Nishino R, Takatori H, Arai K, Yamashita T, Sakai Y, Kaneko S (2011): Identification of a secretory protein c19orf10 activated in hepatocellular carcinoma. Int J Cancer 129, 1576-1585

Szegezdi E, Logue SE, Gorman AM, Samali A (2006): Mediators of endoplasmic reticulum stressinduced apoptosis. EMBO Rep $\mathbf{7}, 880-885$

Taba K, Kuramitsu Y, Ryozawa S, Yoshida K, Tanaka T, Maehara S-I, Maehara Y, Sakaida I, Nakamura K (2010): Heat-shock protein 27 is phosphorylated in gemcitabine-resistant pancreatic cancer cells. Anticancer Res $\underline{30}$, 2539-2543

Takata H, Kudo M, Yamamoto T, Ueda J, Ishino K, Peng W, Wada R, Taniai N, Yoshida H, Uchida E, Naito Z (2016): Increased expression of PDIA3 and its association with cancer cell proliferation and poor prognosis in hepatocellular carcinoma. Oncol Lett $\underline{12}, 4896$ 4904

Tameire F, Verginadis II, Koumenis C (2015): Cell intrinsic and extrinsic activators of the unfolded protein response in cancer: Mechanisms and targets for therapy. Semin Cancer Biol 33, 3 15

Tang CH, Ranatunga S, Kriss CL, Cubitt CL, Tao J, Pinilla-Ibarz JA, Del Valle JR, Hu CC (2014): Inhibition of ER stress-associated IRE-1/XBP-1 pathway reduces leukemic cell survival. J Clin Invest 124, 2585-2598

The International Myeloma Working Group (2003): Criteria for the classification of monoclonal gammopathies, multiple myeloma and related disorders: a report of the International Myeloma Working Group. Br J Haematol 121, 749-757

Towbin H, Staehelin T, Gordon J (1979): Electrophoretic transfer of proteins from polyacrylamide gels to nitrocellulose sheets: procedure and some applications. Proc Natl Acad Sci $\underline{76}$, 4350-4354

Travers KJ, Patil CK, Wodicka L, Lockhart DJ, Weissman JS, Walter P (2000): Functional and genomic analyses reveal an essential coordination between the unfolded protein response and ER-associated degradation. Cell 101, 249-258

Trivedi R, Müller GA, Rathore MS, Mishra DP, Dihazi H (2016a): Anti-leukemic activity of shikonin: role of ERP57 in shikonin induced apoptosis in acute myeloid leukemia. Cell Physiol Biochem 39, 604-616

Trivedi R, Dihazi GH, Eltoweissy M, Mishra DP, Mueller GA, Dihazi H (2016b): The antioxidant protein PARK7 plays an important role in cell resistance to cisplatin-induced apoptosis in case of clear cell renal cell carcinoma. Eur J Pharmacol 784, 99-110

Turano C, Coppari S, Altieri F, Ferraro A (2002): Proteins of the PDI family: unpredicted non-ER locations and functions. J Cell Physiol 193, 154-163

Venables JP, Koh C-S, Froehlich U, Lapointe E, Couture S, Inkel L, Bramard A, Paquet ER, Watier V, Durand M, et al. (2008): Multiple and specific mRNA processing targets for the major human hnRNP proteins. Mol Cell Biol 28, 6033-6043 
van Engeland M, Ramaekers FC, Schutte B, Reutelingsperger CP (1996): A novel assay to measure loss of plasma membrane asymmetry during apoptosis of adherent cells in culture. Cytometry $\underline{24}, 131-139$

Vicente-Manzanares M, Ma X, Adelstein RS, Horwitz AR (2009): Non-muscle myosin II takes centre stage in cell adhesion and migration. Nat Rev Mol Cell Biol 10, 778-790

Vichi P, Coin F, Renaud J-P, Vermeulen W, Hoeijmakers JHJ, Moras D, Egly J-M (1997): Cisplatinand UV-damaged DNA lure the basal transcription factor TFIID/TBP. EMBO J $\underline{16}$, 7444-7456

von Schwarzenberg K, Held SAE, Schaub A, Brauer KM, Bringmann A, Brossart P (2009): Proteasome inhibition overcomes the resistance of renal cell carcinoma cells against the PPAR $\gamma$ ligand troglitazone. Cell Mol Life Sci $\underline{66}$, 1295-1308

Voss OH, Batra S, Kolattukudy SJ, Gonzalez-Mejia ME, Smith JB, Doseff AI (2007): Binding of caspase-3 prodomain to heat shock protein 27 regulates monocyte apoptosis by inhibiting caspase-3 proteolytic activation. J Biol Chem $\underline{282}$, 25088-25099

Wang D, Lippard SJ (2005): Cellular processing of platinum anticancer drugs. Nat Rev Drug Dis$\operatorname{cov} \underline{4}, 307-320$

Wang M, Kaufman RJ (2016): Protein misfolding in the endoplasmic reticulum as a conduit to human disease. Nature $\underline{529}, 326-335$

Weber SM, Chambers KT, Bensch KG, Scarim AL, Corbett JA (2004): PPAR ligands induce ER stress in pancreatic beta-cells: ER stress activation results in attenuation of cytokine signaling. Am J Physiol Endocrinol Metab 287, E1171-E1177

Wise R, Duhachek-Muggy S, Qi Y, Zolkiewski M, Zolkiewska A (2016): Protein disulfide isomerases in the endoplasmic reticulum promote anchorage-independent growth of breast cancer cells. Breast Cancer Res Treat 157, 241-252

Worman HJ, Fong LG, Muchir A, Young SG (2009): Laminopathies and the long strange trip from basic cell biology to therapy. J Clin Invest $\underline{119}, 1825-1836$

Xu M, Dong C (2017): IL-25 in allergic inflammation. Immunol Rev 278, 185-191

Xu Y, Yu H, Qin H, Kang J, Yu C, Zhong J, Su J, Li H, Sun L (2012): Inhibition of autophagy enhances cisplatin cytotoxicity through endoplasmic reticulum stress in human cervical cancer cells. Cancer Lett $\underline{314}, 232-243$

Yadav AK, Vashishta V, Joshi N, Taneja P (2014): AR-A 014418 used against GSK3beta downregulates expression of hnRNPA1 and SF2/ASF splicing factors. J Oncol 2014, 695325

Yadunandam AK, Yoon J-S, Seong Y-A, Oh C-W, Kim G-D (2012): Prospective impact of 5-FU in the induction of endoplasmic reticulum stress, modulation of GRP78 expression and autophagy in Sk-Hep1 cells. Int J Oncol 41, 1036-1042

Yamamoto K, Okamoto A, Isonishi S, Ochiai K, Ohtake Y (2001): Heat shock protein 27 was upregulated in cisplatin resistant human ovarian tumor cell line and associated with the cisplatin resistance. Cancer Lett $\underline{168}, 173-181$

Ye J, Kumanova M, Hart LS, Sloane K, Zhang H, De Panis DN, Bobrovnikova-Marjon E, Diehl JA, Ron D, Koumenis C (2010): The GCN2-ATF4 pathway is critical for tumour cell survival and proliferation in response to nutrient deprivation. EMBO J 29, 2082-2096 
Yoshida H, Haze K, Yanagi H, Yura T, Mori K (1998): Identification of the cis-acting endoplasmic reticulum stress response element responsible for transcriptional induction of mammalian glucose-regulated proteins Involvement of basic leucine zipper transcription factors. J Biol Chem 273 , 33741-33749

Yoshida H, Okada T, Haze K, Yanagi H, Yura T, Negishi M, Mori K (2000): ATF6 activated by proteolysis binds in the presence of NF-Y (CBF) directly to the cis-acting element responsible for the mammalian unfolded protein response. Mol Cell Biol 20, 6755-6767

Yu B, Wen L, Xiao B, Han F, Shi Y (2014): Single prolonged stress induces ATF6 alpha-dependent endoplasmic reticulum stress and the apoptotic process in medial frontal cortex neurons. BMC Neurosci $\underline{15}, 115$

Zapun A, Darby NJ, Tessier DC, Michalak M, Bergeron JJ, Thomas DY (1998): Enhanced catalysis of ribonuclease B folding by the interaction of calnexin or calreticulin with ERp57. J Biol Chem 273, 6009-6012

Zhang H, Sun L, Xiao X, Xie R, Liu C, Wang Y, Wei Y, Zhang H, Liu L (2014): Krüppel-like factor 8 contributes to hypoxia-induced MDR in gastric cancer cells. Cancer Sci $\underline{105}, 1109-1115$

Zhang J, Jiang Y, Jia Z, Li Q, Gong W, Wang L, Wei D, Yao J, Fang S, Xie K (2006): Association of elevated GRP78 expression with increased lymph node metastasis and poor prognosis in patients with gastric cancer. Clin Exp Metastasis $\underline{23}$, 401-410

Zhang Q, Shi J, Yuan F, Wang H, Fu W, Pan J, Huang Y, Yu J, Yang J, Chen Z (2016): Higher expression of XPF is a critical factor in intrinsic chemotherapy resistance of human renal cell carcinoma: Higher expression of XPF is a critical factor in intrinsic chemotherapy resistance. Int J Cancer 139, 2827-2837

Zhang Y, Shen X (2007): Heat Shock Protein 27 protects L929 cells from cisplatin-induced apoptosis by enhancing Akt activation and abating suppression of thioredoxin reductase activity. Clin Cancer Res $\underline{13}, 2855-2864$

Zhang Y, Li N, Wang D, Chen Y, LI G (2015): Expression and significance of glucose-regulated protein 78 in human osteosarcoma. Oncol Lett $\underline{9}, 2268-2274$

Zhao S, Wen Z, Liu S, Liu Y, Li X, Ge Y, Li S (2015): MicroRNA-148a inhibits the proliferation and promotes the paclitaxel-induced apoptosis of ovarian cancer cells by targeting PDIA3. Mol Med Rep 12, 39233-3929

Zheng H, Takahashi H, Li X, Hara T, Masuda S, Guan Y, Takano Y (2008): Overexpression of GRP78 and GRP94 are markers for aggressive behavior and poor prognosis in gastric carcinomas. Hum Pathol $\underline{39}, 1042-1049$

Internetquellen:

http://leitlinienprogramm-onkologie.de/Nierenzellkarzinom.85.0.html (Zugriff am: 27.08.2016)

https://www.tumorregister-muenchen.de/facts/surv/sC64_G-ICD-10-C64-Nierenkarzinom-Survival.pdf (Zugriff am 17.09.2016) 


\section{Danksagung}

Ich bedanke mich ganz herzlich bei meinem Doktorvater Professor Dr. Dihazi für die Betreuung während der Experimente sowie während des Korrekturprozesses nach Fertigstellung der ersten Schriftfassung der Arbeit. Weiter danke ich Frau Elke Brunst-Knoblich für die intensive Betreuung im Labor und die Geduld und Bereitschaft, notwendige praktische Fertigkeiten beizubringen, zu üben und Fehlerquellen zu beheben. Ein besonderer Dank geht außerdem an Frau Dr. Rachana Trivedi für vielerlei Anregungen bezüglich der durchgeführten Methoden und einer intensiven Betreuung im Labor. Ich danke außerdem Frau Kathrin Schierke sowie Frau Lisa Baumgart für ihre Unterstützung bei dem Erlernen der Methoden und ein offenes Ohr für Diskussionen im Labor. Ein letzter Dank geht an Herrn Prof. Dr. Asif sowie Frau Susanne Goldmann für die Unterstützung und Ermöglichung der massenspektrometrischen Analysen dieser Arbeit. 